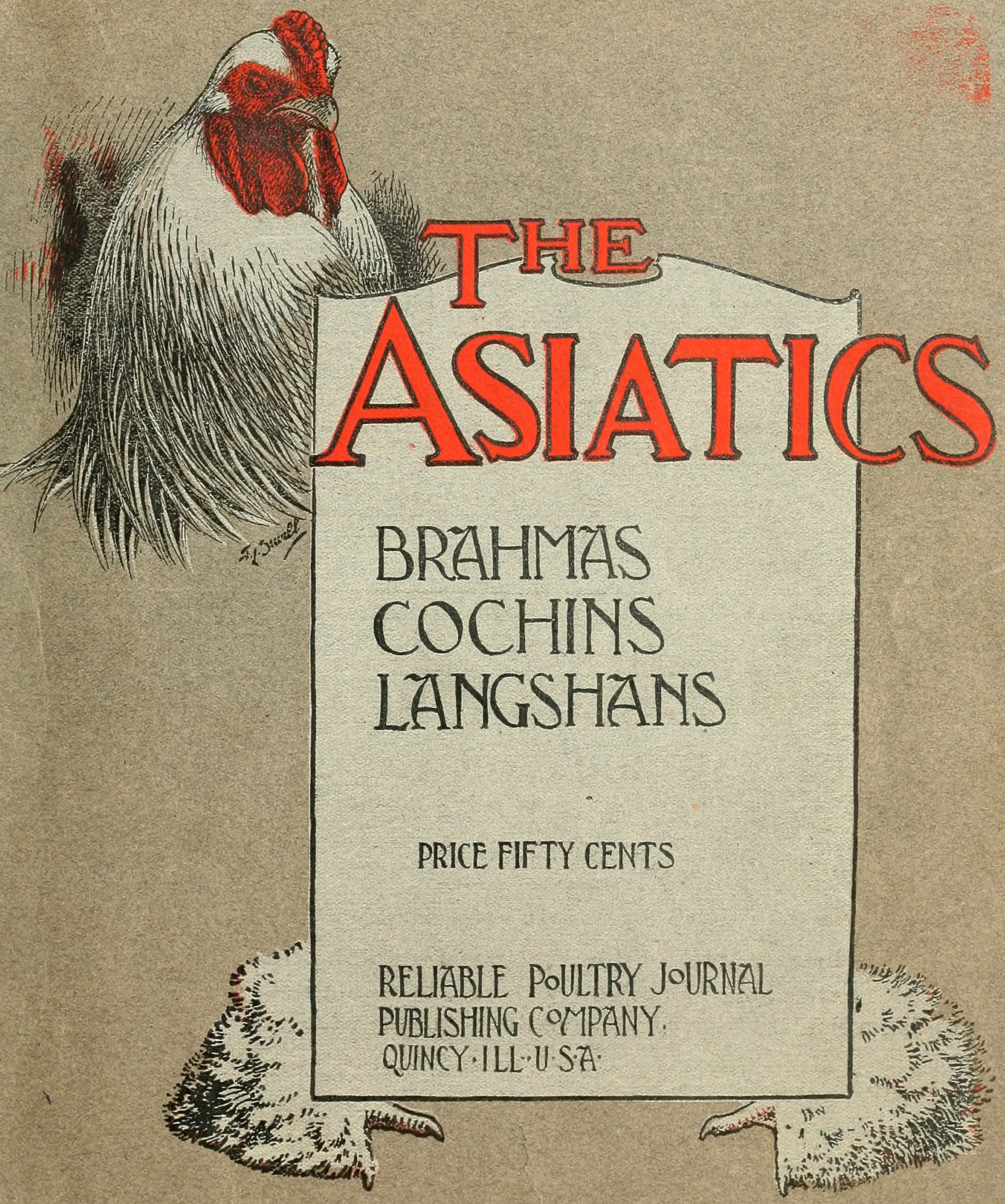




\section{ARTIFICIAL INCUBATING AND BROODING}

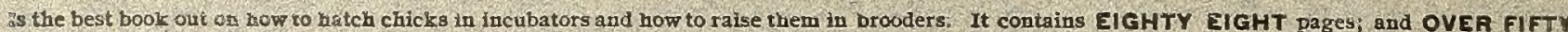

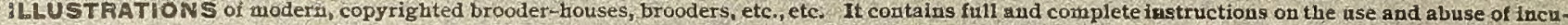

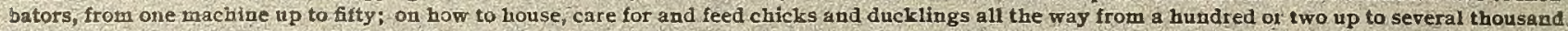

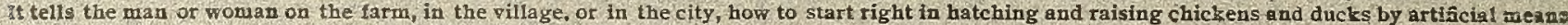
nd, what is more important, bow to GO RIGHT after a start is made

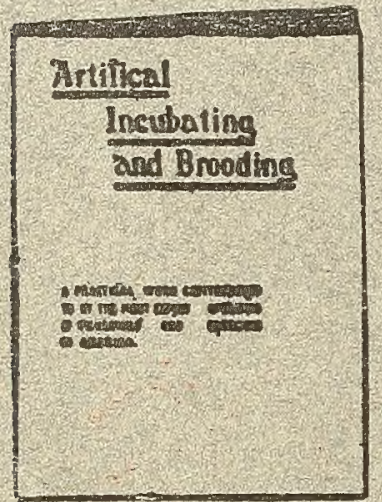

THESE ARE THE CONTENTS OF THIS GREAT BOOK.

Ggyptian Incubatorles.

Strueture of an Egg-Development of the Chick.

Natural Laws of Incubation.

Laying House with Scratching Shed.

Pullets vs. Hens as Profitable Layers.

Best Breeds for Brotlers.

What and How to Feed.

Hatchable Eggs-How to Get Them.

Suggestions on Bullding Incubator Cellars.

Bullding an Incubator Cellar.

Construction of Brood Houses for Chicks. Brooding House-Underneath Piping System.

Brooding House-Overhead Plping System.

Single Row Reliable Brooding House.

Double Row Reliable Brooding House.

Description of House for Indoor Brooders.
Breealng Stock-Incubating-Chicks.

Testing Eggs for Hatching.

Use of Thermometers in Incubators.

The Incubator in Operation.

General Care of Incubator Hatehed Chlera Raising the Chickens.

How to Use Outdoor Brooders.

Feeding and Forcing Brollers.

Profitable Broller Raising.

Incubators on the Farm.

Poultry for Masket.

Pekin Ducks for Profit.

Breeding and Feeding Peldin Ducts.

Té Hatch and Raise Ducks.

Profitable Broller Raising

This book In addition to Illustrations above teferred to, contains illustrations of Barrod Plymouth Rocks, White Plymouth Rooka, Buft Piy seouth Rocks, Silvor Laced Wyandottes, White Wyandottos, Buff Wyandottes, Light Brahmas, Buff Coohins, Singlo Comb and Rese Somb White Loghorna. Houdans, Indlan Games and Pokin Ducks. each and every one of which was executed by the world's graatest poriltry Irtsst, Franklane I. Sewell.

The ptice of ARTIFICIAL INCUSATING AND BROODING is 50 cents postpaid; but we will give it FREE if you send us two new Iubscriptios 0 the Reliable Poultry Jouraal at the regular subscription price of 50 cents feach; OR, we will give you the book and one year's subscription to fs comal at the special price of 75 cents. Address

\section{Reliable Poultry Journal Pub, Co., Quincy, Illinois.}

\section{Poultry Houses and Fixtures THE LATEST BOOK ON THE SUBJECT * PRICE ONLY 25 CENTS *

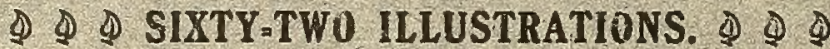

Among the articles contained in this book, are full descriptions of the following:

\section{Low Cost Portable Poultry House, House for Southern Breeders, The Scratching Shed Poultry House, Breeding House, \\ Building a Poultry House, A Convenient Hallway Plan of an Egg Farm}

Also descriptions and illustrations of Nest Boxes, Drinking Fountains, Feeding Troughs, Chicken Coops, and many other Fixtures and Houses.

This book consists of 32 large sized pages, $9 \times 12$ inches, is printed on super-calendered paper, is bound in handsome, durable paper cover. Price of Poultry Houses and Fixtures, sent postpaid to any address, 25 cents, OR, we will give you the book and one year's subscription to the Journal at the special price of 65 cents.

ADDRESS, 

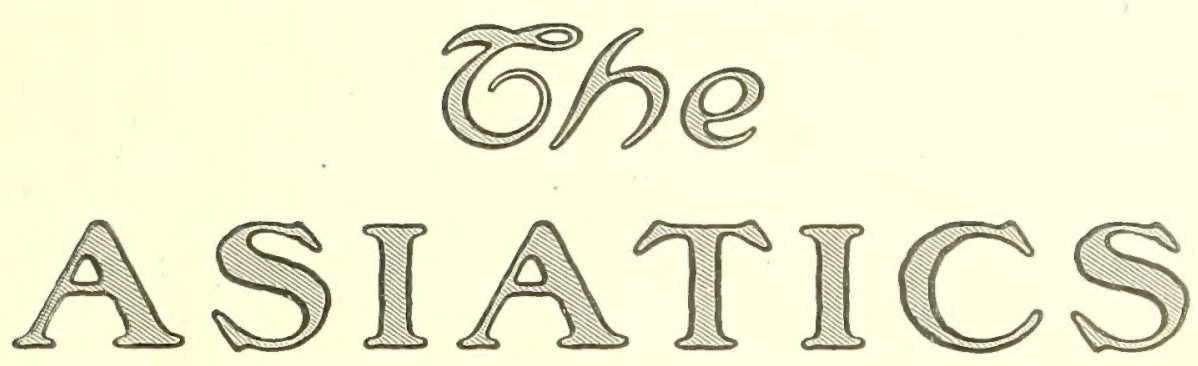

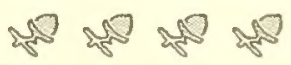

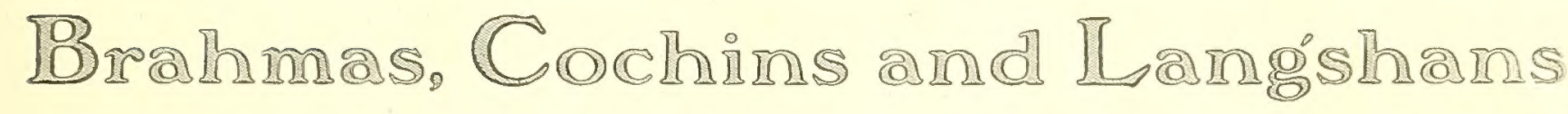

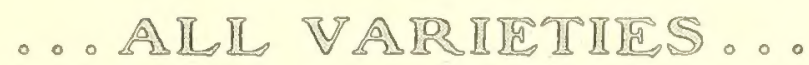

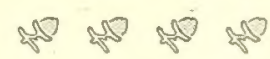

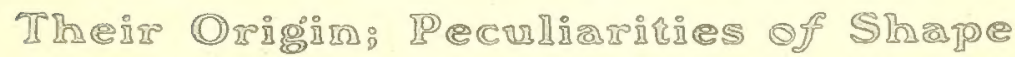

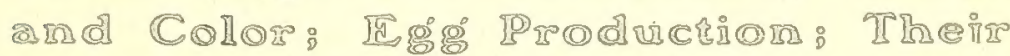

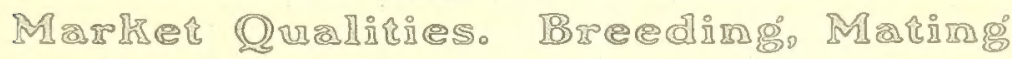
ख

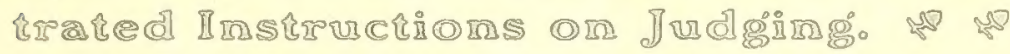

contributed TO by LEadng breEders, EXHibTTORS and JUdges.

TUIIUIIUUSTRATIID。

PRICCE FIEIT CCERS.

PUBLISHED BY

THE RELIABLE POULTRY JOURNAL PUBLISHING COMPANY, QUINCY, ILLINOIS. 


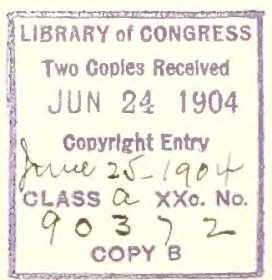
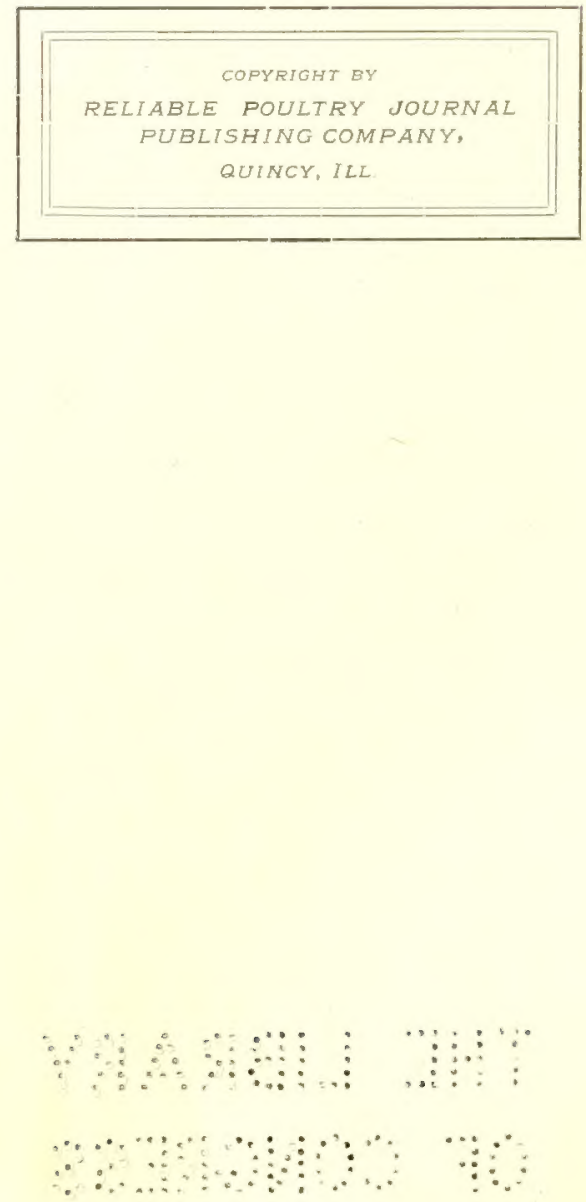
principal nurseries of the world give them a knowledge of stock and prices not obtainable by any ordinary buyer.

This Company expects to continue giving buyers of nursery stock an unequaled and constantly improving service. In addition to giving its employees an opportunity of becoming stockholders, it offers annual prizes for improvement in packing, for improvement in filling orders, and improvement in growing stock. These prizes consist of the payment of all expenses in connection with visits to famous gardens and nurseries in America and Europe.

This Company hopes, in addition to making a commercial success, to establish a first-rate horticultural school of practical training, which will enable young men to become nurserymen, landscape architects or gardeners. A reading-room and a horticultural library is maintained, and employment will be given to a limited number of young men who wish to obtain a horticultural training.

Pittsurg, January I, rgo4

J. WILKINSON ELLIOTT

Landscape Architect 


\section{A WORD OF EXPLANATION}

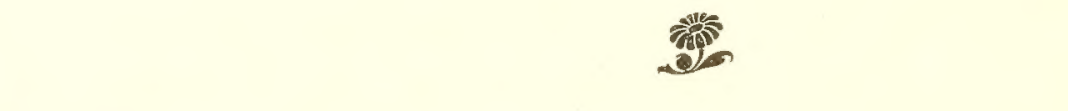

MHE Buying and Nursery Department of my business has grown so rapidly that $I$ found it necessary to make a separate business organization, known as the ELLIOTT NuRSERY COMPANY, for its conduct, which leaves me free for my professional work. This business will remain under my control and general direction; and, to improve the service which has already made it one of the largest businesses of the kind in America, I have given the principal employees stock in the Company.

The men who have served you for years will continue to serve you, with the additional incentive to please that they will get a share of each dollar made.

I think it worth while to speak of the aims and ambitions of this Company. As growers, they make a specialty of Hardy Plants, and have the largest and best stock in the country. They also grow some varieties of shrubs and roses, especially the wild varieties of various countries and old garden sorts not obtainable in other American nurseries. Recognizing that no one nursery can excel in everything, they confine their efforts as growers to the things they can excel with, but supply their customers with any tree, shrub, plant or bulb desired, obtaining their stock from the very best nurseries in America, Europe and Japan. In many instances, the stock is shipped direct from the nursery that grows it to the customer. Long experience and frequent visits to the 



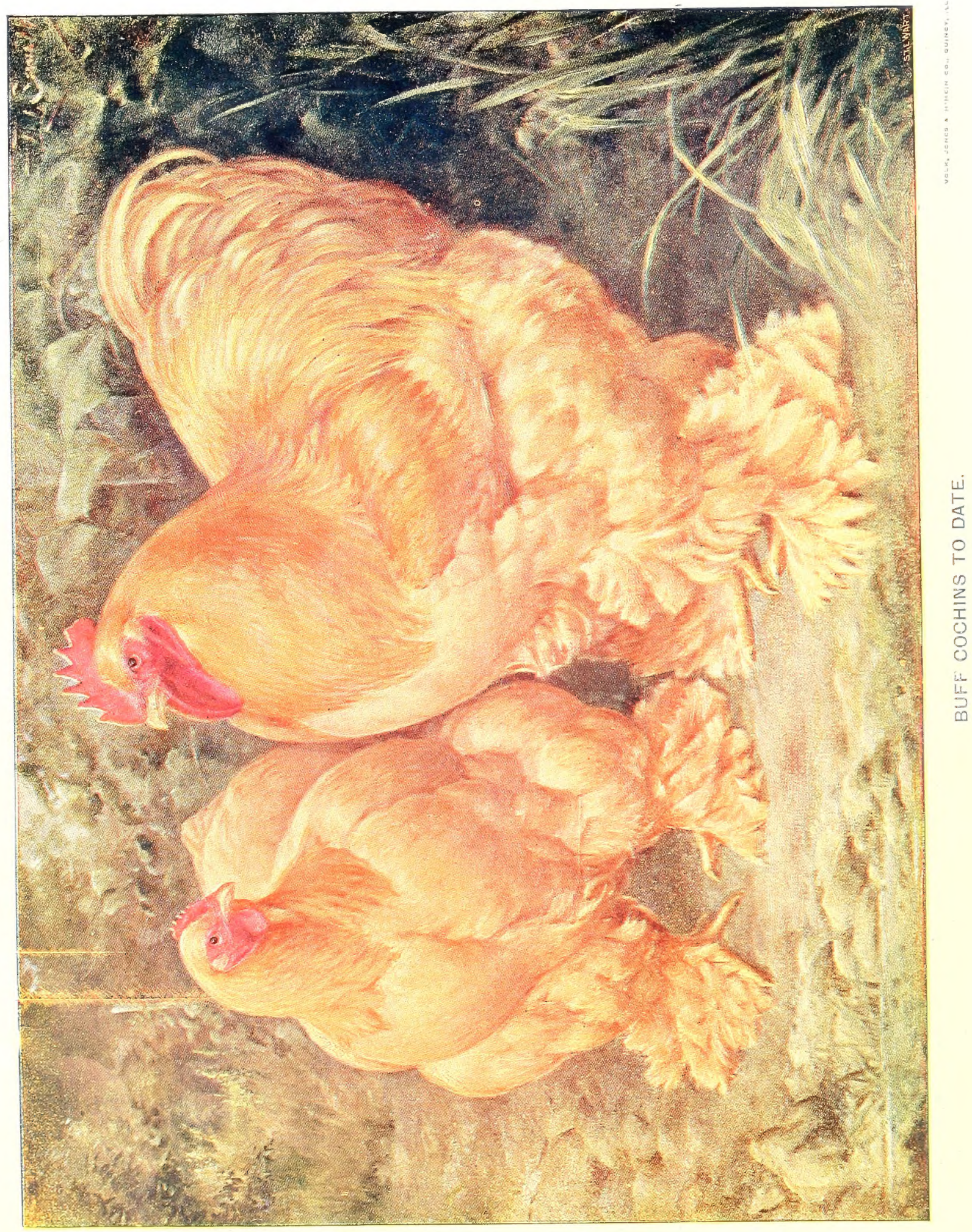




\title{
THE ASIATICS.
}

\author{
A Short History of the Introduction of Cochins, Brahmas, and Langshans-Their Origin is Veiled in \\ Mystery, But From Data Gathered by Numerous Early Fanciers the Period \\ of Their First Appearance is Fixed.
}

By A. F. Hunter, Associate Editor Reliable Poultry Journai.

\section{$\mathbb{M}$}

R. DARWIN tells us that "sufficient materials do not exist for tracing the history of the separate breeds" of fowls, and it is equally true that sufficient material does not exist for tracing the growth (or evolution) of the domestic fowls of to-day as a whole, but from what materials we have and by what we can surmise we can piece together a probable history.

'The domesticated fowl, according to Mr. Darwin, is said to have been introduced from the west into China about 1400 B. C., and we see in the descendants of those fowls a development in a decidedly different direction from that taken by the domesticated fowls in Europe and North Africa. Instead of the small, non-sitting, intensely nervous and active "Mediterranean," we find the large, clumsy, placid-dispositioned and extremely broody "Asiatics."

If we suppose that quantity and quality of meat were preferred to a great egg product we would expect just such a development of the meat producing qualities as those Asiatic fowls possess. Some of us can remember the great Yellow Shanghais, Gray Chittagongs and Malays of fifty or sixty years ago; so tall that, while standing on the floor beside it, they could eat corn off the top of a barrel that was standing on end; cock birds of the descendants of those varieties are said to have reached seventeen or eighteen pounds in weight.

Much ink has been shed over the introduction of what We know as the Asiatic varieties of fowls. Wright's "Now Book of Poultry," speaking of Cochins, says:

"Books of much pretension have traced the origin of this breed to some fowls imported in 1843, which afterwards became the property of Queen Victoria under the name of Cochin China fowls. As regards the fowls themselves this is a total mistake. A drawing of those birds was given in the Illustrated London News of that date (see illustration), from which and the description it is manifest that they had absolutely no points of the Cochin at all, save perhaps yellow legs and large size. The shanks were long and bare, the heads carried back instead of forward, the tail large and carried high, the back long and sloping to the tail, the eyes black, the plumage close and hard. Of what we may call Malay blood they probably had a great deal, of Cochin blood none, or but some trace in a cross. But one thing about them there was; these fowls were not only big, but they probably really did come from Cochin China, and from them and that fact came undoubtedly the name, which will now belong, while poultry breeding lasts, to another fowl that has no right it at all.

"The real stock first reached this country in $1847, \mathrm{Mr}$. Moody in Hampshire and Mr. Alfred Sturgeon of Gray's Essex both receiving stock in that year. Mr. Moody's, so far as we can learn, were inferior in character and leg-。 feather to Mr. Sturgeon's, but were very large and of the same broad type; and all alike came from the port of Shanghai or its neighborhood.

"The birds were undoubtedly Shanghais and had never been near Cochin China, and for years attempts were made to put this matter straight. The first Poultry Book of Wingfield and Johnson (1853) wrote of them as Shanghais, and all American writers strove for the same name years after the attempt had been abandoned in England; but it was no use. *** * The public had got to know the new, big fowls as Cochins, and would use no other word, and so the name stuck, in the teeth of the facts, and holds the field to this day."

Mr. Sturgeon's stock, with subsequent importations from Shanghai, has been the main source from which Cochins were bred in this country; America has had many Independent importations. Mr. Punchard's stock was mainly from Mr. Sturgeon, the latter keeping from choice the lemons and buffs, while Mr. Punchard had the dark birds which originated the Partridges.

The Brahmas were undoubtedly originated in America by selection and careful breeding of what was known as the Gray Chittagongs. Mr. Wright quotes a letter of a Mr. Virgil Coruish, of Connecticut, dated March 2, 1852, as folluws:

"In regard to the history of these fowls very little is known. A mechanic by the name of Chamberlain, in this city, first brought them here. Mr. Chamberlain was acquainted with a sailor, who informed him there were three pairs of large imported fowls in New York, and he dwelt so much upon the enormous size of these fowls that Mr. Chamberlain furnished him with money and directed him to go to New York and purchase a pair of them for him, which he did. The sailor reported that he found one pair of light gray ones, which he purchased; the second pair were dark colored, and the third pair were red. The man in New York, whose name I have not got, gave no account of their origin, except that they had been brought there by some sallors in the Indian ships. The parties through whose hands the fowls came, so far as I have been able to trace them, are all obscure men. I obtained my stock from the original pair brought here by Mr. Chamberlain, and have never crossed them in the least. These fowls were named Chittagong by Mr. Chamberlain, on account of their resemblance, in some degree, to the fowls then in the country called by that name; but it is certain that they never bred until they reached this town."

One strain of these fowls, according to Mr. Wright, was first called "Burram pooters," evidently with the intention of having it believed they were of a different race from the Chittagongs and Shanghais; the name being subsequently dropped and renlaced by "Brahma-Pootre," and eventually simplified into Brahmas, by which name they were intro- 
duced into England by a present of a pen of the birds to Queen Victoria by Mr. Burnham. In his amusing and unscrupulous book, "History of the Hen Fever," Mr. Burnham says:

"An ambitious sea captain arrived in New York from Shanghai, bringing with him about one hundred China fowls of all colors, grades and proportions. Out of this lot I selected a few grey birds that were very large and consequently very fine. I bred these with other grey stock I had at once and soon had a fine lot of brids to dispose of, to which I gave what I have always deemed their only true and appropriate title (as they came from Shanghai), to-wit, Grey Shanghais."

It will be noted that these China fowls were of "all colors, grades and proportions," and it will be readily understood that selection and careful breeding along any one line of color", grade or proportion would ultimately develop a distinct type, which would breed true and become a vari- that ime than the popular Black Langshans of to-day. The same opinion obtained here in America, and the writer distinctly remembers hearing the earlier Black Langshans contemptuously spoken of as "Inferior Cochins." It is probable that the Langshans are descended from the same great parent stock of China fowls as are our Brahmas and Cochins, and they owe it to tine skili of enthusiastic breeders that they are now a distinct variety.

In economic quality Asiatic varieties have been chiefly ranked as table fowls, or meat producers; they have, however, been well known as magnificent layers. When farm raised and with the free and easy manner of farm breeding and handling, they fall off materially in show qualities and develop great laving ability.

Mr. Wright speaks of Brahmas which lay above 200 eggs cach in a year, and Mr. Silberstein had a Light Brahma pullet that by trap nest record laid 232 eggs within a year of laying maturity. We at one time bred what we called am

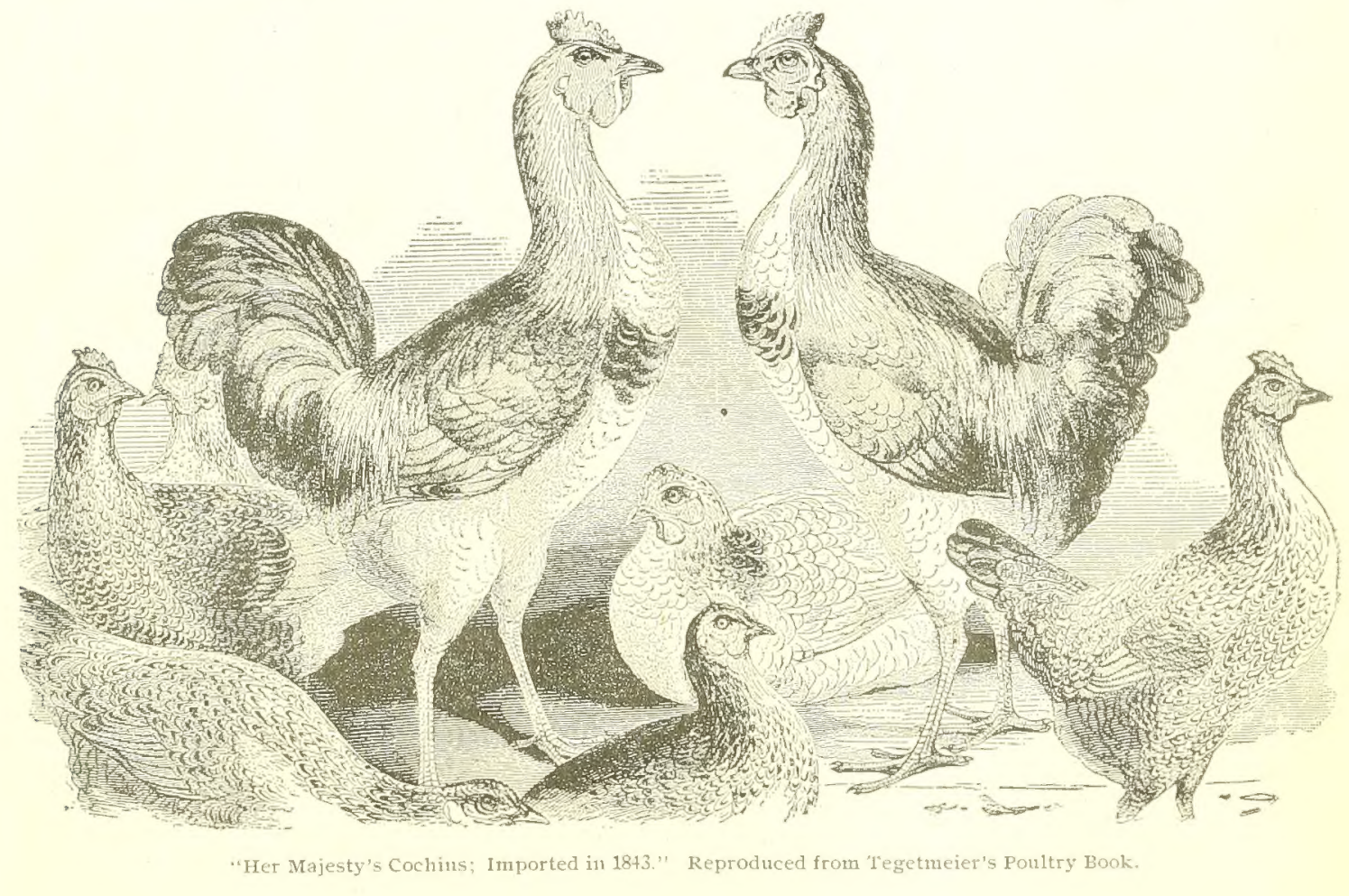

ety. Mr. Burnham elsewhere says that the Dark Brahmas were produced by crossing Grey Chittagongs with Cochins, the Cochins probably being the "other grey stock" of which he speaks, and which were probably earlier importations of China fowls. The illustrations of Cochins and Light Brahmas, which we have reproduced from Tegetmeier's poultry book, give us a good idea of what those early Cochinz and Brahmas were, and a comparison of the birds of (about) 1850 with those of to-day is full of encouragement and indicates what development can be attained by selection and careful breeding.

The Langshans are a much more recent importation, they having first been introduced into England in 1872 and purported to come from the Langshan district in China, and $\mathrm{Mr}$. Wright says of them:

"It seems more than probable that birds very similar" to Langshans have been imported as Black Cochins in the early days of those fowls." And an illustration which he gives of the early Langshans lends probability to this supposition, as they much more resemble the Black Cochins of
"Early Laying" strain of Light Brahmas, which were most prolific layers and pullets of which reached laying maturity at between five and six months old; an intimate friend had what he called "Practical" Buif Cochins, whlch were early and most prolific layers, and we know a farmer in western New York who breeds what he cails "Farmers' Black Langshans" that are likewise great layers. In all of these cases the birds develop with a fineness of bone that makes them at maturity from one to two pounds under weight, and this. characteristic of great laying Asiatics would indicate that the show stock has been bred to rather excessive size, and that breeding them to a finer framed type would increase their economic merits. It would seem chat the same deterioration in economic merit has been evident in England, as Mr. Wright speaks of the Brahmas as follows:

"There are various causes for the decline in jaying powers, which is certainly general. Of course, the one general cause of breeding merely for feather has some effect, as ia all other cases; but that alone is soon recovered from in "utility" stock, such as gets about the country. In addition 
to that, however, the Brahma is a breed in which it is particularly desirable to keep the pullets back from laying with a view to the best show condition; and this, repeated Lor generations, has also had effect. But beyond even these factors, all experience goes to show that activity and close plumage are indispensable to any marked laying power, and the gradual change to looser feather, with wider and shorter body, has had probably the greatest share in the deterioration; the bird has actually been bred to a model which cannot lay so well as the older one. There are still to be found about the country flochs derived from the older stock which keep up the old reputation; but if the Drahma is desired as a layer, some effort should be made to ascertain what the character of the stran really is in that rospect."

This is a strong recommendation to seek utility bred stock if we want burds of the highest economic merit, and that is undoubtedly what is wanted by the great majority of poultry breeters. Fortunately, too, the birds showing the better laying ability are of a desirable fine-framed stock, hence possess better table quality-carry a larger proportion of edible meat. Such stock is of great practical valus. The cggs of the Asiatic varieties are large of size and of the most popular browu color, which commands a premium in the markets, hence great laying ability coupled with their superior market poultry qualities insure them lasting popularity.

A. F. HUNTER.

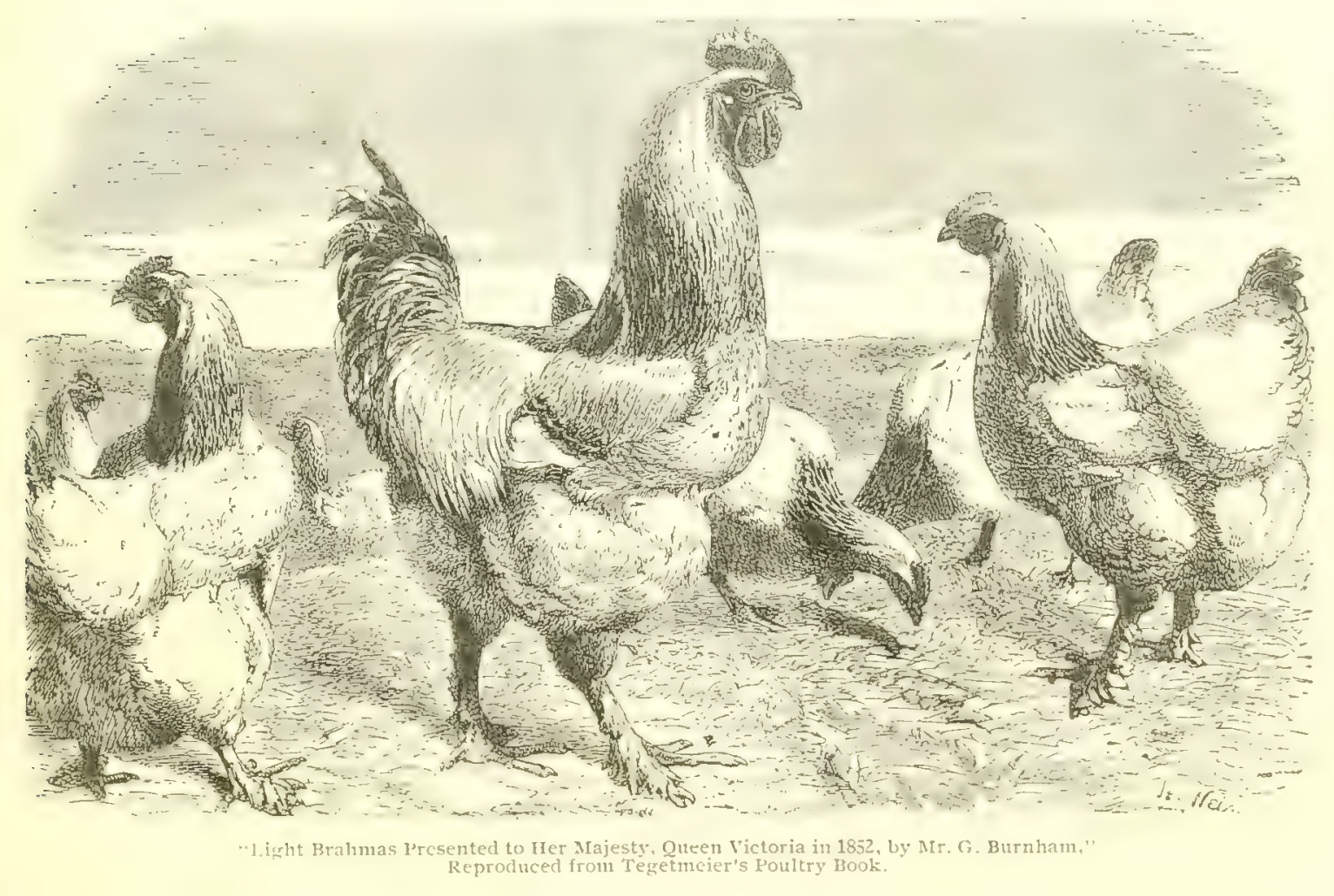




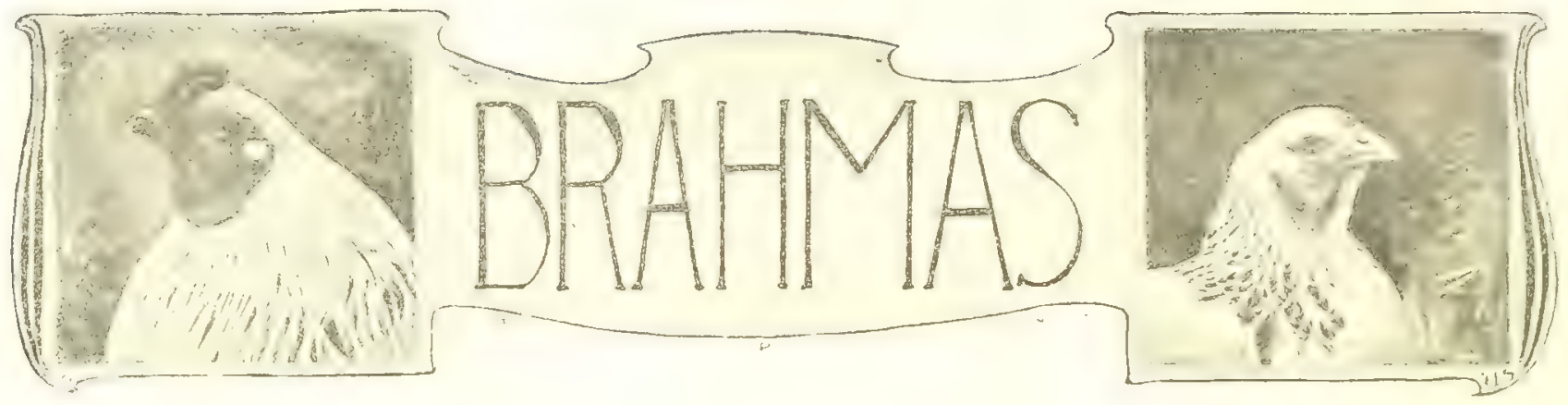

\section{BRAHMA MALE SHAPE.}

Criticisms of Foremost Judges and Brahma Breeders on a Composite Ideal From Live Models, as Drawn by Franklane L. Sewell-A Collection of Opinions That Are in Themselves Authority on the Ideal Shape of a Standard-bred Male Brahma.

From the Reliable Poultry Journal.

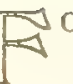

OLLOWING are presented numerous criticisms of Artist Sewell's best individual conception of Standard Brahma male shape. These criticisms, offered in all good feeling, present strong evidence of a disposition on the part of judges and breeders to advance the true interests of Poultry Culture. In more ways than one they prove the existence of a sincere desire to bring about a greater uniformity of ideals in breeding and judging. We have recelved scores of letters expressing a deep interest in this series, and thanking the judges, breeders, the artist and the $R$. P. T. for the parts taken in presenting same:

D. M. OWens, Tennessee, judge and breeder"; "Comb shonld extend further back and conform more to shape of the head at rear. Skull hardly full enough over eyes. Wattles rather small. The head has too much of a feminine appearance. The concare sweep of back commences too neal cape. It should slope slightly downward to the hips, then rise in concave with the saddle to tail. Saddle and tail both carried too high. Sickles should stand a little more upright. Little too full or loose feathered about the thighs. The bird appears rather short from front to rear, but only slightly so."

Theo. Hewes, Indiana, judge and breeder: "I like this bird. He is extra good. Head might be a little broader above the eyes, and he might stand just a trifle longer neck. I would fan the tail a little, making it more upright, and raise the sickles so as to show about balf their length, making them more prominent. Too much covering to thighs. Let's keep away from Cochins in this breed. I like plenty of feathers on their feet, but not too much on the rest of legs."

F. W. Hitchcock, Colorado, judge and breeder: "The drawing of I.ight Brahma male submitted to me for criticism is, I consider, one of Mr. Sewell's best efforts. I can find but little to criticise about it, and what little there is is uf minor importance. "The comi is just a trifle short, making it look a little stubby, but in all other respects the draw- ing comes up to my ideal of correct Brabma shape. It is surely one of Mr. Sewell's masterpieces."

H. S. Babcock, Rhode Island, judge and breeder: "The comb is not clean cut enough for perfection; it might come farther back with advantage. Tail right for cockerel, not full enough for cock. Thighs do not stand out clearly enough and foot feathering is rather more profuse than we see in the best birds in the shows. A bit of tendency towards the Cochin type is shown in this cut. The bird lacks the vivacity that the Brahma exhibits. Still it is a very good illustration."

Charles IIcClave, Ohio, judge and breeder: "Symmetry good. Head outlines good. Comb rather small compared with size of bird; serrations should commence a little nearer to beak. Wattles and ear-lobes are good. Neck shape, front and rear, is about right. Back, length, medium, good, but not high enough at base of tail. The back should show a little more concave sweep. Breast and wings are good. Length of tail is all right, but it looks a trifle pinched. Legs and toes have plenty of feathering, but approach Cochin shape. General outlines are almost above criticism, forming a typical Light Brahma male."

W. S. Russell, Iowa, judge and breeder: "The drawing of male shows a bird too short in body, or in other words, there is not enough of him behind the legs. Fluff is too scanty; back too short, according to my liking. I also think the head is too small and tail too short."

Sharpe Butterfield, Canada, judge and breeder: "I herewith submit the changes I think necessary in the drawing of Light Brahma male. The head is altogether too weaktoo much on the feminine order. Where there is such a head as the one portrayed we generally find wattles almost void. The back is much too short and the tail too much pinched. 'The breast is quite full enough in front, but lacks depth, and the body is not deep enough nor long enough for the ideal Brahma of to-day. The rage in the east is for birds of sreat substance." 
J. Y. Bicknell, New York, judge and breeder: "Back is a little too short for the size of the bird. Head. from top of skull to base of beak, is not quite full enough; the outline representing the head under the comb should be convex instear of being concave. "Comb is too long, and still it does not reach far enough back on the head. It should commence at the front of the skull, rising rather abruptly in front and extend back farther over the head instead of commencing about half way down the beak and running back in a straight line to the top of the serrations. All in front of the serrations shosld be cut out, thus allowing the beak to show to better advantage. Now the latter seems to be blended with the head and comb. Let the beak, head and comb show three sections, more clearly cut, rather than $u$ appear lo be swelged out of one Iump, without disinction. The wing also bleads altogether too much with the surface of the body, and if we were not looking for it where it should be, we might easily imagine there was no wilig there. The shape should show better."

F. J. Marshall. Georgia, judge and breeder: "The cut of Light Brahma male is a very good one, though the head is a little too small, neck a trifle short, as is also the back, although the back is good shape. Tail is very good, but it might be carried just a trifle lower. Breast to be in keeping with what the back should be would want to be a little longer from thighs up and the fluff should show a little more behind the thighs. Thighs and shanks good."

D. A. Stoner, Indiana, judge and breeder: "In criticising shape of Light Brahma male I would say, he is rather tou tall for size of bird and is too much of a $V$ shape. Trim the front parts of his thighs off one-fourth of an inch, and trim body up one-eighth of an inch at thighs, tapering forward to nothing at point of breast bone. Then trim the rear part of body or fluff at hocks one-fourth of an inch higher, tapering out to nothing five-eighths of an inch below vent. Shorten his legs to match body and you have, in my judgment, a much better Brahma shape."

S. L. Roberts, California, judge and breeder: "Head, with lower maudible stouter, and juncture with neck a trifle depressed, I would call all right. Wattles, not large enough. By reason of hackle feathers extending too far over shoulder of wing much of the typical shape of the Light Brahma male is lost-it is a Dark Brahma hackle, and hides the shoulder so much as to destroy the back properties, and causes the wing to appear as if set on too low, and drooping a trille. Breast is very angular. The cut is a good one the best we have seen. Mr. Sewell has excellent Brahma ideas and puts them on paper."

H. B. Savage, Texas, judge and breeder": "I would like the head to be a trifle broader, crown projecting a little farther over the eye; serrations of comb to begin farther front on the beak; beak to curve just a trifle more; breast a trifle rounder opposite and a little below front of wing bow; tail a very little more upright and spread slightly more. The outer toe does not extend far enough out. The cut of male is well nigh perfect, as the defects here noted would cause but very light cuts in scoring, in my opinion, but of course looking at these well gotten up pictures is not like handling the bird itself."

John C. Snyder, Oklahoma, judge and breeder. "I think the comb is a little small for size of bird and a sharle too low in midale. The crook of the arch of the neck is a quarter of an inch too low down on neck. WVing carried too low. tail hardly upright enough. But taken all together he is good in symmetry."

F. H. Shellabarger, Iowa, judge and breeder: "The cut of Light Brahma male is, in my judgment, about all that the Standard calls for. The head appears a trifle slim for a Bralıma, but it fits the Standard closely."

H. A. Bridge, Ohio, judge and breeder: "Head of Brahma male is just a little feminine. The comb should be just a trifle broader and the serrations brought forward more. There does not seem to be space enough between the center and outer serrations. Face below the eye has the appearance of projecting beyond the eye. The crown of the head does not project over the eye enough, but wher face below is darkened up may give the crown the appearance of enough projection. Increase the length of wattle a little so that when the lower edge is rounded up it will stand away from face a little on lower end. Bring the ear-lobe more under the ear and round up the front edge of lobe, making them just a little broader and of course have them level with the wattles. The arch of neck is just a little low down. The back is a trifle short and too deep in concave; this I think, when remedied, will relieve the long appearance of the tail. Wings should be carried just a little higher. Upper portion of tail is a little narrow. Breast is a little fuller than necessary. Thighs should be relieved a little from their slightly Cochin appearance."

F. B. Zimmer, New York, Judge and breeder: "I consider the drawing of Jight Brahma male perfect as far as shape is concerned. In all previous proofs of other breeds sent me I could find sections I would change, but this Brahma represents my idea of shape. Therefore your readers would know about where to find me on this variety."

D. T. Heimlich, Illinois, judge and breeder: "The male bird in all sections pleases me just as it is, and Mr. Sewell should have a voto of thanks from all lovers of this granc? breed for the picture of the male Brahma."

C. A. Emry, Missouri, judge and breeder: "Head not full enough over eyes, breast not full and round enough, tail too small and piuched, legs show too much Cochin feathering anci shape."

I. P. Harris, Nebraska, judge and breeder: "I think the cut of Light Brahma male shape fine, except comb and wattles. The serrations in center row start too far back by the width of one serration; the side serrations are a little too far from the head, and the back point of the comb should tip down on or nearer the head. Wattles are too small anci short."

A. B. Shaner, Illinois, judge and breeder: "The Light Brahma male as submitted is a good model, and should I ever come across one as good I think I should pass him as perfect in shape outlines. He comes as near perfect as the standard calls for."

Geurge H. Northup. New Iork, judge and breeder: "The proofs of Brabma drawings accompanying your letter of the 20 th are received. I consider them very excellent indeed and think it doubtful if we ever see a bird as near perfect in all points as these two birds are. However, referring to the male bird, I think the lobes not quite large crongh and they do not extend quite low enough to com- 


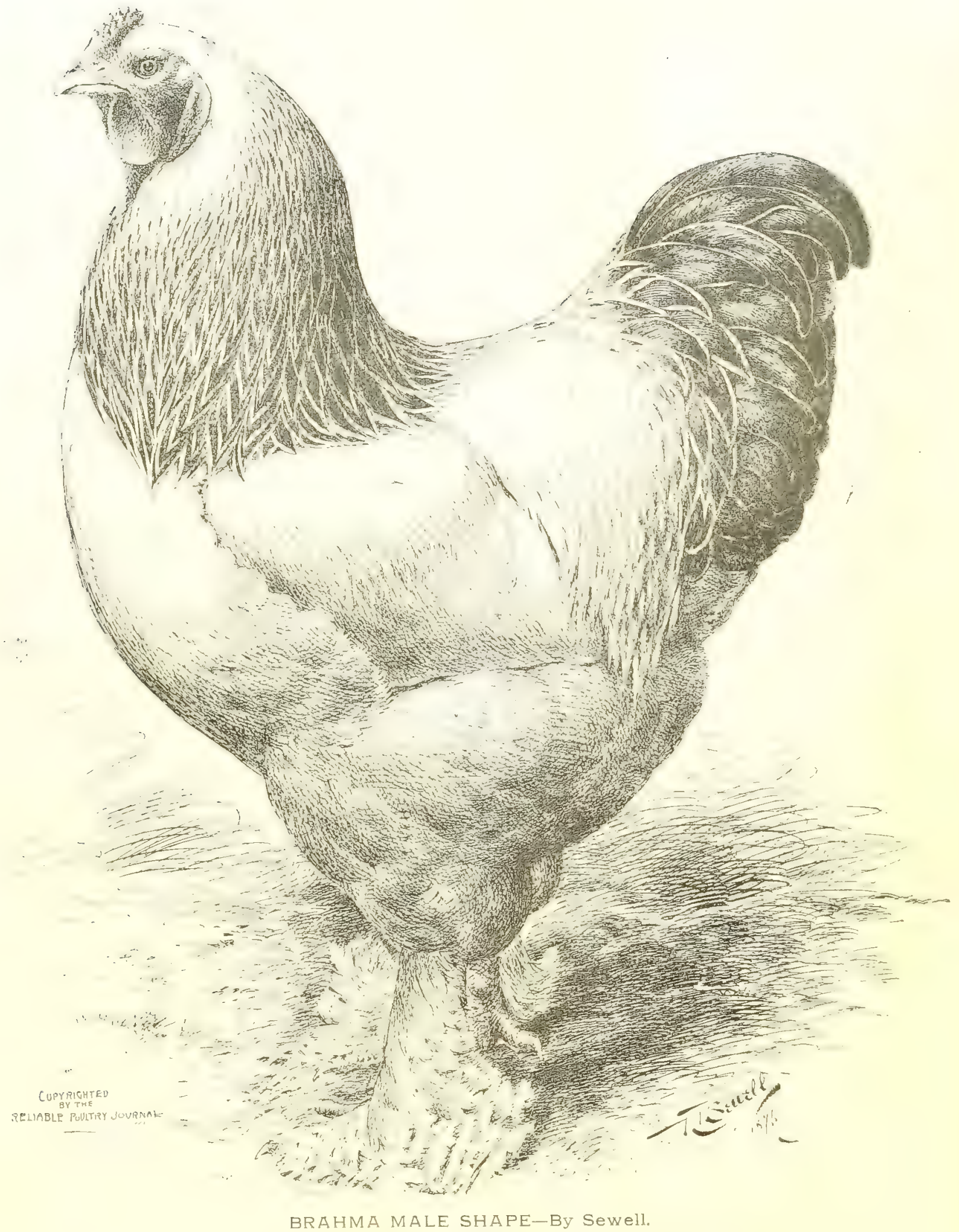

Comprising the Best Points of Several Live Models as Ilustrated by Franklane L. Sewell for the Feliable Pe ultry Journal, and submitted to Sixty-five Prominent Judges and Breeders for Criticism.

Based upon Standard Requirements. 


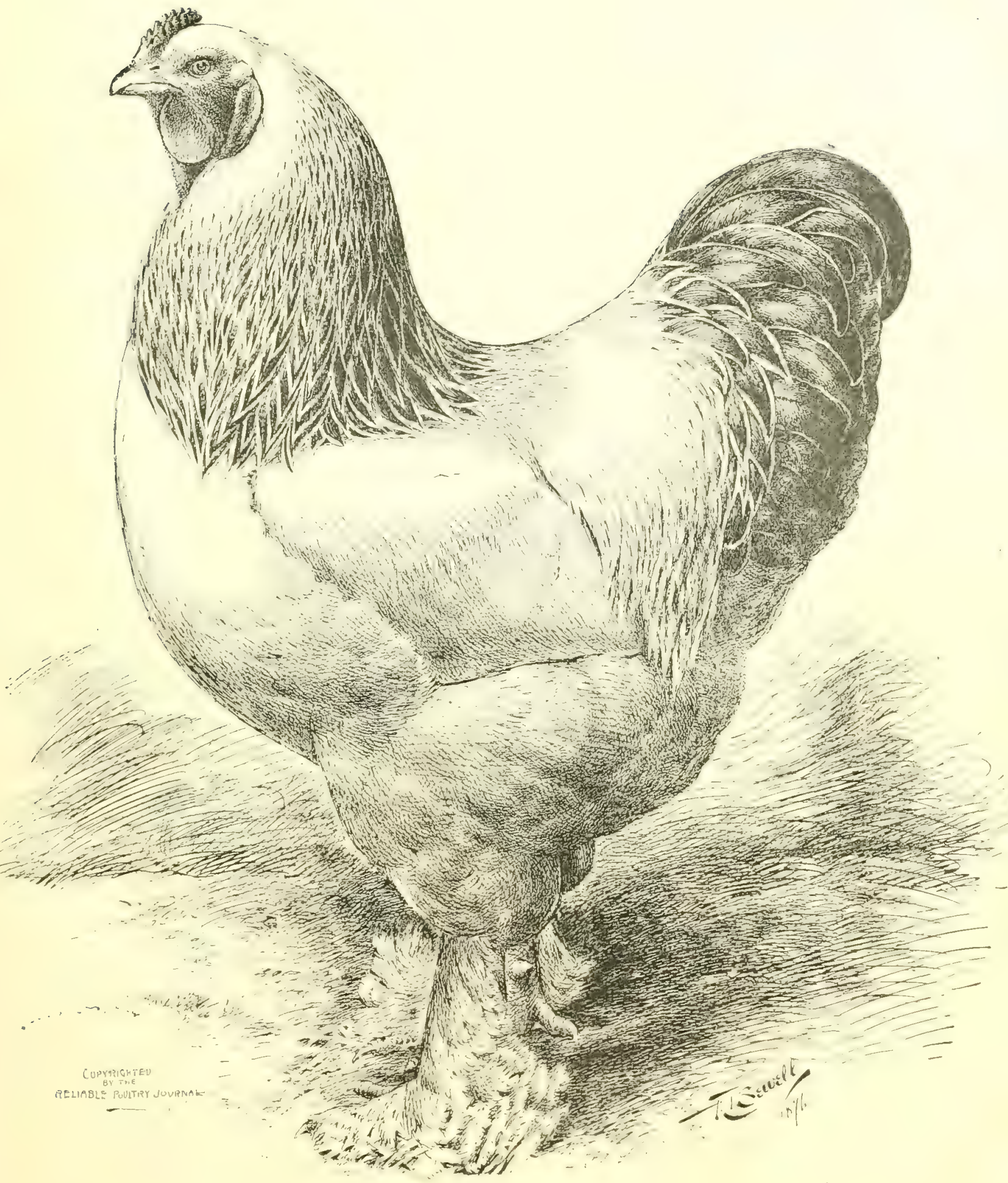

BRAHMA MALE SHAPE-By Sewell

An Ideal Brahma. Illustrated by Franklane L. Sewell, for the Reliable Poultry Journal. under the Suggestions of Sixty-five Prominent Judges and Breeders-The Outcome of Criticism Upon the Brahma Male Shape Shown on the Opposite Page 
pare with wattles. The body seems too short for height, that is, the distance measured in a straight line from point where the hackle rivides at the front of neck, tonching the highest point of wing bow and terminating in the lower parc of tail, is too short. His neck and legs are perfect. Flead, a little too narrow above the eye. His tail is good except that it does not spread enough, the sickles especially."

O. E. STinner, Kansas, breeder of Light Brahmas: "Referring to the proof of Light Brahma male which you sent me, would say the cockerel does not please me at all. I want a bird with a much larger head, broader skull and much larger ear-lobes. His tail appears in the cut too pointed; that is, not spread enough. I should want longer shanks. His breast and back shape is good."

Mrs. B. F. Jackson, Kentucky, breeder of Light Brahmas: "I consider the etching of male Brahma excellent. with one exception-the head is a trifle too small and comb too large or Irrowinent."

T. N. Smiley \& Son, Indiana, breeders of Light Brahmas: "The pronfs of Light Brahmas received, and we think they are excellent. We have no criticism to make on the male. "We think he is grand."

Sid Conger, Indiana, breeder of Light Brahmas: "The male is fairly good in general shape. The head is too small. narrow, pinched in the throat. It fails in the handsome head the Light Brahma usually shows. It is not quite deep enough in the breast for an ideal. The coloring of the neck indicates smuttiness, and white lacing around the lesser sickles is not standard. Shape of back fairly good."

W. A. Irvin, Nebraska, breeder of Light Brahmas: "The excellent proofs of the Light Brahma male and female came duly to hand. I consider the shape and outline of the male the best drawing that I have ever seen, and when we as breeders can breed them up to the typical standard shape. as outlined by Mr. Sewell, there will not be any cause for complaint."

George Luhrsen, Illinois, breeder of Light Brabmas: "In regard to Mr. Sewell's drawing of Brahma male, I will say that in my judgment he is as near perfect as can be drawn. Perhaps some breeders wonld say he is a little too deey in saddle and short in back, but I think him just about risiti."

Mrs. Ella Thomas, Missouri, breeder of Light Brahmas: "In regard to the drawing of ideal Light Brahma male cockerel, as submitted by Mr. Sewell, would say I think it very gond, though I would prefer the comb to extend a little further lack on head, skull broader, wattles slightly longer, first row of tail eoverts solicl black instead of edged with white. Lasser coverts are all right. Body should be slightly longer for the breadth and depth; wings a little longer and tucked slightly higher; foot-feathering mottled well with black. The whole body is too short for true Brahma shape, according to my notion."

(Y)orge Clough, Illinois, breeder of Dark Brahmas: "I consider the male Brahma to he good in shape, but I think he is a little short in back; hardly flat enough at shoulders; breast not round, deep or full enough; fiuff not abundant enough."
John H. Ryan, Lllinois, breeder of Light and Dark Brahmas: "I can find but little fault with Mr. Sewell's idea of Ligint Brahma male. $H e$ is a little too narrow across the haad, hardiy full enough over front of eyes; a little low at basè of hackle; a trifte too much sweep to tail; hackle is too dark, Otherwise he is all right, to my notion."

E. E. Marlow, Missouri, breeder of Light Brahmas: "I think the head of the male Brahma is a trifle small and the tail is not spread enough. But I wish I could raise all my birts to be as good."

II. MIaver, Jr., Illinois, breeder of Light Brahmas: "The drawing of the male comes so near to perfection that there is very little room for criticism. The breast could be a trifle fuller, otherwise he suits me first rate."

E. Dunstan, Mississippi, breeder of Light Brahmas: "In offering my crilicism on the Light Brahma male drawing by Mr. Sewell, wonld say that I think the wattles are too small to be called medium size, and the ear-lobes are certainly not 'large pendant,' as required by the standard. The junction between the head and back part of the neck is not defined clearly enough. The remainder of the neck looks very nice. I consider the back too short, and the wings not being beld high enough, give the back a narrow appearance instead of being broad and flat at the shoulders. And from his saddle to the vent he wilis shailom enough for a Leghorn. I do not consider his tail ts carried high enough to be called 'carried to!erably upright,' and is too contracteri to be considered full, well spread and well filled underneath with curling feathers. The breast is round and full enough, but lacks depth. The thighs and legs are, I think, about right, but from the back of leg to vent he is too short."

Miss Hattie Winship, Illinois, breeder of Light Brahm9s: "When it comes "s calling this the Standard Light Brahma for all strains and cutting every bird one or more on symmetry, which does not resemble this male or female exactly, I think it an impossibility, and would be doing what is unjust. When it comes to this strain, the Mammoth Light Brahma, they are very good, still if my preference was for this strain, I should work for the heavier, more blocky and more heavily feathered itype. The male is too high in proportion to the width and length, is too longlegged; tail too high; breast might he a trifle fuller, and when you have the feathers looser and heavier all over you will have a bird more of the style in the March, 1896, number R. P. J. frontispiece. I would not objec to one or two p9ns of this strain; but as to a large flock ol many pens, and when it comes right down to the movey-making birds (what we are after). I should not wish for them in the least. I had some of that type last year and find they are not layers; the smaller types are those where the feathers are smoother, or not so fluify, and my customers, like myself, met with poorer hatches from this mammoth strain. The male which gave me the best satisfaction is of the type Miss Forbes, of California, has represented on page 242, May, $1 \$ 96, R$. P. J., and is the strain I shall work for There is something much richer in color and form, mal ac tilem a berutiful, noble, lordly type. The large type is nothing but a rough, coarse, lazy bird. If your birds are very small it is well to mix the larger with them to bring them up. I think we need an ideal for each of the two or three strains, as some will prefer one strain, whereas others will choose another. They will never all choose the same." 
J. J. Burnside, Indiana, breeder of Light Brahmas: "I think the male is all right. I cannot see where I could better it."

L. O. Berryman, Illinois, breeder of Light Brahmas: "The illustration of Light Brahma male by Mr. Sewell is a grand type of this noble breed, yet, according to the stand ard, it is a little faulty. I think the comb should be serrated down to beak in front: the back should be medium in length -I call him short. His tail should be carried more upright, especially sickle feal hers. With these changes made, I think we would have an ideal Light Brahma male."

J. A. Roberts, Pennsylvania, breeder of Light Brahmas: "The Light Brahma male is of good shape, but he might bo a little longer in body. Tail might be run in line with back. I expect it is well spread. I cannot see, as he stands sideways to me. I shall be satisfied if parties of whom I order would always send as good as he."

T. R. McDonald, Kentucky, breeder of Light Brabmas: "After carefully looking over the Light Brahma male drawing, I have no comment to make other than that it is exactly my idea of what a Brahma male should be."

Casper Dice, Nebraska, breeder of Light Brahmas: "The cut of male would suit me better if comb ran up farther on head and lower behind. Head seems too narrow. Neck shonld be a little longer and fuller at base of hackle and cape. Fluff. should be fuller to make bird deeper from cape to fuff, and the legs look too short."

F. L. Ackerman, Michigan, breeder of Light Brahmas: "Commenting on the Light Brahma male shape, I would say that if we get as near perfection as this cut represents we will be very near the top of the ladder. But if back and saddle were broader and tail spread out a little, with wings a trifle smaller and carried higher, it would suit me better."

R. R. Clendenen, Missouri, breeder of Light Brahmas: "Mr. Sewell's cut of Light Brahma male is a good one. The comb might be a trifte longer and be drawn a little closer to the head at the back end."

W. S. Campbell, Inlinois, breeder of Light Brahmas: "Your beantiful proofs of Light Brabmas at hand and it is hard to find fault with them. Comb on male is smaller than I like and back of neck is fuller in hackle than we see in nature. The breast is a little full. He looks too tall from bottom of left foot to middle of back for the length of body. and the fuff is a little scant."

N. Porter Brown, Massachusetts, breeder of Light Brahmas: "After examining the proof of the Light Brahma male, it appears to me that there is very little to find fault with, yet he appears to be short bodied. I like to see a cockerel with more length of back between neck and tail. I would also add about one-lourth inch to breast, making him fuller in that section. Most every one likes to see a short legged Brabma, yet the male for his size looks as if he were a little too short in leg."

Mrs. T. W. Ragsdale, Missouri, breeder of Light Brahmas: "First of all I will express thanks to you and $\mathrm{Mr}$. Sewell for the beautiful engravings sent me, and to show my appreciation I have framed them. I think both are good specimens and I have but few criticisms to make, though I have given them close study. I think the head of the male rather feminine for such a large neck and body, and the body from front to rear is rather too short. I like more evidence of weight, strength and vigor."

Simon Lynch, Indiana, breeder of Light Brahmas: "This cut is good. but the comb is too high at rear, eyes too low, ear-lobes too coarse, beak not arched enough, hackle not fine enough, legs too close together. I want a white color."

H. N. Rollins, Massachusetts, breeder of Light Brahmas: "I think the cut of Light Brahma male is very fine. I should like to see the fluff a little more developed, otherwise I like it very well."

William Chamings, Illinois, breeder of Light Brahmas: "I would suggest a few changes in Artist Sewell's cut of male. Comb should extend back farther and set closer to head. Head is a trille small; back should be longer and fiuff back of thighs fuller, so as to give a more massive appearance and a much better proportioned bird. Body a little short."

John A. Meyer, director West Virginia Agricultural Experiment Station, breeder of Light Brahmas: "The excellent proofs of the male and female Light Brahmas, executed by Mr. Sewell for the R. P. J., seem to me to represent very closely the ideal type of Light Brahmas. The male is very satisfactory."

W. W. Kulp, Pennsylvania, breeder of Light Brahmas: "I have no criticism to make on shape of male Light Brahma. I think if I had one like him in shape and as good in coler he would have plenty of 'blues' to his credit. There may be a little too much tail."

E. G. Haywood, Illinois, breeder of Light Brahmas: "The body of the male should be longer and he should be correspondingly deeper in breast. At the point where he measures four and three-quarter inches in length of body I would prefer it full five inches."

Alfred Doyle, Illinois, breeder of Light Brahmas: "Head is faulty in shape: eye is too low down; it should be about even with the top of upper mandible, and a little farther back. Mouth is tco long; wattles should commence a little farther forward on the bill; , ear-lobes should be right under the ear, and not at the rear. Comb could be better. Neck is too thick; that swelling at the back should be trimmed off; the dividing line between the head and neck is not clearly enough defined. Back is too short for a Brahma. Preast should be pared off a little in front of hocks, and also the upper part of neck, and dew lap should be cut away so as to leave a clear space under the wattles. Fluff is a trife too abundant. Lower edge of wing should be rounding and not form an angle as in the cut, and the wing is a triffe too short. Main tail feathers and coverts are a little too long; tail coverts should not be edged with white, as in cut. Hocks and legs are entirely too heavily feathered for the American type of Brahma. Take the bird all through, I consider it too blocky for a Brahma."

F. F. Congdon, Wisconsin, breeder of Light Brahmas: "Etching by Sewell of 'Standard Light Brahma Male Shape' was duly received, and it seems a pity to criticise such a strikingly beautiful illustration; however, I think the head is a little tow small, back a trifle short, the general appear. ance of the bird being too high for the length." 
C. E. IIunze. Iilinois, breeder of Light Brahmas: "We received the Light Brahma sketches, and wish to say only this: Mr. Sewell has a much better idea of what a good chicken is and knows how to put the idea into better form than any other poultry judge or artist anywhere in the United States or foreign countries. The Light Brahma skotches are beauties, and we do not wish to criticise them, as any alteration might hurt more than do good."

James George, Iansas, breeder of Light Brahmas: "It seems to me that the back of the male is a trifle short and the tail is carried a little high. Otherwise I can find no fault with it."

ふ. E. Woods, Indiana, breeder of Light Brabnas: "In regard to the excellent typical drawing of Light Brahma ma!e, I will say I have no eriticisms except that there is too great leg and toe leathering; which, in my opinlon, is against utility."

Mrs. B. G. Machey, Missouri, breeder of Light Bralumas: "As I understand the standald it seems to me that Mr. Sewell has in this drawing almost reached perfection. The comb seems a trifle higher than $I$ understand to be standard and the back icoks to me short for a standard bird."

G. W. Randall, Nebraska, breeder of Light Brahmas: "Regarding the drawings of Light Brahmas submitted, I think them nearer to what the ideal Light Brahma should be llan anything I have ever before seen, and I consider them excellent, especially the male. I think that submitting these cuts for criticism is doing much good."

H. M. Uttley, Nevraska, breeder of Light Brahmas: "I am so young in the business of breeding thoroughured poultry that I am hardly competent to criticise a drawing by almost any one, but I have watched and studied AIr. Sewell's work in your estimable journal with great pleasure and shall attempt to criticise in this matter" (what little I do) with a goor deal of reluctance. In treating the picture of the male, in my judgment it would be an improvement to the shape of the bird to draw a line from the curve of the back across in front of the hock, lowering that part of the breast in front of the hock, that is give the bird a little more depth through that part, and it looks to me on the picture as though it were too much pinclied behind."

John H. Rohrer \& Sons, Pennsylvania, breeders of Light I3ralımas: "The ear-lobes are too short, not being on a level with lower $€$ dge of wattles. Back is a trifle short, also not flat enongh at shoulders. Fluff a bit too scant behind, not having the broad appearance spoken of in standard. Shanks a trifle short. We would say the neck hackle is tou heavy, as it has been our experience that such heary neck hackle in males produces many cockerels with black in back. With these few corrections we believe he would be about our ideal Light Brahma."

H. M. Dawson, Teunessee, breeder of Light Brahmas: "Comb, head and wattles too small for size of bird. Comb should be a little more prominent in front, more curved at the rear and evenly serrated. Neck is a little short. He loaus too far forward; should be tilted, so as to stand a little higher in front and lower in the rear. The shanks should be shorter."

W. P. Deam (Deam \& Eby), Ohio, breeders of Light and Dart Brahmas: "The male's head is too small, body too short for the height. Point of breast not prominent enough. Very good shape to arch of neck and back."

C. F. Foster, Kansas, breeder of Light Brahmas: "While I think Mr. Sewell has produced for you a very fine dlawing in general and I would be satisfed should I produce a large per cent as good as this cut of the Light Brahma male, still. I nutice some minor points I night change. Coml) should reach a little farther back on head, beak lacks a lirtle in stoutness, wattles not quite large enough, back should be a trifie longer, saddle is too concave. The bird would show a better, more rangy Brauma shape if shanks were a little longer:"

T. Carlwallader, Mlissouri, breeder of Light Brahmas: "The Light 3rahma drawings at hand. I regard this series as the besi tling that has been done, to get the fanciers and judges all on one side as to shape, and I believe that the scores will be more uniform on these lines. While these drawings are good, I will offer my criticisms on the male as follows: Wings are carried too low (look at the standarcl). Tail looks well, but is not quite high enough in carriage. Shanlis are rather short, the feathers on the hocks come down too far, giving a Cochin appearance. The cut does not show enough feathers just below the hock. Fluft is not quite full enough. TVattles and ear-lobes are both rather too small."

D. J. Lambert, Rhode Island, judge and breeder: "AIthough my specialties are the American classes, I see where I should cut these outlines of Brahma shape. The head of male is too small compared to size of the bird. Comb should project fartber back and conform to shape of skull. Middle serrations should be a trifle larger. Breast is not deep or full enough. Body is too short and needs more fuff. Upper sickles of tail should be more developed."

Mrs. L. A. Mclleekin \& Sons, breeders of Light Brahmas: "Wish I could breed as good shaped birds. Still I thinls the male curves out too much in front of hackle. Head is not strong enough." 


\section{BRAHMA FEMALE SHAPE.}

Criticisms of Foremost Judges and Brahma Breeders on a Composite Ideal From Live Models, as Drawn by Franklane L. Sewell-A Collection of Opinions That Are in Themselves

Authority on the Ideal Shape of a Standard-bred Female Brahma.

From the Reliable Poultry Journal.

$\Pi^{\mathrm{T}}$

T IS highiy creditable for the judges and brencin of standard-bred fowls to submit their criticisms on these drawings. Their doing so proves that they take an active interest in whatever is for the good of Poultry Culture; proves that they are ready and willing to do their part in the work of developing and improving the thoroughbred poultry industry along right lines. It takes a degree of courage for these friends of better poultry to write down for publication their opinions, pro and con, of Mr. Sewell's sketches. Located, as they are, hundreds, and in some cases thousands of miles apart, they have no way of knowing what the other judges and breeders are going to approve or object to. Each one must depend on his or her own knowledge, on his or her own interpretation of the standard. It is a good training for all. The standard has been carefully read and re-read on account of this serjes! The future is bright for Poultry Culture, for the thoroughbred poultry industry so long as the foremost men and women engaged in it will do such work as this. The R. P. J. greatly appreciates the courage and good will of the judges and breeders. We know that the many readers of the Journal also feel under obligations to them, and to Mr. Sewell.-Ed.

D. J. Lambert, Rhode Island, judge and breeder: "Head is too small; reck is not long enough; hackle should come down more on the shoulders. The back is too long; it wants a more concave sweep to the tail. The tail is uneven; the upper feathers should be longer so as to appear more pointed. The legs and toes would look better if longer.'

J. Y. Bicknell, New York, judge and breeder: "Back and body are too short for the depth of the bird. Breast shows too much fullness; unnatural and undesirable. Head looks as if a portion in front had been cut out to make room for the comb instead of having an oval sweep, and the comb placed above it as it should be. A small comb is desirable, but this one is too small. Give the head the natural oval front, make the comb a little larger, place it above the skull instead of having it crowding the latter out of the way."

L. P. Harris, Nebraska, judge and breeder: "I liave no criticism to make on female Brahma drawing sent to me."

D. A. Stoner, Indiana, judge and breeder: "In regard to Mr. Sewell's Light Brahma female, I would say that in shape she is overdrawn, or she shows a bird so fat that she would be of no use as a breeder. The back is too straight; cushion is not full enough to rise to tail nicely; breast is too full; boxy hangs too low; flufif between Iegs also hangs too low, too much like an over-fat goose. Too much fat, too much fat!"
D. T. Heimlich, Illinois, judge and breeder: "The drawing of female shows too much of a Cochin type of body. The back is straight, not concave enough. Breast is too deep and fluff too full. Leg and toe feathering is too heavy for a Brahma. A line should be drawn from upper edge of hackle where it joins the back to tail to the depth of one-fourth of an inch, tapering. Cut the breast away one-fourth of an incin in front of the thighs to a point, to the lines in front where breast joins the neck. Cut away a full half inch of the fluff back of hocks, tapering to the vent. Between vent and lower tail feathers fill ont more fully. This would then take away the Wyandotte character of tail and make the whole harmonize with the perfect makeup of the male."

F. J. Marshall, Georgia, judge and breeder: "The Light Brahma feruale is not nearly so good as the male drawing, too much Cochin entirely. Head is pretty good, except comb is set too far forward. I like the shape of throat, but the neck is a little short, not much, though if the body were not so blocky looking. Back is too high and straight from bas $\Rightarrow$ of hackle to tail. Tail is carried too low and it is a little too long at the middle of it. The breast is decidedly too full and carried ton low, looks like a pouter pigeon. Body and lluff are ton full feathered, especially about the thig[es. Thighs and shanks are too short and look too much like they came risht out of the body like a peg."

F. H. Shellabarger, Iowa, judge and breeder: "The female is not as good as the male. The neck is short in length, the back too long and not sufficiently concave in front of the tail. The breast is overdrawn and too prominent at point of breast bone. Legs and toes would fit a Cochin better than a Brabma, as they are too short."

H. S. Babcock, Rhode Island, judge and breeder: "The feniale shows more of the Cochin than the male. Back should be more concave-too straight now, which'makes tail set on badly. Body too deep for its length. Thighs too much, hidden by the fluff. Leg and toe feathering too profuse. A hen with such a general shape would be markedly cushioned. I do not like the type of Brahma hen shown in this illistration."

John C. Snyder, Oklahoma, judge and breeder: "The female is too short in neck; crown is too high above eyres; back is too low in saddle; tail is rather large; fluff is too. low, which make thighs too short. Altogether she is not so good as the male."

S. L. Roberts, California, judge and breeder: "The bead. is good with exception of beak, which is too flat at nostril and curves at point too near the tip. Comb appears to be 
good. Eyes, ear-lobes and wattles all right; expression, by reason of projection over eye, Brahmistic. Neck, not of 'medium length' as compared with size of body, and it somewhat deteriorates from the arch. Back, not concave nor flat enough. Freast, deep enough, round enough and full enoush, in all conscience. Body and fluff good. Wings, not square at shoulders by reason of a slight droop at butts. Tail all right. Legs and toes right. All considered it is as good in untline as one need to wish, the foregoing exceptions being made."

Theo. Ifewes, Indiana, judge and breeder" "The female is not so good as the male; it is too low on the ground; too much Cochin. Head and neck are set too far back, and $\pi$ hon you remedy this you get the back too long. The back is too straight and too long. Tail is pinched. There is too much fluff and too much leg and toe feathering. Breast is entirely too prominent, due to the position in which she now carries her neck. We could add a little to the length of this neck, the same as in the male."

D. M. Owen, Tennessee, judge and breeder: "The neck is tro much arched. Breast and body are both toc deep through up and down. I do not like the set of tail. The main tail feathers set too horizontally. The tail should continue the even concave shape of back. Legs are too short, and legs and feet are too heavily feathered. General appearance of the specimen is too blocky."

H. B. Savage, Texas, judge and breeder: "The head is rather too small. Comb is set back too far from front of beak: it needs just a trifle more curve to beak. Breast is too full and prominent; neck a trifle too short. Tail is a Iittle too low, and back is too long. I should like a little better concave sweep to it. Outer toe, like that of the cock, is too short."

F. W. Hitchcock, Colorado, judge and breeder: "In the female there is more to criticise, as it is too gross and heavy for a typical American Light Brahma female. It looks too much like an over-fat hen. There is not quite concave sweep enough to the back. The breast and body are too deep and the stern altogether too keavy. It is also too heavily feathered around the thighs. Head, neck and tail are all right."

W. S. Russell, Iowa, judge and breeder: "I can find but little to criticise. I would prefer to see the back flat at shoulders and then rising with a concave sweep to the tail. If the tail were raised just a trifle it would add to the appearance of the back. I consider the thighs too short."

C. A. Emry, Missouri, judge and breeder: "Too much Cochin in legs and fluff, otherwise it suits me."

George H. Northnp, New York, judge and breeder: "The proof of the Brahma hen seems perfect, except that the tail is a little too long and the back is too flat near the tail. The back should have a more concave sweep."

F, B. Zirnmer, New York, judge and breeder: "What I saici last month applies with equal force in this connection."

H. A. Bridge, Ohio, judge and breeder: "The comb is ton delicately drawn and not distinct enough in formation, especlally outside serrations are not prominent enough. The back at junction of tail should be raised to relieve the broken sween. The encis of main tail feathers shoult be of a length to form a gentle convex sweep from the top main tail feather to the bottom covert as they are in cut, then bring out the coverts to a little less sweep, showing the main tail beyond the coverts in unbrolien lines.

"I did not intend to say anything about color, and will not, except to give my fancy regarding tail and coverts. The lacing on first row is a little broad-make it clear and distinct and sharply defined. Bring out the first row as suggested and add another row, but overiap them just a little more and have one less covert in second row than first. Now arld still another row with one less than the second. These coverts should be overlapped enough to show plainly, and at the same time give feathers of back and side the same conver outline as they finish up on the tail as the breast has; this will give the bird a slightly rounded-up finish at both ends with the snow-white feathers. The breast is too full and the wings are carried a little too low. Legs are a little short; thighs do not show quite enough. Body and fluff are too full and in connection with the legs make the bird a little Cochiny.

"In connection with the above, I wish to say that with all my faultinding I consider these among the very best Mr. Sewell has given us in all the varieties, and as regards their merits as typical Light Brahmas they are the best pair I have ever seen drawn, and had I placed an order with $\mathrm{Mr}$. Sewell fol cuts of Light Brahmas and received these I should have been very much pleased. My criticism of the drawings is not so much on the work of Mr. Sewell, but rather more to give my idea of the ideal.

"Sickness prevented any remarks on former drawings; but I assure you $I$ enjoyed them very much and $I$ hope to be favored with invitations to participate in all future criticisms of ideal cuts, as this worthy enterprise of the Reliable merits the support of all true fanciers."

Charles MeClave, Ohio, judge and breeder: "Symmetry is good. Shape of head is good, but it is a trifle too deep from eye back, giving back of head and upper neck a heary appearance. Back is rather long when compared with that of the cock, and too low at base of tall. The breast is plenty full and in fact, Cochin full. Tail is a trifle too low. Shanks are too short, Cochin type. Feathering is pretty heavy for a Brahma. General outlines are a little after the Cochin type with the exception of the tall. The Brahma and Cochln shapes seem to be drifting nearer together in females."

O. E. Skinner, Kansas, breeder of Light Brahmas: "Referring to the proof sheet of Light Brahma female I would not suggest any great changes in the bird. I would want a littlo larger head with broader skull and more throat wattle and ear-lobes a little more prominent. Would want quite a little longer shanks. Shape of breast, back and tail is gond"

W. P. Deam (Deam \& Eby), Ohio, breeders of Light and Dark Brahmas: "The female's head is too small, it has not enough expression above the eyes. The neck is too short and too large at base. The body is too low between the legs. Point of breast is not prominent enough. The tall is too long for size of bird. The eut looks too round, it does not show points that should be prominent."

C. F. Foster, Kansas, breeder of Light Brahmas: "The female is so near my ideal that I pass her, only saying that she has a too sluggish and listless expression. In my opinion the Reliable is to be complimented on this good work in the interest of the poultry fraternity." 
T. Cadwallader, Ohio, breeder of Light Brahmas: "While the drawing is good, I would offer the following criticisms: Ear-lobes are rather too small; wings are carried just a little too low; the back is too straight, it should have a more concave sweep to tail; the neck is a little too short; the legs and coes are too short, giving the bird too much of a Cochin appearance; tail is too large."

T. N. Smiley \& Son, Indiana, breeders of Light Brahmas: "We think the female is a little long in back, and perhaps a little full in breast, otherwise it is excellent."

W. A. Irvin, Nebraska, breeder of Light Brahmas: "I an pleased to accept as typical the shape and outlines of the Brahma female, as drawn by Mr. Sewell."

Sid Conger, Indjana, breeder of Light Brahmas: "The hen is coarse, too deep and coarse for her length. She is too small up and down in front of her" tail, head and neck too small and thrown back too far. Taken all in all, the hen is not good and will not do at all for an ideal."

G. W. Randall, Nebraska, breeder of Light Brahmas: "The female seems to me to be a ittle full in the tail. I am glad to see less tendency to stimulate breeding toward the Cochin shape than has been shown in some previous cuts. To put the Cochin shape and feathering onto the Brahma would destroy its chief beauty -its grand, majestic appearance."

H. M. Uttley, Nebraska, breeder of Light Brahmas: "I have no suggestions to offer in regard to the female Brahma shape. Older breeders and judges may, but I should say that a bird which fitted the picture in every respect would be almost entitled to a score of $100 . "$

Alfred Doyle, Illinois, breeder of Light Brahmas: "Head is faulty; eye should be a little higher up and a little farther back; mouth is too long; wattles should be placed a little farther forward; ear-lobes should be directly under the ear. Neck is too thick back of the head. Some of the lower hackle feathers are entirely too large. Back is entirely too straight and a little too short and not rounding enough. Breast is too full and should be cut away a little from top to bottom. The lower edge of fluff should be cut away a little; wing is not quite long enough; tall looks to be too narrow; middle feathers should not be longer than the upper ones, and the upper tail coverts are entirely too large. Hock and leg feathers are entirely too heavy-they would look well enough on a full feathered Cochin, but are out of place on the American type of Brahma. Take her make-up all through and I consider it too blocky."

Mrs. B. G. Mackey, Missouri, breeder of Light Brahmas: "It appears to me the female is a little too flat at base of tail and the tail is carried rather $10 \mathrm{w}$. Otherwise I see no fault in the shape."

Miss Hattie Winship, Illinois, breeder of Light Brahmas: "The female is better than the male, still I should prefer her more blocky and more heavily feathered with a back broader and not so slanting, such as you find in frontispiece of March, $1896, \mathrm{R}$. P. J."

James George, Kansas, breeder of Light Brahmas: "The neck of the female is a little full at base. The bacis is al- mest, too straight; it should be a little more concave. The tail might be elevated a little."

N. E. Woods, Indiana, breeder of Light Brahmas: "The beautiful renresentation of a perfect type of Brahma female is almost faultless, as I look at it, except I would suggest that the back from cape to root of tail is too straight, the legs are too short and there is too much feathering to represent activity and usefulness."

F. F. Congdon, Wiscousin, breeder of Light Brahmas: "I think this etching shows a bird a little too high for the length, and, as in the male shape, the head is a little small. I like to see Brahmas with a head that looks as though it were full of knowledge. I want the crown to project well over the eyes. Would like 'a thousand of 'em,' however, as good as the etching."

W. W. Kulp, Pennsylvania, breeder of Light Brahmas: "I do not like the shape of the female. The breast is too much of a circle; they do not grow that way. The standard 'roundness' is more around horizontally than up and down. The breast line is straighter; should not be one continuous curve. There is too much tail. I would be satisfied with less. It extends down one-third too far and is too long at the end. Fluff is too full also for a Brahma."

ㅍ. G. FTayward, Illinois, breeder of Light Brahmas: "I think the shape of Brahma female is all right."

H. N. Rollins, Massachusetts, breeder of Light Brahmas: "The cut of Brahma female suits me very well, but I should prefer to see the back more concave."

William Chamirgs, Illinois, breeder of Light Brahmas: "The Light Brahma female cut I consider extra good (much better than the male) and I suggest but two changes: Back at base of hackle should be flatter, and the two upper tail coverts extend back too far over main tail feathers."

N. Porter Brown, Massachusetts, breeder of Lighr Brahmas: "The proof of the Light Brahma female I consider perfect. She fulfills my ideal to a dot."

W. S. Campbell, Illinois, breeder of Light Brahmas: "The tail of the female looks too long and has a pinched appearance just in front of the coverts. The comb is smaller than I like. The hackle is a little fuller than we find in nature's productions. Breast is a little too full."

Simon Lynch, Indiana, breeder of Light Brahmas: "This cut is excellent, but I would want the back with a shade more concave sweep. Hackie is too coarse. Fluff extends too much on hock joint. I want a white color."

Mrs. T. W. Ragsdale, Missouri, breeder of Light Brahmas: "I can see no fault in the female Brahma unless the neck is rather short for such an immense body. She is all I could wish for. I only wish I could raise such as this engraving represents."

T. R. McDonald, Kentucky, breeder of Light Brahmas: "I have very little fault to find with the cut of Brahma female. The tail might be raised a little, it gives the back the appearance of being a little too long." 


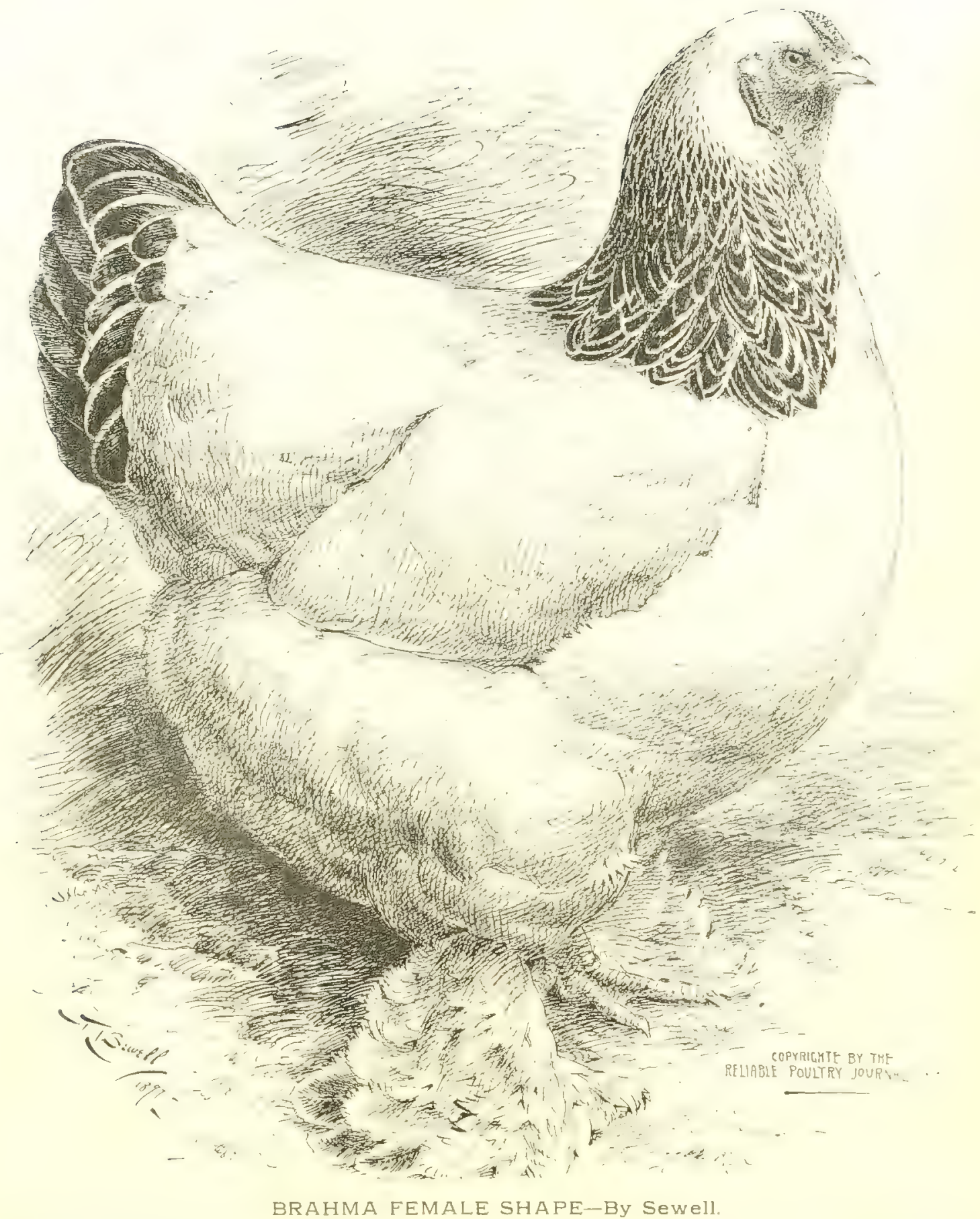

Comprising the Best Points of Several Live Models, as Illustrated by Franklane L. Sewell for the Reliable Puultry Journal, and Submitted to Sixty Prominent Judges and Breeders for Criticism

Based upon Standard Requirements. 


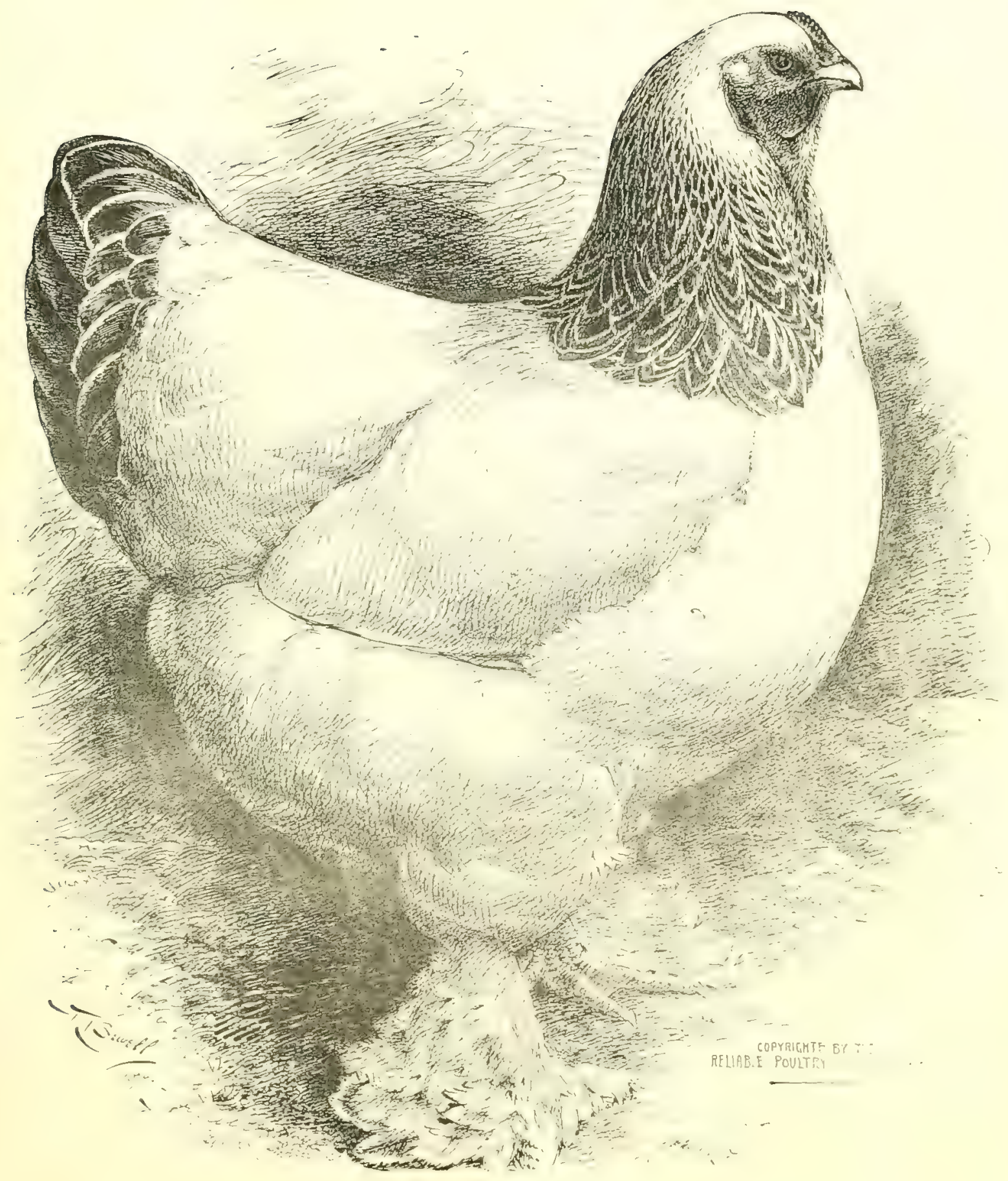

BRAHMA FEMALE SHAPE-BY SEWELL.

An Ideal Brahma, Illustrated by Franklane L. Sewell, for the Reliable Poultry Journal, under the Sudgestions of Sixty Prominent Judges and Breeders-The Outcome of Criticism Upon the Brahma Female Shape Shown on the Opposite Page 
Casper Dice, Nebraska, breeder of Light Brahmas: "I thiuk that both neck and legs of female are too short for body. Back is too straight and narrow and the tail is pinched too much. It looks as though the lower feather were gone."

John A. Myers, director West Virginia Agricultural Experiment Station, breeder of Light Brahmas: "In the female I think the Huff extends down and back a little too far, and the line extending from the cape to the back part of the cushion seems to me to be too straight. In other words, I think the back should be depressed somewhat over the cuskion so as not to give it such a cocked up appearance. I graut that many Light Brahma hens have a tendency to carry themselves as shown in the cut, but I would prefer the other form as ideal. It is a small matter, however, more a question of taste than otherwise in selecting our model."

F. L. Ackerman, Michigan, breeder of Light Brahmas: "The back is too long and flat. Breast a trifle too full and deep, with wings a trifle large and not carried high enough. Tail too large and a trifle too short in shanks. Otherwise it is good."

R. R. Clendenen, Missouri, breeder of Light Brahmas: "The cut representing standard shape of Brahma female is good, but I think it might be improved. The wing is not carried high enough; the back does not have that perfect concave sweep to tail that I admire. It is too low on saddle and perhaps the fiuff above vent is not quite full enough, giving her a pinched appearance in front of tail."

L. O. Berryman, Illinois, breeder of Light Brahmas: "The female is all $\mathbf{O}$. K. except I would give her back a little more concave sweep to the tail and perhaps lengthen her legs a trifle."

J. A. Roberts, Pennsylvania, breeder of Light Brahmas: "The Brahma female is good. The eye, which we suppose is bay, might be a little larger, and the tail should run straight, not raised, bus run in line from back."

M. Mayer, Jr., Mllinois, breeder of Light Brabmas: "The female shouid have a little more cushion, otherwise I conside!" it an ideal drawing."

I. J. Burnside, Indiana, breeder of Light Brahmas: "The female is too straight on back from point of hackle to the tail."

George Luhrsen, Illinois, breeder of Light Brahmas: "The female drawing of Light Brahma from Mr. Sewell is excellent in my estimation, unless it might be a little long in the back. I think her as near to the standard as any I ever saw, and do not think there is much room for criti"isin

Mrs. Flla Thomas, Missouri, breeder of Light Brahmas: "The model for the female is better than the male, lhough the comb should be slightly longer and extend back farther on head; skull broader, wattles heavier, back shorter for the length of body, with more of concave sweep to tail. The body should be longer in front of thighs, hocks more closely rounded, and more distinct. Foot feathering with the amount of black would be elegant. They are grand specimens, but not quite far enough away from Cochin shape. hardly up to my ideal of true Brahma shape."

Mrs. B. Tr. Jackson, Kentucky, breeder of Light Brahmas: "The female is better in comb than the male. I think the back is a little too straight and long."

John H. Ryan, Illinois, breeder of Light and Dark Brahmas: "I think the Brahma female, as drawn by Mr. Sewell, excellent, but I think she is a little too short and compact. I wonld suggest that her body should be somewhat longer, and I think the back is a little too full and straight. It would look better if more concave. Wing is carried too low at rear. Otherwise it is all right."

George Clough, Illinois, breeder of Dark Brahmas: "The female is indeed excellent in shape. If she is faulty anywhere it must be in tail, which is, I think, a little bigh, and the. fluff should be more abundant."

F. E. Marlow, Missouri, breeder of Light Brahmas: "The back of the female is too long and there is not enough concave sweep to the tail. Otherwise she suits me all right. Both are extra good drawings."

5. Dunstan, Mississippi, breeder of Light Brahmas: "Regarding the Light Brahma female drawing submitted for criticism. I would say that I think the head, comb, bill wattles and ear-lobes are all right, but the neck is tar from being of medium length and well arched. The back seems broad and of medium length, and flat at the shoulders, but it lacks the concave sweep to the tail, and the tail is too large and coarse to be described as rather small. The breast, 'round, hroad, deep and full,' is overdone, and the same with the body and fluff. Take the cut altogether it has the appearance of an over-fat Light Brahma with a very ill-proportioned ueck. If the neck were lengthened onequarter and in same proportion as presented, with the excessive fullness of breast, body and fiuff reduced to every day proportions, I think you would have a comparatively good Light Brahma hen. As it stands, I consider it a very illproportioned bird and not in accordance with the Standard of Perfection."

Mrs. L. A. Mclleekin \& Son, breeders of Light Brahmas: 'Back of female is too much of an incline, instead of having a concave sweep to the tail. Instead of the sweep, the tail rises too abruptly. The bird is a little too much Cochin in shape." 


\title{
LIGHT BRAHMAS IN NEW ENGLAND.
}

\author{
Fifty Years of Improvement and of Advancement in Popularity-Points of Recent Improvement-A \\ Comparison of Winning Types.
}

By 'T'. E. MCGREW.

From the Reliable Poultry Jonrnal.

$\square$

ROM the time of what is known as the "Cornish importation of Brahmas" into Connecticut, in 1849, via the Port of New York from some south sea country. the Brahmas have become the pride of all New England fanciers. New England, of all the world, is the home of the Brahma; there they are produced in all their glory and modern perfection.

Early in the seventies-almost thirty years ago-Mr. Lewis Wright, of England, wrote the following words: "Fach breeder should fully acquaint himself with the proper characteristic of his favorite fowl and have in his mind a definite idea as to the standard of perfection after which be aims. If such ideas have been formed intelligently and on good grounds, they should not be lightly given up for the fashion of the hour, which can often not be depended upon longer than that of a lady's bonnet. It will often be better, and in the end even pay better, to sacrifice some prizes for a year or two than to give in to the present fancies of second-rate judges and degrade a stock in order to meet them."

These timely spoken words of the "King of the Brabma fancy" in England saved the Brahma from ruin and maintained their characteristics, while not in our cherished type, yet of the same fashion, only more cobby than we select. At that time, in England the opinion of the judges, whether right or wrong, had great influence and many followed the lead of these experts and tried to fashion their Brahmas on Cochiu lines by shortening their legs and encouraging heavy hocks. The words of Mr. Wright changed these plans somewhat, and called the attention of all to the true rule of breeding to a true type. Many times with us could this same warning be sounded as against following a fashion that is made popular by the placing of awards in opposition to the standard rule. It would be well for us at times if some one of authority could save us from ourselves when we wander from a true type while searching for a solid wing flight, or a handsome covert, as if these constituted the whole thing.

Too much attention cannot be paid to the rich coloring of our Light Brahmas. The neck feathers of the males, when examined singly, may be quite handsome, but the proper coloring of the hackle should present a beautiful blending oi color from just at the juncture of head to well down over the shculders, the whole presenting a picture of beauty in black and white that is most attractive. The black centre of the hackle should be rich and bright and the white edge of the same pure white, without any shading of black whatever. The black should be clear cut and distinct-no running of the black into the white, the white border or edging of each feather should be pure white and entirely free from any shading of dark or black.

Such rich, pure coloring of the neck is very beautiful when the black centre is of a rich shining black that tapers to a fine ending at the point, and the whole edged or laced all about the black centre clear up to the very start of same, with clear, pure white that has no tinge of color in it. When such coloring extends close up to the head and well around in front, marking the entire hackle plumage, leaving no pure white portion upon the plumage, then the perfect neck is present. No more will the white ring about the neck, just back of the head, pass muster as the perfect marking, nor will it do to have clear white portions of the hackle on either side in front, lacking the black centre; the backle must be well marked in every feather.

The pure black flights in the male are most difficult to obtain in these handsomely marked specimens that have the nice white lacing about the coverts, and the pure, clear, rich black tails which are nicely filled in with feathers laced with white. This beautiful combination of clear black and white, with the black or almost black flights, gives us the present up-to-date rich colored show specimens. Many such were seen at the Boston show, of a quality that surpassed any yel produced in this country, their form, color and markings being the admiration of all who saw them.

There are many fanciers throughout New England who pride themselves on the high quality of their Brahmas who never send a bird to a show, and there are many more who breed them for the keenest competition and come to the ring side; as it were, to contend for supremacy. The latter are the backbone of the New England fancy; they form the membership of the New Fngland Brahma Club; they are the men who guide and guard the future welfare of the Brahma, and to them the world must look for the greatest advancement and quality in this breed.

The alplication of all rules of law can be so construed as to fit almost any existing condition; it seems to be much the same in applying the Standard of Perfection to the Brahmas in our several shows. After the awards were placed in Boston in 1900, the accusation was made against the winning pullet that it was Cochin in shape. Under the approval of the New England Brahma Club this claim was made emphatically, Next year they had the exhibit and the selection of judges in their own hands, and we find second on cock birds and first on cockerels placed on specimens that showed more of the Cochin type in their make-up than had the pullet of 1900 .

When we compare the awards of one year at Boston and New York, we find that a cock bird of admitted high quallty was first at Boston. This same cock bird, when he came to New York two weeks later, was superceded by one that was selected two weeks before at the Boston show because he was considered to be the style of bird most preferred by the New York judge. All the Boston pullet winners were turned down at Now York in favor of one that did not gain a place at Boston. The winner at New Fork was small in size, trim in form, beautiful in hackle plumage, not clear white in body plumage, and her wing flights almost too weak in color for an old hen. Here we have a demonstration of the great gap that divides the opinion of these two experts.

This shows the importance of having a better understanding and of getting closer together on the whole matter. T. F. MeGREW. 


\section{LIGHT BRAHMA IDEALS.}

The New England Light Brahma Club is Content With Nothing Short of the Best-Mr. Franklane L Sewell Engaged to Portray the Ideals of the Members-History of These Ideals.

By G. W. CromaCk.

(From the Reliable Poultry Journal.)

$\prod^{\mathrm{T}}$ WAS a long time after the idea of securing ideal illustrations of Light Brahmas was first mentioned by members of the New England Light Brahma Club that an atlempt was made to embody their various preferences

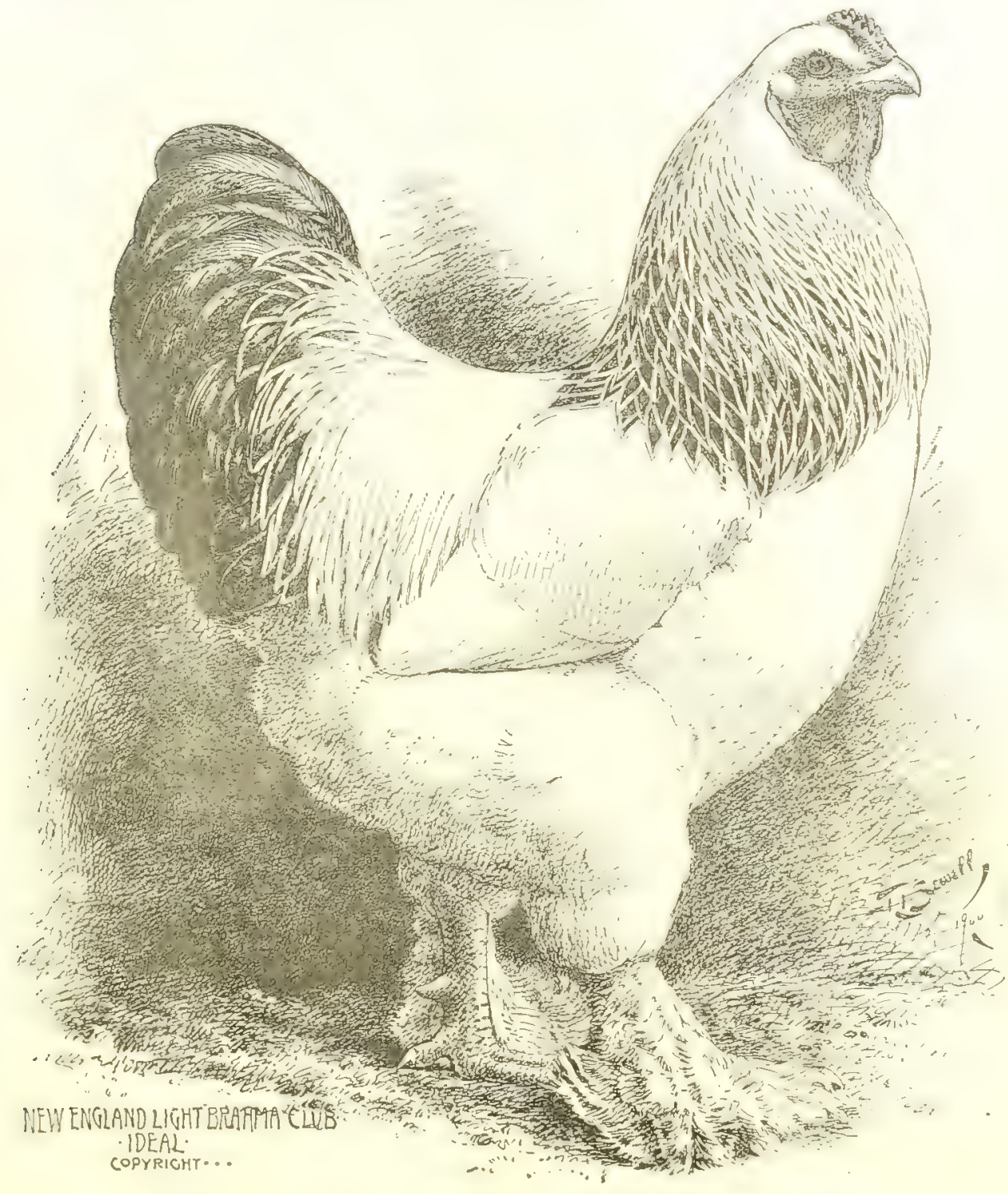

Light Brama Male adopted as the Ideal of the New Fngland Light Brahma Club. A sewell Production Based upon the Ideals of the Members

were commencel with an artist with a view to getting draw. ings submitted, and then, having criticised and perfected them, to order composite illustrations which should represent the club's ideal. Well, the drawings were submitted, und no fowl was ever plucked more quickly or more mercilessly than were those unfortunates. In short, the subject of securing an ideal male and female was for a time abandoned.

As the years llew by there were continual calls for the club catalogue, and finally at the annual meeting in April, 1900, the secretary stated he had sent in answers to calls for catalogues, old premium lists, and that the supply of those was nearly exliausted. It seemed, therefore, that a catalogue should be prepared. This question having been settled in the affirmative, "ideal cuts" were again suggested-they must be had to place in the proposed catalogue. This time the secretary was instructed to correspond with $\mathrm{Mr}$. sewell and inform him as nearly as possiule what would be expected in drawings of ideal male and and femaie Light Brahmas.

The drawings arrived.

The male as published is identical with that submited by Mr. Sewell, while the female has been changed several times.

All of this took months to do and it was January, 1902, before the cuts were published in the catalosu

in composite ideals. There were many men of many minds, and most of them were very decided in their opinions. Their ideas of shape had taken years to formulate, and were not to be lightly forsaken. After a good deal of talk (everybody admitted the necessity of the New Fingland Light Brahma Club having an ideal male and female), it was decided to procure cuts. A committee was appointed and negotiations
It is no: to be supposed that they represent everything that every member wishes to see in Iight Brahmas, but every one belleves them to be the nearest possible approach to the ideals of the members generally, and we hazard nothing in saying that they are by all odds the finest replesentations of ideal Light Brahmas in existence.

G. W. CROMACK. 


\section{THE LIGHT BRAHMA A GENERAL PURPOSE FOWL.}

They are Good Layers of Large Eggs; Make Desirable Broilers, and May be Cheaply Housed and Easily Cared For.

By E. ERICIKSON.

$\mathbb{W}$

ARE often asked by visitors in the show room if Light Brahmas are good layers. We believe we can truthfully answer, that they are very good layers. of course we do not claim that they will lay more eggs than the Leghorn or some of the other small breeds, but if the size and weight of eggs are taken into consideration, they will head the Iist. We have jus, placed on the scales one dozen Brahma eggs, that were gathered from our yards to-day, and they weigh one pound fourteen ounces. We also weighed one dozen White Wyardottes, that weighed one pound nine ounces, showing a difference of five ounces in favor of the Brahma. Thus it would take a little more than fourteen Wyandotto eggs to equal the weight of twelve Brahma eggs. At this rate for a year, allowing the Brahma an average of one hundred ană fifty eggs per year (a record which they will easily make, and many. of them will lay more than that), the Wyandotte will have to lay one hindred and eighty to equal the weight of the Brahma eggs.

One of our customers told us that he kept a record of his flock for a period of 190 days. By the use of the trap nest boxes he found that one hen laid 145 eggs in this time. With good care she surely would have reached the 200 mark in a year, as he had 175 days more to go.

We will suppose that the birds are kept for market only, and that the old hens are sold off along in Juiy after the laying and hatching season is over. A flock of good Brahma hens will average about nine pounds each, while most of the smaller breeds will not average over six. Let them sell, say at ten cents per pound. Here again the Brahma. Will gain thirty cents per head over the small, heavy laying competitor. Some one will say that the smaller hen has already gained that much in the extra number of eggs laid. Yes, she may have, if she has been ?aying heavily during the winter. But it must be remembered that the Brahmas are naturally good winter layers. With their low combs and heavy feathering, they can stand more cold than any other breed that we know of, and for this reason they do not suffer or lose any time on account of frozen combs. They do not need as costly built and warm houses as the high combed varieties. Any kind of a house that is tight and dry will do for them.

If early broilers are wanted, there is no bread that will reach a weight of two pounds each in less time. We have 


\title{
THE LIGHT BRAHMA.
}

\author{
Its Origin and Introduction Into America-The Standard Male and Female Described Section by Sec- \\ tion-The Principal Defects Explained and the Cuts for Each Given-The \\ Method of Mating This Variety to Produce Exhibition \\ Birds Set Forth in Detail
}

By I. K. Feưn. Associate Editor Reliable Poultry Journal.

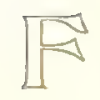

OR nearly fifty years I have been known as the champion of the Light Brahma and today I affirm that among all the breeds mentioned in our standard, they are most worthy of consideration. They are the best of the Astatics and are entitled to first place among the three or tour best money making varieties. No matter how often one writes about them, there is always something good left unsaid, and the lover of the pure Brabma type may well sound the alarm against the encroachment of the Cochin shape in his beloved variety. Leaving others to display their rhetoric and classic learning, I simply wish to express in plain words what I know about this variety from experience. I will tell of their origin, their development and their influence upon the poultry culture of our land. I will describe the true Brahma shape, their plumage, and tell how to mate and how to judge them. This I will do for the benefit of those who are starting in poultry culture and those who are to follow in this industry, which is fast becoming the greatest of agricultural pursuits.

ORIGIN OF THE LIGHT BRAHMA.

The breed came to us in America completed, if we may use the term; that is, it yassed through no mongrel, no transitory state. So perfected was it then that fifty years have failed to make them one whit better, and a breeder is not able to-day to produce a bird with a higher score than those we had in 1876. One specimen has reached the remarlkable score of 97 .

About 1847 they were discovered by a Mr. Knox, on board an India ship in New York harbor, and those six birds are the ancestors of the American Light Brahma. Mr. Knox purchased them for a Mr. Chamberlain, of Hartford, Conn. These birds and their progeny later became the property of Virgil Cornish, who placed them on exhibition in 1850 at the Fitchburg Depot show at Boston, where they were named Brahma Pootra, or short-legged Chittagong. At thac time there was a large, ugly variety known as Chittagong. It was the largest and the most popular breed. The breeders of that variety were jealous of the Brahma's advent and did all they could to prevent them from forming a distinct variety, but the Brahma's more symmetrical shape, its pea comb and its prolific laying soon overcame the opposition, and in a short time they became known as the Light Brabma and were acknowledged to be the best of all large fowls. They gradually absorbed the Chittagong blood and that breed disappeared, while the Brahmas, as such, were put into our first standard. There was an effort made later to resuscitate the Chittagong under the name of Singlt Comb Light Brabmas and they were exhibited at one or two shows, but the race soon became extinct.
The first birds imported were capable of reproducing themselves and the variety to-day is able to produce progeny, ninety per cent of which will score 90 to 96 points. It shows a strength and prepotency not excelled by any other breed of parti-colored fowls. The standard written for them in 1876 is, and ought to be standard to-day, for birds of that type are most prolific. One hen, Rebecca, has a record of 313 eggs in 333 days, and trough she laid no more eggs during the other thirty-two days that finished the year, it was still a wonderful record. Another hen, Pareppa, laid for iwentythree consecutive months without showing any desire to incubate, and eight of her sisters showed no desire to sit.

But one swallow does not make a summer, nor does one bird with a remarkable record prove the superiority of a variety, but I know that birds of the Chamberlain-Felch strain will average 150 eggs a year besides hatching and rearing a brood of chickens. Flocks of thirty-five, fifty-five and seventy-five have records of $921 / 2,107 \frac{1}{2}$ and 110 eggs whell one year old. Other flocks have jearly records of 160 to 168 eggs each, and seven-twelfths of the number of eggs were laid in the five coldest months of the year when eggs bring the best prices. Eight pullets have a record of 192 eggs each, besides raising 64 chicks in the yards of the late G. P. Fay. They lay large, heavy eggs, which weigh more per dozen than those from any other fowls. They will make tender roasts at a greater age than other varieties and if the roosters are kept in celibacy they will make tender meat when a year old. When the Light Brahma females have been crossed with Wyandotte and Indian Game males, the result of these crosses are sure to win the prizes in a dressed poultry contest.

Such are the records that have been made by the oldstyle Light Brahma, and it is the old-style to which we must return and adbere if we will have these records remain unexcelled. The variety has been injured by the desire of some persons to breed them with short necks, backs, thighs and shanks and with the looser, longer plumage and excessive foot feathering. The poultry coops used in our large shows have been greatly to blame for the change to the Cochin type Brahma. These coops were too low for a normal Brahma to stand in them free and clear. Therefore, only a Cochin-shaped Brahma looked well in the coops, and consequently, birds of that character won the prizes and a large number of breeders, noting the style of bird.that had been winning, irmediately began breeding to that type of bird and ignored the standard. This would not matter so much if it did not damage the utility and injure the egg productiveness of the variety. But I know that breeding Bralnmas to this Cochin type has diminished the egg produc- 
tion of such altered strains sixteen to twenty-five per cent. I have seen this demonstrated under my personal observation during my long years with the Brahma. To bring the race back to its old time prolificness and beautiful shape. we have only to breed them according to the early models. They should have a close, smooth surfaced plumage. The neck, back, thighs and shanks should be of medium length and the general appearance should be oblong. The Honorable Geo. Loring, as he stood looking at them at the Middleser South Fair, exclaimed; "They are a vertitable oblong band-box on legs," a quaint expression, but to the men and women of his time it was a forceful one, telling of the equal breast and posterior weight, with their clinging plumage, the hocks showing in profile below the body line, with the
THE STANDARD MALE AND FEMALE

A cock in his second year should weigh twelve pounds or more in exhibition condition. A cockerel in his aduli coat should weigh ten pounds, a hen nine and a half or more and a pullet eight pounds. The birds should bo sufficiently fat to have their plumage show its best sheen when on exhibition. During the breeding season the birds should be allowed to fall one pound under these weights, which will put them in their best working form. Weight is valued at ten points on the score card and is as much a part of the standard's demand of excellence as any other section; and a judge in scoring must cut two points for every pound that a bird lacks.

The judging of fowls is no longer confined to exhibi-

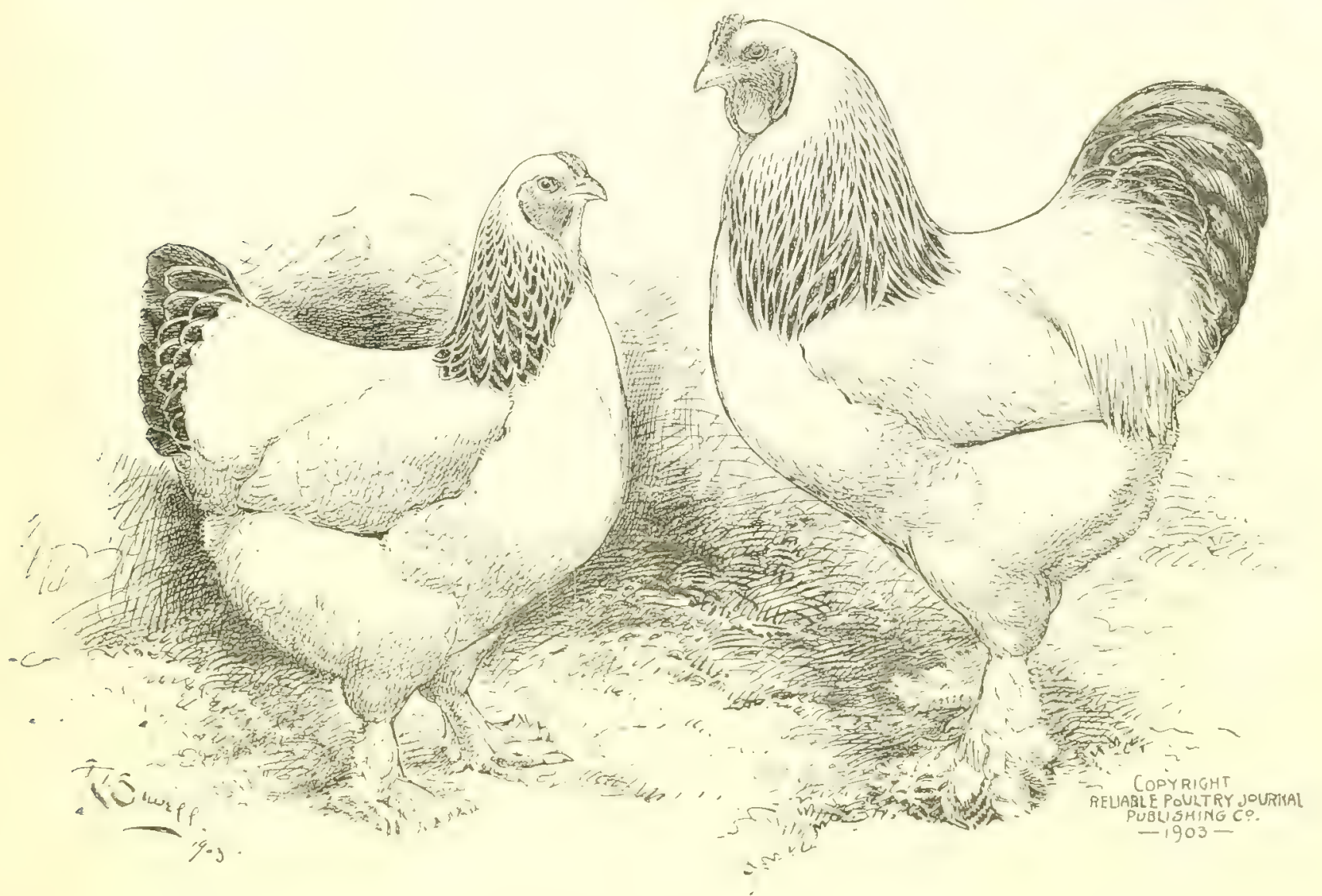

Ideal Light Brahma Male and Fefuale shápe, Advocated by I. K. Velch.

thigh plumage curling closely and smoothly about the hock joint.

In 1876, there appeared in the American Poultry Exhibition in New York City, a Light Brahma cock which was named "Autocrat." It was a bird that was found in Fulton market and no trace was ever discovered of its antecedents. He varied little from the bird from the Chamberlain strain known as the Imperial 300, but afterwards called the Felch strain. These two males, "Autocrat" and "Imperial 300," are the founders of the two strains of. Light Brahmas, the Autocrat and the Felch, whose progeny are to be found in every state in the Union. The popularity of the Light Brahma has declined occasionally, when some now varjety has been boomed and amateurs have been tempted to try them, but each time the Light Brahma has regained its hold and has even grown more popular. tions, although articles upon this subject generally refer to birds in the show room, as they vary less than the specimens constituting a whole tlock.

The first article 1 ever wrote treated of the general defects found in floclis as they existed in the days when our first standard was compiled. To-day so much private scoring is indulged in that there seems to be a necessity for an exposition of the subject of judging the average merit as seen in the whole flock. Lest the novice and beginner may incline to be satisficd with mediocrity, we illustrate this article with perfect male and female shapes, while stating that divergencies from these ideals are faulty in proportion as they differ.

$$
\text { THE HEAD }
$$

The plumage of the head is white. The beak should be stout at the jucture with the skull, and should be nicely 
arched to the point, yellow in color, striped with dark brown color or black in the upper mandible and the under beak should be yellow. The beak in the female may be yellow, or yellow striped with a dark color. In the male the face deep red; eyes red, large and bright; ear-lobes large and pendant; wattles well developed and hanging, their lower edge being well rounded on a line with the lower edge of ear-lobes. The face, ear-lobes and wattles should be rich crimson. In the females all these features are much smaller in comparison with the male, and the wattles are closely rounded to the throat.

The skull should be large, with heavy brows overhanging the eyes. Especially should this be prominent in the male, as seen in our perfect model. Heavy ear-lobes, long and pendulous, with wattles that are large and long enough to place their lower line on a level with lower point of earlobes, are the conditions that insure s rong, procreative power. In early days cocks with only rudimentary wattles

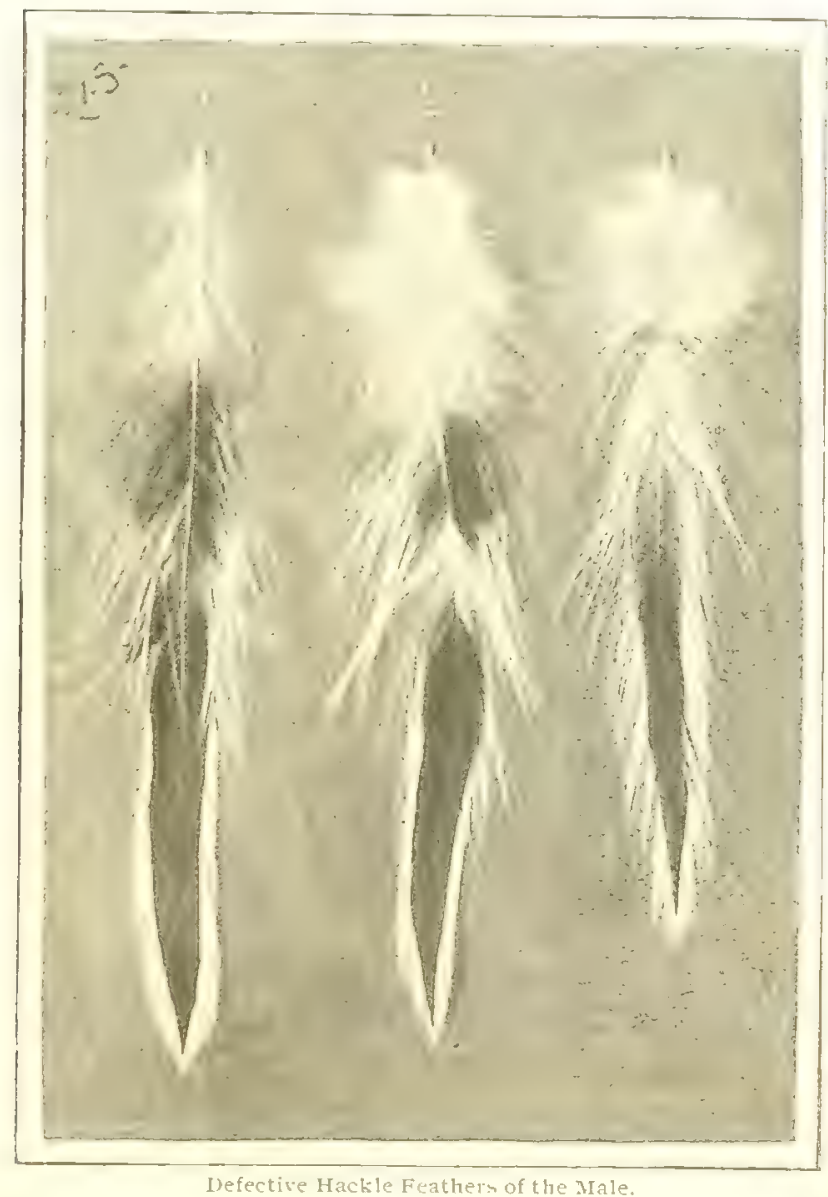

were disqualified and ought to be to-day, for they are worthless, save only as poultry meat.

The defects of head and its adjuncts are generally: Narrow in skull, depressed in front of eyes; for these cut one point; eyes, when rot bay or red, one-half point; rudimentary wattles, one-half to two and one-half, and when cntirely absent, the specimen should be disqualified.

$$
\text { THE COMB }
$$

The comb is what is called a pea comb. It is like three small combs joined together at the front and base, the side divisions merging with the center division near its rear point. The channel between the center and side divisions should be deep enough so that if all the small points were frozen off the comb would still show its three divisions. In an absolutely perfect comb the center division should have seren small points and the sides each five points. The top line of the comb should follow the curve of the skull. While we may say that the comb is small, it is still in keeping with the size of the bird. In the female the comb is very much smaller in wroportion to the weight of the specimen, in fact, the smaller the better, so that it is perfect in shape. It is of the same shape as the comb of the male and is subject to the same cuts.

A comb may be ever so perfect in its three divislons, yet so thin at. base and junction with skull as to flop from side to side of the head. Such a specimen would be disqualified; yet a comb, if from some cause it leans to one side, but is firm in its position, would be cut from one-half to one and one-half for failing to stand erect upon the head in a straight line from front to rear. The comb could be gross and large with crumpled or sernentine divisions, the channels between the divisions so slight that were the small points frozen or shaved off, the comb would be literally a short, single piece of comb flesh. In both these cases we tinink the defect could be so aggravated as to he cut one-half to two points, and when loose at juncion with the skull, we would withhold all score card record as being a specimen unworthy of recognition as a ihoronghbred. If the comb should be single or so liefective otherwise as to stultify standard description, we would also pass it by.

If it is too large, but still stands erect, it would be cut one point for size. On the middle division, if the points are so large and "wide that they crowd in a zig zag way, although side divisions are all right it demands a cut of one point. Taken altogether (size and shape), even if the comb were erect, a cut of two points would be demanded. There is another style of comb frequently seen, a short, very small comb, stubbed off at rear, which causes the bird to look like a man six feet tall, wearing a very small boy's hat. The comb on. some birds has but four points in the middle and three points on the sides, and iue channels are not deep, though straight and stiff upon the head. Such a comb should be cut fully three points. Want of development should always be cut with more severity than over-development. I believe in a generous development of comb and all head embellishments, for it denotes procreative work. Diminutive combs are surely an indication of failing productive power.

\section{THE NECK}

The neck should be medium in length and prominent in its juncture with the head, nicely arched to the center, the hackle then falling in a concave sweep, completely covering the shoulders. Each hackle feather must have a black stripe the full length of the web, ending in a fine polnt at or near the end of the feather. The black stripe must show a rich green sheen for fully three-fifths of its length, and the white must form a complete edge the full length of the web. Tho under-fluff may be either black, dark slate or white, neither having the preference in the show room. The throat should be white.

In the fomale the neck appears shorter and has the same arch and concave sweep that it has in the male. The feathers in the female are more correctly described as black edged with white. The backle should cover the cape when the head is thrown back, which gives apparent fulness to the breast.

In this section there are seldom defects in shape sc glaring but they are overshadowed by color defects. Yet if the neck be short and the effect be that known as Cochin shape, or if the neck be of sufficient length, but head carried so far forward as to give the feature too straight a poise, it should 
be cut one point for shape, for the latter has the dppearance of robbing the breast of its fulness.

It is not by any means understood that every feather of the hackle shall be perfect in order to pass uncut, but that the perfect feathers should be in overwhelming numbers, of the character as seen in our models. But when the neck plumage is in a general way made up of feathers like No. 1, the neck would most likely be cut one point for color; if like No. 2, one and one-half points; like No. 3, one and one-hall to two points if void of sheen. Feathers still worse should condemn the specimens as breeders, and surely they could not be show specimens. They should be sent to the kitchen pen. When the head is carried so far forward as to destroy the full arch of the neck and the hackle fails to fully cover the cape; or when the white lacing fails to extend along the entire edge of the web; or the black and white are mixed, or there is straw color in the white or black spots in the throat, cut one-half to one point. A more severe cut should be made if the black stripe is very poorly defined.

\section{THE BACK}

The back should be medium in length, but sufficiently long so that in conjunction with a full, round breast it will give an oblong appearance to the body. The back will appear much shorter in the male, because more of the cape is covered by the hackle and also on account of the saddle leathers. The standard describes the back as broad and flat, which appearance is caused in part by the hackle feathers spreading over the cape and the feathers on the upper part of the wings. From the cape to a point just in front of the hips, there is a slight downward slope, but the saddie rises in a concave sweep to the tail. The saddle should be wide encugh to balance the breadth of the shoulders, the saddle hangers traiing down over the points of the wing bays. The surface of the back proper should be pure white, except where the last row of saddle feathers take on the character of the tail coverts, being black edged with white, which is not to be cousidered a defect. The under-color of the back may be bluish grey, white or slate color in the male. If there should be slight traces of black in the saddle plumage near the tail, it must not be considered a disqualification under the disqualifying clause of "black prevalent in the web feathers of the back," etc.

In the female the back has a longer appearance, due to the lack of saddle backle. The rear portion of the back is more properly termed "cushion" in the female. The back should have a slight downward slope from the cape to a point in front of the hips and then show a slightly curved line from the hips to the tail. The surface color should be white and the under-color may be white or bluish grey. It the last row of cushion feathers resemble the tail coverts, it should not be considered a defect.

Cut one-half to one point, according to the degree of imperfection, if the plumage is straw colored in place of white or if the lark under-color shows on the surface. Cut two points for pronounced yellow shade of feathers.

Occasionally in any fiock there appears an aggrarated case of roached back, being oval from cape to tail, rnd as is general in such cases, wings are carried low and the back appears narrow and oval from side to side. The bip may be siipper also. As he siands, the birdisdisqualified, but were hip in position, even with all his roached condition, the specimen would be cut from one-half to two points. A specimen with a slipped hip and a crooked back may be an excellent stock bird, yet he is disqualified, while the roached back bird surely is worthless as a breeder when in this aggravated form, yet we cannot disqualify him in judging.
A crooked shell bone causes what is termed a wry tail. Sometimes a few black ticks appear in the saddle of the male. He may have rifteen to twenty near the tail. This is exempt from disqualification, but becomes a defect, subject to a cut of one-half to one point; the condition we mention is cut one point. The under-color may be so dark as to approach black in the fluffy portion and should be cut one point in the male; if dark slate in female, the same cut. When black ticks appear in the web of the feather in the female, but are not prevalent on the surface, they are a defect, to be cut one point. If so pronounced that one was forced to cut two points, the specimen should be disqualified promptly.

Should the black ticks, described for the male as a defect, become prevalent, reaching down to middle of saddie and appearing in the saddle hangers and under the wings at the sides, he, too, is a disqualified specimen; yet he may be a valuable breeder with hens that have lost color by age and service in the show pen. This defect often corrects itself as such cockerels molt into their cock form; they grow lighter with age.

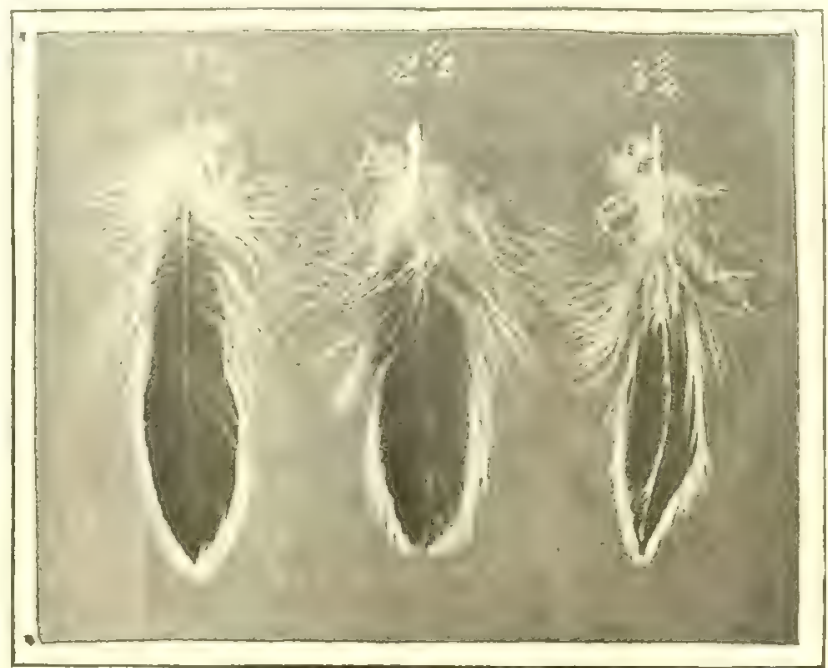

Defective Hatrle Feathers of the Female.

Feather No. 7 is a black ticked one; these feathers, according to their prevalence, are cut one-half to one point. This is as far as the license for their appearance should go, for a pure white surface color is desirable and it is a fact that where the under fluff is a bluish gray the surface color is far more liable to be a pearl white so much coveted in show birds

\section{THE BREAST.}

The breast should be full, broad and round and the quarters prominent. This will give a full, oval outline from shoulder to keel, and from shoulder point to shoulder point that is so much desired. This section is seldom faulty in color, both surface and under-color being white, though the latter may be bluish gray at its juncture with the body. The reason we find this section so perfect in color is because it is protected, so to speak, and never rcceives the direct rays of the sun, nor the full force of storms. This description applies to both male and female.

Sometimes the ticking oll throat extends downward, or a slight straw tinge invades the upper part so as to secure a cut of one-half to one point; so rare is this that judges pay little attention and generally make the breast cuts under the head of shape; and it is as well. Shape becomes the defect in ninety-nine cases in one hundred.

In viewing the specimen from the front you see the 
shape from quarter to keel is $V$-shaped, not rounded at the sides. This and a want of fulness in front generally go together, and are generally cut one point. When the quarters are full, giving rounded shape to side lines, the breast is sure to have a rounded front from wing to wing front. This fulness of the shoulder or quarters, as its effect in breast is called, is what gives the effect of the breast being carried well forward of the thighs, when such appearance is called perfect.

\section{BODY AND FLUFF.}

In the old standard the body and fluff were considered together. The keel should be carried rather low, but not so low as to hide the full profile of the hock, and the keel muscle must be full and firm to the touch. The fluff should be moderately full and with-the full thigh fluff gives a broad appearance to the bird when viewed from behind. The surface and under-color are white, though the latter way be bluish grey.

When keel is so crooked as to affect the shape we have described as perfect, showing a hollowness in front of thighs and a want of depth to body, a cut of one-half to one point should be made, and we have seen cases where one and a half and even two points were necessary; but slight notches or slight turning of the keel, if no apparent alteration to shape of body appears, may pass uncut in Brahmas, but should a tie appear, the crooked keeled bird should lose, or be given a check for the defect, which would decide the tie without another examination.

If the thigh fluff be scant and fluff proper be shrunken as compared to our model, a cut of one-balf to one point will in a !arge majority cover these defects.

$$
\text { THE WINGS. }
$$

Here agaí color comes in with such effect that shape is too often overlooked. "ight Brahma wings are a trifle more

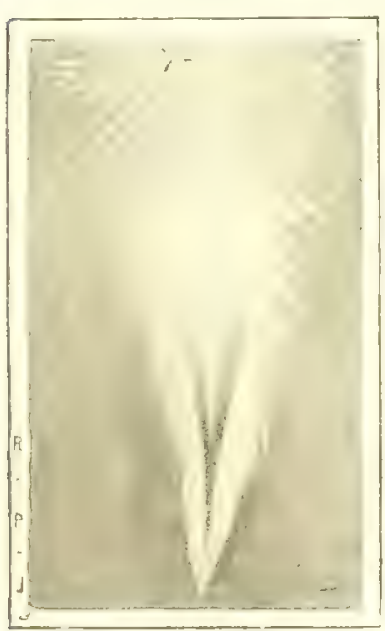

A Black Ticked Saddle Feather. than medium in length and are well cupped in the rose. that is, they should have a prominent round sweep from cape downward. The primaries are folded smoothly under the secondaries, which lay under the saddle hangers. The wing fronts are strongly muscled and covered by the breast plumage at the quarters. In color the fronts are white, or slightly mixed with black. The secondaries are black, but have white on the lower web of sufficient width so that the wing bay is white. The white along the upper edge of the upper web, growing wider as it extends around the tip and along the upper edge of the upper web, growing wid ' $T$ as the secondaries comb upward. The five feathers between the secondaries and the cape have less and less black, until the top one is altogether white in order to secure the white surface color. The primaries are black, or nearly so, having a white edge to the lower web.

The same description applies to the wings of the female, except that the primaries are black in the shaft, the balance of the feather being black and white, but to escape a cut for defective color the black must predominate in the feather. The wings should be carried high enough to secure the flat cape across the back and should be so folded that the points lie under the saddle hangers in the male and are well bedded between the cushion and fluff of the female.
Cut one-half to one and one-half points, according to degree of imperfection, if the wings are carried too low, on the primaries are loosely folded, showing below the secondaries; if white predominates in the primaries of the females and is too prominent in the males; if straw color shows in the surface color, or brick color in the white of flights. If the wings have a generally bad color, or have twisted feathers in them, cut one-half to one and one-half points. If the primaries are folded outside of the secondaries, refuse the specimen a score card, for such birds will not prove worthy breeders.

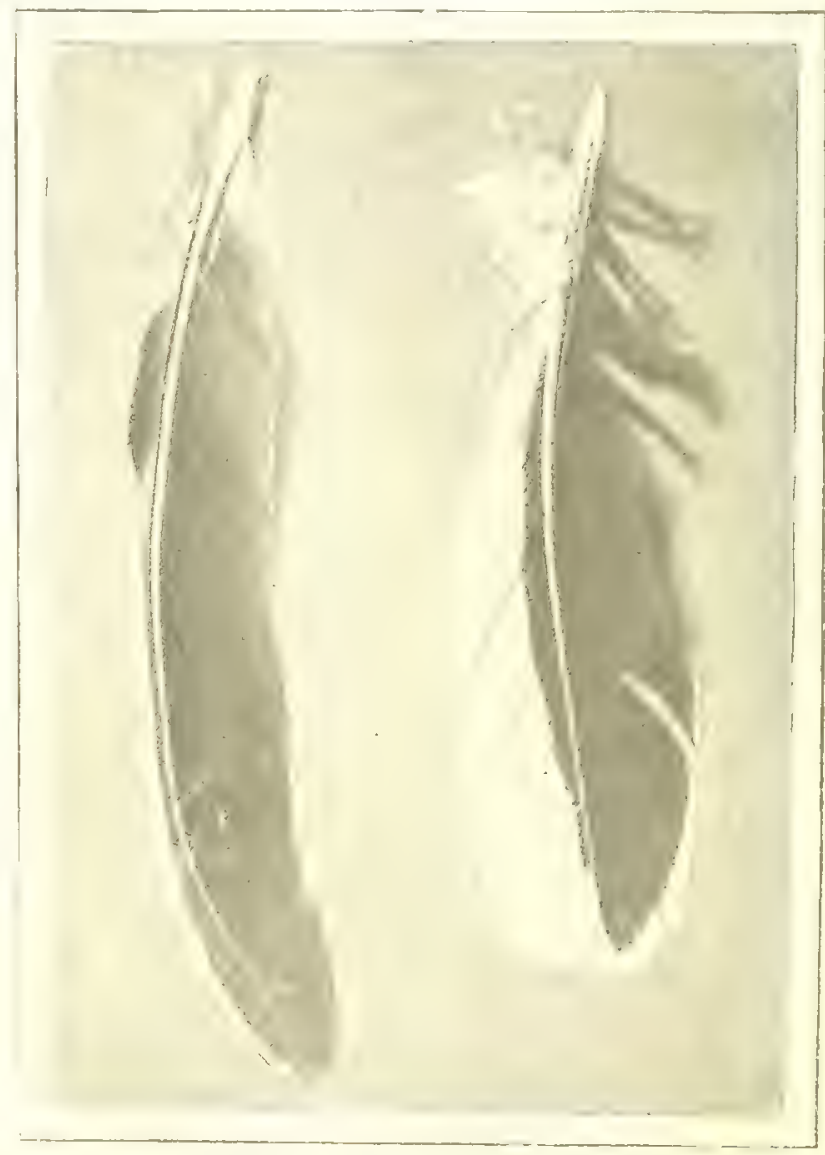

Wing I'rimary and Seconlary of the Male.

For color, see feathers forming illustrations Nos. 12 and $121 \%$. Such feathers making up the primaries of a male, should not be cut under the rule "black or nearly so, but showing a white lacing to lower web," while in the female white may appear as in No. 13 so long as the surface be black in the larger proportion as here seen, but upper web may be solid black. In hens one often sees nearly all white w:'I the shaft only black, yet both colors are clear in shade; one and one-half may be a reasonable cut, but when the colors are neither black nor white like feather No. 14, we think one and one-half to two and one-half should be the penalty. This defect is more frequent in old hens.

The secondaries are a white feather with the centers being a very dark slate or black, but all color showing on the surface must be white. Where the surface of wing is shaded with straw or yellow, one-half to two points will cover this defect. Of the feathers (five in number) between secondaries and cape, the fifth must be white and the others sufficiently white to secure white in surface color. The cut then almost always comes in surface color and primaries.

Should the primaries be composed of feathers like Fig. $14 \frac{1}{2}$ the cut surely should be all of one and one-half points, and lesser defects one-half to one and a half. 
THE TAIL

The tail should be fairly well developed and carried tolerably upright and spread latterly like a capital $\mathrm{A}$, which should be filled in underneath with rich, curling feathers of mized black and white color, the darker the better. A line dropped from the deck feathers to the ground should just clear the tip of the lower tail feathers. The sickles and lesser sickles should reach but little beyond the tail proper and should curve outward laterally. The larger coverts should lay in form of a simitar on the side of the tail and reach far enough to the rear to just cover the tail proper. The sickles, lesser sickles and tail proper are to all appearances black, but the quill end next to the skin and along the lower web of the lower tail feathers may be white and on the very lowest feather the white may extend two inches. The lesser coverts in the male may be black, or black edged with white.

In the female the tail proper extends beyond the tail coverts and to all appearances the feathers are black; except the two deck feathers, which are edged with white, but the quill ends for one-half to two inches along the web of the lower feathers are white. While the tail is called fanshaped, it must not be exaggerated, but it is a fault if it comes to a point like the Cochin tail. It should be filled underneath with rich, curling white feathers which may be mixed with black and not be considered a defect. The coverts may be black, or edged with white. When the last row of the cusiion feathers are black laced with white, the larger rear coverts may be black.

We have said that when shell bone is crooked by a falling hip joint, the tail becomes wry, that is, carried out of a straight line from neck, this becomes a disqualification. It is really no fault of the tail proper, it being only the result of a deformed back. If the carriage of the sickles is too straight and the tail proper is not spread laterally into what some term fan-shape, in other words, viewed from behind, the space between the sides is not A-shaped, cut one and one-half points for either of these defects.

But color cuts a large figure here, as it does in wings. If an inch of white appears in sickles above the coverts, cut one point; if more, cut to two, as the length of white increases. White appearing in large coverts, with lesser coverts in characters like feather No, 17 should be cut a full point. When this is the case the third set of coverts next to the saddle will be nearly white.

Fiere is where the judge or novice has a work to do. Lift the saddle entirely off the tail and you will see every tail has three sets of coverts; the large ones that lie upon the tail proper and curve downward are to be black; the other two sets, black laced with white. When the saddle is wholly white, the second and third set do not show on the surface, yet our model shows what looks like two sets, showing the second set laced with white. This is only a case where the last, row of saddle plumage has taken on the eharacter of tail coverts and is not rated as a defect in back, as it has added brevity to tail the same as if the second set of tail coverts showed. No female ever showed the second set of the real tail coverts unless she had been faked of her last row of saddle feathers. The judge who knows his business will uncover the tail to judge of its coverts. The specimen that shows this last, row of saddle plumage black laced with white, will have tail coverts wholly black, without the white lacing. When the tail feathers proper are tipped with white like our illustration, Fig. 18, cut one full point, or if the defect is less pronounced, cut one-half point.

Fig. 18 is one of the lowest tail feathers. Note the white near the quill point. This is the normal condition of all tails and is not a defect, for all feathers of tail and corerts, when full grown, are white at the quill points. The defective conditions are at the tip of the feathers. To decide on the amount of white at the base I examine the white in the tips, that being the sign of the evil and generally of its extent. White in sickles and coverts will sometimes appear in an alarming degree in old birds, sufficient indeed to cause a cut of one to three points, but if more than two surely the specimen should be passed as unworthy.

If the tail is drooping or carried above 45 degrees; if the black is devoid of the desirable green sheen, eut one-half to one and one-half points. If the tail is carried to either side sufficiently to be termed a wry tail, the specimen must be disqualified and refused a score card.

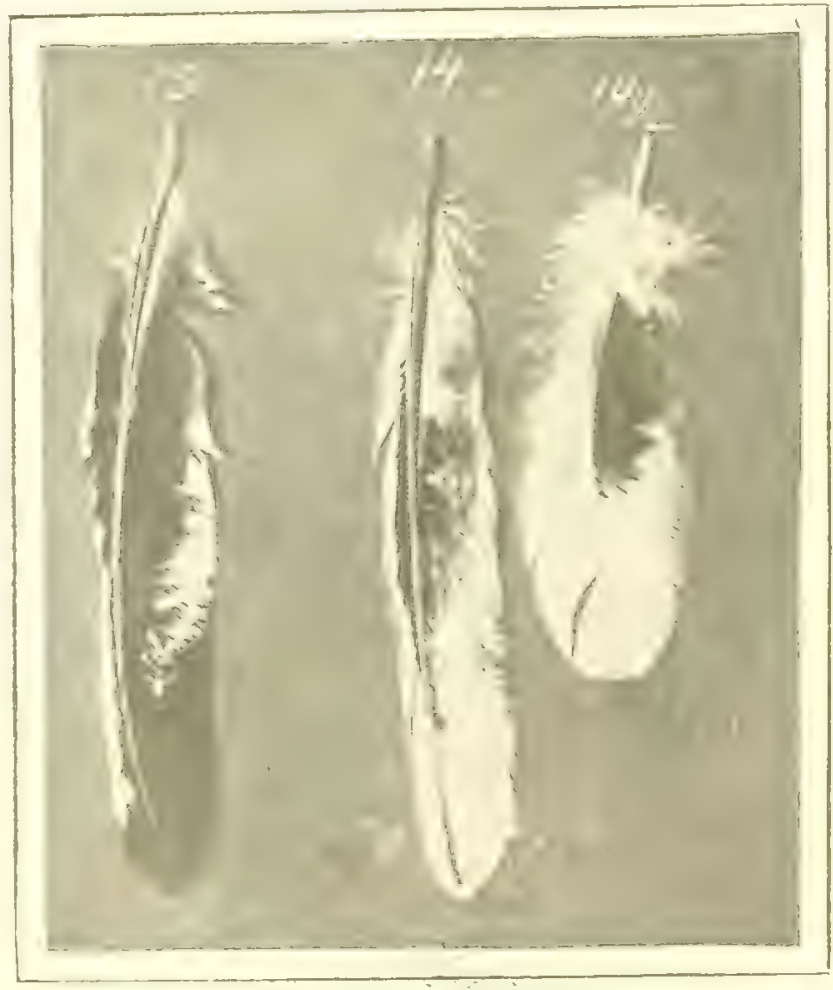

Wing Feathers of tic Female.

LEGS AND FEET.

The thighs should be medium in length, showing the hock in profile below the body line. The lower thigh should be well and firmly muscled and covered with close, clinging plumage that curls about the hock joint preserving its distinct outline. The shanks should be medium in length, looking neither short nor long and should be well feathered down the outside, the feathering blending with the foot plumage in a smooth, outward curve. The toes should be straight, the outer being feathered to the tip joint and the midale toc bearing feathers enough to fill the space between it and the onter toe. The shanks and feet should be yellow. but they may be straw color as the birds grow older. In the female the hook joint is less prominent than in the male and the shank and foot feathering is not so heavg. The feathers may be mottled with black in the male, or may he white in the female.

Occasionally we find a case of complete knock-knees. Such specimens are disqualified. When they diverge from the perfect, as seen in our model, to this condition the cuts range from one-half to two points. If the shanks are lightly featbered and the feathering does not grow to tip joint of outer toss, then the specimen is disqualified. If toes are, 
a majority of them, crooked, as we have herein depioted them, they are to be passed as unworthy. For a crooked toe cut one point; if middle toes are not feathered beyond the joint with shank, cut one point for each middle toe thus affected; but if feathered sufficientiy to fill space between middle and outer toe they should not be cut, for it is not expected that the demand be to tip joint. For shanks thinly featkered (the foot plumage being up to the requirements of the standard), cut one-half to one point.

If the thigh be so short in males as to bide the hock in the fluff plumage, cut a full point. It is the length of bone in the second joint, so called, that allows the lower thigh and hock joint to appear in smoothly plumed profile below the lower body line. A Brahma should appear in an uystanding, active poise.

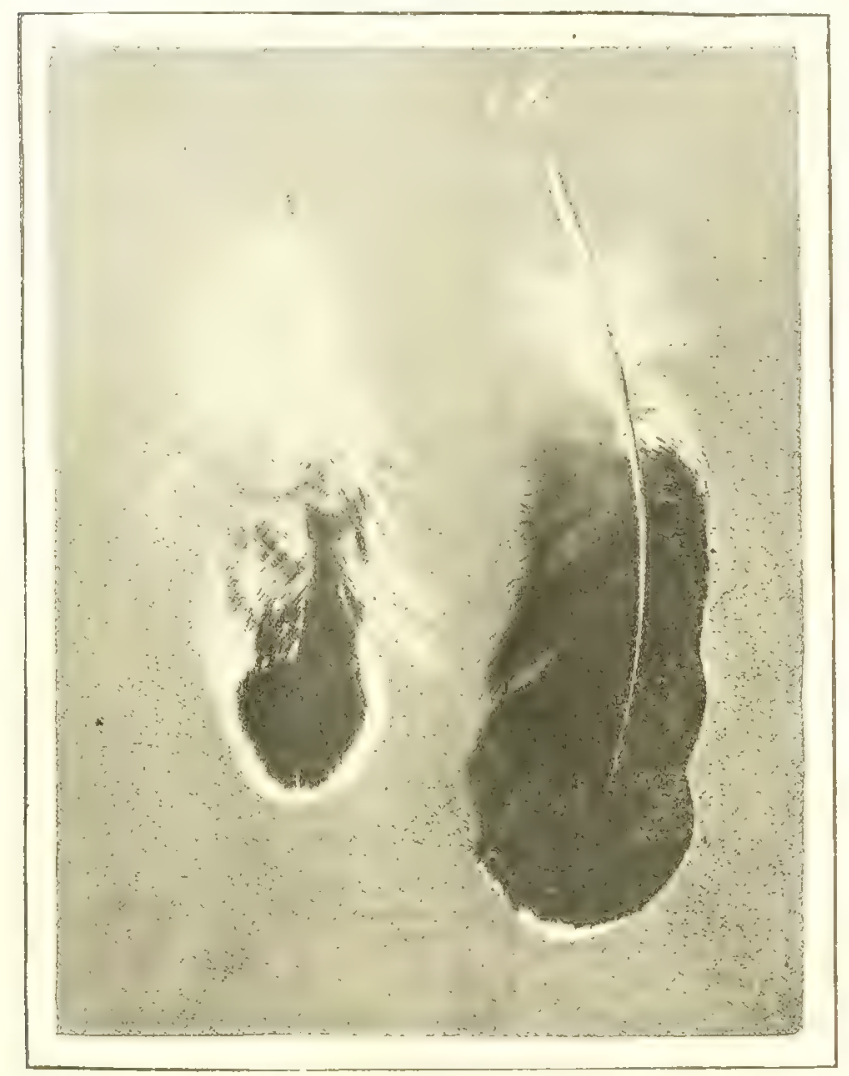

Defective Tail Feathers

The above are the general defects and more damaging to appearance in the breed. The lesson is a long one, yet we are aware more might have been said.

Could we obtain birds such as we have described in the foregoing, they would be perfect and score 100 points, but defects appear and cutting them according to the standard, we are able to produce only birds that score from only 90 to 16 , and occasionally one is found that will score $96^{1 / 2}$ honest points. We have described a perfect bird and given the cuts that are the penalty for defects. But our task is not completed until we give our experience in mating to pioduce the best results.

\section{MATING LIGHT BRAHMAS.}

Of all the varieties of thoroughbred fowls, there is none that will give us so large a percentage of chicks that will score 90 to 96 points as will a single pair of Light Brahmas when mated accorcing to the standard. But we wish to get the greatest number of chicks possible during two years, which is the usual length of time we use our breeders and exhibition birds. To do this we must mate our stock so that our medium colored birds will give us show specimens in their first season, because they lose color when breeding and with age. When we make our selection for shape, the shape takes care of itself, but to secure approximate perfection in color is hard and the artist (breeder) may be said to be nainting with live colors and brushes.

Pen No. 1, First Division-When we mate a cock and pullet of the color I have described, we make a real scandard mating.

Pen No. 2, First Division-Select a cockerel that is as dark as the standard permits and mate him to hens that in their second year are standard in both shape and color. This is also a standard mating in the truest sense. The hens selected fol this pen were, as chickens, dark specimens that have come to standard color by the loss which age inflicts and by the work of reproduction. For my part, I should not care from which pen I set eggs for hatching. I should expect the cockerel to molt enough lighter to be prime standiard color as 2 cock and in the second year take his place in Pen No. 1 and to mate him to his own pullets, which would be of standard color. Out of such pens as No. 2 we expect fowls to come which each year will form pens such as No, 1.

To mate the balance of one's stock is a question for the breeder to solve. All matings should be such that the stzongest and best exhibition color will be found among the medium colcred specimens of the flocks raised.

Pen No. 3, Second Division-Use a cockerel that is extremoly dark, one that has very dark wing flights, black tail and coverts, with the rear saddle feather showing characteristic tail coverts and the hackle with wide black stripes. The object, as you will perceive, is to have a surplus of dark color. To such a male mate pullets of pure standard color.

Pen No. 4, Second Division--For this mating use a cockerei or cock that is as near standard color as possible, and mate to him pullets that are exceedingly dark, even those that world be disqualified for excess of color, but be sure that it is a defect that will disappear after the molt. The hackles should lave very narrow white lacings, the tail coverts and the primaries should be black. If possible they should have a bluish-grey under-fluff. They may even have black in tile under-web of the back. Such pullets will ripen into show hens and form a part of pen No. 2 the second year.

The progeny from these four pens will not vary a point in their average merit. A third division now becomes necessary, because the pullets that have molted into hens have lost so muck in color that they need an exceedingly dark cockerel to mate with them, like the one described in Pen No. 3.

Pen No. 5, Third Division-Use a cockerel such as described in Pen No. 3 , for we must supply. the loss that the hens that were in Pen No. 1 have sustained during their first year of breeding.

Pen No. 6, Third Division-Select a cock that came from a dark cockerel and still retains the color of a younger bird, even if he has black ticks in the back and dark slate undercolor and Jeg and toe feathers well mottled with black. Then to him mate pullets that have fights in which the white predominates, which are white in under-color and whose neck hackles appear right on the surface, but when examined, we find that the black does not extend the full length of the feather. They may also have white leg and toe plumage.

After four months in the breeding pen they will molt out wortbless light-colored hens, fit only for kitchen use, and are used only for breeding from necessity. It would bo 
foolish to use a male from this pen in subsequent matings. Another male should be used from pens in which both males and females are strong in color and strictly prime, but females from this pen may make valuable mates for excessively dark cockerels that have come from the first four pens, for remember, these are sisters of birds we have in our best pens who lost color, perhaps, from the indisposition of their dams or at some time when the sire was out of condition. Health and vigor are essential to successful breeding, as are shape and markings. A strong, healthy, active hen is the motuer of the best chickens, especially when we persevere in pedigree breeding and the females in the pen are sisters and so the pen is reduced to a single pair in blood. The best chickens we obtain may have different mothers, owing to the varying physical conditions, but the blood in the chickens in the same.

All these matings may be calied standard, for both males and females scoring from 93 to $96 \frac{1}{2}$ points are as likely to come from one pen as another, provided we have made careful selection in regard to standard shape. The birds are all pedigreed and all of them are reasonably standard in shape and color when mated, or they ripen into standard color when they molt. Jn our matings we aim to allow for the deterioration of age and to protect the ofispring from adverse ancestral influence. The breeder who does not take into account ancestral influence has not gone beyond the A, B. C of the alphabet of breeding.

The matings described are far different than double matings. inasmuch as exhibition males and fenales will come in a like percentage from each and every pen. Standard color will cieteriorate and birdz from the first division will probably give us a greater number of light birds than dark, while in the second livision we will get probably more specimens that are too dark for show purposes, but not so many that will be of standar. color the first year, but as hens they will prove winners, for the dark pullets ripen while breeding into show hens. All pullets that are what we call medium specimens of standard color are reduced in value when they molt into hens.

There is a great difterence in what different persons understand by white. Specimens having dark under-color are always a purer shade of white in surface color, and white under-colored specimens have a creamy white surface color. which ofteu during the breeding season becomes sun-burned or straw colored and sometimes has a red shade when they begin to molt. A bluish-white or bluish-grey" under-color is the safest to breed from. We all like to breed males whose primaries are pure biack with an outside rim of white. A female with pure black and white, the black predominating and the shaft of the feather being black, will prove the best breeder. The fad for wholly black primaries in females will in the end prove of more harm than good, and judges have no right to give such a bird the preference on account ol it.

Breeders of Light Brahmas should read and commit the standard to memory and then mate strictly according to it, understanding that the standard description applies to a cock

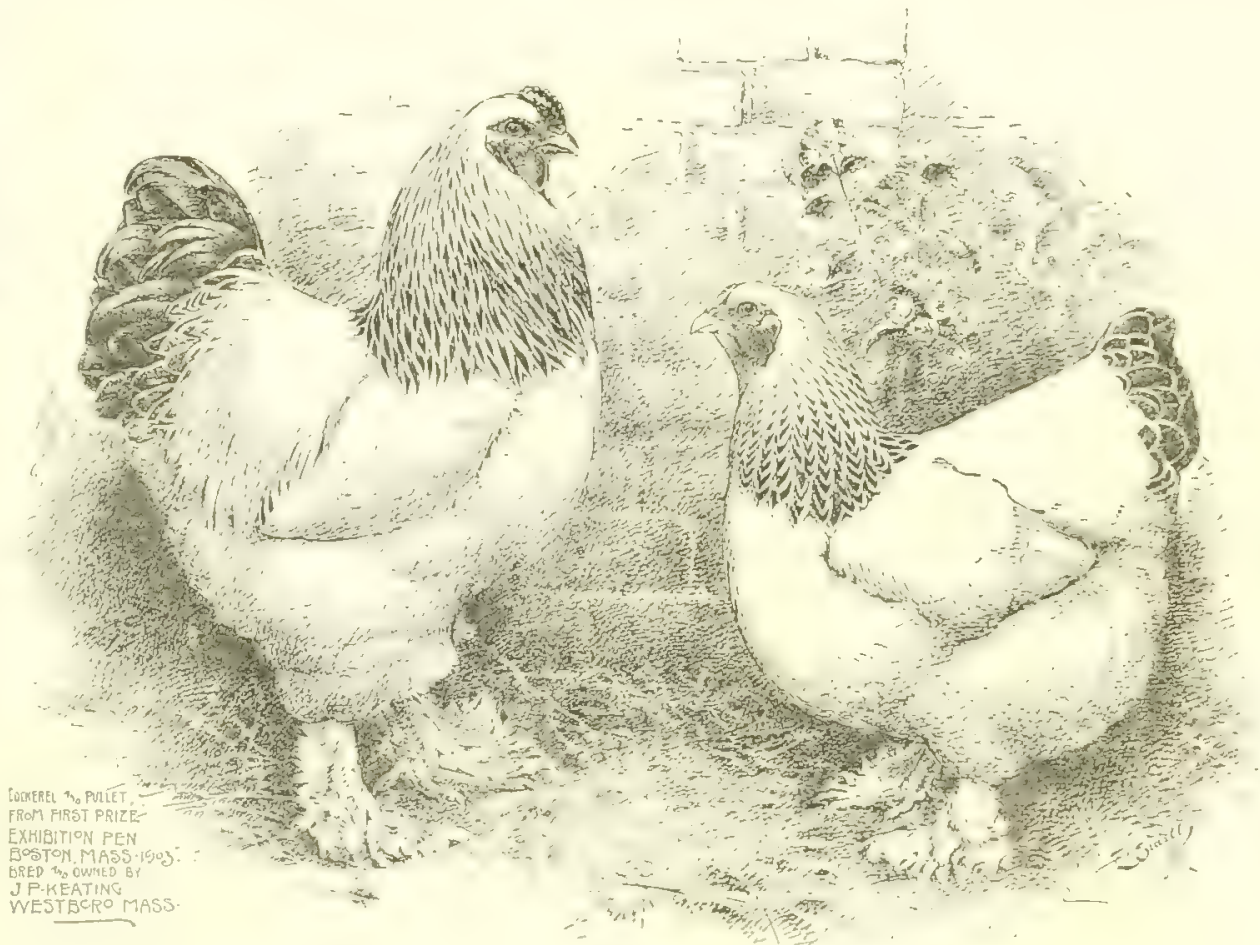

The Male and () ne of the Females from J. P. Keating's First Prize Pen of Liglut Bramas at Boston, 1003.

and hen. When we are considering young stock we must make allowance for age and remember that as they grow older thein colors will become less pronounced, and we must insist that there be a sufficient reserve color to carry them through. The amateur must not expect to reap success in a single year, but he should give heed to the older breeders and take their advice until he learus by experience.

The breeder who took the Light Brahma in his keeping fify years ago, acknowledging their worth then, is to-day their staunch friend and he tells you with the same enthusiasm that they are the best fowl on earth when they are allewed to appear in the shape and color that is their birthright.

I. K. FELCH 


\title{
THE IMPROVEMENT OF LIGHT BRAHMAS.
}

\author{
Line Breeding Necessary to Secure and Maintain a Uniform Type-A System of Mating Birds of \\ Standard Color in Which Like Produces Like-The Relation of Under Color \\ to Surface Color Discussed.
}

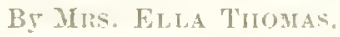

\section{II}

F I should consider myself even now anything but an amateur in mating Light Brahmas, I should go against my own convictions in the matter, but as I have had some degree of success, I will be pleased to give you my ex. perience, as none of us "liveth unto himself," and I think it essential to beginners in poultry culture to be able to profit by the success of others. It will save them years, perhaps, of unsuccessful labor, and often inspires success where many new breeders would become discouraged and quit the business.

I find my ideas of several years ago are only strengthened into facts that we cannot depart from, if we would produce an ideal fowl in points, pedigree, size and vigor, 7ith egg laying qualities, I believe the parties who condemned line breeding are revolted and gone, or will be, for they have so of ten spoiled their flocks by mixture of blood from the different strains. Grood food and plenty of it will make any "strain" large, while lack of it will produce the opposite. In the hands of practical breeders it is the only safe plan to line-breed; as like, when the "blood" is established, will produce like, and give us vigorous specimens full of usefulness.

I condemn Cochin shaped Brahmas, because they are not American-bred, because they lay fewer eggs, and are not like our Ameri. can-bred, rustling, practical, vigorous birds. Many of the Brahmas of to-day, as in the past, show a loss of the broad, short head; heavy, overianging eye-brows; full throat, short, strong, well archerl beak; broad, well-spread tail : broad, deep breast; oblong hody,

with proper length, etc., that characterize our best Brahmas. You will find them in the show room and elsewhere with long, narrow heads; long, slim beaks; very small combs and wattles; nalrow, fiat breast; and Cochin leg and toe feathering; and short Cochin body. There are many good flocks of Brahmas in the United States, I am happy to say, but we do not find all yards alike as we should do. We should try to work together to weed out all characteristics other than Brahma, and we still have years of work before us on scientine lines; even now that we have our National Light Brah- ma Club we have that much more reason to establish a unffor'm character in our Brahmas all over the United States.

One objection many find to Light Brahmas is the profuse font farthering, lut I like tho feathering when not too

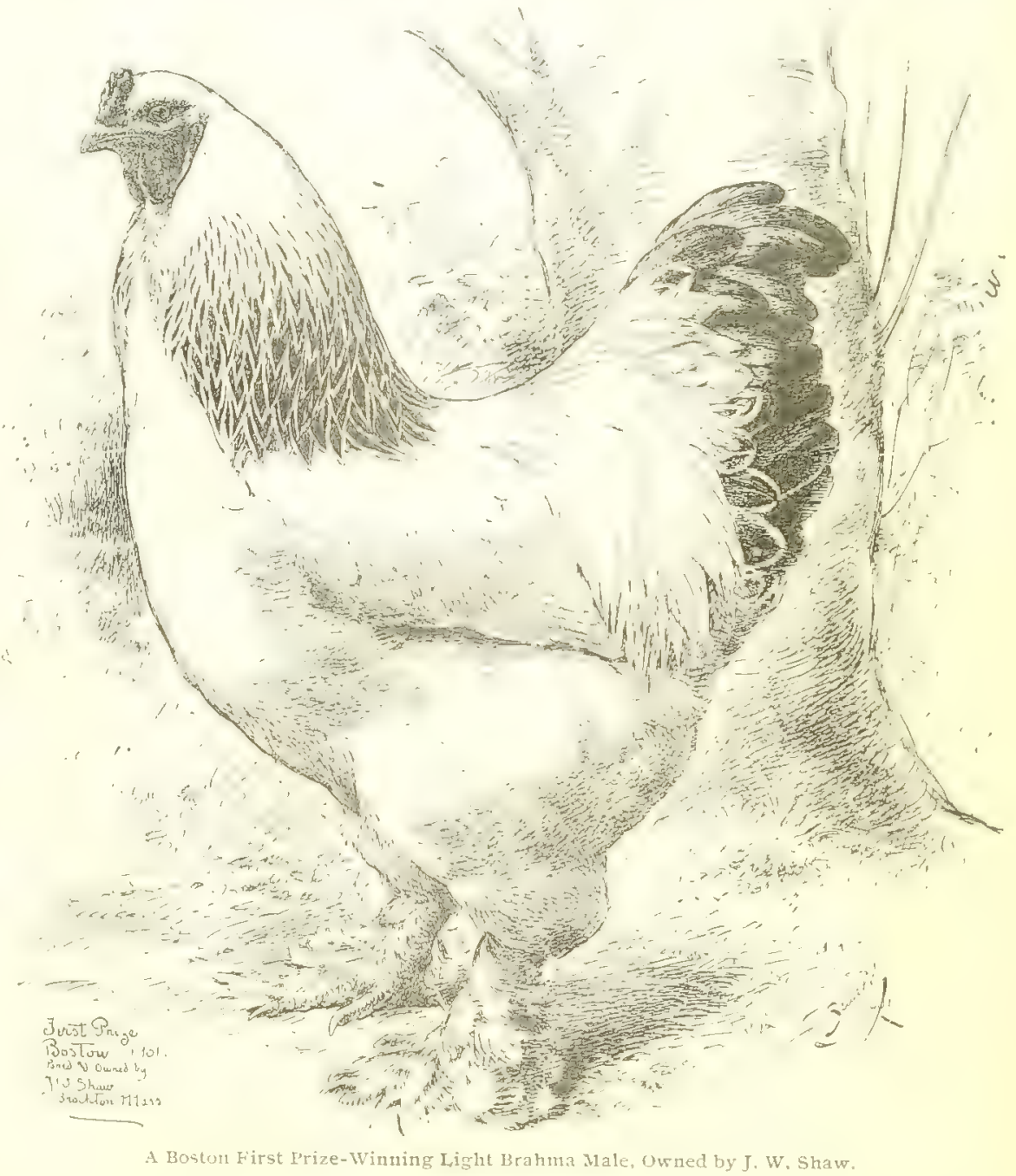

lilsfuse, and find no hindrance to the quality of $m y$ birds on that account. It is easily overlooked when we consider their gl'vat size, marked vigor, hardiness and practical qualities. They arc loved by all fanciers who know their gentle disposition. They respond to kind treatment with evident affertion. They leard to know their friends and trust them. It is pleasant to note the enthusiasm of the fancier of this breed, who understands mating and breeding them, because most of them breed them without injuring their util$1 ! y$ and increase their fine quality each year. I shall always 
hold as a pleasant remembrance a conversation with Judge Ball, of Massachusetts, who was a very enthusiastic lover and breeder of this noble breed. Though he seemed to be surprised at my knowledge of this breed, I was equally pleased at his love and enthusiasm for them, because therein laid the key to my success in mating and breeding them.

MATING BY USE OF THE STANDARD

One very good mating I find is birds of equal color, that is, as near the Standard as you can get them, selected from a promiscuous flock of hens and pullets, mated not akin, all good individuals, cut not over one point in any section as pullets, or one and one-half as hens, as all birds do not hold their color at two and three years old. I find they seldom do from the old strains, and that is why I value so highly the strain that does. That is why I described in the Reliable Poultry Journal so minutely my choice matings and my mode of keeping them, and why I consider it so important that where we have a hen, or several hens, that hold their color at two and three years old, they should be put where every egg can be carefully set and pedigreed. 'This is the only way, I believe, by which we can increase and "fix" the color of our birds, or, rather, produce a strain that will not fade at one year old, or even at two years of age.

In mating number two I mentioned, we must select birds, both male and female, to come as near up to the Standard requirements as possible. The cock or cockerel should be medium high on legs, not too long nor too short-legs of a deepyellow color, heavily feathered, the feathering mottled with black. He should be of Standard weight when in good flesh, and if he is over Standard weight (not too fat), so much the better, though I do not faney the extra large males, nor do I find them as good breeders as the medium sized. Medium sized cockerels mated with large hens make the best matings. The comb should be set evenly on the head, be deeply serrated and extend well on top of the head. The head should be broad and short, with overhanging eyebrows and a full, well-developed throat, full, wellarched hackle, long and flowing, fourfifths of the feather black. The wattes and ear-lobes should be a bright red, as well as the comb, and well developed. A very particular point in this mating (as well as in the first mating mentioned) should be a deep bay eye in both males and females. Wings of both male and female should be as near solid black as you can get them and there is generally a white rim on each wing feather, the web being black to the flights. Our best breeders get fine colored backs, that is, with bluish under-color, and if you practice the mating I have first described you will soon have color in wings of pullets as well as cockerels and have an even bluish undercolor in both rales and females, with few black "ticks" in backs of pullets-none in cockerels. This has been my" experience, and I believe it will be yours, and as I have several pullets entirely free from the "ticks" in back, also bens one and two years old that have almost solid black flights, I feel confident that I can in a short time have them breed true enough to be entirely free from them and be in color equal to the males.

The coverts of the cockerel for the pen mating called number two should be, first row black, also main tail feathers black; second and third row of coverts black edged with pure white like the hackle. Breast, broad and full; body long as compared with a Cochin; wings well folded and colded high enough to give breadth to body as well as to back. He should be broad across the saddle, nearly as much so as across the shoulders. The wings should be folded high enough to give a broad, flat back across the shoulders, well l'ounded, yet broad as it sweeps in concave line to tail. I like black mottling in the foot feathering of the females as 
as given in the Reliable several years ago. I like black points in the females as well as in the males and breed for it by mating my darkest males and females together sometimes. I like black mottling in the foot feathering of the females as well as in the males, and believe it is impossible to get uniformity of color in our females where it should be and maintain it, unless I breed as above stated.

I always have some specimens of Light Brahmas that I especially like, because I like shape as well as color, and color as woll as shape, in both males and females. Despite the years of breeding this noble breed, I believe most breeders, like myself, are very far from obtaining the acme of perfection, but the few females I have have almost solid black flights, heavy haclile edged with pure white, tails black to the skin, with two or three rows of coverts edged with white, deep blue under-color in backs and throughout the plumage, heavy leg and toe feathering, mottled with

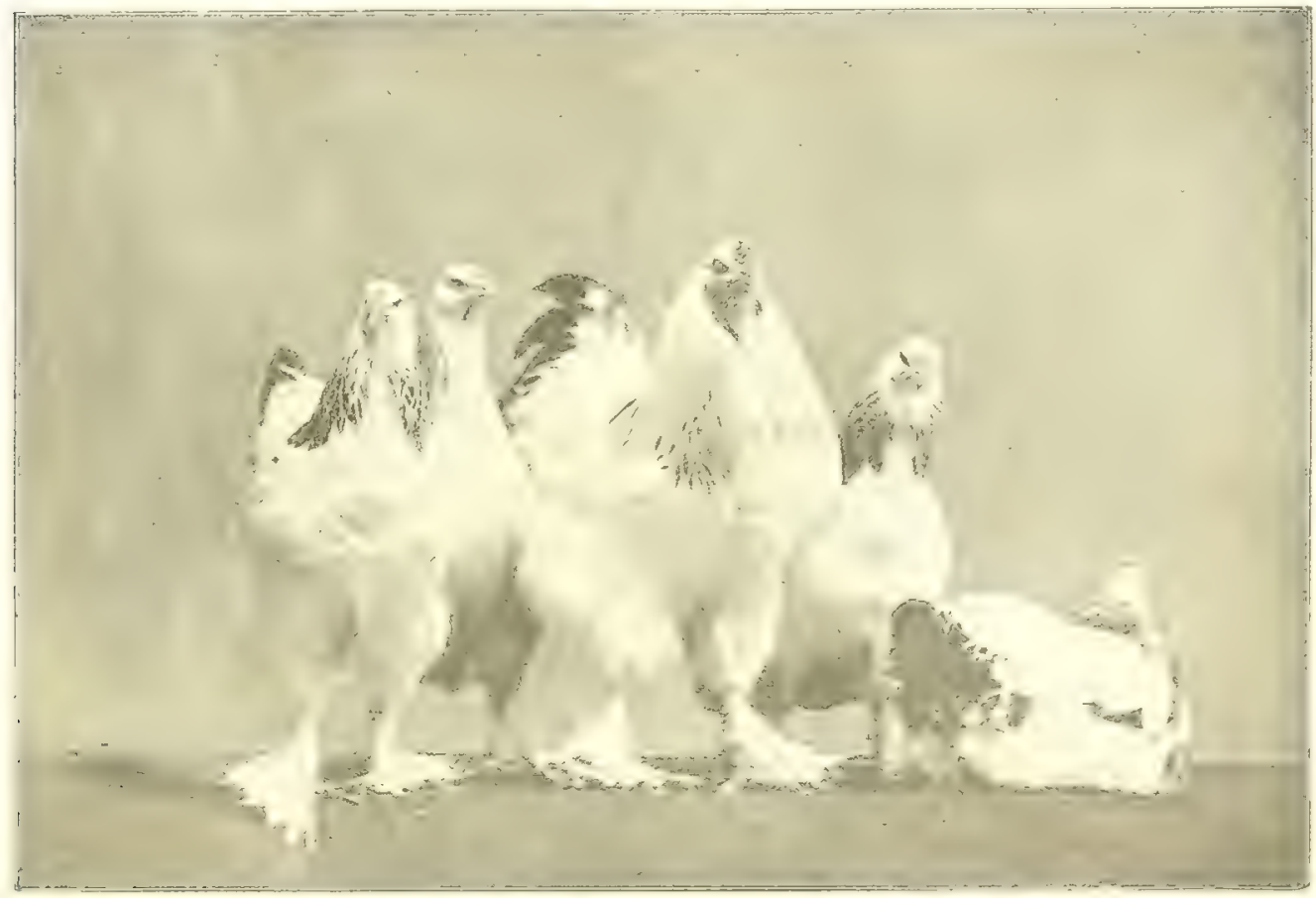

A Pen of Mrs. Flla 'Thomas' Mammoth I, ight Brahmas. charcoal under-color, when they have the needful color in wings, tail and hackle. Cultivate and work for the even, bluish under-color throughout the entire plumage and to extend one-half or one-third the length of the feathers from the skin outward, and this, when everything is favorable, will give us black wings and pure white surface color. We do not need to breed for black on head to retain these characteristics if we use judgment and pay strict attention to color of birds in my own or my customers' hands that are too light, and to produce extra fine dark males with no disqualification, and this I do by mating black and white males, that is, intense color where it is most needed, and I do this by mating these very fine males to such hens or pullets. We must breed our birds in such a manger as to produce a strain that will reproduce good specimens in the hands of the purchaser, or we fail to make a breeder of the purchaser, I find that by breeding carefully for blue under-color throughont the plumage and keeping in reserve the darkest old hens that are free from black in back, to mate with a male near the standard requirements, $I$ can produce offspring that secures the highest honors in many big shows.

I am heart and soul for the advancement of the Light Brahma, and am full of solicitude for the co-operation of the breeders in all parts of our country, feeling that whatever is for the good of one part of the country would eventually be for the good of all. Let the west and east, north and, south, all work for the advancement of this worthy variety, for you know "in union there is strength" and in union of minds there will be mutual blach, presenting the Brahma hen and pullet absolutely beautiful to me.

When it comes to pounds of meat and eggs in a year, with a combination cf beauty in shape and color of this grand old breed, the west certainly leads at present, and has for some years. After fourteen years' experience in mating our gains and losses in mating for certain points. I keep a number of such hens as a reserve of color, to increase the and breeding this noble bird, I cannot agree with some of our fanciers (I trust they will pardon me for this assertion) who purchase many winning birds and advocate the same methods as we of the west do, although some of them claim to cespise our methods. They will come to them by and by when the successfully establish and breed their own s'rain.

Those who contend for pure white in under-color in all their birds will find to their sorrow, when too late, that they will soon sacrifice the beautiful rich, glossy black wings. tails and coverts that are plentiful in the west. Brother and sister fanciers, avoid as much as lies in your power the charcoal under-color. Do not cast away those grand old hens that have some black spots in bacis, even if they have some benefit, and aid in producing harmony and zeal among breeders in perfecting the fine points of our birds, in securing vigor, great laying qualities, pèrecting them as a practical fowl, breeding for that beautiful shaped body that is their characteristic, increasing the rich black markings and bluish under-color that yives so beautiful a white surface color. The whols, a grand make-up that never has and never can be attained by any other breed than the Light Brahma.

In this article I have endeavored to give plainly, so that a nuvice can understand it, a description of my metrods of mating this variety which after years of careful study and painstaking experience I believe to be correct and best calculated to advance the worth and popularity of the variety from a fancier's viewpoint, while preserving to the greatest extent the true value of the fowl for all practical purncses. I am aware that the opinions of many, whose experience and success entitle them to consideration, will not agree with mine, but no other methods have given me so much satisfaction.

MRS. ELLA THOMAS. 


\section{LIGHT BRAHMA TAILS.}

The Advent of Laced Coverts on Females and a Prophecy That They will Yet Be Required on Males.

\section{By George PURDUE.}

$\mathbb{A}$

CONVERSATION with Mr. Sewell at the late New York show, during which we discussed the progress that had been made in Light Brahmas, brought to both our minds the pullet "Progress" that was ex. hibited at the first show held by the "New York Poultry and Pigeon Association" In the American Institute Building of New York City fifteen years ago. At that time Mr. Sewell made me the accompanying cut and it was published the same year in the Poultry Monthly of Albany.

This was the first pullet ever shown with tail coverts laced. For a number of years I had been trying to bring it out in a creditable and well devised manner. In those days the east was still tolerating the score card and you can imagine how I felt when I found the judge had cut her three on the tail. He had run against something so foreign to the ordinary tail of the day that he made as heavy an impression as was possible. At the present time a female that has not a laced tail is not a show bird and there is not any question in any breeder's mind but that it has done more to beautify the breed than any other one development.

Did you ever stop to think that it is within the limits of nature to have every covert and saddle feather in a light Brahma male laced and that it would add to the bearty just as much as the coverts have to the female. I know many of the wise judges will shake their heads and turn them down just the same as they did the pullet "Progress" fifteen years ago; but it will come just the same, and when it does it will be one more stride toward beautifying the breed.

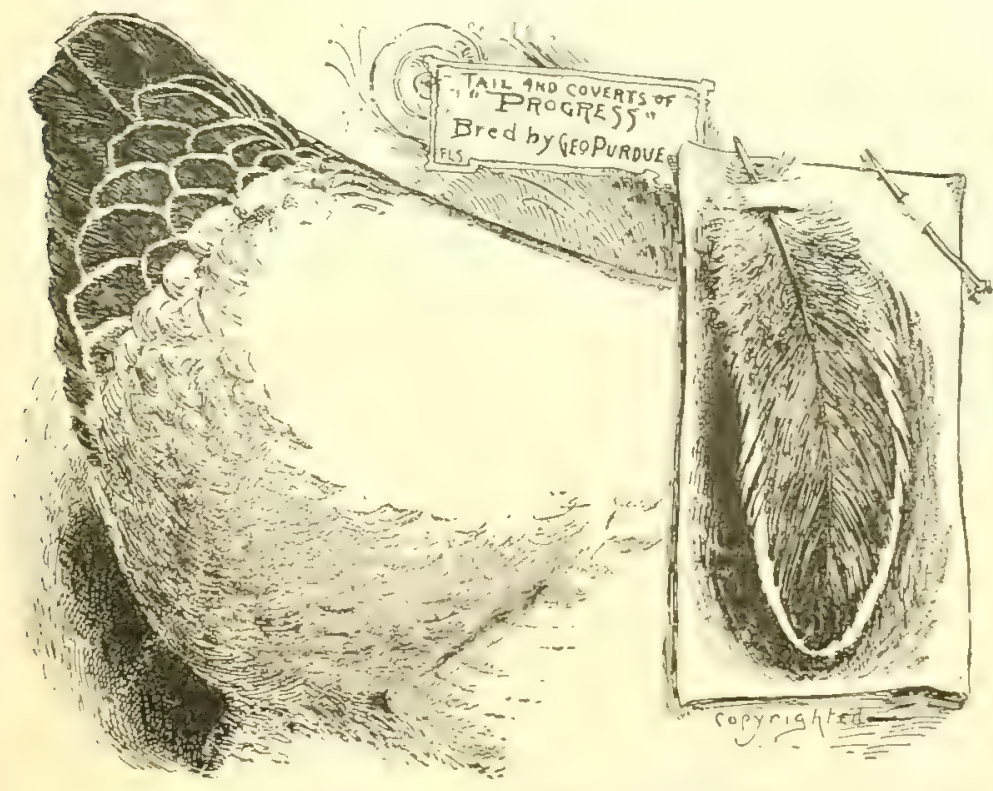

Laced Coverts of Light Brahma Pullet exhibited at the First New York Show and sketched by MI. Serrell fifteen years ago in illustration of "the first pulle ever shown" with covert lacing: Bred, owned and exbibited by George Purdue, Proprietor, Norwood Farm.

We exhibited in the New York show last winter three cockerels, from one of which Mr. Sewell made the illustration which appears in connection herewith.

This article is not written to encourage the sale of birds of this character, nor do I advise young breeders to go in too strong, but keep "Progress" in mind; increase your color; educate your judges; show them what quality is. At the time "Progress" was shown the standard requirement was a

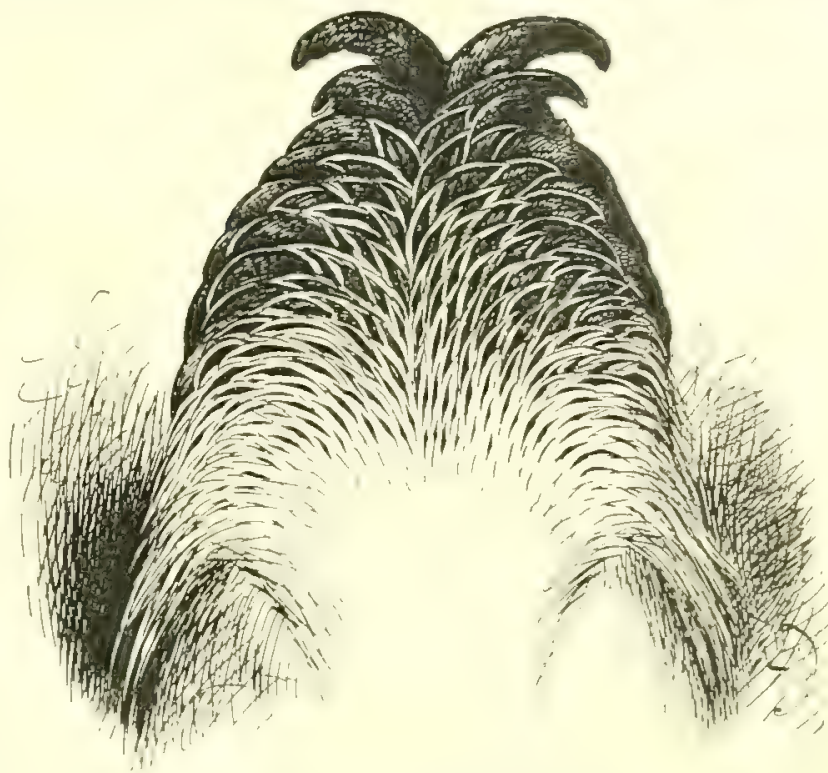

Illustration by Sewell of Laced Tail Coverts on a Light Brahma Cockerel exhibited at the recent New York Show by George Purdue,

clean back. As the color of the breed increased disqualification for black was modified to "prevalent" in the back. I do trust that the next step will be to wipe out every disqualification except for fraud. The American Standard has done more to retard the progress of the Light Brahma than it has ever done good and has kept the Light Brahma twenty years behind what it should be. My standard consists of that which is most beautiful to the eye and without it we cannot make progress. Shape and color well defined is quality. GEORGE PURDUE.

\section{Light Brahmas as Market Fowls.}

Of those who first took up the raising of market pcultry and made it a special and profitable leature of their business, a considerable proportion pinned theiv faith to the Light Brahma. Those in particular who catered to the demand for roasting chickens, which combine large size and soft, tender flesh, found this variety well suited to their use. Their experience indicated that the smaller breeds, approaching maturity earlier, could not be brought to the size and weight required to obtain the highest price without acquiring enough hardness of flesh and toughness of muscle to graduate them from the quality desired.

A good majority of the large growers of these birds prefer this variety to-day and some dealers will pay a higher price fol the Light Brahma carcass, assuming that the name guarantees the quality to some degree. The wisdom of this choice of variety is proved by frequent, well authenticated reports of sales involving numbers of these Brahma roasters at over two dollars per head. James Rankin stated in the Reliable Ponltry Journal that he raised a flock of this variety to roaster size and disposed of them at a price which netted him $\$ 5$ an hour for the time he bestowed upon them. 


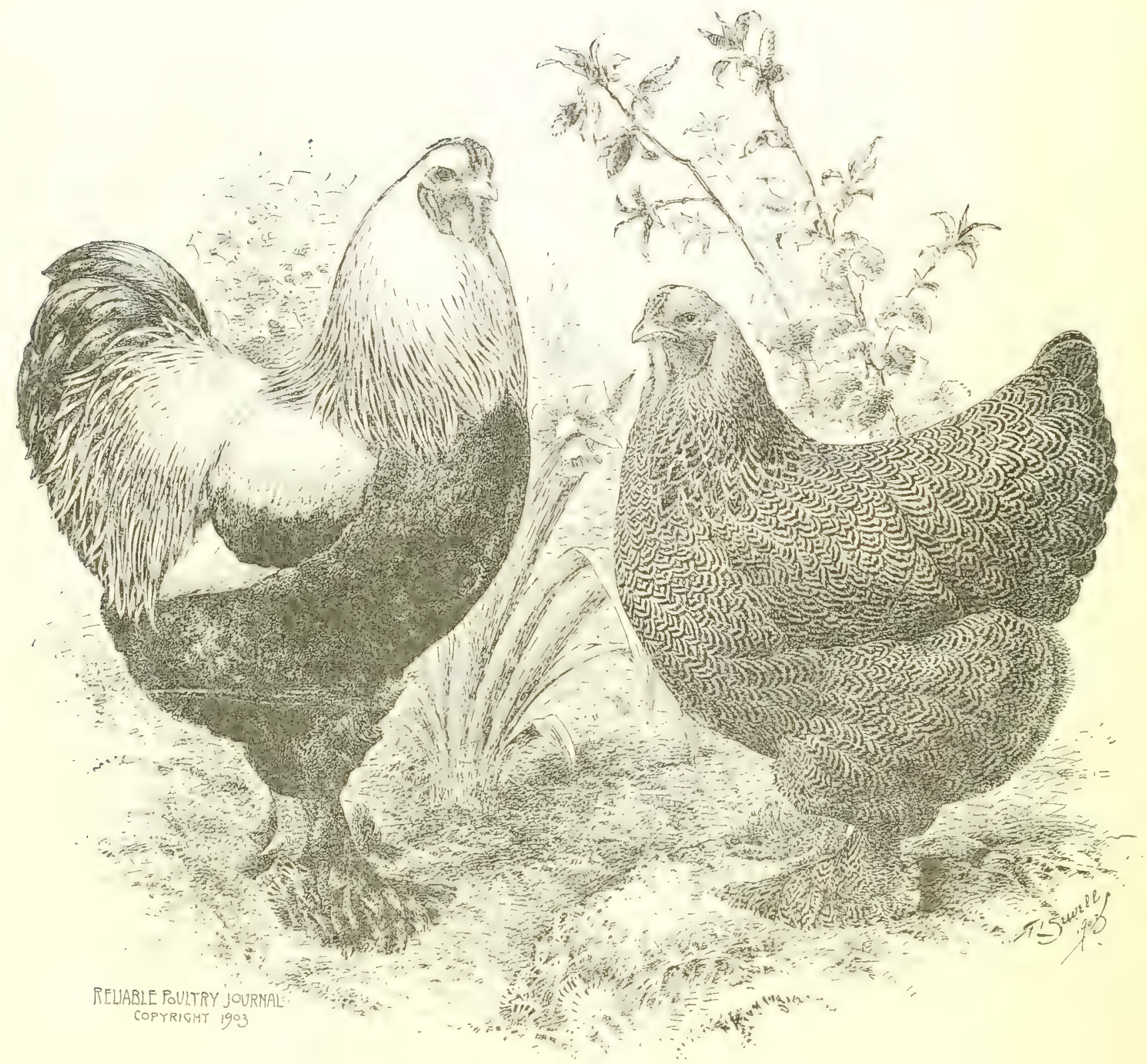

STANDARD IBRED DARK IBAHMAS-BY SEWELL. 


\title{
TWENTY-FIVE YEARS WITH DARK BRAHMAS.
}

\author{
The Value of This Variety for Eggs and Meat-The Colors of the Male and Female Described- \\ Useful Hints Upon Mating for Best Results.
}

by Cifarles A. Ballou.

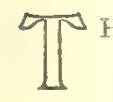

HIS breed is one of the oldest established breeds in America, and I can say, after twenty-five years breeding them, that it is one of the best. They are extra fine layers of rich, brown eggs; mature about six weeks earlier than their cousins, the Light Brahmas, and my experience has been that they will lay more, though not so large eggs. For table fowls, they cannot be beat. In competition with nearly all varieties at the Rhode Island exhibition they won first three years in succession; first for plumpness and first for best dressed poultry in the hall. For broilers they are excellent; any time after the age of six weeks they are ready to kill and a more toothsome piece of flesh cannot be found.

The hens make fine sitters and good mothers. They will commence laying while with their chicks and care for the chicks just the same. The chicks are very hardy and under ordinary care there is no need of losing many. Feed them well, keep them growing and no breed will show a more rapid improvement than they will.

It requires no fitting process to get them ready for the show room. They are always dressed for exhibition, their color being such that it needs no washing or cleaning, if their surroundings are kept reasonably clean.

They can be kept anywhere and under all conditions. They always look well, the male bird.having a stately carriage, a clean silvery white head, with a fine pea comb and a beautiful hackle, with a dark stripe running down the center and a pure silver edging to each feather. The back is of medium length and a pure, silvery white in color. The breast, although required to be pure black, is never so pretty as when evenly mottled with silver, and males so marked are particularly valuable to breed from to secure evenly penciled pullets. The tail should be black with flowing sickle feathers, lesser sickles with black centers edged with silvery white, like the saddle feathers. Wings must have a beautiful black bar and the outer edge of the flight feathers silvery white.

The female presents a pure steel gray head, darker than that of the male. Neck, the same color as in the males. Back and breast must be gray penciled, not barred, with a pure steel gray, the lines of penciling following the contour of the leather.

Don't think you must have a solid black breast in the male; when you find a nice evenly mottled breast you will find a bird with cleaner color on hackle and back and one more likely to be free from yellow. A certain cock bird that won first at Buston and special for best shape and color had a fine evenly mottled breast. Be careful in your matings; the Dark Brahma is one of the hardest birds to breed that there is in the Standard. Never use a short backed, high tailed male, but if you have a female that is short in back, that is extra good otherwise, it is safe to mate her to a long backed male, but if you have none such to use you had better discard her entirely.

Another great trouble is with foot and toe feathering. This is hard to retain and I know of only one way to keep the feet and legs properly feathered, which is by using, occasionally, vulture hocked hens and pullets, never sacrificing an extra nice female because of this defect; but never use a vultured male, unless for some special purpose and then only as a last resort. It is not advisable to use a male with a poor comb, my experience having proven that the male exerts far the greater influence upon the combs of the

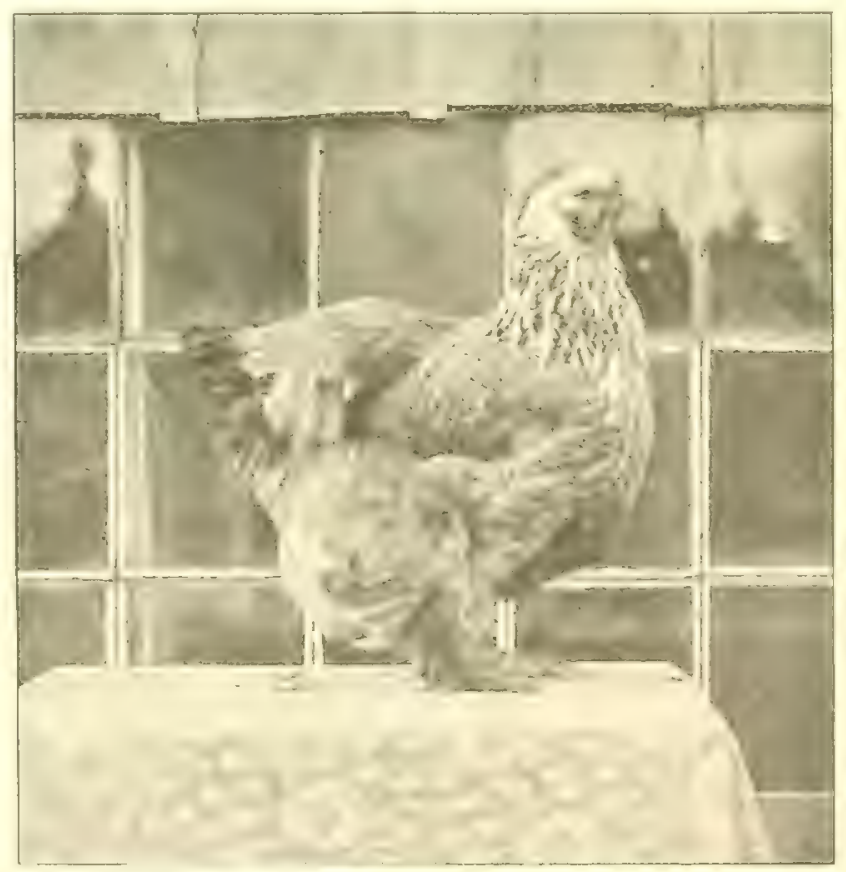

Wirst Prize Dark Brahma IIen at Ontario, 1904, Exhibited by L. C. Sage.

chicks. As in other breeds, we must look to the female for size and we have always found it advisable to use females of large size and males of medium size in preference to large males and hens of medium size or smaller.

That this meritorious variety is not more widely bred is due principally to ignorance of its practical qualities. Its beauty is universally admitted and any one securing stock from an up-to-date strain and giving them the intelligent attention necessary to achieve success with any variety will have no cause to look further for an all purpose fowl.

The future of the variety is in the hands of its breeders and they should not fail to give it the prominence it deserves. The quality is there, but it needs to be made known.

This is the advice of a breeder who has bred this fine Asiatic variety for twenty-five years. C. A. BALLOU. 


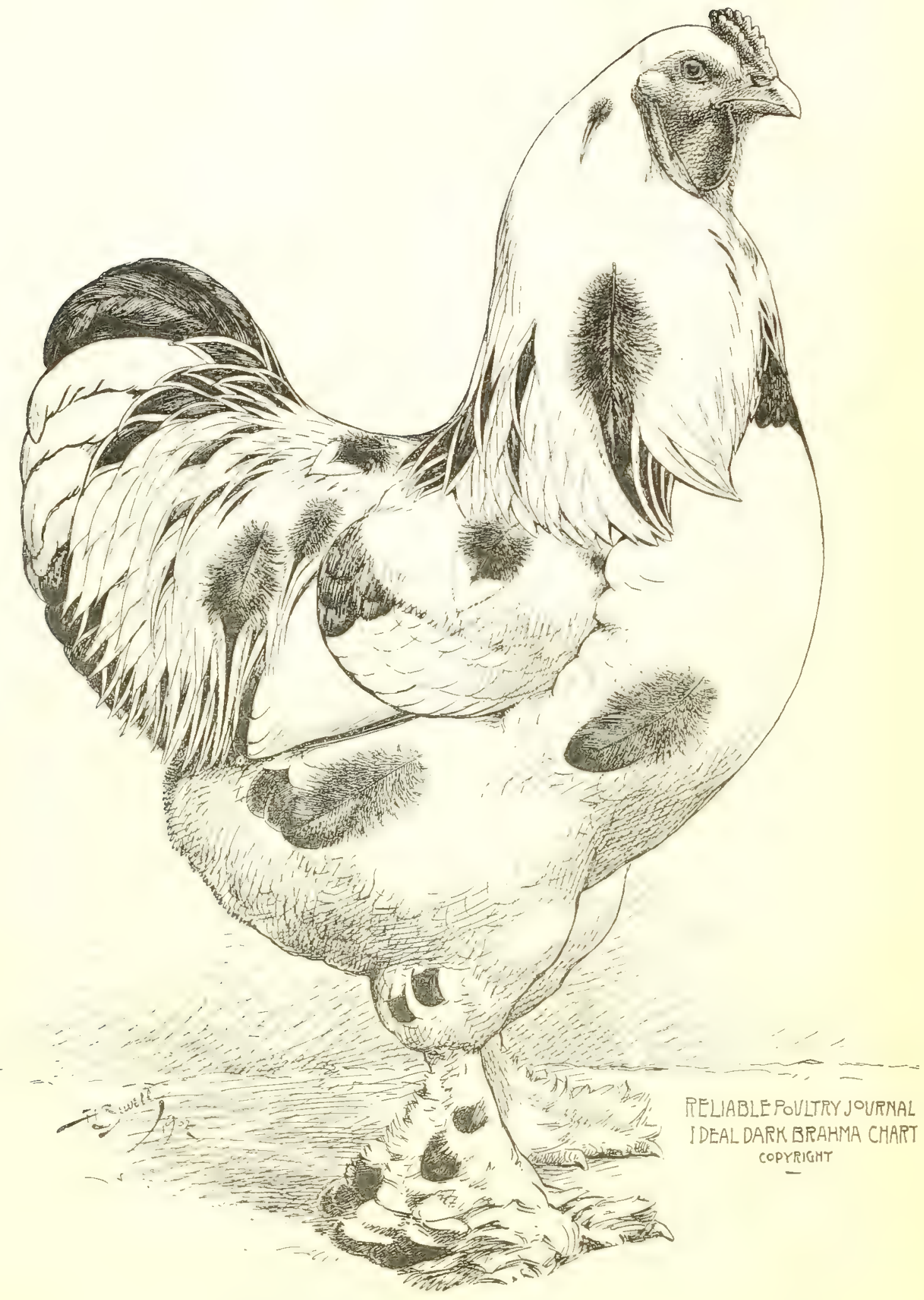

CHAR'T OF IDEAI DARK BRAHMA MALE.

Illustrativg tie Drstribution of Color as Required by the Americax Standard of Perfectiox.

The above chart is prepared to assist in a correct understanding of the ideal shape and color of individual feathers in all sections of Dark Brahma males. It is, so far as it goes, an illustrated standard of these requirements; the outline too, is that of an ideal standard-bred well matured Brahma cockerel. By studying this chart section by section the breeder may become familiar with standard requirements to the extent that he can better select from his own flock the birds most desirable for breeding and exhibition and so be aided in his efforts to produce the correct type in Dark Brahma males. 


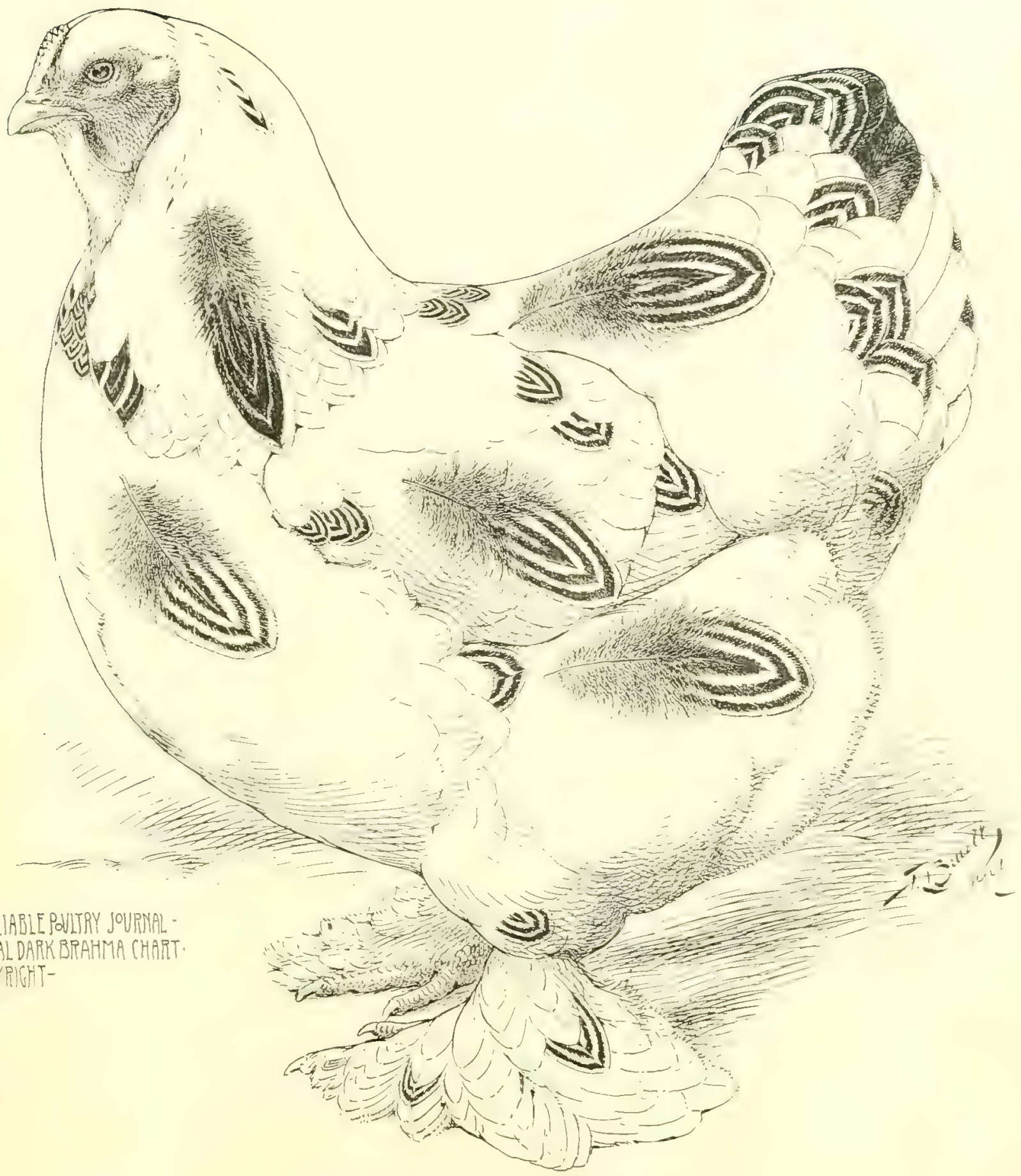

CHART OF IDEAL DARK BRAHMA FEMALE.

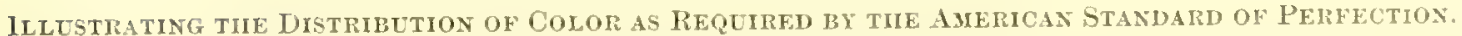

The above chart is prepared to assist in a correct understanding of the ideal shape aud color of individual feathers in all sections of Dark

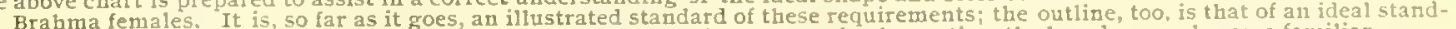

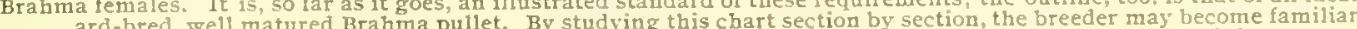
ard-bred, well matured Brabma pullet. By studyt with standard requirements to the extent that he can better select from his own fock most desirable for breeding and exhibition and so be aided in his
to produce the correct type in Dark Brahma females. 


\title{
BREEDING DARK BRAHMAS.
}

\author{
Double Mating of This Variety Adyocated-The Matings Described-Caring for the Laying Stock- \\ Feeding, Yarding and Housing the Growing Chicks.
}

By L. C. SAGE.

$\mathbb{M}$

TCH has been said and murh mort remains to be said regarding the mating, breeding and rearing of the Dark Brahma fowls. Good judgment must be used in selecting the birds to be mated if the best results are to be obtained. In the first place, two pens are necessary, one for pullet and the other for cockerel breeding. When breeding for the latter a healthy cock or cockerel must be selected; one with nice shaped head, the hackle a pure black and white, and both hackle and saddle well striped. The top parts must be free from red and of a silvery white; the under parts black, and tall well spread, a glossy black and free from white. The feet must show no sign of white feathers or vulture hock. He should have an upright, graceful carriage. Now the hens that are mated to such a bird should be large, well feathered, good shape and the less marking they have the better, or mottled breasts in the cockerels will be the result. Always avoid the Cochin shaped hen when mating for show pullets and get a cock or cockerel as good in all points as possible, but he should have

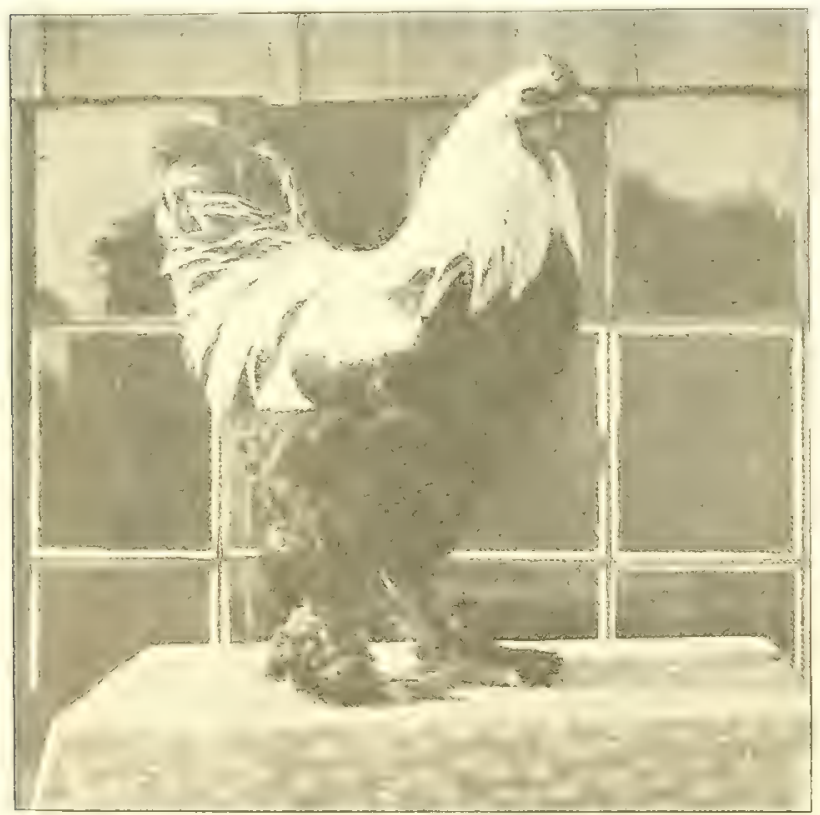

First 1rize Dark Brahma Cockerel at Toronto and Y,ondon, 1903, Exbibited by I. C. Sage.

hackle and saddle well penciled. His top parts sivery white, with fluff a good black nicely laced with white, and breast evenly mottled. The head small and well shaped.

The henis or pullets for this pen should be a good steel gray in color, well penciled all over, especially on the fluff and well up to the throat, with hackle well striped. From such matings you would surely get good show birds. You but never a good show pullet from a cockerel breeding pen. Many breeders, especially beginners, have been heard to complain that the Dark Brahma is not a good egg producer. But it can be proved that if properly fed they will lay as well as any other breed. The fault with most breeders is that they get the females too fat. One thing must be borne in mind, not to overfeed them.

Give a good feed of dry oats in the morning and let them scratch around until noon. Then give a mash made of table scraps mixed up dry with shorts and bran, and for a last meal, a generous feed of mixed grain. On this diet the hens will lay their share of eggs and keep in good health.

In winter when kept in confinement it is well to give green food in the shape of cabbage or turnips hung up within easy reach and plenty of grit. Never allow them to drink stale or mucky water.

The most satisfactory way of feeding chicks to avoid the many complaints they are liable to have, is to wait until they are about twenty-four hours old. Then give dry bread crumbs and hard boiled eggs chopped fine, shell and all, for a few days, then a variety of small or crushed grains, millet seed and grit; feed four or five times a day. Do not keep food lying around to get stale, as this is the chief cause of bowel trouble in young chicks. Let them have only enough feed to eat up clean. Give them plenty of fresh water" or milk in a shallow dish until they are large enough to reach the drinking fount.

At the age of three months they should be fed only three times a day. Give grain in the morning, at noon mash the same as the old birds have and the evening meal should be of grain, with a little green ground bone or meat just before going to roost.

It is a good plan to put a little flowers of sulphur in their mash at noon about twice each month when they are finishing out, as it aids the growth of the feathers.

Growing chicks must have shade as well as sunshine. If there are no trees for shade a good substitute may be had by growing a few groups of sunflowers or hills of corn in the yard where they run. This will answer the purpose, besides providing food, as it is a fact that fowls fed a few sunflower seeds once a day will add a nice gloss to their feathers. Chicks should not be over-crowded at night, for if given plenty or room they will grow faster.

This last point is all important, but is often neglected by those who otherwise take the best of care of their chicks. The coops in which to spend the hot summer nights should be wholly open or covered with wire on at least one side and provision made for protecting the inmates in stormy weather without cutting off their supply of air.

By following the rules laid down here you will have good and strong, vigorous birds, as I have proved by twenty-five years' experlence as a breeder of the Dark Brahma fowl. 


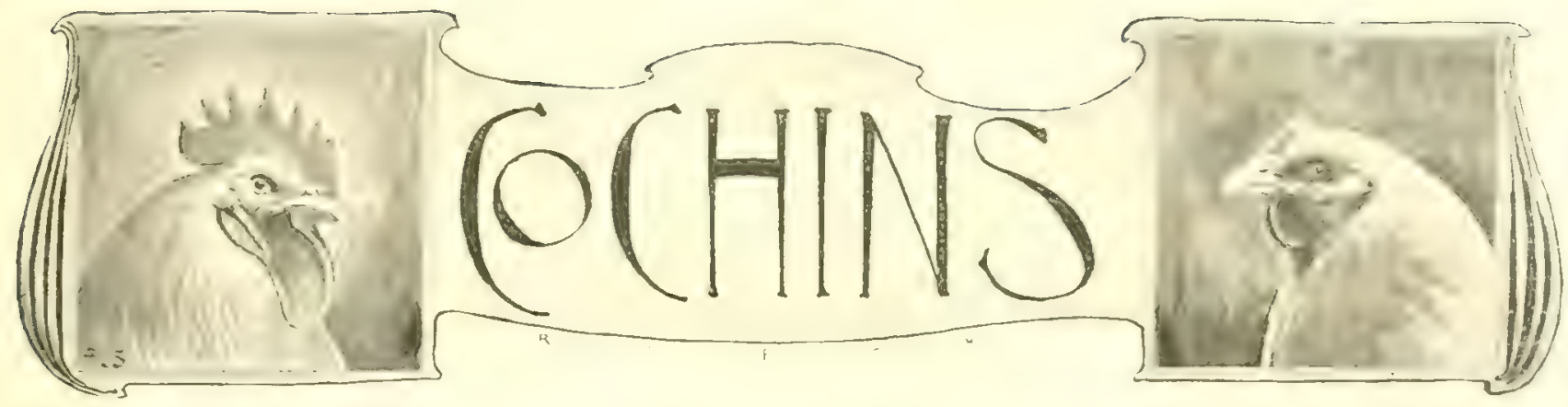

\section{BREEDING COCHINS.}

The Value of All Varieties of Cochins for Practical Purposes-The Best Method of Feeding and Housing Growing Chicks and Mature Fowls-A Discussion of the Prirciples of Mating Standard Cochins, and Instruction in Preparine for Exhibition.

By J. D. NEVIUS.

$\mathbb{M}$

ANY years ago, just at the close of the war. I became attracted towards the tren most ropular Shanghai or Cochin fowl. There was something about their general appearance and attractiveness of color that led me to select the Buff Cochin fowls and to follow them continually from that day to the present time. During the past thirty-five years I have kept constantly in touch with all the advancements and improvements made in the Cochin family. To speak of their early history would simply. carry us back to the opening day of the gates of Pekin to the English, about 1840. From that time on there came to England and this country specimens of the Asiatic type of fowls of many kinds and colors, and the colors most irregular and unattractive.

From these several types, kinds and colors of Asiatic fowls have been built up the four varieties of Cochins, also the two varieties of Brahmas and the Langshans might weil be classed with them. The most interesting part of Cochin history is the fact that the American fanciers, of which I am so pleased to be one, have contended from the very first for a true Cochin type and distinctive high class coloring. Long legs, flat breasts and stiff hocks should be discarded and kept out and away from the entire Cochin family.

It cannot but be admitted that the full rounded breast and the proper Cochin formation adds not only to their beauty, but to their value as well for market poultry. Free range is of benefit to all poultry, and while the Cochins will stand confinement when properly cared for and fed, better than almost any other poultry, they gain equal advantage with others through having a free range. The trouble that confronts us in the confirement of Cochins is that they are apt to become too fat, but if they are largely fed on oats, either clipped or hulled, wheat and but little fattening food they will do very well.

I give my young growing Cochins after they are six or eight weeks old, the free range of a three acre orchard that has been sown with oats in the spring. What they do not consume as green food ripens and is eaten in that condition. In addition to this they are fed all the whole wheat, cracked corn and mixed food that they can be induced to eat until grown to maturity.

There is a general misunderstanding as to the abllity of Cochins to produce eggs. It is not unusual at all to have early hatched pullets begin laying in October and continue a profitable egg production throughout the entire winter. It is largely a question of proper care and feeding. When Cochins are properly fed they are quite as apt to produce a large egg yield as are any ว: our meat or general purpose fowls. It is not reasonable to compare the egg yield of Cochins with the Mediterravean family, they producing so much more flesh and feather than is produced by the nonsitting varieties. At the same time I am fully satisfied that equal profit can be made from the Cochins as marliet poultry and eggs as from any of the breeds.

I feed the laying hens but very little corn, depending almost entirely upon wheat, oats, buckwheat and mixid food largely made from the products of wheat, and in addition to this ground oats and cut clover. My mixture is two parts of fresh cut clover, two parts ground oats, one part ground meal. This is fed once a day in reasonable quantity. There cannot be any set rule for all to follow in the selection of foods for the Cochins. The surroundings and advantages at gaining good food products for egg production may be different in one locality than in another, but you may rest assured that when you wish to have eggs from Cochins, you must feed for eggs, make them exercise and work for parts of their grain food the same as other poultry. The relative value of the Cochins as egg producers in my experience seems to be as follows: TWhites, Blacks, Partridge and Buffs. Whites and Blacks lay the largest egg and the Partridge the smallest, their advantage over the Buffs being that they produce a larger number of eggs.

It has always been my earnest endearor to select my matings of such a quality as to make it almost unnecessary to sell any of the chickens for table poultry. For this reason we seldom have enough of the inferior quality to furnish our own family table. IIy former partner, one of the largest buyers and shippers of dressed poultry in this state, much prefers a Cochin or a Cochin cross to any of the varieties that he can purchase in heavy poultry, the meat boing remarkably fine, tender, juicy and soft.

\section{FEEDING FOR GROWTH}

In feeding my young chicks I hare always selected that manner of food whlch seemed to get the greatest size in the shortest possible time. In this we must conslder the growing of bone and muscle as well as flesh. 
Feed for growth, feed for bone, feed for size and trust to add the flesh and fat when necessary for exhibition purposes when the time for finishing for the show arrives. While I have never kept the increased weight month by month in the growing chicks, I experience no trouble whatever in having full grown Cochins ready for the fall fairs in September and October. One of the largest Cochins that I ever saw I raised in 1901, at eleven months old. This cockerel weighed fourteen and a half pounds. I have known some Partridge Cochin hens in show condition to weigh twelve and a half pounds.

Never have experienced much trouble in leg weakness. This I have avoided by feeding plenty of bone forming foods. When Cochins are grown on a soil that has the natural influence that comes from a limestone sub-soll, they do not need so much care and attention in the feeding of bone forming material. Bone meal, green cut bone and any good food material that adds the proper element for bone forming and strong growth may be used to advantage to keep away the troulle of leg weakness. There is another kind of leg weakness which comes as the result of attempting to raise poultry in low, damp places. The Leghorns are quite as apt to be affected by these conditions as are the Cochins.

During the summer months and up to the time that is far better not to waste time and money in trying to improve the condition of such as will not grow and feather properly on solid, wholesome grain, cut green bone, bone meal and beef scrap.

My growing cinicls have all the wheat, hulled oats and cracked corn that they will eat. In addition to this they are fed once a day with a rich mash food composed of ground meai, gronnd oats. Wheat bran and beef scrap. A self-supplying feed box full of bran is aways at hand where they can help themselves. One inudred young chicks will eat up one-half bushel of bran from a feed hopper in about two weeks. If the feed hopper is kept perfectly sheltered from rain and a little catch box kept under the feed hopper there will be very little of it wasted. That which falls into the catch box can be either put back into the hopper or made itse of in the mash feed. Statements above as to the feeding of the old fowls may be considered. To make it more plain, the absolute rule for feeding Cochins with me is to feerl them strongly on egg forming foods throughout the entive year, except when in molt, when they are fed more fattening foods to assist in renewing their coat of feathers. You must watch the Cochins continually or they will get too fat to be useful.

\section{POINTS ON MATING COCHINS.}

In mating your Cochins perfect Cochin type must have

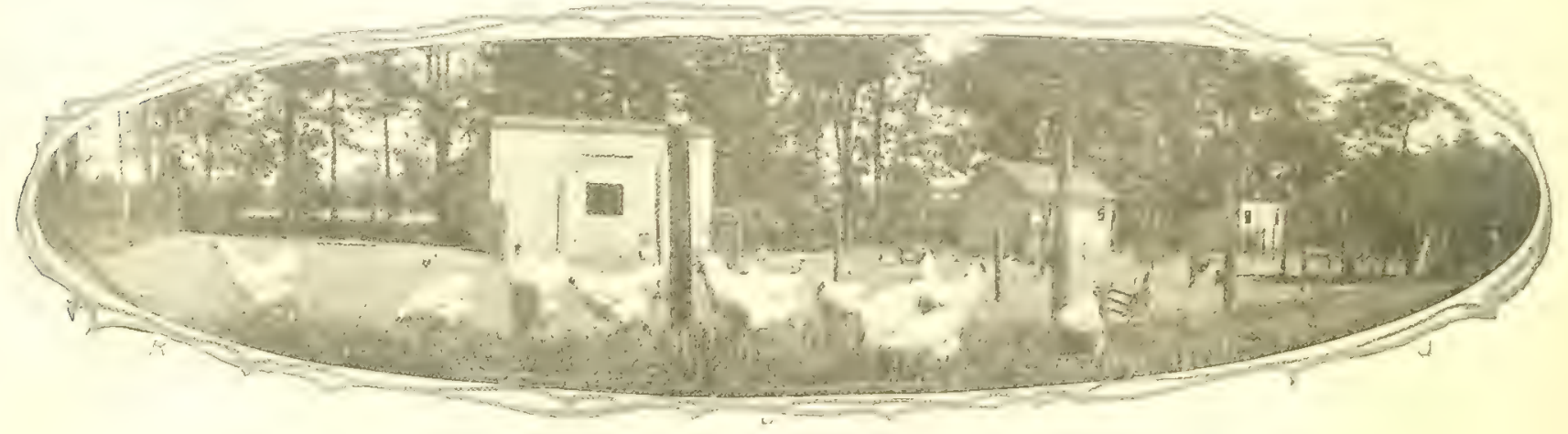

A Group of Colony Houses and Yards, occupied by J. D. Nevius' White Cochins

coild, frosty weather is at hand, my growing stock is left out in the orchard in open or slatted colony houses. When the cold weather necessitates removing them indoors, they are housed in colony houses, made as plain as they can possibly be, that stand in the center of large sized enclosures, sreat attention being paid to have them perfectly dry, free from damp or drafts and constructed so that they may have proper ventilation, with plenty of floor space and roosts, the latter being hung very close to the floor. These may be easily removed for cleaning and quite accessible to the heavy Cochin, leaving the floor space free for the poultry and the nests. I prefer cheese boxes for my Cochin hens to lay in. Around these colony houses are four feet wire fences, which seem to be all that is needed for the confinement of Cochins, either young or old.

There is very little trouble in our section of the country with the young growing Cochins being bare of feathers for many weeks, or even months, as in some localities. From experience I can say but little as to this, but my information is that it is caused largely through the lack of having plenty of feather forming foods. Usually young Cochins that do not feather out for several months never amount to anything and it would be money saved, as well as time and trouble, to destroy such as soon as you notice their inclination not to grow a coat of feathers. We have seen the recommendation of many who advocate feeding a mixture of pulverized bone, beef scrap and iron. We believe that it the first consideration. Mate together the very finest shaped Cochins you can possibly select and remember that you cannot hope to have good colored offspring unless you have the finest possible color in the parent birds. Do not hope to grow good colored Buff Cochins from poorly colored parents. This is equally true of the Whites and Blacks. When selecting your matings for Partridge Cochins, in addition to the very finest of form, you must have absolutely the very best of color and marking in the females from which you hope to grow your pullets, and they must be mated to males that are strong and rich in the blood lines of the females that are the best producers. It is a well known and established fact that the rich mahogany color of the female with a distinctive pencilling is the only thing that can win at the present time. You must have this color and this penciljing of the highest character upon females of the most exclusive Cochin form and feather or you need not hope to win in Partridge Cochin alley.

In mating Partridge Cochins many follow the coubl mating system. In using this system you would mate fo: females as above described. For males choose the vory darliest colored specimens, both males and fomales, the males having a very dark red top color, very heavily stripe with metallic black. Such matings when followed up year after year produce the richest colored males. I have, however, always followed the single mating plan, mating the very highest character and type of form and color for fe- 
males and depending upon these matings co produce my. exhibition males. You cannot have too much feather on your Cochins, providing you do not have any vulture hocks. The only advantages to be gained in the use of cockerels over cock birds is in their greater activity and vigor. I would rather have a few chicks bred from males and females in their second year than double the number from birds in their first year of production. The very best of size, shape and colur comes from the very finest two year old hens. You need not hope to have large sized offspring from under sized Cochin hens.

It is ouite as difficult to produce fine color in the Buffs, Blacks and Whites as in the Partridge. You must always select the very best color and under color for the reproduction of all varieties of Cochins. Some prefer a lemon, some a darker, verging on a cinnamon. I myself prefer the very best of rich golden buff, but perfect evenness of color throughout is of the greatest importance.

There are a few features in the breeding of the fowls that have the same influence with Cochins as with the others. These are bad combs, ugly, ill-formed heads, long ungainly wing bow on either your male or your female. Always select good even colored specimens to breed from. Do not havo anything to do with mixed or mealy colors. In Buffs, when you know that they were formerly of good even color, any slightly uneven or mottled plumage need not be so much feared. Always mate together nearly even shades, having a male just a little darker than the female. Mealiness and bad color in Buff Cochins come largely from pairing together uneven shade. Undercolor is of the greatest importance. A male should always have a good rich undercolor, for color comes largely from the male, and it is always best to have goot undercolor in both male and female. A line of Cochins that has been bred with care in the selection of surface and undercolor is much more apt to produce and maintain a good even shade than a promiscuous selection from mary flocks.

\section{BLACK AND WHITE EQUALLY OBJECTIONABLE.}

The Standard tells us that white or black in the plumage of the Buff Cochin fowl is equally objectionable. The facts are that if there is white in wings and undercolor of

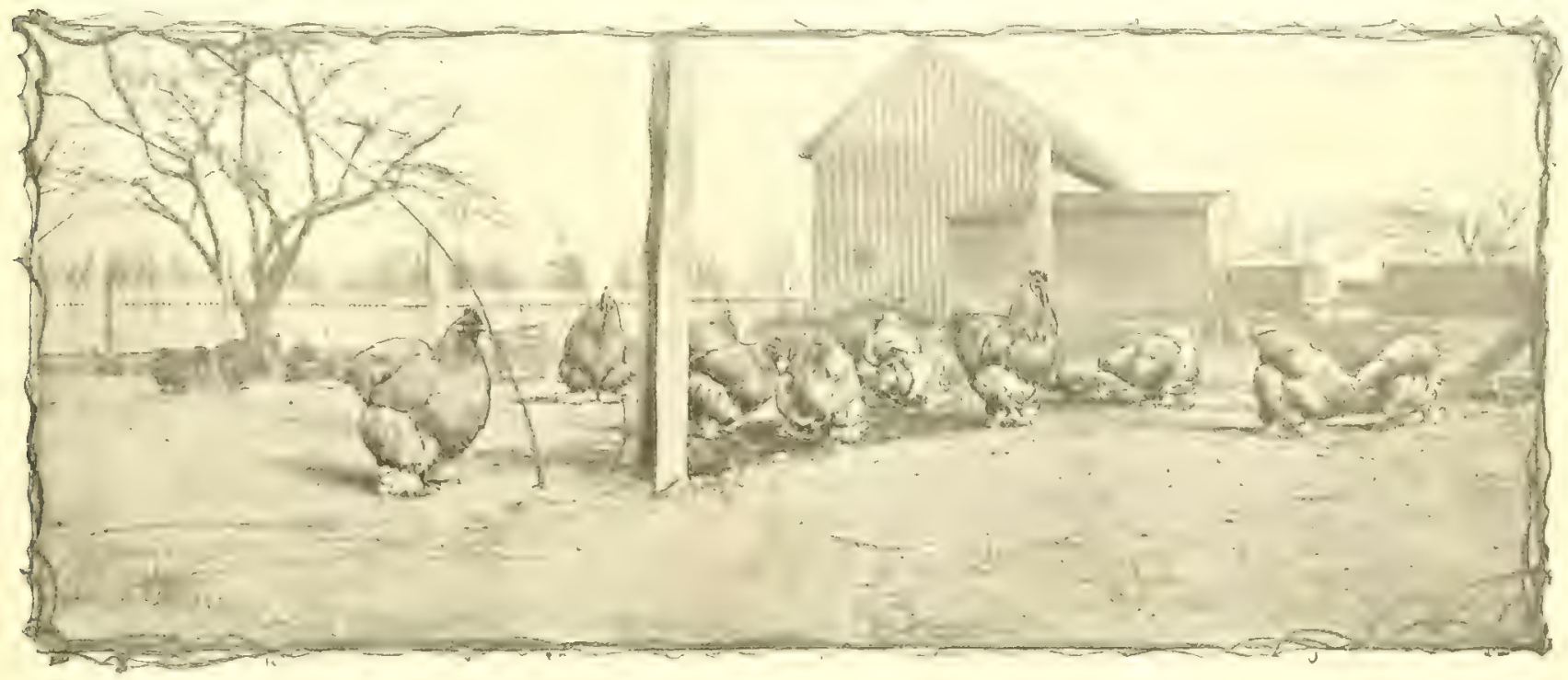

Two Breeding Pens of Buff Cochins - Owned by J, D. Nerius

backs and vulture hocks. These features seem to transmit most readily in the Cochin, but one could scarcely meet with any' so neglectful of their interests as to use birds showing such defects in their breeding pens. When you have in view the production of Cochins for the show room, the most difficult problem is to unite the three points that are demanded in all exhibition Cochins-form, feather and color. If you do not have Cochin shape, you do not show 'Jochins. If your Cochins lack feather, there is but little chance for them to succeed in the show room, and after you have the form and feather, if you lack in color, you again fail. The successful Cochin breeder must unite all three of these qualities if he would be successful.

There is a natural loss of color in the Buff variety. There is no way to guard again this; every one is fully acquainted with the fact that Buff is the very hardest cclor in the world to produce and to retain. All shades become more or less mottled. This shows more distinctly in the dark colored females and is caused by bad molting. We have seen some of these mottled hens, dry plucked at molting time, that grew a very smooth, rich coat of feathers quite unlike that of the season before.

Never tolerate in any of your breeding stock the red either the males or the females, it has a tendency to produce lighter colored offspring. With black shadings in wings or tail this has an influence in the opposite direction, as it is apt to produce dark body colors. Personally I have much less fear fur white than for black. I always prefer and select, so far as possible, even, true colors and mate them together. In reckoning for defects in the show room, you must follow the law of the Standard, which says black or white shading in wing or tail shall be considered alike objectionable.

As to the coloring of Partridge Cochins, what we all aim for is to have the neck color of the male and the female exactly as demanded by the Standard. Bright red for the male, with a distinctive black stripe, the same for the female. But whenever you establish a long line of high quality penciled females, you will find that the shade and color of neck become very much lighter, and ofttimes almost as much penciled as the body plumage itself. We all prefer to have the exact color demanded in the Standard, but I have not met with a half dozen females in the past three years that possessed both the proper color and pencilling of body plumage and the Standard demand for color in neck. We must all strive to gain the color and markings 
of neck exactly as described in the Standard, but it is better by far to have a weak colored neck than to have bad body coloring and pencilling. I always find that the finest colored offspring come from the pen of birds that are mated exactly as described for the exhibition pen, provided they have been bred in line long enough to establish the influence that comes from such matings. It is almost useless to hope to produce ligh class Partridge Cochins from chance mating.

Formerly there was some trouble in getting the proper size in White Cochins. Years of selection and of using the very largest White Cochin females as producing stock, to be secured by hatching them early and feeding them plentifully throughout the whole season, have very much improved the size, and the size of the Black Cochins has been improved in the same way until it is not unusual to see White and Black Cochins fully the equal in size of the other varieties. Whites are just as apt to have bad color in the plumage as are any other white fowls. This can be bred out and kept out throngh care in selecting pure white plumage in your producing stock. The shanks of all Cochins have a tendency to a little bad color, from the fact that they are so completely covered with feathers that but little of them is seen. Buff Cochins and White Cochins have naturally rich colored yellow shanks and there is but little trouble in getting them to equal the Standard demand except that they lose a little of their color wih age.

The shanks of he Partridge Cochin and Black Cochin are of a darker shade of color than the others, and there is less trouble experienced in having them of the proper Standard color. One great trouble with Cochins of all kinds is that they seem to be more afflicted with scaly legs than some breeds, and it is hard to get this out when once it gets a hold. The way to prevent it is never to make use of Cochin females for mother hens that have this affliction, for so sure as you do, all the young chicks that such a hen raises to maturity will be afflicted in like manner.

In preparing birds for the show room, you must have them in the very finest of health and condition, absolutely clean throughout, and their foot feathering as well preserved as possible. Foot feathering is usually kept in good shape for exhibition by keeping the fowls on dry sand, feeding them all their food from troughs or boxes and never inducing them to scratch or break the foot feathering.

J. D. NEVIUUS.

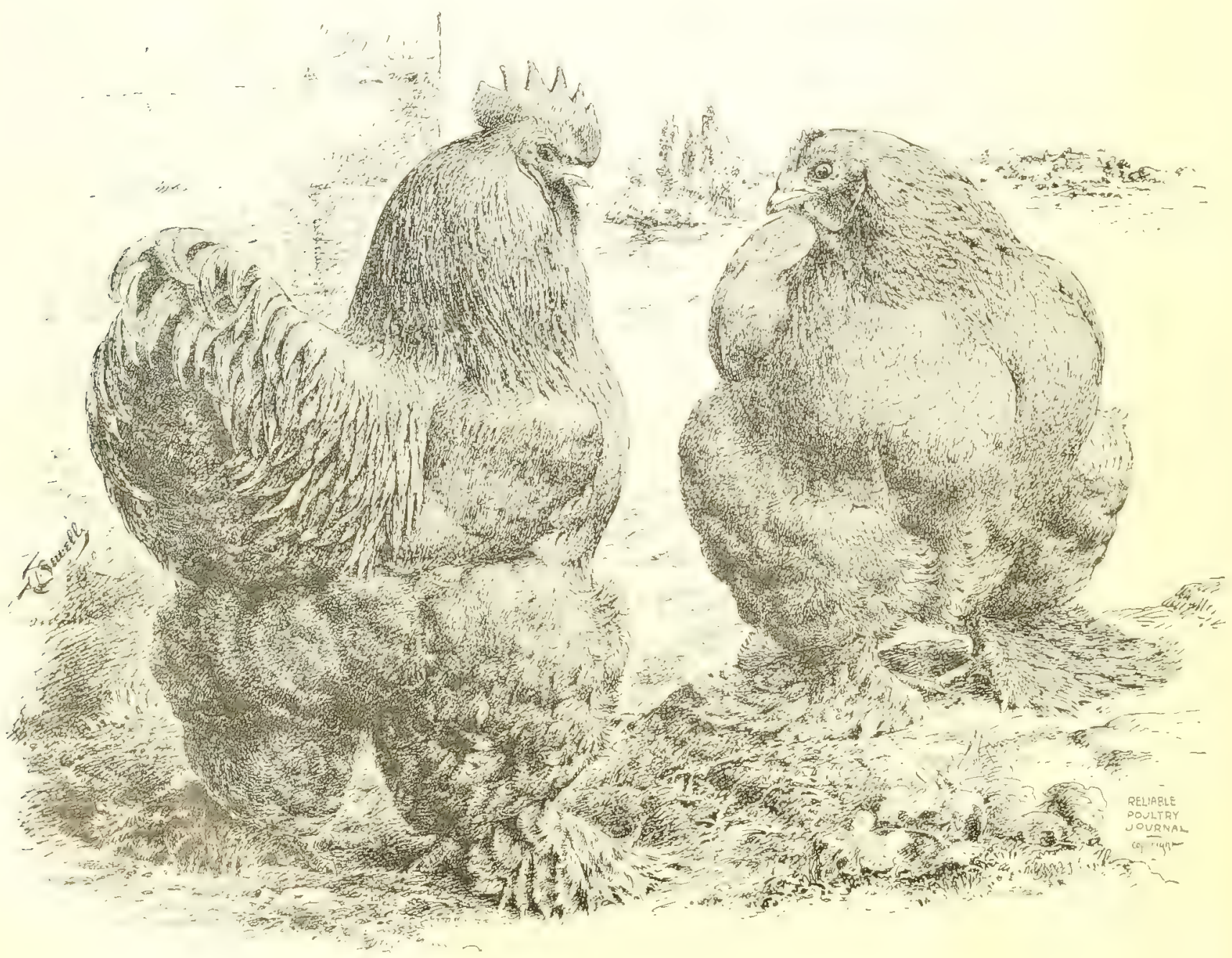

Standard Bred Buff Cochins-By SEWELL. 


\section{COCHIN MALE SHAPE.}

Criticisms of Foremost Judges and Cochin Breeders on a Composite Ideal From Live Models, Drawn by Franklane L. Sewell-A Collection of Opinions That Are in Themselves Authority on

the Ideal Shape of a Standard Cochin Male.

From the Reliable Poultry Journal.

$\mathbb{W}^{\prime \prime}$ l'RESENT the following eriticisms of Artist $\mathrm{F}$ L. Sewell's delineation of Standard Cochin male shape offered by those most interested in the Cochin fancy in an honest endeavor to secure a more uniform type for the guidance of breeders and judges:

G. O. Brown, Maryland, judge and breeder: "The male appears too much wedge-shaped, lacks fullness of both breast and fluff in comparison with height. Comb too far front. Wattles too large and should not fold. Leg and toe feathering a trifle too full for American Cochins, but if full feathered or English is to become the prevailing fashion, all right. Short in neck in comparison with size of specimen."

F. H. Shellabarger, Iowa, judge and breeder" "The coshin male as submitted is, in my judgment, too high up to his back from his feet. Or, in other words, strip his thighs and shanks of the feathering and his legs would be long enough for a Brahma. His neck is also full short for the proportion he shows otherwise. His wattles are also a trifle long for a Cochin."

George H. Northup, New York, judge and breeder: "Cochin male nearly perfect, wattles a little too long, breast not quite full enough. Too much length from lower edge of wing to bottom of feet. I do not notice any other section that can be improved."

D. T. Heimlich, Illinois, judge and breeder: "The Cochin male appears entirely too high on legs and too short in neck. The leg feathering and the feathering under breast are entirely out of proportion to the size of his body. Back, tail and body shape are all $O$. K. If the breast were a little deeper it would make an improvement in his appearance."

S. L. Roberts, California, judge and breeder: "The first impression one receives from the Cochin male etching is that the distance from center of back to foot is too great. Shorn of the shank and toe feathers the bird would appear very stilted. Head is not carried forward as Cochins carry their heads. Upper mandible of beak is blunt. Comb is small for massiveness of bird. Breast is too full at throat and down to point of keel. Neck is too short. Shoulder is held too low. Flufe is not heavy enough latterly on thigh. Tail is too rounded and blunt. The etching is evidently done to meet the requirements of the modern bunch of plumes known as Buff Cochin, whereas it should have conformed to a composite Cochin type; for, sad to say, all Cochins are not characteristically of same form, as now bred. In some respects I like the work very well."

Theo. Hewes, Indiana, judge and breeder: "The outline Mr. Sewell has furnished does not leave very much room for any one to pick flaws. The position of the bird makes him look as if he were standing on an uneven surface. I should like the bird to show a little broader in breast, and a trifle deeper; back broader and tail a little more upright. In feathers he is immense and fits the new Standard well."

W. S. Russell, Iowa, judge and breeder: "Male bird is not deep enough in body. Is too narrow in breast, too seanty in fluff, too short in back. The bird in total is too high for his depth."

H. S. Rabcock, Rhode Island, judge and breeder: "The Cochin male from top of back to bottom of feet is too long; ton pronounced a $\mathrm{V}$ in the whole outline. Otherwise very good, though personally I prefer to see the legs a little better defined."

H. B. Savage, Texas, judge ard breeder: "Male-Well, these illustrations, to my mind, are so near perfection that there is little left to say. Would like the neck a trifle longer, breast a little more plump, and legs a trifle shorter, with fluff a little heavier."

A. B. Shaner, Illinois, judge and breeder: "The head shows a little coarse, wattles are too long. Neck should be short, but in my jadgment, the one submitted is a trifle too short. The convex curve of back is a trifle sharp. Lower breast might be a little fuller. In general, he stands in a trifle too much of a neck-drawn-in posture."

C. H. Rhodes, Kansas, judge and breeder: "I consider the cut of Buff Cochin male about right; the outlines are Cochiny all over. The great abundance of fluff and loose feathering fills up all angles and represents a Cochin in every sense of the word. I have no comments to make."

S. A. Rigg, Illinois, breeder of Buff Cochins: "In regard to the etchings of Cochins, I think Mr. Sewell must be a mind reader. The male is exactly the mental picture $I$ have always formed of ideal Cochin shape, though I must confess I can not get my hens to see it just that way."

F. B. Donisthorpe, Nebraska, breeder of Buff Cochins: "I do not wish to criticise too severely friend Servell, for I am a lover of his work, but I cannot help thinking that in sketching this male he had not fully obliterated from his mind the old English Shanghai that we used to raise twenty-five or thirty years ago. I apply this simply and solely to the height of the bird. I think that if about an inch were taken off from the height we should have a better Cochin shape. Of course, to-day we are breeding for a 'blocky' bird. We want to get, if possible, a ball of feathers. I admire very much, indeed, the tall of the male, neither too high nor too low. I have been trying for the last two years to have my males so that a horizontal line could be drawn from top of head to tip of tail. I would furthermore criticise in a slight degree the comb of the male. I think 


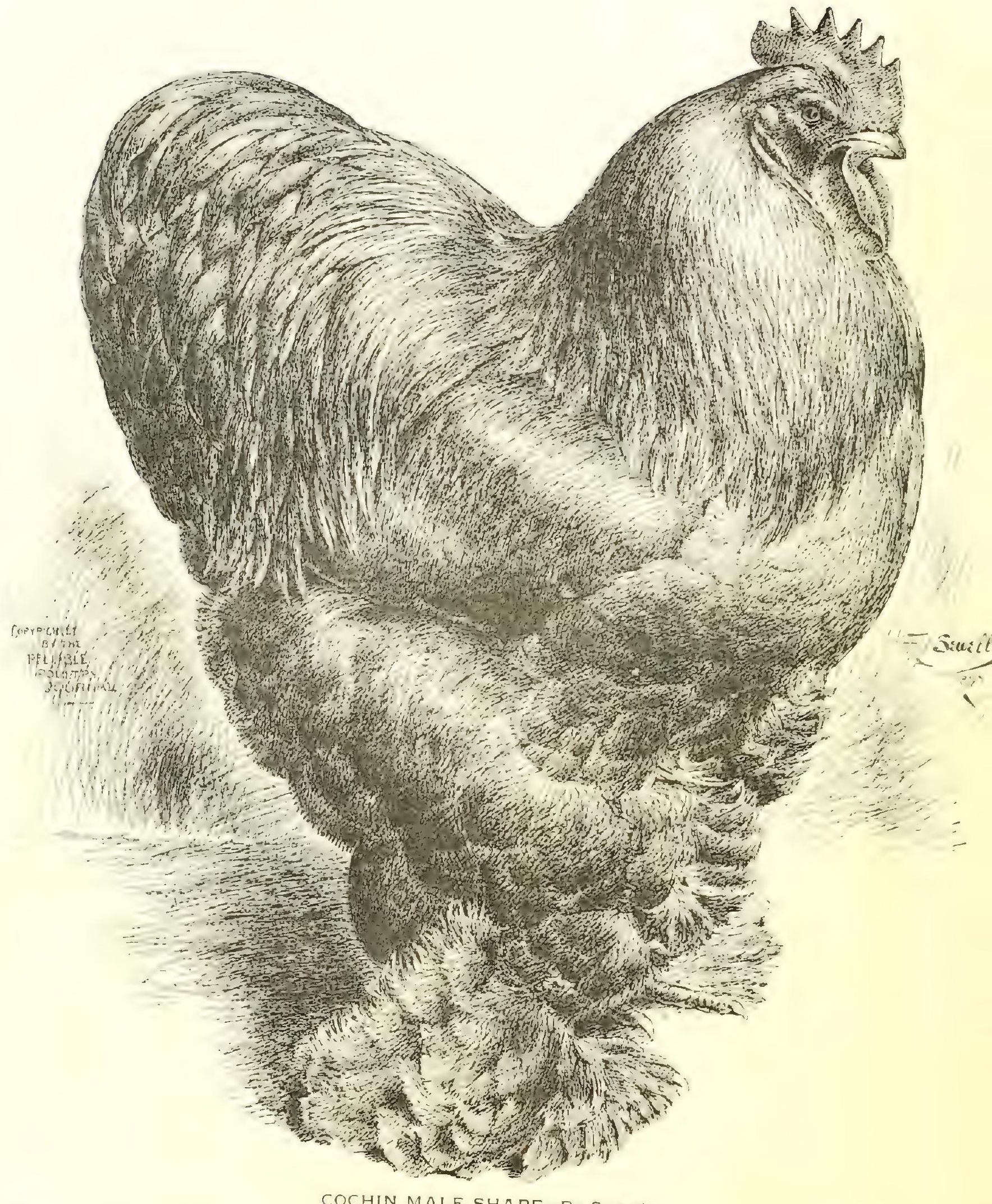

COCHIN MALE SHAPE By Sewell

5 . : m.+... to Prominer. Jadjes and Breeders for Franklane L. Sewell for the Reliable Poultry Journal and 


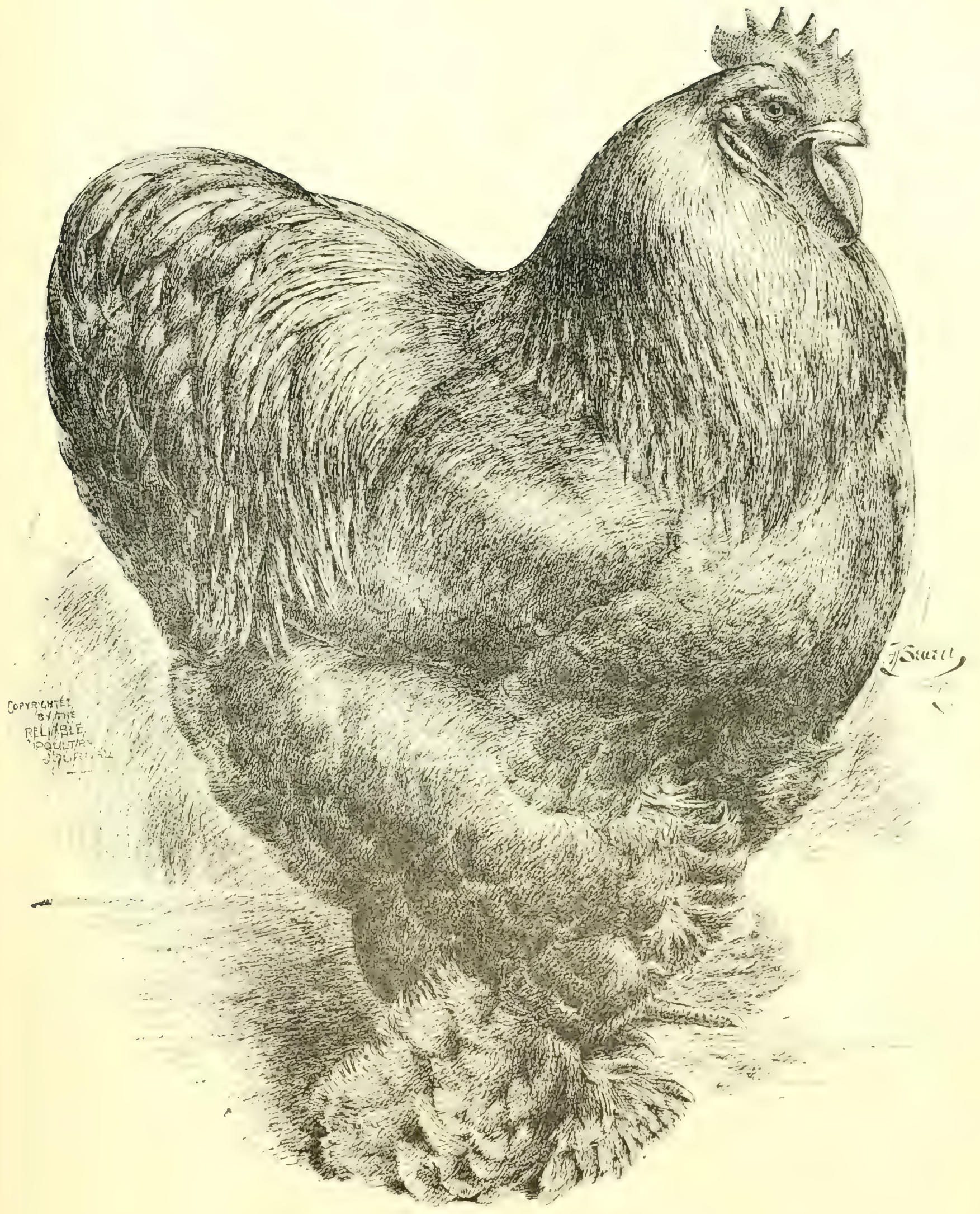

COCHIN MALE SHA PE-By Sewell.

An Ideal Cochin, Drawn by Franklane L. Sewell for the Reliable Poultry Journal, under the Suggestions of Prominent Judges and Breeders-The Outcome of Criticism Upon the Cochin Male Shape Shown on the Opposite Page. 
it a little too stumpy, and the serrations seem too blunt. I like a fine serration, even on a Buff Cochin male. of course I want the comb thick next to the head."

O. E. Skinner, Kansas, breeder of Buff and Partridge Cochins: "Referring to the Cochin cuts just received, I beg to state that while this shape is fine to look at, if you undertake to breed birds of this type, exactly, you would surely fail in Standard weights. They are too short in back and body. I am not criticising the shape to any extent, but my judgment is, a longer back and body, or else less weight for mature birds. I find my best shaped birds, like these cuts, are always short on Standard weights, although I admire them."

W. A. Ryon, Missouri, breeder of Buff Cochins: "The proofs of Standard Cochins, as submitted by Mr. Sewell, are just about the thing. He might make forty more and not come so near the real Cochin shape. Were I to offer any change it would be to have the male more 'English' or full feathered, and bill just a little longer."

J. H. Parrish, Illinois, breeder of Partridge Cochins: "The Cochin male cut is very fine. I do not see how it could be improved. I am well peased with it."

Sid Conger, Indiana, breeder of Buff and Partridge Cochins: "The male ought to be as long as he is high, but Mr. Sewell has him two inches higher than long. The wattles are too long and too much folded to be natural and neat. He needs some trinming to make him more natural and life-like."

Samuel S. Sherman, proprietor Banner Poultry Yards, Iowa, breeder of Partridge Cochins: As regards the Cochin male and female shape, as submitted, would say that Mr. Sewell lias certainly produced the ideal in the English, or 'full feathered' class, and I, being a breeder of the American class only, would not attempt to 'split hairs' in a criticism of the proofs submitted, but confess at once that I am one of those oid fogy fellows who cannot just keep up with the extremes of the fad for bloomer legs and pillow cushions, which latter almost conceal any appearance of backs whaterer."

O. L. MeCord, Illinois, breeder of Buff Cochins: "The etchings of Cochin male and female shane received. I pronounce them fine. I cannot see where there is any fault to find with them."

Dr, A. Gaiser, Nebraska, breeder of Buff Cochins: "Profile of Cochin male at hand. While the shape of male is good, I like a little more breast, more fluff and a trifle Ghortel legs, otherwise he suits me in every way."

Dan Robertson, Illinois, breeder of Bulf Cochins: "Etchings of Cochins received. The male suits me. Wish I had one as good as he."

E. Dunstan, Mississippi, breeder of Butf and Partridge Cochins: "Mr. Sewell's drawing of Buff Cochin male l'Eceived, and in offering my opinion as to its merits as a suitable sketch for a place in the Standard of Perfection, to guide and govern Buff Cochin breeders in forming an outline, I would condemn same as not fit for such an evaltea position. The general ontline of head and neck is suggestive of Mr. Sewcll's drawing of Royal Blue strain of I3arred
Plymouth Rocks. Examine it by the wording of our Standard, which says: "Wattles medium in length, well rounded, fine in texture; ear lobes, large, etc.' We find here the wattles long and coarse and ear lobes small. Standard also says: 'Neck short, neatly curved.' The neck is certainly short in the drawing, too short to suit my fancy, but tho neatly curved part should be condemned by all followers of the Standard. Again it says: 'Breast broad, deep and full.' The breast may be broad enough, but it is cartainly not full enough to ill the requirements of the Standard. In looking at the thighs, I should say they are one-third longer than is demanded, to be symmetrical, but I am inclined to think the great length of thighs shown is caused in part by the breast not being deep enough. On the whole, it suggests to $m \theta$ a Shetland pony set up on a pair of elephant's legs. Try again, Mr. Sewell. Give us something from life; for instance, the bird 'Oakland,' winner' ar Madison Square Garden, January 2, and at Boston, January 26, 1897, which suits me much better than this drawing."

J. A. Ayers, Missouri, breeder of Buff and Partridge Cochins: "The sketches of Buft Cochin male and female, by Sewell, sent for criticisms; were received. For my part I would lengthen the body of the male bird. I would extend the fluff farther back and the body farther forward of the legs. The head is too nearly over the legs for a Buff Cochin. The comb extends too far back and fits too closely down on the neck. The comb also extends a little too near the end of beak. I would suggest he be a little deeper in breast; he is a little too shallow from lowest point in back to breast just in front of thighs. Otherwise he is tip-top."

E. T. Blood, manager Crescent Farm, Ohio, breeder of Buff Cochins: "Our criticisms on the Sewell sketch of Cochin male are: Male, too tall for length of body. Would add to depth of breast and length of fluff at rear. Tail, while nice in general shape and carriage, shows an unnatural evenness in outline."

Robert M. Dale, Illinois, breeder of Buff Cochins: "This bird appears to me very good with but few changes. In my estimation the comb projects out over the beak too far and is a trifle too high in front. The bird is also too high for his length of body. If the legs were shortened a trifle I think it would improve the bird in symmetry. With these few changes would call the bird a winner of the blue."

George Clough, Illinois, breeder of Buff Cochins: "The proof of Cochin male received and I must say it is hard to find any fault with it. It is an excellent proof and suits me, except that the wattles are too long."

Julius J. Klein, Illinois, breeder of Partridge Cochins: "I think the male is perfect."

I. V. Hardy, Kansas, breeder of Buff Cochins: "The drawing of the Cochin male appears to be overdone as to feathering from breast down. I think the bird a trifle too leggy."

J. H. Lewis, manager of Hanlin Poultry Farm, Pennsylvania, breeders of Buff Cochins: "Outlines of Cochin male and fernale received. I think the male is the better of the two, though both are better than most breeders get thcm. I would like the male's saddle not to rise so close to harkle. Head a little too much crouched in feathers, making wattles rest too much on feathers. Otherwise he would suit me." 


\title{
COCHIN FEMALE SHAPE.
}

\author{
Criticisms of Foremost Judges and Cochin Breeders on a Composite Ideal, From Live Models, Drawn \\ by Franklane L. Sewell-A Collection of Opinions That Are in Themselves \\ Authority on the Ideal Shape of a Standard Female Cochin.
}

From the Reliable Poultry Journal.

\section{$\sqrt{1}$}

HE wide difference of opinion expressed by judges and breeders, in criticising the work of our foremost poultry artist, is ample proof of the urgent need of exacrly such work as is being done along this line. If we are to attain a greater uniformity of judging and breeding, it must come through efforts of this kind. The judge or breeder who is in earnest in his desire to progress will not fail to give careful attention to these sketches and criticisms.

George 0. Brown, Mtaryland, judge and breeder: "The female appears squatty. Shape makes her appear as if walking down-grade instead of standing on the level. Head carried too low for the size of the cusbion-which is a trifle too high, anyway. Comb does not go far enough back on head. Trifle short in neck in comparison with size of figure,"

F. H. Shellabarger, Iowa, judge and breeder: "The Cochin female is much the better of the two, yet her neck should be a trifle longer, with the head increased in size to harmonize with the rest of the drawing. -The Standard calls for a short neck on a Cochin compared with that of a Brahma or Langshan, but it does not want to look like a mud turtle on a fish line, nor to have a head so small that it looks like the eye of a rhinoceros compared to the size of the body."

George H. Nortbup, New York, judge and breeder: "The female is just my idea of a Cochin hen, the embodiment of my ideal when I was breeding them."

D. T. Heimlich, Illinois, judge and breeder: "The Buff Cochin female is too short in the neck. The back breaks too abruptly into the cushion. She does not show depth of breast in proportion to general size. As a whole sle represents well the fad now in vogue, without the practical features so desirable in an utility fowl."

S. L. Roberts, California, judge and breoder: "The bird appears to be taking a walk toward her keeper, evidently looking for something to eat at his hands. Comb is too small. Too great a sinus between cushion and joint of hackle, and not enough at juncture of tail with cusbion. Cut breast away at center thereof a trifle, throw the head forward some, and with the foregoing aiterations I should consider the study a grood one."

Theo. Hewes, Indiana, judge and breeder: "The female is overdrawn. The head should be pulled up a little and some of the cushion taken away. I will not say a worl about this bird below the wings. She is elegant. But the cushion runs too far forward. We do not want to call for something that we cannot get. Modify it just a little and raise the tail a sixteenth of an inch."

IV. S. IRussell, Iowa, judge and breeder: "The female is good with the exception of back, which is too short, and tho convex sweep is too abrupt. I should prefer to see swoep rise more gently."

H. S. Babcock, Rhode Island, judge and breeder: "The cushion rises too abruptly from back and too near neck. A very good cut, otherwise."

H. B. Savage, Texas, judge and breeder: "The female, like the male, is a cracker-jack. I should prefer the head just a little larger, breast a little deeper and just a trifle more distance between the hackle and the rise of the cushion."

A. B. Shaner, Illinois, breeder of Buff Cochins: "The head shows coarseness. Beak is a trifle long. The cushion is too large, and rises too sharply. Lower breast is not full enough, and the tail is carried a trifle low."

C. H. Rhodes, Kansas, breeder of Black Cochins: "The sketch of the female would suit me better if the breast were carried lower and were fuller in outline. The position may have something to do with it. Otherwise it suits me."

S. A. Rigg, Illinois, breeder of Buff Cochins: "In the female I make some objections. The cushion is a little too abrupt in start from the back. The body seems not well balanced-ton much behind for what there is in front-looks as if she were standing by muscular efiort rather than an easy equilibrium. Take her a section at a time and she is fanitless, but those fellows who are always rawhiding about the symmetry cut can find use for it on this bird. These drawings are great educators and are worth fifty times the cost of a year's subscription to the breeder who wants to lieep 'up to snufi.." "'

O. E. Skinner, Kansas, breeder of Buff and Partridge Cochins: See page forty-six for criticism. Mr. Skinner thinks birds of this type cannot bo brought to standard weights for adults.

W. A. Ryon, Missouri, breeder of Buff Cochins: "No fault to find with the lemale."

J. H. Parrish, Illinois, breeder of Partridge Cochins: "The Cochin female cut I think could be improved a little in cushion. It is most too long from rise to the point of tall. Very good all over." 


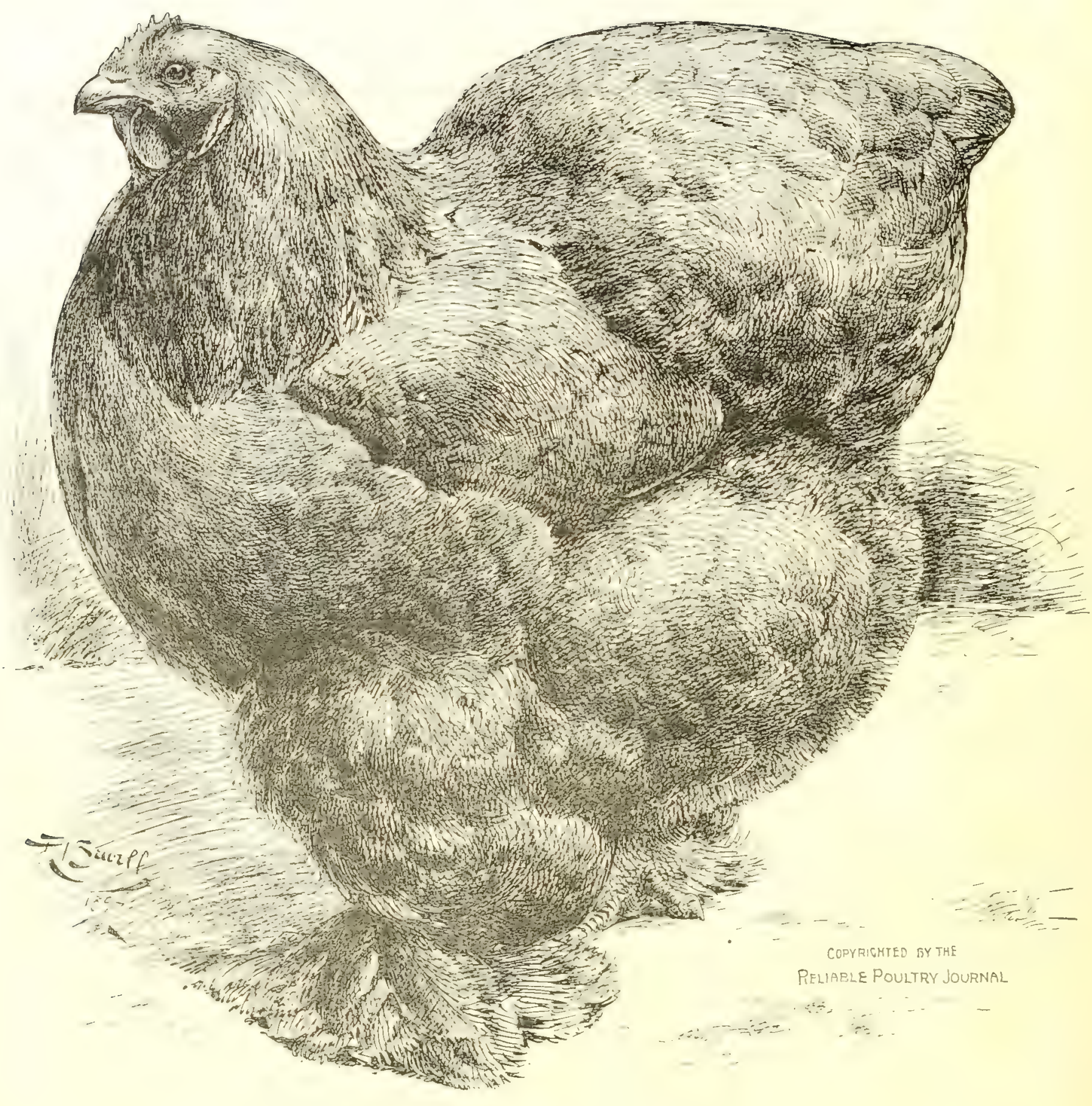

COCHIN FEMALE SHAPE-By Sewell.

Comprising the Best Points of Several Live Models, Dramn by Franklane L. Sewell, for the Reliable Poultry Journal, and Submitted to Prominent Judges and Breeders for Criticism Based Upon Standard Requirements, 


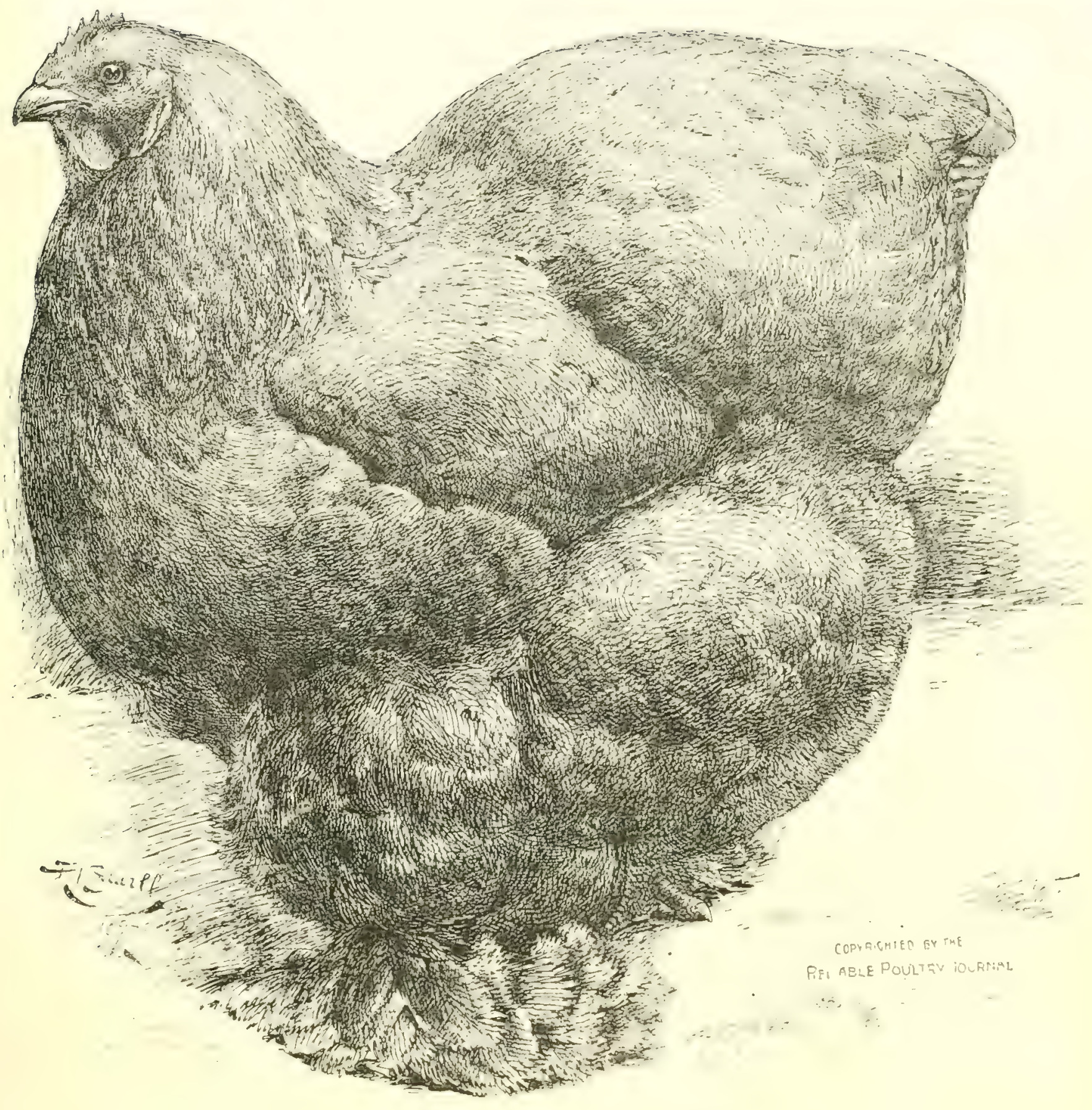

COCHIN FEMALE SHAPE-BY Sewell.

An Ideal Cochin. Drawn by Franklane L. Sewell, for the Reliable Poutry Journal under the Sugn the Opposite Page Judges and Breeders-The Outcome of Criticisms Upon the Cochin Female Shape, Shownonthe Opposite Pege 
Sid Conger. Indiana, breeder of Buff and Partridge Cochins: "The female should have one more point on comb and comb should not be so wide between the serrations; they are hollowed out too much, not cut V-shaped enough. She should hold her head up a little more, making it higher than her back."

Sam S. Sherman, proprietor Banner Poulty Yards. Iowa, breeder of Partridge Cochins: See page forty-six. Mr. Sherman helieves in more chicken, less feathers.

O. L. MeCord, Illinois, breeder of Buff Cochins: Finds no fault with this cut.

Dr. A. Gaiser, Nebraska, breeder of Buff Cochins: "The female Cochin profile is before me, and if she were a little fuller in the breast I should call her about perfect. I like a very full breast in a Cochin."

F. B. Donisthorpe, Nebraska, breeder of Buff Cochins: "As to the female, my criticism in the first place would be. breast not low enough. Breast should be at least fiveeighths of an inch lower, and I dislike the division as it appears betwcen the foot and hock feathering. The leg feathering is hardly fuil enough. The tail just suits me, it does not droop like some, neither is it erect like others. I wish we could have had color given, then there might have been more room for criticism, but I would say candidly, as a Buff Cochin breeder, if I could raise all my birds as good as the proofs received. I should be perfectly satisfied."

J. A. Ayers, Missouri, breeder of Buff and Partridge Cocinins: "The female I would suggest be a little deeper in body from the lowest point in back to breast just in front of thighs and her hackle a shade longer. Otherwise she is o. K., and wonld be hard to improve on."

Dan Robertson. Illincis, breeder of Buff Cochins: "The female would look better if she were fuller in lower part of hreast. That is about all I find bad about her."

Julins J. Kleiu, Illinois, breeder of Buff Cochins: "The female suits me."

Robert M. Dale, Illinois, breeder of Buff Cochins: "Head of female appears to me a little too small for size of body, and beak is too large for such a small head. Otherwise to me she appears good enough to win, and that is what we all want. It will take a good one to etch a better female than the one now hefore me."
George Clough, Illinois, breeder of Buff Cochins: "I am well satisfied with the shape of the female. I can find no fault with it."

E. Dunstan, Mississippi, breeder of Buff and Partridge Cochins: "I have received Mr. Sewell's drawing of Buff Cochin female. Would say that I think comb too small and it conforms a little too closely to shape of head. Beak not curved enough and rather too masculine in appearance. Whole head and neck set too far back. The live specimens I have seen and admired have a more slanting, stooping forward shape, and if a perpendicular line were dra. $/ \mathrm{n}, \mathrm{com}$ mencing at back of neck, it would strike the front oart of thigh and toe feathers, while this drawing shows a line from eye would touch front feathers of thigh and toe, consequently the breast aoes not show either full or low enough. The fluff and back parts would pass as Standard, but I am inclined to think the cushion rises too sudkerly and is slightly ovprlone in size."

E. T. Blood, manager Crescent Farm, Ohio, breeder of Buff Cochins: "Female, head just a little bit small. Breast carried a trifle high, not showing prominent enough in proporlion to fluft and cushion."

I. V. Hardy, Liansas, breeder of Buff Cochins: "With the female it strikes me that her cushion rises a trifle too abruptly, and that she would look better if the lower part of breast were a trifle fuller."

J. H. Lewis, manager for Thomas and F. M. Sankey, breeder of Buff Cochins: "Female cushion rises too abruptly and runs too high, making a hump on back. I like a full cushion withont so much hump. Point of tail too low. Breast a trifle low, otherwise she suits me."

Frank W. Breed, California, judge: "It is diricult to get 3 correct idea of this female's shape, owing to the poise caught by the artist in illustrating his ideal. As here presented, the bird was caught in the act of stepping down and of some object, thus throwing her weight on the extended foot and consequently forcing her whole contour out of symmetry. Did she stand so as to give us a square side view her neck would not be strong enough in arch and breast would lack a trifle in depth. If main tail had more of a tendency to point downward a rounded appearance would be given to her cushion, ihus adding to her beauty." 


\title{
STANDARD BUFF COCHINS.
}

\author{
Their Introduction and Development in America-A Description of Standard Shape and Color of \\ Each Section-The Defects Found When Judging and the Penalty for Each-Selecting \\ and Mating to Produce Exhibition Specimens.
}

By I. K. FeLCh, Associate Eulitor Reliable Poultry Journil.

\section{$\rrbracket^{n}$}

ANY breed in America deserves to stand at the head of the list of fowls this breed does; for it was in its crude beginning, under the name of Cochin China, the means of awakening the American fancier farmer and breeder to the importance of poultry culture. While 1819 may be said to be the first year of studied effort in the importations of Chinese fowls to America, for several years previous there were many foreign specimens that came in as surplus stock left over in ships' cabins that were called Chinn fowls, wore from the fact that they were found on ships employed in the Chiua trade. The "Hen Fever" between ' 49 and '55, however, was the incentive for studied importations of these large Asiatic fowls that were brought. from Shanghai, China, the white, grouse and buff specimen, the latter in number predominating. The improvement of these Buff Gigantus have resulted in the improved product we now call Buff Cochins. Yet their importance and real benefit to the nation were in a very large measure achieved under other names as above. Previous to 1850 our birds were small; but such was the influence of the Cochin blood upon our native stock that the average weight of the specimen upon the poulterer's tables in 1852 was found to be fully one and one-half pounds more per fowl than ever before. That this race gave to our native stock renewed life and productive merit none can deny, and to it must all the buff races we now have in our best breeds date back for their color and ancestry. Thus in a collateral way are they the progenitors of mexit and utility, while in their present condition do they present and hold a premier position as one of the grandest of exhibition breeds, that have demauded the very highest prices known among fowls.

The development of the Buff Cochin has been erratic, yet remarkable; it has at times held the favored esteem of nearly all the poultry loving nations of the globe. The pride of possession in the fanciers has carried the prices to the remarkable sum of $\$ 300$ for a single specimen, $\$ 500$ for pairs, with current and repeated sales at $\$ 100$ each, and by the trios hundreds of them at that sum until at the present writing we can truthfuliy say of the Bufi Cochin, that they are the pride of the Cochin family, the source from which emanates that gem of all colors seen in forls, convexed lires of beauty which give that shape to the breed's secticns so in harmony with their color that as a whole makes the breed hold the gazer spellbonnd, forcing him or her to exclaim in viewing them, "Perfection of color!"

The six months' old pullet, with her full, broad, rounded development of breast, with length of back sufficient to secure that full curved outline from cape to tail, with full thigh flufs, broad, full body fluff, with tail proper nicely folded to a point beneath the ample cushion and coverts. this with lower thigh plumage hanging full in front, as well as rear and about the hock joint in soft flexible feathering. meeting the shank and foot plumage in a smooth outward sween, covering completely the feet; such a plumage col- ored in a rich orange, ocherous shade; then do we have perfect harmony in shape and color, which puts to rout the assertion that shape has nothing to do with color in poultry culture.

But we say each is dependent up on the other, this harmony essential for the fullest and best effect, and this breed our most ablc witness for the position we take that shape and color shall receive equal consideration in adjudicating for prizes. It is this very harmony that has enabled the breer to hold its position as one of the strongest and most popular exhibition varieties and secured for it the high prices.

We have many breeds of which the same color is demanded. but do they present the same strength and perfection found in tilis ocherous shading of the Cochin?

When practical useful merit is coupled with pure color then do we see such breeds meet the popular demand, for then the poor and middle classes will buy and propagate them and the breed no longer is dependent upon the rich and those who prize them solely for exhibition purposes. It is exhibition quality that brings the fabulous prices, practical merit that makes any breed popular and secures for them satisfactory prices year after year, and as there is nothing that stands exclusive and alone, thus we see the advantage of massing the plumage in pure convexed lines upon which to display a pure orange ocherous color. No other satisfies. The feather itself must be convexed from base to tip and from edge to edge of its fiber, which aids in producing this desired outline.

But let us begin at the beginning as we trace its listory and comp!etion as a breed in America.

From $1 \$ 46$ to 1852 there were many Chinese fowls received in America. They must be called chance receipts, for. as I remarked above, they were the unused cabin supplies found upon shins in our forcign trade, usually called Cnchin Clina or often named for captains of ships upon which they were found. Not until the year ' 49 or ' 50 were there many if any special importations. The specimons in the two shades of hrown plumage were called marsli fowls. later Grouse Cochins, and finally they assumed the shape, color and name of Partridge Cochins: others came into the country white and huff in plumage, but all classed as Shanghais.

As a boy I carne into nossession of a Black Red male and Buff pullet that weighed ten pounds. Will I ever forget her magnificent proportions? You who to-day gaze unon the general flock can have no conception of the difference in sizes experienced in 1849. TWhen we consider the fact that fowls are marketed at about two-thirds their full grown weight, and understand that in thirty months the arerage market weight was raised one and cne-half pounds, yoll may understand the surprise of those who s.aw the efficts of this pair upon my flock of native fowls.

The nrevailing colors in the progeny, however, were 
ocherous, either light or dark, shading from lemon to light brown, and when these colors prevailed the shape approached that now achnowledged as perfect and their shanks and feet were more heavily plumed.

This country is fast following in the footsteps of Englanc. There is a strenuous effort to produce an over abundarce of plumage and in too many cases it has produced nothing less than an excrescence. But for all that a properiy feathored Cochin is, even in comparison with the other sub-varieties of its class, most profusely feathered in the Buff variety. As the Brahma is the largest of all breeds, so is the Buff the longest and most profusely feathered Cochin. For all that I do not think this should license pronounced vulture looks to win prizes in our exhibitions. We had vulture hocks in 1852; we have them to-day. They werc unsightly and a disqualifying defect then; the Standard so declares trem to-day. Yet oftentimes we see the law ignored and see vulture hocks on the winners. They are an objectionable extreme and usually such birds are mated to pullets having bare middle toes, both being disqualifications by our Standard. let because the breed is acknowledge the heaviest plumed of all breeds, nineteen-twentieths of the judges become a law unto themselves and pass them, and the worst feature of it all, they allow them to pass uneut. Were the disqualifications raised in our Standard and the defect cut a reasonable amount these specimens would not win, and it would, soon reduce the plumage to a reasonable condition, and the egg product would be the grcater for it.

The use of any disgualifying extremes is but to harbor inherent hefects to be reproduced from time to time, and the breeder known to thus indulge in their nse hazards his reputation; eventually his loss in sales will far outweigh any gain ha may derive through the use of disqualified stock.

All the breeders both of Englanil and America hare striven to breed out this eye sore, and why? It is not anly unsightly, but this stiff, coarse plumage that results in vu!ture appearance generally has accompanying it a long stiff tail plumage, very objectionable in a Cochin sense, and the progeny, even thugh they in themselves may be lermed first-class, still have the repeating infuence in transmittirg the defects of their sires, even producing the bare toes of the females and the vulture hocks of the males.

"We can never be free from our ancestors" is as trut here as in the mammals, but this breed was destined to have the greatest effect upon American fowl culture and to awaken in the minds of our farmers and fanciers the fact that the raising of poultry could be made one of the largest agricultural industries. Who has not read Burnham's "Hen Fever'?" Ludicrous and a burlesque that it is, it disclosed the fact that over the ancestors of the Buff Cochin was created the wildest excitement ever experienced in poultry culture. It reached presidents, kings, queens, senators, as well as the humble occupants of our village homes and farms, and $\$ 20$ to $\$ 300$ was paid for specimens.

Crude as the breed then was, I fear that to-day in their accepted exhibition form they do not maintain the merit of egr production that they did, when not required to carry the volume of plumage now demanded of them.

\section{REQUIREMENTS OF THE UTILITY BUFF COCHIN}

This leads up to the question: What do they need to make a more practical, money earning breed?

I believe I will be sustained in the assertion that to-day they are shorter jointed, shorter bodied, heavier and more profuse in plumage, the eggs smaller and thicker shelled, with the need of fully twenty-five per cent more males, compared to females, than formeriy to secure satisfactory fertility. (This last is equally true of all Asiatics.)

I fear the shortening of body structure, the lowering of the weight center and the greater amount of lower thigh, shank and foot plumage has proved a sad mistake for the practical merit of the breed, and has lessened the call for the breed outside the exhibition demand; even with the coveted outline, of hocks, we would have more of them if bred to a longer conformation.

The earlier birds I speak of in 1872 to 1876 were longer bodied and more generally pronounced in the convexed feature of hock and cushion. Fads make shuttle cocks of any breed.

The desire to intensify and develop to a wonderful degree any one single section, such as enormous leg and foot plumage, or to make a fad of unnatural developments that have come in the place of features sought for in our matings, should sints jnto utter insignificance as compared to a development of beauty that has come in company with wonderful development of muscle growth or egg production. To produce the latter is much greater honor and surely of greater profit to the breeder.

The angular, over long. flat sided specimens of early days are being supplanted by birds of the other extreme, until these excessively short necks, short legs, backs and excessively feathered specimens have lost so much of merit in egg production that we hear the clamor for the old time excellence and productive power.

Is it not history that the most practical and prolific elements in a breed carry it into popular favor and secure for it a prominent and lasting position there? Surely it is such that secures continued demand in the purchasing world at large.

Periodically does this breed come to the front to demand the breeder's attention and adoration.

It is hard to forget the furor and fire of interest kindled by the advent of the Hodgen trio at New York in 1866, at which exhihition they sold for $\$ 315$ at auction, the record price at that time, and for a decade breeders were not considered in it that could not boast of the blood of that trio in their breeding pens.

For a score of years following the above the interest drifted west, where in Ohio, Indiana and Michigan seemed to center the home of this breed, the breeders there becoming their champions and defenders. During this time it was my lict to judge, at Indianapolis, a class of 180 specimens, nine of which had cost twenty pounds or more each in London.

The eastern states for a time found other favorites, letting the Buffs fall into careless hands, but would they have maintained their position even in the states named had they been other than the catchy and beautiful color that they were:

History has been repeating itself ggain with this breed and, as with others. we see about every ten years a revival of interest in them. The last time the controversy was over trpes-the effort of the breeders to raise the disqualifications of vulture hocks, even going to the extreme of giving classes outside of the Standard which allowed such to compete mnder the name of Full Feathered Cochins. The controversy served to awaken the American breeder, to sustain and in fact triumph with the American type and breeding, and the full feathered classes were abandoned. To the Sharp Brothers, of Massachusetts, should be given the credit for they have demonstrated that the American bred specimens are in every way the equal of the full feathered birds, and that the soft, clinging plumage, to fall about and down upon an ample foot plumage, can be secured without the ob- 
jectionable and unsightly vulture hock. While we must admit that the American type is somewhat altered, yet have we retained the fine rolling tails and soft and wonderfully flity feathering accomplished.

The sales have been marvelous, $\$ 250, \$ 150, \$ 100, \$ 75, \$ 50$ each in the past tive years have been surprisingly frequent. With this breed so prominently before the breeders, can we not agree upon a shape that will improve their egg production? Cannot the breeders, for their own general interest, agree to a less heavy plumage and a longer body structure that they may improve the breed's productive merit?

It has been our hope that our efforts may do something to make the race more practical and moro universally appreciated in the future, for it is those especially useful and practical merits that add most. to a nation's wealth. What will make them heavier, quicker growers, and more prolific layers, and thus more profitable, will make the rank and file of the breeders the larger purchasers.

What has been the grand reason for the late strenuous effort to introduce these superb colors in other sub-varieties more generally used by the poulterers?

The plain unvarnished truth is that the controllers of the Buff Cochins have ignored productive merit for feather. The conservative middle ground is where the majority meet and where the greatest money value is found. A rich buff color in its purity as a color in fow Is ean never be excelled in any other breed than in the matchless convexity of outline as found in nature's champion of that color, the Buff Cochin.

Now make this breed matchless for color, as matchless in practical worth, by converting their type to that which will give the very largest amount of flesh for food consumed and that produces the largest number of generous sized eggs (for they are by nature winter layers) thus will you make them money earners, as well as show specimens, and all other similarly colored breeds will become obsolete, as have Pea Comb Plymouth Rocks, Jersey Blues, Dominique Leghorns, Whice Javas and all such that have failed in their harmony of color with the shape their breeders have tried to marry.

A multiplicity of breeds of one color has and will prove a raistake for the breeders; first it only divides the demand and sale, that would be controlled by the one breed, could it enjoy the sole position as representing the color in question. One has only to cuop an oblong bodied, reasonably plumed flock, to find that such will lay about twenty eggs a year more than will those excessively short in body and of vulture hock character of plumage. This very difference in the egg product will go far towards securing and keeping up the sales, for a large number of breeders must look to the money earning feature of any breed for support and pleasure.

This breed is the oldest that has been acopted by America, and should have been the best, but the fads of its fanciers have been its worst enemies. Any fad that introduces extremes in a breed has always proved detrimental. The excessively heavy plumage that has been demanded has caused the breed to be given the go-by by the poulterers. Thus has the surplus stock other than show specimens sold so slowly as to cause many to cease breeding them.
It is the fancier who establishes the lines and beauty to be called standard; then is it in their power io make the accented type a money carning one and thereby make the breed of their ehoice far more popular and valuable "Give this ireed all the exuberance of plumage that can be secured without bringing with it stiff quilled feathers in lower thighs and very long sickles in tail, for a rulture hock becomes a feeder upon the juiciness and mars tho flavor of its meat;" so says the poulterer. Then why produce such volume of plumage as makes them a lad: They are not beautiful, they are only grotesque, a burlesque, so to speak, upon beauty, just as excessive dress becomes dudish and subject to derision.

But too many breeders fail in moral courage; they may come out and demand a practical money earning position for all breeds and exclaim that all poultry breeding is but a faì, but when fashion turns its cold shoulder, give up the breed altogerher. A moral obligation to poultry sulture, as a calling they ignore. But has not poultry culture become a business in America? We think so and fail to see in the past the same keen insight and action in its control. The same parties exist in the bank. store and factory in which they are interested.

It will be remembered that during the excitement in which the full feathered craze was at its height, the following appeared in an English journal:

"The carrying by storm of the Cochin world in America by the English full feathered type of birds should convince our American cousins on the other side, that two of a trade will never agree, and that while the supporters of our type of a bird are engaged in smashing up the favorites of their rivals, the public, who afier all is said and done are responsible for a most important part in the development of a breed, become scared by the dissensions that exist and will be found by the time the matter is financially thrashed ont to have quietly invested their money in some other breed."

Wre acknowleaged tile force of the prophecy at the time, but how true has it becolne in the strenuous effort to perfect buff in other breeds to the disparagement of sales in the Buff Cochins. Extreme views and contention among the breeder.s of any variety are a misfortune to the breed.

To be sure, these Cochins are an English product. The exkibitors there do not have as an end and aim the improvement of those qualitics that make breeds in America wealth producing money earners nutside the show room. To breed these beautiful colored gems of the show world, without merit in egg production, is folly for the American breeder. Statistics give us three per cent tbat get rich and thus are able to support a fad. The balance are forced to couple with their pleasures work that helps to a living, but all of us enjoy seeing those things we are interested in appreciated by the many.

You ask me how I would make a standard, that which lived up to will secure the greatest practical virtues in the breed. I answer, just as I would make a standard for a horse, one that has all the features acknowledged as perfect. You say there is no such specimen, but there are the best of a thousand good ones and among the whole thousand 
cannot we find a perfect section for all the sections that go to make up a perfect whole in our best one of a thousand? We have only to substitute perfect sections for the ones found faulty in him and the trick is done, and when done have you not a standard by which to compare and judge all defects found?

Apply this rule to Buff Cochins and I ask: Is your concention of perfection in the head other than the best head you ever saw: Then suppose you take the first prize male, exhibited in the class of American Buff Cochins at New York, 1893, that scored $961 / 2$ points by the score card system of applying the Standard. This specimen was claimed by all the judges present, to be the best ever exhibited in America, which I believe is true, nor has he ever been beaten since, yet his comb was not absolutely evenly serrated, having but four points; while cutting one-half point for his defect, how easy to describe his comb with five points so graded as to make the middle one the largest and stand the highest, when our work presents perfection. His back was fanitless in shape, but a triffe faded; what had we to do but

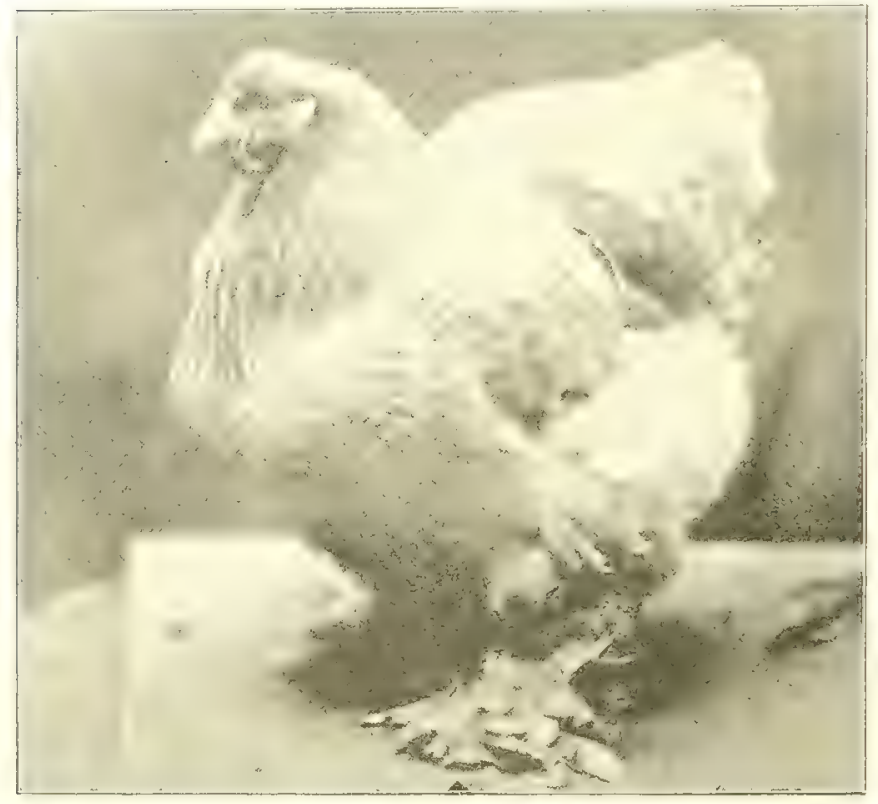

An English-Bred Buff Cochin liemale.

describe his hack as it was and to describe perfect color. Tlus, by such deduction, we easily obtain in the end a perfect standard. At the same time, note his defects, give him a score card value of $961 / 2$ his specific value as tried by your perfect standard.

This bird was a grand compromise between the champions of full feathered and American Cochins and accepted as strictly first-class, and worthy to win the "first and all specials" that he did. But our pen picture of the breed must be our ideal of a perfect Cochin. Any further development of plumage, we believe will be at the expense of practical worth, and as it is we make a partial sacrifice to exhibitors' demands.

\section{OUR STANDARD.}

\section{WEIGHT AND CONDITION}

In the Cochin, as in all the other breeds of fowls, the authorities have wisely left the value of weight to be determined by the scales, by deducting two points to the pound for all deficit of full standard weight, that being eleven pounds for cocks, nine pounds for cockerels, eight and one-half pounds for hens and seven pounds for pullets.

The question of condition becomes one of general health, cleanliness and breakage of plumage. The percentage of damage is left to the decision of judge, with right to banish from the show room for disease.

Defects. Puffed cheeks, watery eyes and soiled plumage beyond reasonalule effect of cooping. For these cut one-half to one and one-half points as a reasonable per cent shall dictate. In this breed an isolated feather broken should be ignored, but general breakage to disfigure should be punished under the head of section where breakage occurs.

As a matter of fact condition is a resultant, and the utility of the unused points for the defects of condition always appears in some other section and becomes more intelligently punished in the section where located, yet it is the effect of condition. To cut such under the head of condition usually has the effect of cutting twice for the same defect.

\section{IHE COMB}

The comb is single, small as compared to size of breed, should be serrated into five points, the middle one the largest and highest; forward llanges, counting with first point, rear flange and rear" point-counting together, leaving three between top line, the top forming a line parallel with the natiral eurve of the crown of the head. The sides smooth, free from wrinkles, corrugations or side sprigs; these last having a specific cut of one point for each sprig developed; th whole perfectiy erect and in a straight line from front to rear.

Defects. For each point less or more than five cut onehalf point; for turning to left or right at rear, or corrugations along the sides, excessively large or ill-shaped, one-half to cne and one-half points; twisted or falling combs in females one-half to two points, according to degree. Combs other than single in either sex or twisted in front or falling to one side in males, condemn as unworthy a score card record.

The rear flange is not uniform in males, nor do the artists illustrate them correctly; some are turned smooth, others have upon the flange two and three small points. It is only the rear perfect point in front of llange that is counted to secure the five described above or by the Standard. This has been a fruitful cause of the disparagement of scores between judges. Whether the flange be smooth and rounded from its real point, or has the scalloped character that presents the three minute points is immaterial if both give a graceful finish to the rear portion of the comb.

\section{HEAD AND ITS ADJUNCTS.}

In this breed the head is wide in skull, deep in face as a whole, appears short and shows prominently in its junction with the neck. Plumage a dark orange ocherous color, ejes large and bright, bay or red, beak heavy at junction with skull, but evenly arched to its point, being a deep yellow in color. Ear-lobes well developed, especially in the male, wattles hanging in a pendulous manner below lower point of lobes. This feature when developed is much smaller in proportion and more closely rounded to throat in the females; the whole free from ridges or coarseness in texture, the head as a section carried well forward (a drop line from point of beak to ground will clear the breast by an inch).

Defects. Skull long, narrow and depressed in front of eyes, beak too straight or turned slightly to one side or tainted with foreign color; ear-lobes very small, eyes other than bay or red, face shriveled from disease, should be cut one-half to one and one-half for each according to the degree of the defect. Wattles in males too small or nearly absent, one-half to three points. When the wattles are absent or mereiy rudimentary. the bird should be deprived of score card record. 
A generous developmen't of comb, ear-lobes and wattles is a sure sign of procreative vigor. The desire for a small fine head in the males of any breed is a mistake for the above reason.

\section{IHE NECK.}

Hackle should be full; this with head carried forward gives a nice curve rather than prominent arch to the neck; hackle profuse and in length sufficient to cover cape and shoulder, even covering back in part; surface color and quill a rich orange ocherous color with outer edge shading off into a perceptibly lighter shade than center of web. Under color hidden well, up to surface color without the sheen (or hard finish, so to speak); this under-color must be free from white, a slight shade of blue may be ignored, but when pronounced, it is a defect, but of less magnitude than white.

Defects. Head thrown too far back, neck too long and scantily feathered, the hackle failing to cover cape and shoulder points, surface color faded to drab or light lemon color, or so dark as to show shades of brown in the undercolor, a very pale shade or reaching white, to be cut from one-half to one and one-half for each, according to degree.

We may as well here define the individuality of the feather in Cochin plumage. In this breed we have the very largest amount of under-fluff, often reaching more than half the length of the feather, which does not web out smooth. This causes the puffed character and causes the feathers to lie in a curved form, its function being to give us the convexed outline in all the sections throughout. In shape we describe that much of development as shail pass uncut and which in our judgment can be reached without detracting from productive merit. Any surplus that nature shall give us, which does not mar or alter our standard should not be deemed a defect in the show room. To-wit: A specimen may have a wonderful amount of plumage in competition with one that fulfills the law. Both must. receive full score, but in case these specimens tie, an honest question arises, which of the two should win? The one over-developed in plumage has been the favored one heretofore, but when it has been so forcibly demonstrated that such detracts from productive merit, shall we continue thus to favor such? These are the questions that arise outside of any general law we may make; but in color these exceptions do not arise and we can apply the law with arbitrary force. A rich orange ocherous color is perfect, but the question is how much shading therefrom may be admitted and pass uncut in judging. The evenness of a shade throughout, surely is of prime importance.

Suppose we make seven, nine, or eleven shades between what we call a light lemon color, and a light brown, or even thirteen divisions, the middle one will be our rich clear ocherous color. Now of the three or five center shades, either should pass uncut but they grow lighter, or toward brown, it becomes defective color. As in other breeds, five shades of described color are advisable. (A light cinnamon might be termed a shade of brown or an ocherous shade.) While we cannot disqualify or rather we would not deem it justice to disqualify, still this shade of brown must be cut as defective color. Prime surface color with poor undercolor, is far preferable to prime under-color and poor surface color.

BACK

While the back is broad and flat across cape, the hackle which is long and flowing on to back, gives a very short appearance to forward portion; the saddle being full and broad, rising well upon and with the tail coverts envelopes the tail proper. All serves to give that short appearance to the back as a whole. The profusion of saddle hangers, reaching well down over wing tips, but being slightly flattened on the top destroys any pronounced convex outline of back from hackle to tail in the male. In the female this saddle, or cushion, as it is called in her case, must be a pure convex outline from neck plumage to tail so profuse as to be a complete circle from top around base of tail, meeting the circling plumage under tail, the back long enough to secure the convexed formation and give a slight oblong appearance to structure. Exposure to sun and storms will, in a vast majority of cases, cause surface color to be somewhat faded from the rich ocherous color demanded by our standard, but we must demand a tolerably clear shade in quill, however, and permit a shade lighter, but free from the sheen in the fibre of under-color.

Defects. Back narrow, too straight, or concave, lines. 
to keel presents a fulier profile than in the male. The color in both, while having less sheen, is generally a pure shade of ocher and more free from any discoloration by false color for the reason that it is protected from the direct rays of the sun, there being generally but little difference between surface and under-color.

Defects. In males if very flat in front, or flat in females, quarters not being prominent, thus giving pronounced wide shape viewed from the front, the color mottled, faded to drab. or too brown, a shade of surface color too light o: white in under-color: each of these to be punished by a cut of one-half to one and one-half according to the degree of refect in eacl.

\section{BODY AND FLUFF}

Feel in this breed is carried low, its muscle full and firm to the touch. "This large muscle and full plumage give great apparent width to body, and with well rounded wings, come well rounded sides. Fluff well developed, especially the thigh flufl, which together give a broad appearance from rear.

This feature in the female causes great apparent fulluess The upper thigh fluff should be very full between wing bay and hock, for to this feature are we dependent for that full, Cochin appearance so desired. The loose fluffy condition of this feature robs it of the sheen seen in other sections, but in color it must retain the rich ocherous shade described above.

Defects. Keel so crooked as to mar shape and depth of body merits a cut of one-half to one and one-half points. It is not so much for the fact that the keel is crooked as when it affects the shape as a. whole: the fluff may be shimkon, or the thigh fluff not standing out. Failure of convexed ou line in all these, too light in shade or positive white in under-color". surface color faded to drab, should be discounted one-half to one point each.

\section{THE WINGS}

Wings are small compared to weight of specimen. strong and heavy in muscle, front buried in breast plumage. rose well cupped, which, with full quarters, secures a circular line from back to point of keel. Primaries smoothly folded under secondaries, the whole wing presenting a smooth, shceny suriace of "rich orange ocherous color, reaching its deepest shade in the rose of the wing, where it may he a reddish orange shade in the male and not a defect. as it is sure to be accompanied by a perfect colored back. such being grand mates for hens having lost color by age.

In the female the evener the shade and more pure the color thronghout the entire plumage, the bet:er. Wingbays a rich deep ocherous shade with no mottling of other color. (Set neck section.)

Defects. Failure to fold primaries completely under secondaries, the rose shading to red or brown sluades outside of ocherous: white or black in primaries or secondaries, motiled or faded surface color, white quills or white fibre in under-color. The rose 1 at, losing its cupped form, the whole carried so low as to give an oval shape to cape. For those cut one-half to one and one-half points, according to degree. Twisted feather one-half to two points. Primaries folded outside secondaries pass as unworthy specimens.

A single broken feather, the mate being perfect, is not a defect, for it does not cover a chance to disqualify, but a general distumbance and breaking which is really condition will receive a more just punishment by checking condition thus, $x$, and cutting the defect in the wing where effect is apparent.
TAIL.

The tail proper is short and nearly enveloped in an abundance of tail covelts and lesser coverts which secures the rolled tail, so called, and the carriage of tail proper. It is the abundance of saddle and tail coverts that gives the drooping appearance in the female, although as a matter of fact it does not exist. The sickles and lesser sickles are so short and small as to appear like enlarged coverts; these whole upper tail furnishings should be a rich orange ocherous color, the under-color admitted at a lighter shade; tail proper a clark chestnut, shading to a light shade in such portion as shows to surface. That of the female may be of chestnut at quill, but surface color should be pure orange ocher and nicely folded into a round point just beyond the coverts.

Defects. Showing end of feathers in a lateral spread aifecting Brahma shape; the whole section too large or irregular in the combing with sickles too long and prominent; positive black or white in any part. For these cut one-half to one and one-half according to degree. If tail be carried to one side or twenty-five per cent white, withhold score card.

There has been the demand by many judges for pure buff, as they have termed the color in this section. This we believe will prove a grave mistake, for if none but such males are used we may look for an increased amount of white in primaries and tail proper, with a decided light sharle of surface color with white in under-color in our females and with the culls vastly increased in the breed.

In all breeds, no matter what their color, there is the tendency to become light and for absolute white to appear; why cause in a greater degree this danger by a requirement advocated by the few, when to do so is to oppose nature in he: effort to do her best for the breeders, as a whole. What we propose as the proper color is, at the best, all we can demand of nature; the word buff is surely a misnomer as applied, for scientifically there is no buff in Cochin fowls.

\section{LEGS AND TOES}

The lower thigh and shanks should be apparently short, heavy in bolle; thigh muscle large; plumage long, soft and profuse, hanging in front of hock two-fifths the way to foot plumage, curving about the hock free from stiff vulture hocks; shanks heavily feathered; meeting without a break in an outward and forward sweep, with foot plumage covering outer and middle toes, all of which in surface and quill should be a rich orange ochelous color. Toes should be stout in bone, well spread and with shanks in scale and skin yellow, permitting straw color with age.

Defects. Scant covering of hock joints, feathers not hanging below and filling the space between hock and shank plumage; apparently bare middle toes; for these cut onehalf to one and one-half points for each, according to degree; turning inward at hocks with shanks too long or being cow-hocked one-half to two points. For actual knocked knees: exposed hock joints; middle toes actually bare to iristep, debar as an unworthy specimen.

The act of the bureau of judges to protect from disqualification superior specimens that had feathers upon middle toe from instep to edge of web, and not to blindly disqualify such, because middle toe from web to point was bare, was a just dissension. All law should be applied with equity and common sense. Technical application to save or to destroy is not the intention of the standard law. The judge should protect the good and destroy the bad. The A. $?$. A. demand to disqualify all Cochins having bare middie toes, we believe a mistake. For no disqualification should apply to one variety and not to all of its class, and 
especially in this case should females be exempt. To cut bare middle toes one and one-hall points would destroy all chances of the specimens winning a first prize. But the card, disclosing her true value otherwise, might discover in her a valuable specimen for the breeder. Any disqualification that shall work to destroy a really nice specimen is not just and had best be ignored. Therefore, notwithstanding the standard may disqualify for bare middie toes, the judge should and can protect nice spccimens. When the plumage grows from instep joint to web of the middle toe and close inspection here should be the rule and cut for the defect for not extending beyond the web, many are disqualified off hand through the adjudicator failing to examine closely. The judge should protect by a cut of two points as defect before going to the extreme of disqualifying. Our standard is continually criticised because of its too neager use of language, but however exhaustively the subject be treated, the novice fails somewhat of its meaning until he has had experience. To excite the reader to investigate is the writer's aim in writing these notes.

In the past under-color has been ignored, and this has led to discrepancy and differences between judges.

But show record as made by the score card application surely should be a guide to mating and breeding, not a mere surface consideration. The older breeder understands this and scans closely the under-color.

\section{THE MATING OF BUFF COCHINS}

It shall be noted that while we may give a set of rules for matings based on the experience of breeders. they must be based upon the antecedents of the breed that have been mated under similar rules and conditions, when we may surely expect first-class results. We may in the foregoing have described the best shape, best color and best conditions which have given the best attained results even the photos of best specimens we have yet seen.

But now comes the all important question, how shall we produce more like them, with a hope that in a few we may have those that excel in beauty, brilliancy and prolific merit, the best we now have. But decay is written upon all things animate and inanimate, and the vast majority come poorer than the merit we have described. It is nature's best that are the peers, not better than we have pritrayed.

As a rule even in old and tried breeds like this one, we should first cull closely fully twenty-five percent of the males, consigning them to the kitchen's use before making our selections for our breeding pens and exhibition room. This in ordinary flocks of one hundred will leave us some forty pullets for our work. Cockerels may have ten consorts, and cocks five to not more than eight.

We divide the pullets into two divisions, of light and dark under-color, then arain we divide each of these into the long-bodied, cral rizked, and the short bodied more concaved backed.

In Pen No. 1. The nearest we possibly have in a male, cock preferred, that fills our foregoing pen picture for the breed, both as to shape and color; to him mate females, which are in surface color as described, but retain the dark under-color, the quills all having the orange ocherous color. This is our pen from which we expect our best male specimen, having a strong reserve of color, as progenitors. For a mate pen we would select a cockerel that had a strong under-color as well as surface color and with all else as in our pen picture. To him should be mated hens that in molt= ing retained their rich ocherous under-color and a prime even shade of surface color, even if in its general stade it could be considered somewhat light. These hens would in nearly all cases hare been, in their pullet form. like the dark pullets of our first division, we mated with the coch in pen number one.

The pullets mated to the cock being the darkest short bodied specimens.

Pen No. 2. The male as large and as long in body and full in quarters as can be confined within a reasonable likeness of our ben picture for shape, being a cockerel of rich ocherous colol, rich in his profusion of plumage.

To him we will mate the long bodied convered backed pullets of good weight and of fairly first-class surface color, with a reasonably medium shade of ocher, retaining in the quilis the color of surface plumage. This pen will produce females the equal to any.

Pen No. 3. A male that is an even shade of color, but so dark as to have nearly the golden brown shade found in this breed, with chesinut colored tall coverts and tins, with neck and rose of wing a reddish ocher or orange bay shade of color, and a very dark shade of under-color, securing in shape all the convexity of form of wing, thigh fluff, back and roli of tail. To him mate the hens in our second division that have faded to an even light shade

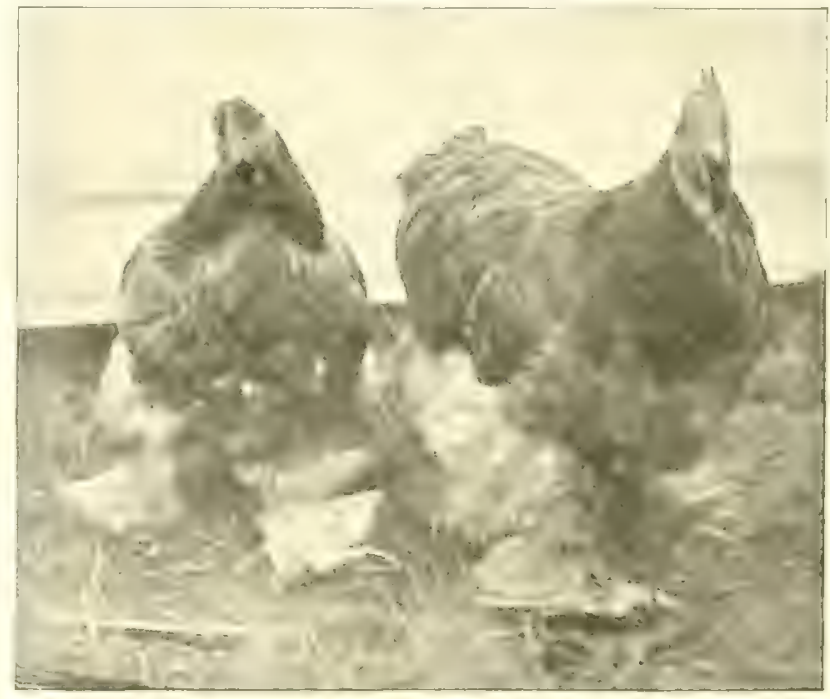

$$
\text { A Pair of Buff Cochins, Winners at St. Louis Owned by }
$$
Gelder \& Robertson.

of surface color, which will most likely have a rary light under-color and shafts to plumage - those long bodied convexed backerl. nice old business hens that have lost their hold upon the exhibitions. Do not confound these with the white under-colored specimen we abandoned to the cull pen before commencing to mate, for from this pen we will have fine pullets and many fine males.

Pen No. 4. For this pen we have lef the smallest short bodied females from the first division, also the darkest short bodies females of the second division, to these we propose to mate a large boned, long bodied, rery dark male, whose tail reaches the chestnut color, with neck and rose golden bay, and with a very dark under-color. The pullets from this pen will be the desirable part of its progeny, for they can be materl to perfect colored males, to produce males. It is a fact that all lose color by breeding: white and gray constantly creeps in. Another fact; we cannot make radically extreme matings for color without producing a mottled or mossy plumage. By the use of these pullets we sustain the color derived from the dark color of their sire, and use it in so diluted a form as to be absolutely controlled by our perfect colored lines in this second year use.

I do not believe in any disqualifications except the following: Crooked back, positive wry tails, and all specimens 
scoring less than 87 points. This last will prevent anything like culls or scrubs from taking premium honors. It condemns such to strictly kitchen uses.

All the above surely would demand a price for breeding equal to $\$ 3$ to $\$ 20$ each for females, with males at $\$ 4$ to $\$ 35$, leaving all others at a personal consideration of buyer and seller, outside the thoroughbred trade.

Then winners will breed winners and from any one of the pens described we may expect to breed winners. They are one of the oldest breeds; is there any reason why they should not breed true if proper care is taken of them? Close, grassless runs will destroy the chances of even the best matings from winning, except by accident. I am sorry to be obliged to chronicle the fact that nine-tenths of the breeders Who confine their stock thus as a rule neglect them. A prime breeding pen is not all there is to poultry culture.

Experience has taught that when very dark colored males have from necessity been mated to very light colored, faded out hens, even those with white appearing in their flights, feet, and tail, very gratifying results have followed, but faded, white tainted males are a failure whenever they are used as breeders. When loss of color is marked in the males, it is surely time to kill them and take a new source of color supply. It is only when we consult the entire question of color, that we are safe.

I call to mind a case in St. Louis, when a pair of pullets had been tied for first place. Their owners calling my attention to the fact, as they put it, of two pullets being exactly alike. I looked them over and said, "They are exactly alike in surface color, but in no other particular, for one is solid makogany while the other is simply veneered, that is three full points difference in color alone." One had a fine undercolor, while the other was white quilled and white in undercolor. When breeder or judge ignores under-color in Buff Cochins, they have both sadly missed their calling.

A knowledge of the antecedents of any flock is highly necessary for the breeder to make correct predictions in regard to the results of his matings. The show specimen should by no means be the darkest one raised, but as near as possible should represent the medium color of his flockfor should he be caught without darker color he surely can feel he has entered a stage of decay in color production.

In this breed, like many others, a cock and hen that have ripened into standard color, both as chickens leaving been deemed too dark for standard demand, surely are the very best mating to preserve color. Such is beyond all question a standard mating. I have come to the conclusion that in a general sense there is no single mating. The distinction should be: Middle matings, not extreme or double mating, though this breed is like Brahmas, one of more nearly single mating than any other breed.

\section{THE SPECIAL CARE}

For best results this breed requires to be furnished a cool and shaded retreat in which they can repose between 9 and 4 o'clock when molting. Their hearts beat 150 times each minute and as they cannot sweat like the horse, you can see what a tax there is on their respiration, besides the effect of the hot harvest sun is very disastrous to their deli. cate plumage, when in its pin feather state.

To have an even shade of color during the last stage of growth of their adult or new plumage it is necessary that all premature growth and the old coat be removed, that all plumage of back and saddle may be of the same age, or you will have a spotted back or mealy wing to militate against the specimen if she or he is to be shown. Even for one's own selection in one's breeding pen, this care will be needed. If these birds have been early hatched and are liable to grow their adult coat in July and August, then a grove or tent or artificial shade will repay you well if you furnish it.

Continued soft and sloppy food is not good for this or any other breed, but a free use of scalded milk to drink and one meal each day of mash, twenty per cent of which shall be meat, such as desiccated fish or granulated beef scraps, (avoid pork scraps) may be fed, the whole day rations being so fed as to consist of fifteen per cent of meat, twenty-five per cent vegetable and sixty grain. These are the main points to be followed if you would raise strictly first-class Cochins.

For your chicks until three weeks old or older, you will find it will pay you to have corn cracked as fine as millet seed. A bread made of excelsior meal, thoroughly baked and moistened in scalded milk, is fed for the forenoon, whilo the afternoon feeding should be millet, rolled oats, fine cracked corn and wheat. After a month begin the feeding of meat in the morning food, giving for the first two weeks the scalded milk to drink; if this be followed, there will be no bowel trouble, or loss by death because of it.

This care will start them at one month old with a-strong constitution that will earry them through life with a low death rate in your flocks.

Little things become great things in their results. If you watch the combs as they commence to develop, it may be a surprise to you that they start with anywhere from four to even rrine points. Pinch the ones that are desired to be absorbed; nature does not always absorb the right ones to secure for us the even, regulation five point comb. But if this care is taken, the one which is pinched and whose growth is thus checked, will be the one to be absorbed into. the two one each side and a serration is secured in place of the point. Little cares win premier prizes.

I. K. FELCH. 


\title{
MATING BUFF COCHINS.
}

\author{
The Influence of Past Matings-How to Overcome Prominent Defects And Maintain the Required \\ Size and Proportion.
}

BY A. W. BELL.

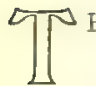
most desirable shade of buff is a question yet in a very transient and unsatisfactory state. Of course, if one has the room to produce chickens of any one variety in the hundreds, doubless he can by proper selection obtain a sufficient number of good birds to exhibit and sell his customers. But if on the other hand his space was limited to about forty or fifty chickens each year, then comes the test of his resources. This is as true in any of the buff varieties as in Buff Cochins. I have visited the yards of a large number of prominent breeders of other buffs, and have found where they are raised in large numbers, all shades of buff from a light lemon to a color bordering on cinnamon.

What is the cause of this?

No doubt they are cases of reversion to some ancestors of these shades, going back to a time when they maied these dark birds to a lighter one to produce a good under-color, and whilst that purpose was accomplished, it has left a taint in the blood of their progeny that will take years to breed out, but to a certain extent will be continually cropping out. In these days so much more specialty breeding, that is, mating a male with one or two females, is done than formerly.

In all articles, in mating one most universally finds statements like these that the male bird gives the color to the chicks, and the female the size and shape. I do not believe this is the case, but on the contrary, that the female has as much to do with the color as the male, and not only is this so in color, but a]so in shape, i. e., one parent has as much to do with producing color and shape as another. Breeders of other stock do not lay as much stress upon color from the male and shape from the female as we do in poultry.

This was brought to my notice very forcibly the other day when discussing this subject with a breeder of horses for a number of years, and he showed a pair of horses, filly and gelding, the former a brown and the latter a bay. The dam was a bay and the sire a bay. He told me that all this stallion's colts were of the same color of fillies, whilst the geldings almost universially in color took after the dam.

But can all the characteristics of breeding in one line of stock be found or carried out in another? This year I bred a very heavily hocked male with much foreign color in wings and tail to females solid buff in these particulars, and whilst we would expect to get bad winged birds, yet the females take mostly after their dams, whilst the cockerels follow the sire.

The chief obstacles to overcome in breeding Buff Cochins are color, shape and size. In color, we have the unevenness not only in surface color, but also in under-color, for if you have the latter you will undoubtedly have the former.

To overcome these, select in both parents stock of as uniform a color all over as you have, one whose hackle, back, saddle and body shades are all tha same. These properly mated will give you birds that will be a pleasure to behold. Under no circumstances use dark surface colored birds for present day exhibiting.

I do not object to a little black in tail or wings, in breeders, as you must have this to retain your rich surface color, and if your birds are too dark, a little white in the wings will soon tone this down, though many look upon white as a most serious defect, yet if one's birds are inclined to be too dark, the presence of white will in a season or two work wonders.

Another serious color defect is shaftiness. This, to me, is the hardest point to eradicate, but if one will persist in

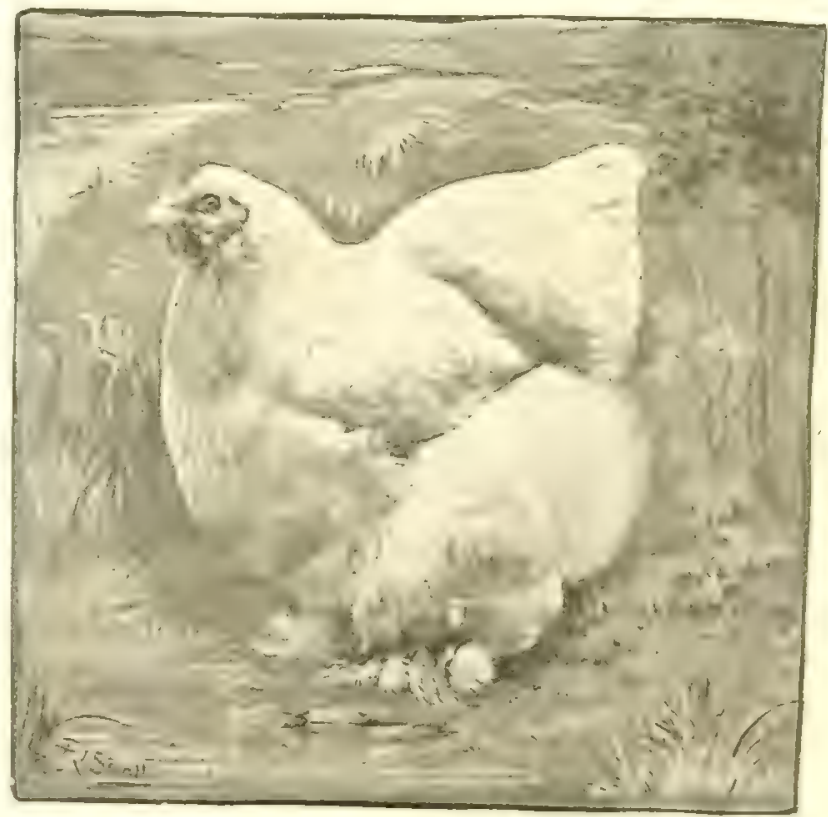

A I3uff Cochin Female of Rare Shape and Color. Winning First prize as Pullet at Boston (Novice Class), Eastern Ontario aud Chicago. As Hed, First at the Fastern Ontario and Ontario shows, also at Chicago and New lork. Owned by $\mathrm{A}$. W. Bell.

using those birds with good under-color, not too dark, and the quills of the feathers buff both on the surface and underneath, which can be easily noticed by looking at the wing spread out from the under side.

Endeavor to breed from birds having a rich bufi (not red) quill, superficially, and one will be highly satisfied with the result.

Mealiness is most prominent on the wing bows of females, but is very seldom seen in first-class birds of to-day. This was caused by formerly breeding dark males to light females to produce under-color, but as this is not practiced at present to any extent, it is not much seen.

In breeding for shape, I like to employ birds as short in every particular, save length of feather, as I possibly can obtain.

A Cochin should have a short neck, short in back, which 
should be wide, his breast reep and full and carried forward, body short and wide, his legs short-I have not yet seen a Cochin too short in legs for me-and set well apart, covered with long soft thuft feathers, giving them the appearance of having a thigh eight to ten inches arouni

The same is applicable to the female, only of a more feminine nature. Her cushion being more pronounced and tail carried low, if anything, that is, below or at the horizontal line. What I like to see in young stock is a bird, when you notice it, looks as broad as it is long, and seems to be creeping on the ground, due to its large soft fluffy hocks and short legs.

A real good Cochin should look as if it had been raised in a pail and as round as one.

Linder no circumstances use a long-legged Cochin, for as sure as you do, you will produce Brahma shaped birds, which would be as much of au eyesore to a Cochin man as a Corhin Branma is to a Brihma breeder, Do not use for breeders, in either sex, birds with long tails or with tails carried high, for you cannot produce stock with gool cushions from these.

To the casual observer the Cochins are possibly the largest looking of all fowls, due to the long fluffy feathering, and to secure this with a body of good size is a very important point.

Size is due more to breeding from large birds and the care they receive. Some could take the same parents and with their plan of feeding produce birds very different from what others could.

By gool care also can shape be vastly improved, for what can you expect a half-starved of search-my-own-living bird to amount to, especially in Cochins. Give them a generous supply of nourishing food containing an abundance of protein, and you will have birds with large frames and loose in feathering. Do not endeavor to fatten young Cochins: get the frame on them first, then add your flesh.

A. W. BELL

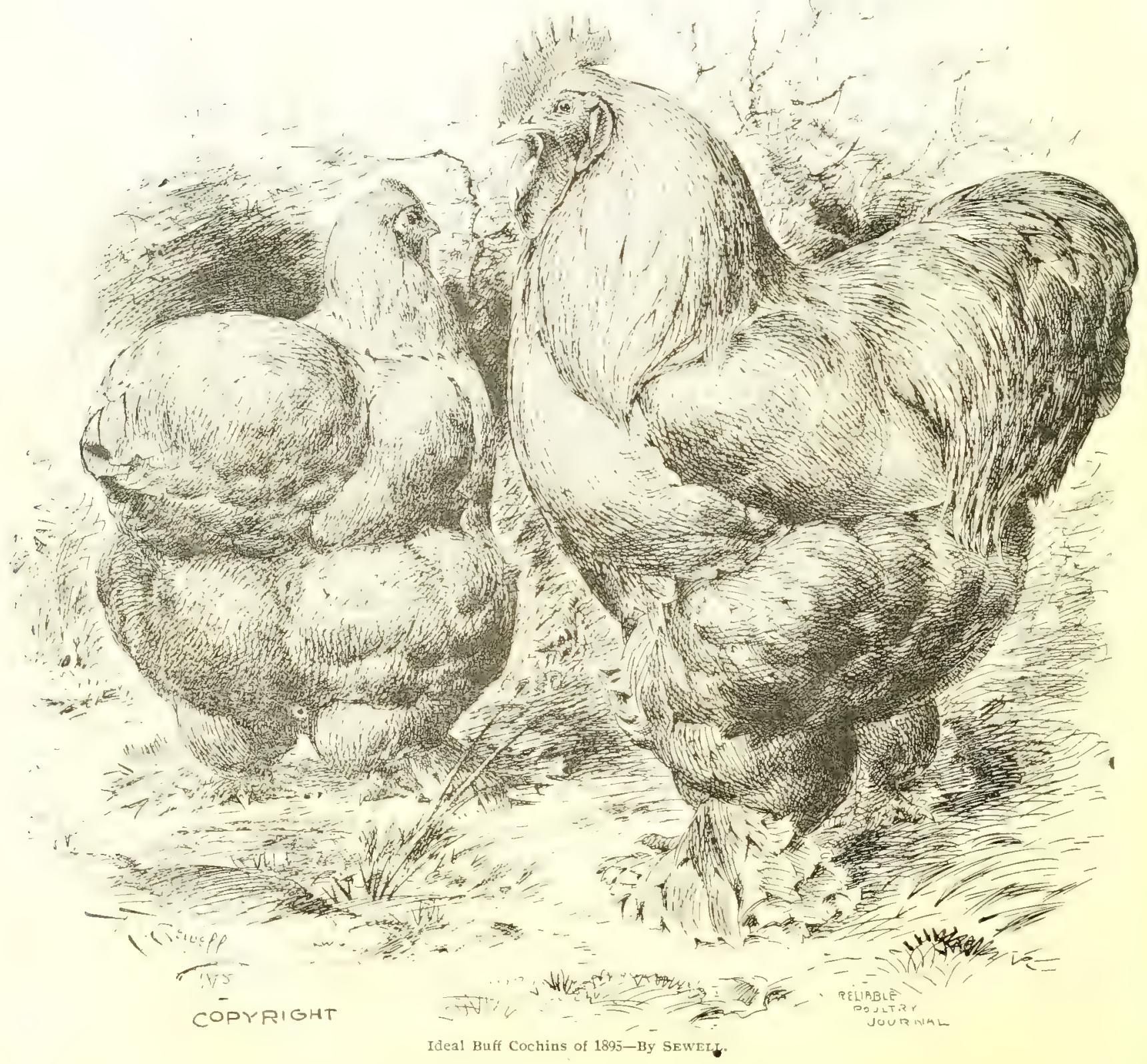





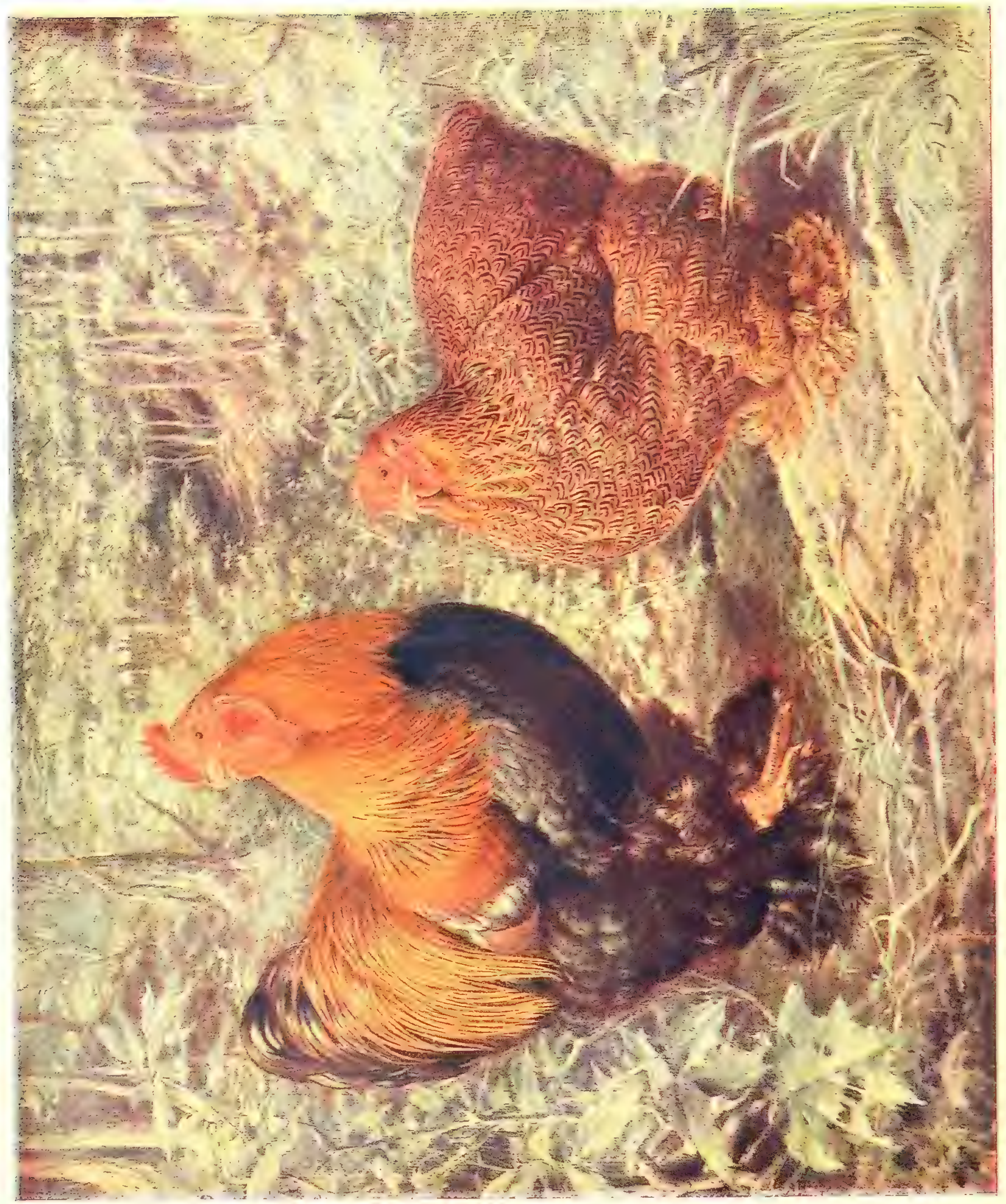




\title{
STANDARD PARTRIDGE COCHINS.
}

\author{
An Illustrated Description of the Standard Requirements for This Variety-The Cuts Scored by \\ Judges for the Defects Found in Each Section.
}

By 'THE(. Hewes, with Illustrations by SEWELL.

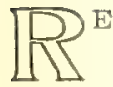

EALIZING that one must have ideas of his own and by a careful study of the different breeds, together with the Standard description of them, arrive at some definite conclusion, I offer to the readers my ideas of the different breeds, and I believe if the amateur will siudy the chart and defective feathers, together with my description, he will arrive at a fair conclusion as to what constitutes perfection and gain a fair knowledge of the defects tha! he may expect to find in breeding the different varieties.

I will take up the Partridge Cochins, and since there is the same general shape in all varieties of the Cochin family, it will not be necessary to give a detailed description of the other varieties.

In Chart F'ig. 1 is shown a male that can truly be called an ideal. While, as jn the cases cited above, there are a few minor changes that could be suggested, the picture is so goof, that I agree to pass without discount on shape such a specimen when found in the show room. The Standard says in describing outine for the Cochin male, that he should be a very deep, massive bird, showing great constitution, having a dignified carriage and a tendency to lean forward, the keel carried low and the saddle or cushion well up. The outline of every section should be well rounded and free from any flat or concave surface. Mr. Sewell has certainly filled the Standard description in the outline Fig. 1.

In color the Partridge Cochin should be rich, deep black in breast and body; neck and saddle, bright red or dark orange with black stripe extending down each feather. In Fig. 1 Mr. Sewell has faithfully portrayed the correct color as described in the Standard, and in the accompanying drawings I call your attention to defective feathers with their discounts as measured by our best judges. It is a well known fact that some males are used in the breeding yard that are decidedly off color so far as the Standard is concerned, and our best breeders tell me they have to use them in order to get the fine penciling and proper ground color on the females, so that a discount in the show room is not always so serious a defect as the cut would lead one to imagine. As an illustration, a male bird might be cut on color of neck, back, breast and body, and still be the highest priced bird in the breeder's yard, or in other words, his best breeding male. I call special attention to this so that the amateur may learn the difference between a show bird and a pullet breeder.

I will now take up the different sections, using a few feathers from each section for comparison.

\section{NECK.}

This section should be bright red or dark orange red, with a distinct black stripe extending down each feather running nearly parallel with the edge of the feather and tapering to a point near its extremity, the red or dark golden edge to be free from black. Such necks as the Standard describes are met with quite often in our fancy show specimens; in fact, so exquisitely are some of them colored that an artist could hardly improve on them with his brusb or pencil. There are others, however, where many defective feathers are found, and to better illustrate these defccts I call the attention of the readers to Fig. 2. Feather No. 1 of this group is taken from the lower part of neck, and is fairly well proportioned in black and red, but the under color is ton light, and there is a s'reak of red running along the shaft, and black runs to the end of feathers, making the point look black and smutty. A neck with plumage like this

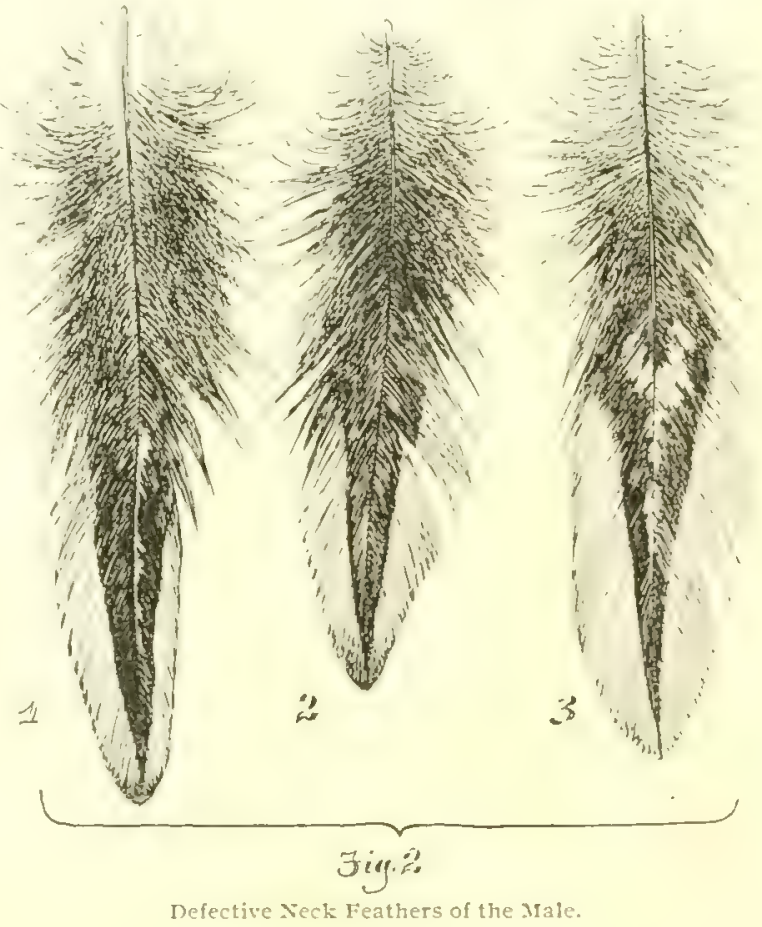

should be discounted one and one-half noints. Feather No. 2 is taken from upper part of neck and is quite a good one, except the tracing of black on outer edge of feather. Discount one-half point. In leather No. 3 is found a defect quite common among the pullet breeding males. The black and red mingle up in the center of the feather, and rhe outside edging of red is too light, and there is a trace of black on its edge. A neck like this should be discounted two points.

\section{BACK}

This is the most important of all the shape sections, and nearly if not quite the most important in color. The Standard says in describing this section, in shape, apparently short, very broad and well rounded. You will cote the words "apparently short" are used in describing back. This breed if bred to featker as the Standard calls for is very deceptive. A glance at the Chart Fig. I would lead one to 
believe that the bird was short in this section, but a closer inspection shows you he is quite long in back, and it is only the long feathers around body and legs that give the bird the short appearance. While inspecting the chart place a piece of paper over the lower part covering up to lower part of wings, and you will he surprised to note the difference in the length of the specimen. The Standard in describing the color of this section gives the same description as in neck. There is a slight difference in the shape of the feather, as will be noticed by a study of the chart.

In Fig. 1 is shown a well proportioned, finely shaped back and one that fits well this breed of fowls. In Fig. 3 are illustrated some defective color, all three feathers in this group taken from the back of one male, and still the back, taken all in all, was far from a bad colored one, as there were any number of nearly perfect feathers to be found.

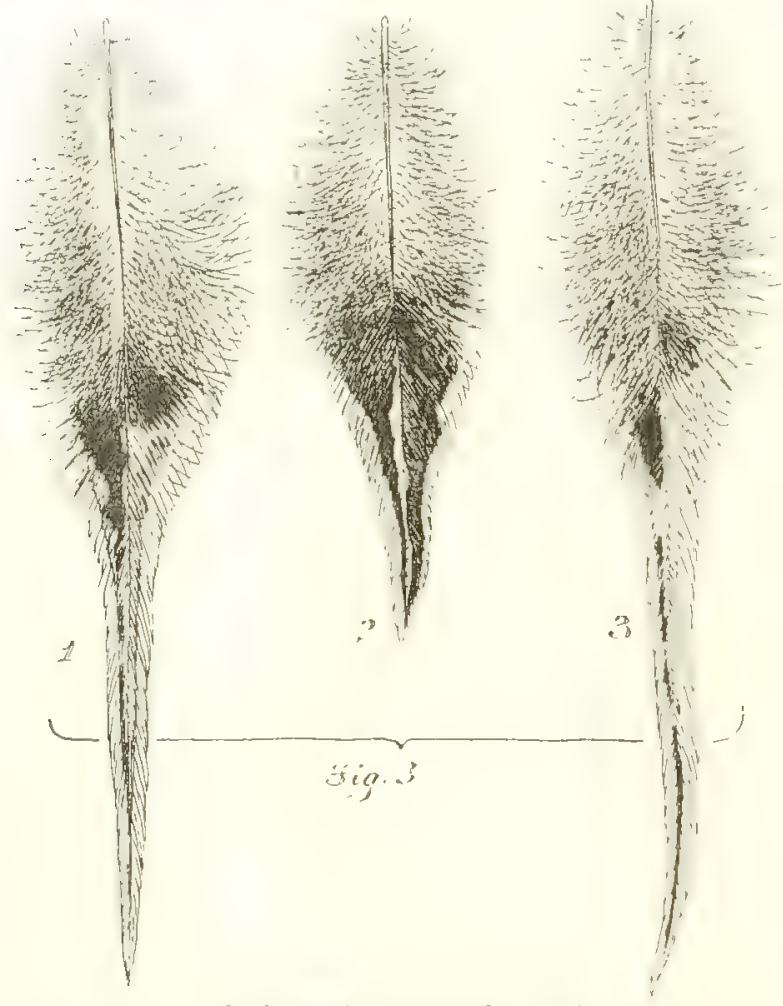

Defective Back Feathers of the Male.

Feather No. 1 is light in under color, is not black enough in center of featler and fails in the black stripe. If all the featiers in a section were as defective as this one the section should be discuunted two points. Feather No. 2 is taken from just back of the wings, and shows a fairly perfect feather for that section. There is slight stripe of red running through the center of feather, which should discount one-half point. Ftather No. 3 is one of the long side hangers, and is very defective. It is too light in under color, shows but little black in body of feather, and the stripe is almost entirely lost. $A$ back showing all feather's like No. 3 should be discounted three points.

\section{BREAST}

Like back, this is a very important section, especially in shape, and next to back is the most important from a breeder's standpoint. It is doubtful if there is in the Standard a better description of any breed than the one used in connection with the Cochins, which is as follows: Breast carried low in front; full and well rounded, with great breadth and depth. With this description and the Chart Fig. 1 the reader should have no trouble in gaining a good general idea of the shape of this section. You will note the breast is carried low as compared to any other of the large breeds; this gives our Cochin males a peculiar pose, and one that harmonizes well with their quiet, docile disposition.

In color the breas't should be black, and in our choicest show specimens it is seldom this section is discounted in color. However, there are some defects that show up, and in order to explain them to the reader, I call your attention to the feathers as shown in Fig. 4. In feather
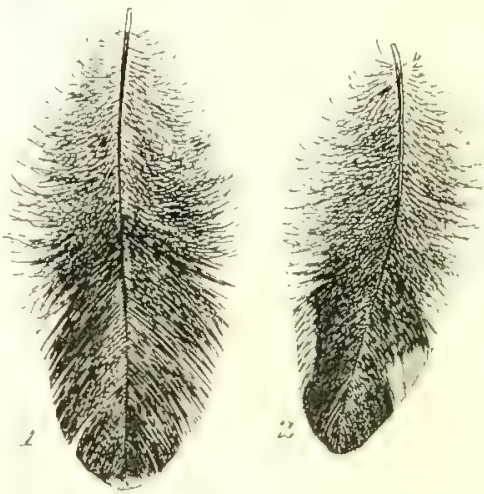

Fin 4

Defective Breast Feathers of the Male. No. 1 is $\mathrm{show}$ a faint trace of red on lower edge, and the discount is onehalf point, while feather No, 2 has red on both sides running well down, and the discount is one point. Feather No. 2 is one that crops ont quite often in the pullet breeding males, and is not considered a serious defect when breeding for females.

\section{BODY AND FLUFF.}

This section has a valuation of eight points and is divided. giving five to shape and three to color. It will be noted in the division of points the Standard makers considered the shape of this section of more value than color, and in most of the Asiatic varieties this is true, but in Partridge Cochins and Dark Brahmas it is doubtful if the scale of points should not be changed, giving four for shape and four for color, as a more intelligent card could be given in that way. However, a full feathered Cochin must be good in body and fluff to be Standard, as so much stress is laid on the rounded outlines of these sections. In Chart Fig. I is shown a full feathered bird, one that conforms to the new order of things and one tha: we must admit makes a pleasing picture. In color the Standard says the feathers should be black, but there are a very few males that are entirely black in this section. Quite

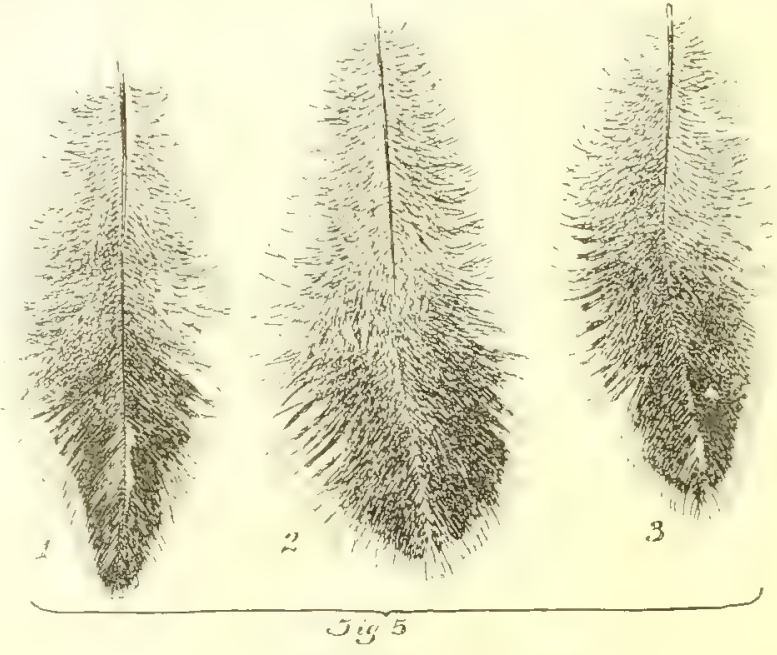

Defective Body Feather of the Male.

often every feather in breast and front of body will be black, still there will be quite a trace of red in the surface of fluff and rear of body. The Standard description of body, like 


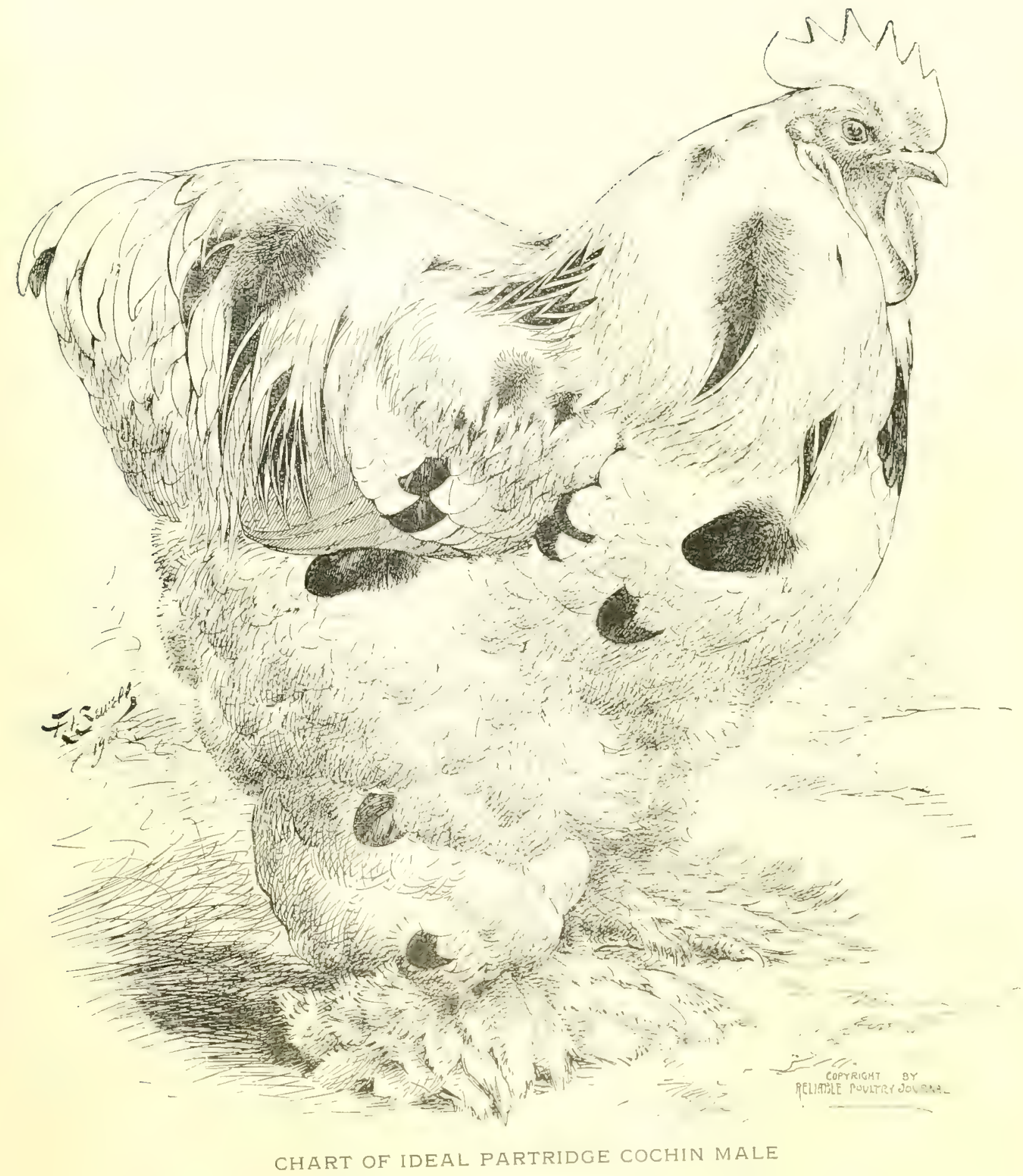

Fig. 1-lllustrating the Shape and Color Required by the American Standard of Perfection 
that of breast, is well worded; in fact, there is no better description given in all the book than the one describing this breed. "The body should be from point of breast to ablomen brcad, deep and well rounded; medium in length. The abdomen well let down between the legs, broad and well rounded up from breast bone to tail, depending more for its fuliness on the length of feathers than upon muscular development.

In Fig. 5 will be found three feathers that were taken from a male that slowed fairly dark in breast and body. Feather No, 1 is red on outside, with a tracing along the shaft. A section showing feathers like this should be discounted one and one-half points. Feathers Nos, 2 and 3 show a lacing of red on the outside and should be discounted one point. Feathers 2 and 3 are quite common on pullet breeding males and quite often this lacing of red will run down on thighs and feet. The cuts of one and one-haif seem slight as compared to other discounts, but it must be remembered there are only three points allowed for color in this section.

\section{WINGS.}

This section in a Partridge Cochin male is usually good. Broken feathers sometimes mar the shape, and occasionally a trace of white will show in flights, but as a rule the wing is gnod, and quite often passes without discount in either shape or color. Where feathers are broken the cut is from one-half to one, as in degree. If white shows in primaries or secondaries, the cut is from one-half to one and one-half, as in degree.

\section{TAIL}

This section has quite a bearing on the shape of a Cochin male, and it seldom passes as perfect. In fact, there is unloubtedly as much tinkering with this section as any one on the bird, including the hock. The aice short tail, well furnished with long, soft coverts, doesn't grow on every Cochin male.

In the Chart Fig. 1 is shown a tail that is slightly overdrawn; in fact, the stiff feathers are entirely out of sight. This bird shows a tail nicely filled in underneath and just such a one as our Cochin breeders are striving for, and one I hope soon to see common with this breed, without the aid of artificial help. So much trimming has been indulged in by some of our breeders that when I see a good, well balanced tail I am the least bit skeptical about it. But the radical improvement that has been made in this section within the past fivo years encourages one to the belief that it is only a matter of a chort time until we may expect to find many of our best specimens with such tails as illustrated in the chart. There is a color disqualification in tails of Partridge Cochin cockercls that some of the breeders seem to overlook, and should white creep in the web of main tail feathers or sickles, the bird is disqualified. When under color is allowed to run too light, one may look for this de= fect, and it is well at all times to keep a watchfnl eye in this direction.

\section{LEGS AND TOES}

In Fig. 1 is shown a male bird that has sufficient plumage on legs and thighs to please the most fastidions. It was this extra heavy feathering that put so many of our Cochin breeders at variance, and in many cases caused the old-time breeders to give up the Cochins altogether. The claim made by them that the heavy feathered bird was not so good an egg producer was in some cases exaggerated. Some strains may have been affected by this introdnetion of the longer feathers, but breeders to whom I have talked who at first were radically opposed to the change, have admitted that they seo no difference in the laying qualities of their birds. There have been some radical views taken on the leg and toe feathering, many seeming to think the stiff vulture hocks were being called for, and the birds exhibited in the ful! feathered class some eight years ago were abominable looking scrubs, and it is really wonderful that the breeders came to adopt the full feathered ones at all. Careful mating along intelligent lines soon eliminated the stiff hocks and produced in their place a profusion of long soft ieathers, covering the thighs completely and curling as much in front as behind the leg. A careful study of the chart will show the readers that a Cochin male when properly feathered comes pretty near filling a perfect triangle. They will also note the entire absence of stiff feathers on hocks. Such birds as pictured in the chart are rare, but only from such may we expect to breed the ideal Cochin.

\section{COCHIN FEMALE.}

Perhaps of all the Standard varieties there is no female of the heavy weight breeds so strikingly handsome as a well bred Partridge Cochin. Their beautiful color, with well rounded slrape, is surely a pleasing picture; add to this their gentle disposition and we have something well worth our time to study and care for. In my opinion the two handsomest females recognized by the Standard are the Partridge Cochins and Dark Brahmas. The Cochins, with their grand penciling and their rich mahogany red ground color, the Brahma, with its graceful tracings of white on the steel gray, make a study for an artist.

The lacing is the same in both breeds, being a distinct triple in back, breast, body and wing bows.

In Fig. 6 is shown a chart that represents an ideal cochin female. So far as shape goes there is little chance for improvement, and should any Pariridge Cochin breeder get one as good in color as the tracings on this chart, he is protty certain of a place in close competition. With the chart as a guide there is no great amount of explanation necessary for a clear understanding of shape, and it is this ease of demonstraring by outlines that convinces the writer that an illustrated Standard is not only valuable, but a real necessity if we wish to educate the breeders to a better understanding of the different varieties. With the chart as our guide for perfect shape and color, I will call attention to some defective feathers, and place a discount on them similar to the male.

This section is seldom good in color if other sections of the bird are nicely penciled. Instead of a black feather with golden lacing, we are quite likely to find the feather laced like the back and wing bows. The Standard says in describing color of neck: Bright red $01^{\circ}$ dark orange red, with a distinct black stripe extending cown each feather, running nearly parallel with the edge and tapering to a point near its extremity. The black stripe may be slightly penciled. In my opinion the wording should be changed to read lower part of hackle penciled similariy to the back, then we can breed without asking nature to reverse her markings in two sections that join each other.

\section{BACK.}

In Fig. 7 are shown some defeclive feathers taken from the back of a female that possessed remarkable color in breast and body. The back had a good shade of ground color, but was almost entirely void of lacing. Feather No. 3 shows a faint race of lacing, but is badly mixed up and should be discounted one and one-half points. Feather No. 2 in the same group is entirely devold of lacing and should be cut two points. Feather No. 1 is not only devoid of lacing, but has a shading of gray on edge of feather, which gives the surface a faded out appearance. 


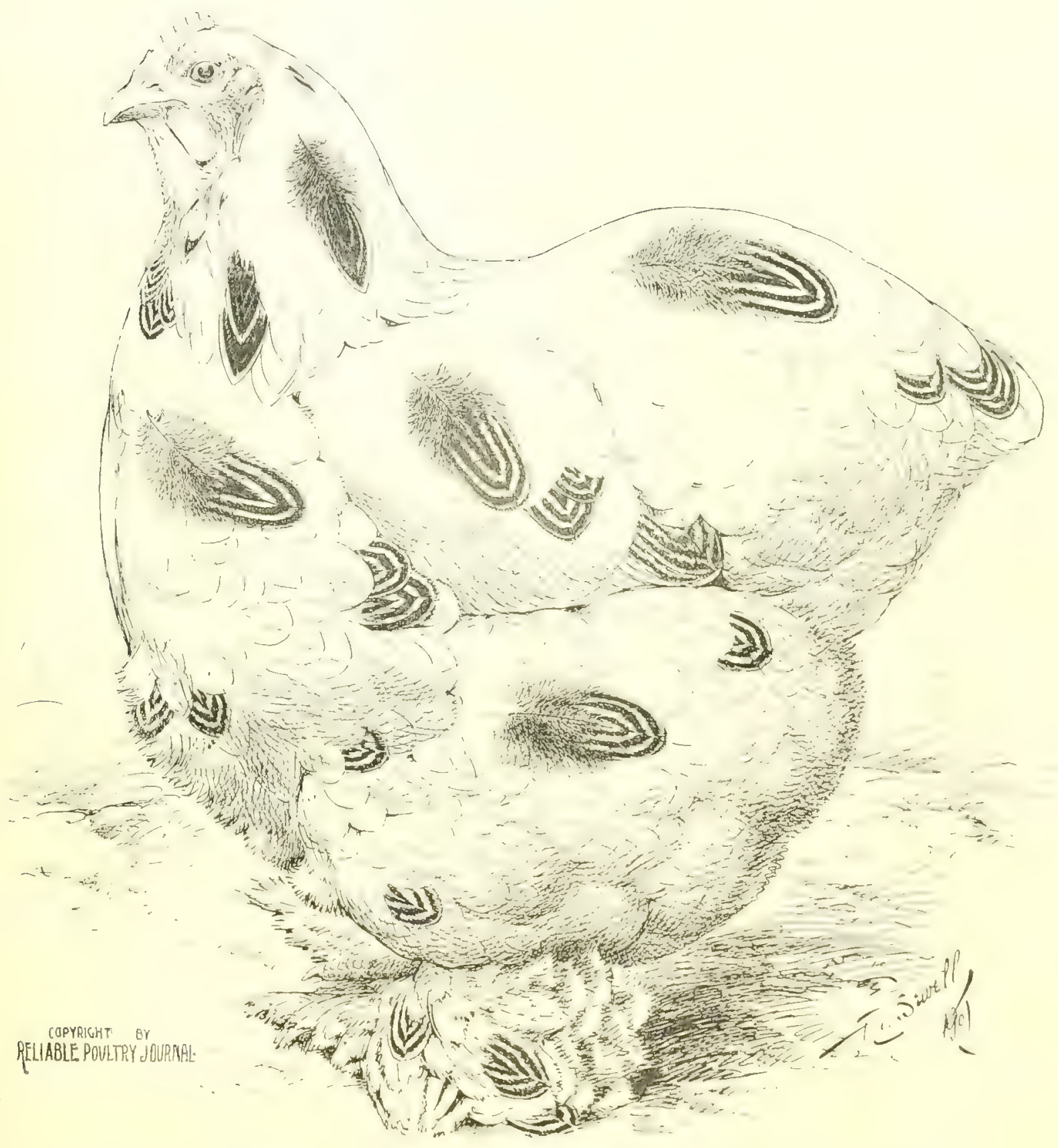

CHART OF IDEAL PARTRIDGE COCHIN FEMALE.

Fig. 6-Illustrating the Shape and Distribution of Color Required by the American Standard of Perfection. 
A back showing feathers like this should be discounted two and one-half points. In shape it is doubtul if a better outline will ever be offered than the one $\mathrm{Mr}$. Sewell has portrayed in the chart. Perhaps a little overdrawn for our best Partridges, but well in hand for some of our Buff

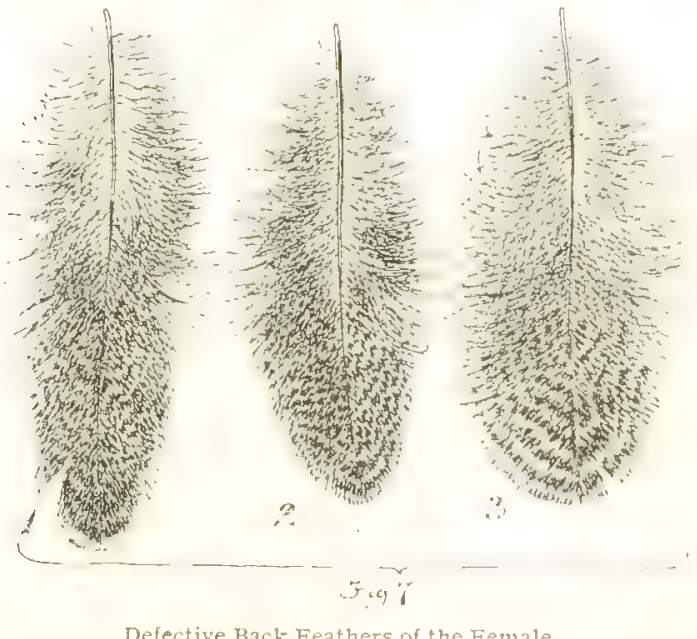

Defective Back Feathers of the Female.

females; in fact, the first pullet at Illinois State show. January, 1902, was only a shade behind this drawing. The Partridges have only within the last few years been shown with the loug, soft plumage so common with the Buffs, but with such men as Mitchell, Baylies, Harrison and others in the chase for perfection, it is only a matter of time till the Partidges will take their place alongside the best of the Buffs.

\section{BREAST}

This section usually shows as good color as any on the bird; in fact, we quite often find good lacing on breast when other sections are quite defective. In Fig. 8 is shown a group of feathers frequently found on the breast of this variety. Feather No. 1 has a fairly good style of lacing on outside, but pencils up too much in center of feather. A breast with feat $\mathrm{h}$ ers like this should be cut one and one-half points. Feather No. 2 is taken from up near the throat and shows a faint trace of lacing, but not distinct enough, a n d center of feather is penciled and runs together. A section showing feathers like this should be discounted one point. Feather No. 3 is

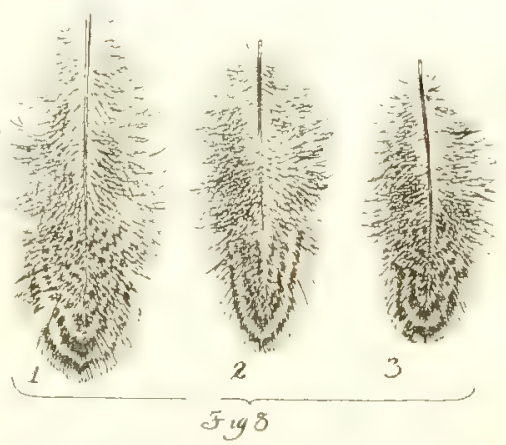

Defectice Breast Feathers of the Female. laced on outside; in fact, two rows of lacing show fairly plain, but mingle too much near the shaft. A breast showing plumage like this should be discounted one point.

In shape the breast should be full and well rounded. with great breadth and depth, carried low in front. In Fig. 6 is shown an outline of breast that fills the Standard fairly well. However, this breast might be carried a trifle lower at point of breast bone, still not go beyond the Standard description.

\section{BODY.}

This is another important section in all Cochins; in fact, thore are but few if any breeds where this section is considered of so much importance especially in shape. To be perfect it should be from point of breast bone to abdomen, broad, deep, full and well rounded, medium in length, the abdomen very full and round from breast bone to tail, with great length and fullness of feather.

In Fig. 6 is shown an outline of body that would be hard to improve upon. The long feathers of the lower body completely hide the hock, making a nicely rounded out profile that is pleasing to look upon and one our Cochin breeders are striving to breed. In this, as in other sections where the long, soft plumage has much to do with the outline, it is well to remember that but few of our best Partridge Cochins are so profusely feathered. The Buffs of this breed have a tritle the best of the long feathering thus far, but year by ycar we see the improvements in the other varieties, and it is only a matter of time, and a short time at that, until all varieties of the Cochins will be as profusely feathered as our chart shows.

In Fig. $y$ are shown some feathers taken from a female in s pen mated for general results. It will be noticed there is scarcely a trace of lacing, and the feathers are badly off in penciling. Feather 1 looks more like the fluff of a cockerel hreeding Brown Leghorn. There is no lacing and black extends almost half way through the web of the feather. A body with plumage like this should be discounted two
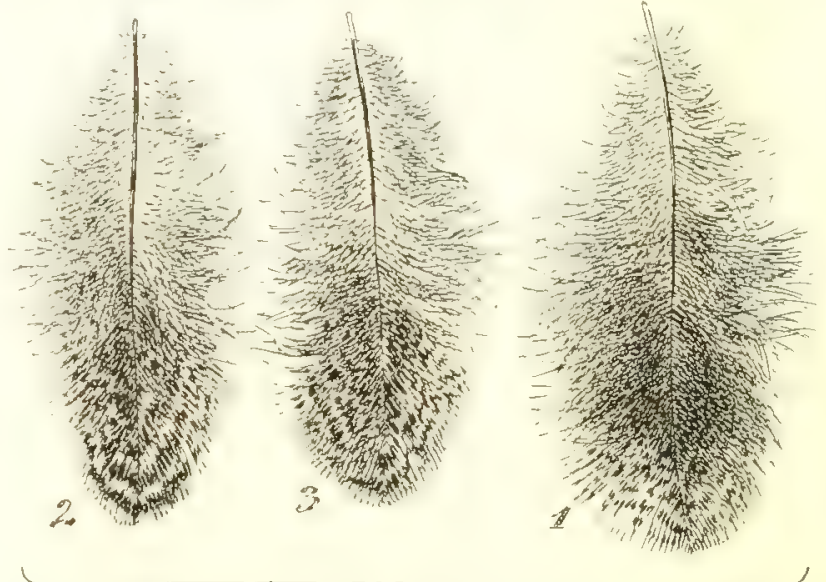

Fig 9

Defective Body Feathers of the Female.

points. Fearher 3 has some of the same defects as feather No, 1 and there is also a tracing of light lemon on outside. A body showing color like this should be discounted two and one-half points. Feather No. 2 is not so bad as 1 and 3, but is void of the lacing and black runs too far into the web and should be cut one and one-half points.

\section{WINGS.}

In shape the wings should be small and completely folded, the fronts embedded in the plumage of the breast. The tips concealed between the cushion and thigh plumage. In color the chart Fig. 6 is shown correct in lacing for this section, and like breast is usually good, as compared to other sections.

In Fig. 10 are shown three feathers that are more or less defective; all of these feathers. taken from the wing bow of one bird, show how defects will multiply if careless breeding Defective Wing Bow Feathers of the Female 
is indulged in. Feather No, 1 in this group shows a trace of laciug, but is not distinct enough. The penciling runs into the ground color, and should be cut one point. Feather No. 2 is so penciled as to practically destroy all trace of lacing and should be cut one and one-half points. Feacher No. 3 is one of the small feathers taken from upper part of wing bow: Like feather 1 , it is not clear enough in lacing and should be cut one point.

\section{TAIL.}

This section in the female, like that of the male, gives the breeder more or less trouble in keeping it at the proper length. A nice short tail is a wonderful help in rounding out the back, while a high stiff one will mal the symmetry. However, there is not so much trouble experienced in producing good tails on females as on males. The Standard says in describing the shape of this soction: Short and broad at base, well filled underneath with a profusion of soft feathers and nearly enveloped in the tail coverts, which help form the cusbion. The tail in Fig. 6 is slightly overdrawn; the tail proper should show at an angle of about 85 degrees, while the feathers in Fig. 6 would show they grew out on almost a straight line. The point for the breeder to take into consideration is to breed the main tail feathers as short as possible. with a profusion of coverts and cushion feathers. In color the tail of a Partridge Cochin female should be black, except the two highest main tail feathers, which should be penciled. The penciling of the two top feathers carries the handsome color effect from comb to enu of tail, but tail, like neck, is pretty hard to ketp free from penciling, when other sections are sood in color, and it is a question in my mind if penciling should not be allowed in the main tail of Partridge Cochins, Indian Games and Brown Leghorn females; but so long as the Standard reads as it does, all we can do is to discount the peuciling.

In feather 1 in Fig. 11 will be found a penciled feather quite often met with in tails of well colored females. A bird showing this amount of penciling in tail should be discounted one point. Feather 2 is taken from down on the side of tail, and only a trace of red appears. A tail like this should be cut one-fourth point. Feather 3, like feather 1, shows the penciling on both sides, also shows a streak of very light ashy color on surface, and should be discounted one and one-half points.

\section{LEGS AND TOES}

'Ihis section is not only important in shape, but in color as well. Thighs, shanks and feet should be profusely feathered, and tbe lacing on feathers should extend to the toes. It is only within the past few years that good lacing on body and fluff was considered wonderful, but with the great improvement in mating we have to-day not oniy the handsome coloring in body and fluff, but on feet and toes as well. In fact I have within the past three years found several females with foot feathering as well laced as Mr. Sewell has

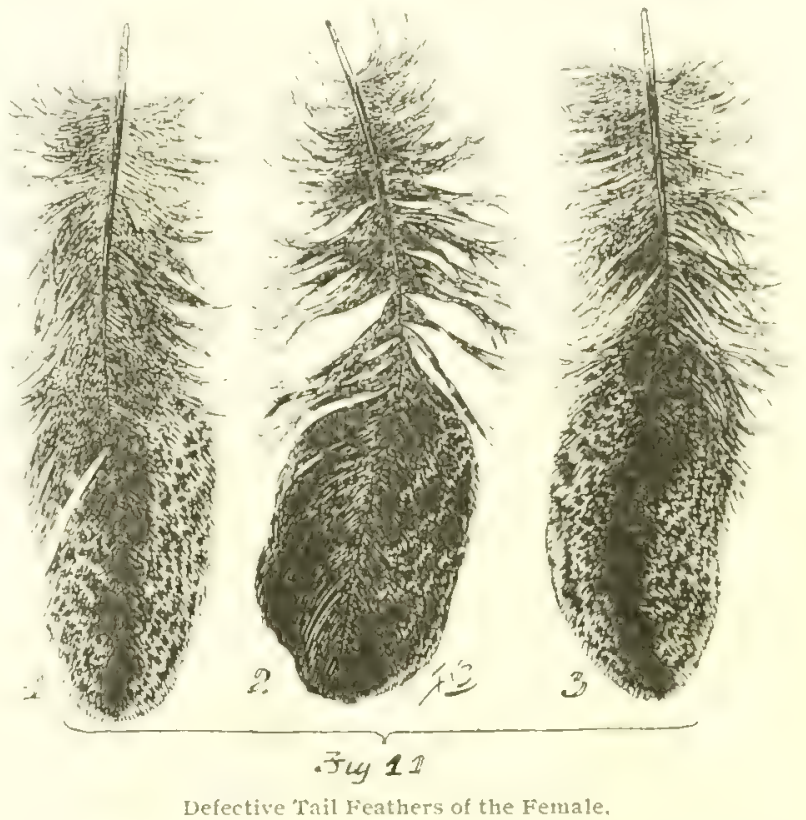

shown in the chart. In shape improvement would be hard to make, as Mr. Sewell has portrayed one of our very choicest Buff pullets. She has a sufficient amount of feathers on legs and toes, and the length of leg is in proportion to the well rounded symmetrical body. T. HEWES. 


\title{
TWENTY YEARS WITH PARTRIDGE COCHINS.
}

\author{
A Variety Adapted to Any Locality-That Thrives in Confinement and Lays When Eggs Are High \\ Priced-Feeding, Mating and Judging.
}

BY O. E. SKINNER,

¿ IAVE bred Partridge Cochins nineteen years. History has it they originated from the same sitting of eggs as the Butf Cochin. A skipper brought the eggs from China and when hatched one party took the chicks looking most like a partridge and the other the Buffs. It is needless to say that they have been very materially advanced in color and shape since.

Partridge Cochins prove highly satisfactory in cities and mining districts, as they do not show soot and coal smoke like other varieties.

They are easily confined. To illustrate - I have only a two-foot fence between two pens of Partridge Cochins and they do not bother any. Three feet I think amply high I am, from varied experience, an advocate of low houses and low roosts, but they must be kept absolutely clean and dry. Twelve to fourteen inches is high enough for roosts. They bear confinement exceedingly well, and do not get overly fat like Barred Rocks and other more active hreeds. To get the best results in close confinement, straw or other lit. ter should be liberally supplied to induce exercise.

I have succeeded in producing a larger number of eggs in zero weather with Partridge Cochins than with any other breed. I have bred all the leading breeds of fowls side by side with them. I tested five Partridge Cochins (three hens and two pullets) with forty Leghorn pullets and hens in the exceedingly cold January and February of 1899. These fowls were kept in the same kind of a house with the same food. Now for results. These Partridge Cochins averaged two and a lualf eggs per day with the temperature running as low as twenty-four balow zero, and for nearly one-half the time the forty Leghorns laid absolutely none. Some will say, "Youl houses were not warm enough." Yes, but the same conditions applied to the Partridge Cochins: besides, one egg laid by one old Partridge Cochin has produced a pullet that commenced laying at four months and twentynine days old. 'They are considered by many the very best table fowl.

Here are some weights-Hatched June 24th, weighed August 24th:

Four Partridge Cochins-3 pounds.

Four Light Brabmas-23/4 pounds.

Four Barred Rocks-31/4 pounds.

Four Light Brahmas-41/4 pounds.

Four Partridge Cochins-4 11-16 pounds.

Four Barred Rocks- $-4 \frac{3}{4}$ pounds.

Weighed again September 7th:

The Partridge showing a gain over the rest.

A great many breeds of fowls are subject to leg weakness when young and growing fast. In nineteen years of breeding Partridge Cochins, I cannot recall a single case of leg weakness. Where it does occur in any breed a little copperas in the drinking water is valuable.

Another good point about Partridge Cochins is that when bred for winter layers, having been laying all winter, they are ready to sit early for early show chicks. For hatching in incubators, Partridge Cochin eggs knock the Light Brahmas clear out and are far better than Buffs.

The longer I breed fowls the less I think it requires any special kind of food to raise young chicks successfully. It is the air surrounding the hen or in the brooder that does the deadly work and not the food. I believe this, however: the kind of food has a great deal to do with the rapid growth. I am at the present time using Spratt's food. Corn bread baked with plenty of eggs and oatmeal mixed with hot water for one feed a day for chiclis up to two weeks or more old helps them make a very rapid growth.

For mature Partridge Cochins I feed one mash in morning with some variety of meat and potatoes cooked. In the evening I feed whole grain, corn, oats and wheat mixed.

About six to ten females to one male for breeding is the

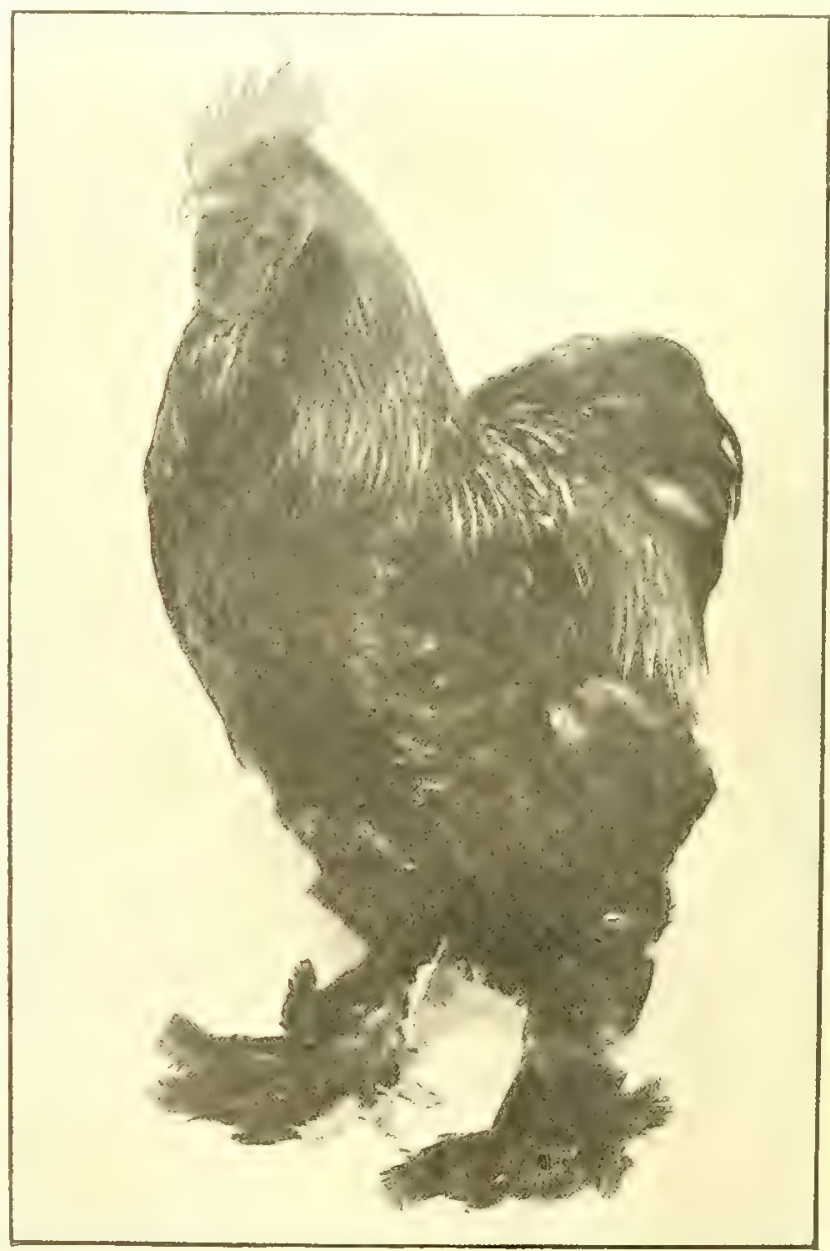

Third Prize Partridge Cochin Cockerel, in a Large Class, at the Great Mid-Continental Exhibition. Bred by $0 . \mathrm{E}$. Skinner. 
proper mating. I always prefer cockerels with hens and early pullets, as I make a specialty of raising winter-laylng Partridge Cochins batched from eggs laid in the winter. Cocks are all right for summer breeding, but the most active cockerels are required for cold winter breeding. In breeding for show birds, I always advocate mating as near standard as possible on both sides, using a male as high as possible in cushion with as short a tail as possible and broad across back.

In breeding good Cochins, it is difficult to get good shape in males and good penciling in females. In color, white is the hardest to keep out. My idea is if you use a special mating, that is, a cockerel with penciled feathers, you soon will have a white strain of Cochins in males. On the other hand, in mating for cockerels, you soon would have a strain of females without any penciling. I much prefer cherry red in males and females with a rich golden edging to hackle, rather than lemon edging. The new standard calls for the same hackle in females as in males. 1 think this is a printer's error.
In judging I have seen the most noted judges make bungling work, allowing a little under sized pullet, for instance, to take first because she was of good color, leaving out shape and size altogether.

If I were judging Cochins, I would look over the entire lot and select the one with good size, good shape and best color possible, with the other qualities, and score this one first and then be very careful that I got none higher. I believe, if this system was adopted in judging, a better and evener type of Cochins could be established. Then a longlegged, out-of-shape and under-sized bird could not win over other birds far more valuable as breeders.

In the accompanying photo of a bird I bred is shown the cockerel winning third prize at Kansas City, twentyseven competing. He is a trifle long on legs, but tine shape of body. His present position is a little more erect than usual, owing to his standing near a coop containing another cockerel. His comb is a trifle larger than I like, otherwise he is a fine specimen.

O. E. SKININER.

\title{
MATING PARTRIDGE COCHINS.
}

\author{
Characteristics Specially Valuable in Male and Female--Inbreeding Necessary to Fix These Char- \\ acteristics-Improvement in Recent Years-Double Mating Advocated.
}

BY A, W. BELL.

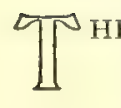

HE main difficulty in breeding Partridge Cochins is to obtain the desired penciling in the females, with proper mahogany ground color, which is so earnestly sought for by all breeders, but as yet has been the reward of the few. In the male the most important, ontside of shape and looseness of feathering is to secure a well-striped hackle and saddle, free from what is called mossiness in the edge of the feathers, and the quill of feather being light, the latter being the result of use of English blood to a greater or lesser degree.

I know of no special mating that will in one season produce birds with a standard hackle and saddle, except that by breeding from males strong in under-color will assist, and all one can do is to mate such birds with the best procurable characteristics in these sections following a good deal in-breeding until you have this point thoroughly fixed in your strain, then attempt another section of the bird, unless you are fortunate enough to possess one good in all points, though of course it is much more expedient to accomplish the perfection of two or more sections at the same time if possible.

When we turn to the female though is where the persistence and resources of the breeder are taxed to their utmost. To produce every feather on the body as distinctly penciled as if it had been done by an artist, in fact, often say that an artist could not do such work, is an undertaking that not every one is capable of accomplishing.

A lew years ago most judges would pass a hen with peppered fluff sound or cut one-half, whilst now she would lose two points because in this section alone has there been such wonderful improvement. I saw last winter a female Where one could almost truthfully say every feather on her body was perfectly penciled, and to a Partridge breeder she was worth a considerable sum.

Your male should be from what they call a pullet breeding strain (would that though the single mating was all that was required to produce any variety), i. e, a bird whose breast, body and fluff are penciled with black, and not a solid black as for cockerels. Added to this with a light under-color, and do not object to a little white or grey in wings, as you will easily notice the improvement in your females.

To a male of this type should be mated a female as distinctly penciled in all parts as you have, of a mahogany red shade, her under-color being light.

To one who has bred Partridge Cochins, no more beautiful bird exists, and no doubt after they become perfected more in color, especially among females, they will be bred considerably in excess of the present time. There is no doubt this deters many from taking up those beautiful birds, the same as with Dark Brahmas.

I have said nothing as to shape and size, as rules for other colors will answer the Partridge, only the majority of strains are a little too much inclined to a great length of leg in both sexes. This can be remedied a good deal by breeding later in the season, as a majority of birds sc bred are shorter legged than those hatched earlier; possibly also they are being inbred more than they should be, which explains their smallness and tightness of feather in comparison with the Buffs. A. W. BELL. 


\title{
BREEDING HIGH CLASS PARTRIDGE COCHINS.
}

\author{
The Combination of Form, Feather and Color Necessary to the True Cochin-How to Obtain These \\ by the Single Mating System-Value of Inbreeding, Wholeome \\ Food and Proper Care.
}

By GeORGe W. MitchelL.

$\rrbracket^{*}$ the production of high class Partridge Cochins it has becn my constant desire to have not only the best quality of this variety, but to equal the Cochin qualities of any variety of the breed. To handle them in a manner to gain such quality has been an extremely difficult tast, demanding the closest attention as well as continuous thought for the furure. In the production of all the qualities required to have them fill the demands of the Standard it is absolutely necessary to line breed, even to the verge of dangerous in-breeding. To continue in this line of work and maintain all the Cochin qualities has been a problem that has given occasion for thought.

The best way to convey to those who are interested such information as will be valuable is by telling how it is possible to maintain size, shape and feather when line-breeding for color. First, the size can be maintained only by the selection of the largest and most vigorous females, those that show good constitutions and bone force, with thick heavy shanks and thighs. Cochins must have strength in these sections to enable them to carry the weight that comes with increased size. The thighs must be long to carry the full feathering of the present type and must be so located, or set on the body, as to spread well apart so the body may be wide and full and at the same time let the body down between the shanks that we may gain a broad appearance both fore and afc. Stich hens can be depended upon to produce good size and vigor at all times, even if bred in line for years.

Another thing that must be done is the forcing of the chick from start to finish with good, strong and wholesome food that contains a iarge per cent of bone and feather forming properties. Much more depends on proper care and feeding than is generally uncerstood. A Cochin that is allowed to falter in its growth at any stage of its development will never make a large, vigorous bird. Poor or irregular feeding, over-crowding, damp or cold coops, all have quite as much to do witk loss of vigor, size and luster of feather as has the method of mating. The chicks must be regularly fed and properly looked after all the time or they will not become high quality fowls, even if the eggs they came from were from the finest of hens.

\section{DISCARD YULTURE HOCKS}

To gain the best Cochin shape and feather we must have the right tendencies in our breeding stock. The progress that has been made in this line has come from the use of the heaviest feathered females to be obtained. The use of males that have long and heavy vulture hocks stamps this evil quality so strongly in the blood that it gives continuous trouble for years. Select the heaviest feathered females ynu can find, and the heaviest feathered males without the stiff hocks and breed these qualities into your young stock gradnally rather than to have the bulk of them discarded for vinture hocks.

of all things, do not tolerate a specimen that lacks Cochin shape. In selecting for this do not make the mistake of having them so short in body that they look dumpy or deformed, nor so low in front nor so high behind that they have the appearance of falling forward. The most desirable Cochin shape is the rounded, full form in all sections, as large and full as possible, and as long as can be had without losing the well-rounded form that is the beauty of the Cochin.

If these rules of maintaining shape, size and feather are followed, you may feel assured of reasonable success. and improvement in the stock from year to year.

Color and markings give this variety a grace and beauty of feather that seldom are excelled. The combination of the black and red of the male, and the mahogany red with brown or black in the female, gives us a pair of birds beautiful beyond the power of the pen to describe. When the featbers show the smooth, glossy, velvety sheen that indicates good health and breeding, you have a sure evidence of vigor, without which you cannot gain the best condition of color and feather.

\section{INBREEDING-ITS GOOD RESULTS.}

For many years I have practiced line breeding and the good qualities so much desired have been infused into the blood by the mating together of the specimens having in the highest degree the qualities most desirable for the show pen. Always having in mind the methods set forth above for the control of shape, size, vigor and feather, it has been possible to mate together the finest specimens produced, even to using in the same pen full brother and sister. If asked if I would advise such close breeding, I must answer, "Yes, but-." The "but", is added only to remind the amateur that the greatest care must be exercised along the lines set forth, and then success is the reward.

Should one not desire to give the time and thought necessaly to produce the results mentioned he can hold to the male line and breed these males to two or three separate female lines that can be kept separate by knowing the pullets from each hen, and hold these over to be mated with the cockerels of the year, or with cocks that are a very little removed from full brother and sister. In this way color can be improved from ytar to year, providing you make use of the trie Standard colors in your matings. Our Standard calis for the same color and striping of the hackles of both males and females.

Real beauty demands that the Standard be obeyed in your matings or the result will be inferior hackles in the females at least. Nature gives the proper backle to the male more readily than to the female, and to keep the proper shade and markings in the hackle of the females we must see to it that the hackles of the breeders are as we wonld have them in the young stock.

The mahogany red of the female helps to keep the brilliancy of the top color of the males and the dark penciling helps to add richness and gloss to the black of breast and body color of the males. The proper use of the Standard colors in youl matings will aid in establishing a line of birds that will produce winners in both sexes from the matings 


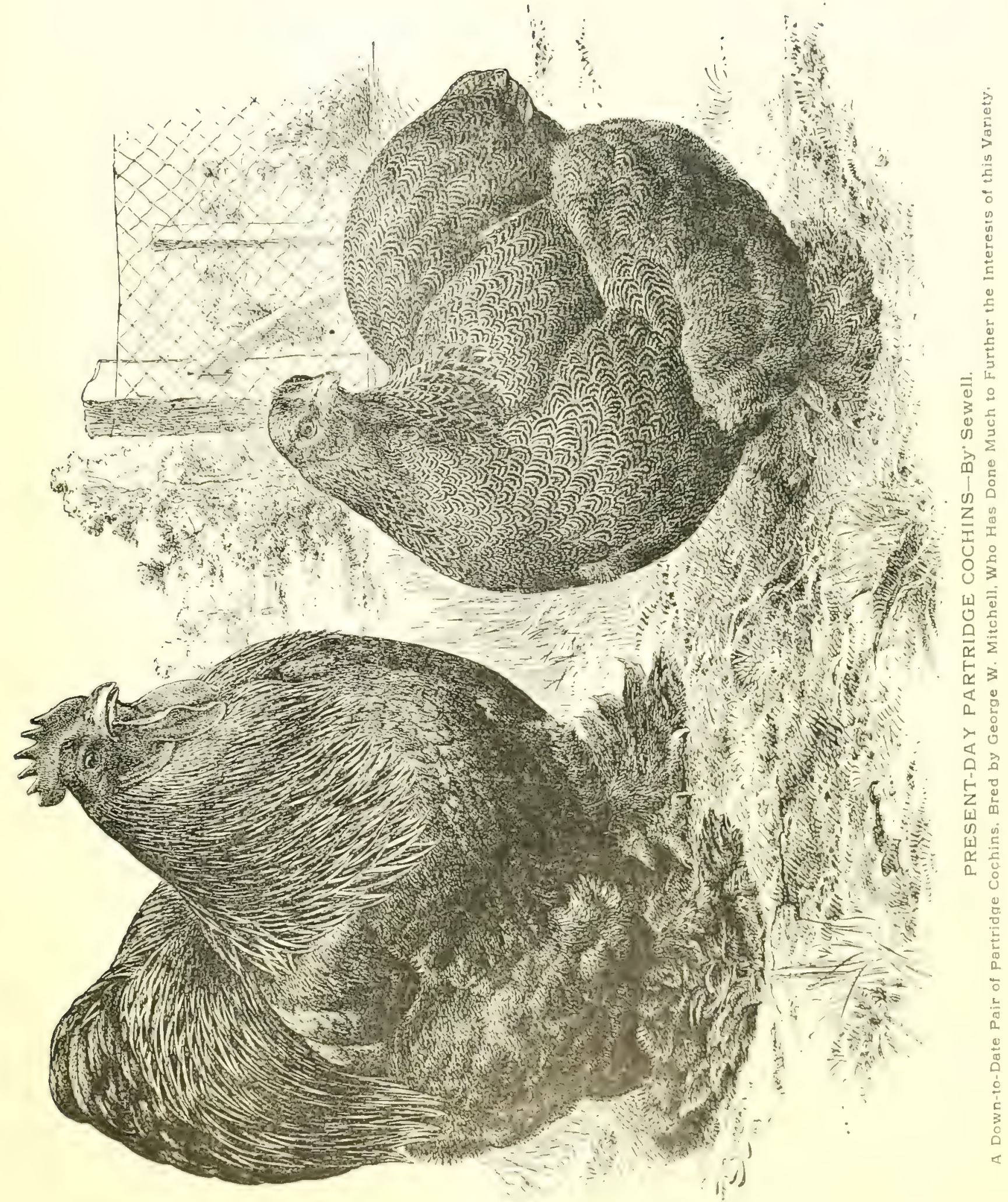


as mentioned, while the manipulations neeessary to the double mating system cend to force your blood lines so far apart that the intraduction of one in to the other injures both color and markings.

The only way to hold in check the white that is so likely to make its appearance in the wings " . 1 d about the roots of the tail feathers of the male, is to hive a good, rich black in breast, body and wings and with these good, strong under color is necessary. These are the only safeguards against the white or gray, that naturally belongs to all fowls whose plumage shows the black-red shades. The same fauit, if fault it must be called, was found in the early-day males, the Earl Derby Games, our present-day Black Red Games, Brown Leghorns and others with similar colors. The presence of white or gray has a very undesirable influence upon the richness of the surface color. For all these reasons it is quite difficult to hold the shades and markings of Partridge Cochins together with perfect Cochin type, but it can be accomplished if the proper care and attention are given along the lines as I have suggested. GEO. W. MITCHELL.

\title{
STANDARD BRED BLACK COCHINS.
}

\author{
An Instructive, Convincing Article by a Fancier and Judge Who Has Bred Them Continuously \\ During Twenty-two Years.
}

B. C. H. RHODES.

$\mathbb{A}$

FTER a fancier has made the breeding of a certain variety of fowls a specialty for a number of years, it is hard to keep his mind free from prejudice toward other varieties. Very naturally his special variety of fowls become his favorites, and he desires to have other breeders recognize the true merits of his variety as seen by himself. The true fancier, however, will avoid prejudice or favoritism, conceding to all varieties the true merit they deserve. Whenever an article is published from the pen of a contributor showing a desire to depreciate any special variety of fowls, you can rest assured that the fow is he depreciates are strong competitors of public favor. It is to be hoped that the readers of this article will recognize the desire of the witer to

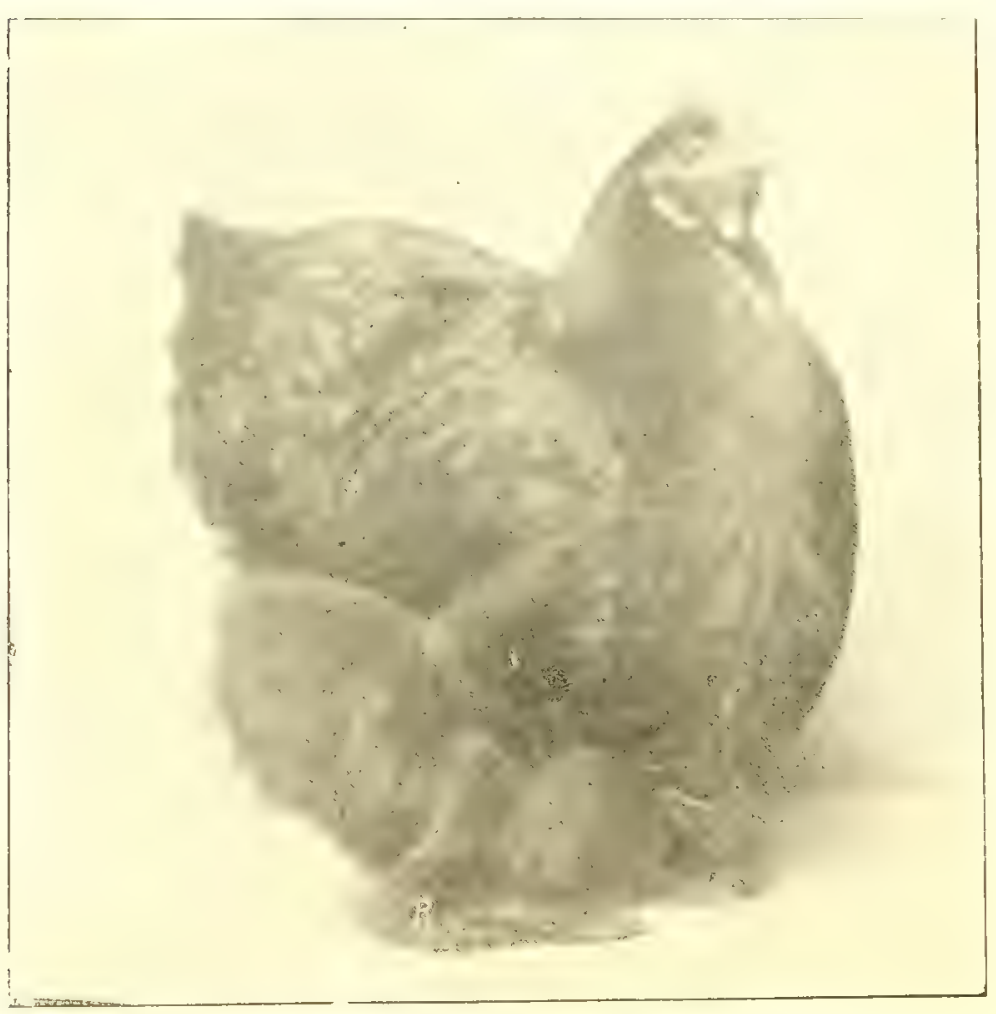

A Black Cochin Hen of Grand Shape and Color, Bred by C. H. Rhodes. call attention to the excellencies of the Black Cochin, giving to all other varieties of fowls most respectful consideration.

It is not the purpose of this article to go into details regarding the origin, history or advent of the Black Cochins in this country. Many articles as to the history of these fowls have been published heretofore. The purpose of this article will have been accomplished if it produces in the mind of the reader a recognition of the sterling qualities possessed by the Black Cochins, and assists in placing them in the front rank with other varieties.

The breeders of these fowls thoroughly understand and appreciate them for their economic worth. As compared with the other Aslatics they stand second to none as egg producers. Their eggs are large and uniform. The hens are not prone to sit very early in the season, but when they raise a brood of chicks, they makethebest of mothers. The better strains of these fowls under careful handling breed very uniform as to size, color and shape. The epicure will find in the Black Cochin a fowl that for table use will fill all requirements. The tissue of the fowl is tender and easily prepared for use. Unlike many varieties of black fowls, the skin dresses yellow and is free from any bluish tinge, which is so objectionable in many of the markets of the east.

The Black Cochins are very hardy fowls. They stand exposure and fatigue, changes of climate and temperature with impunity. As a class they are exceptionally free from predisposition to disease. During unfavorable seasons of the year, when other flocks are infected with disease, they are immune. The typical fowl has a beautiful greenish black metallic luster. A flock of these well-bred fowls is most pleasing to the eye, and would please and enthuse any admirer of fine poultry.

\section{MR. RHODES LONG DEVOTION TO BLACK COCHINS}

My attention was first called to Black Cochins in 1872. A Wisconsin friend was at that time giving his especial attention to these fowls. The early breeders were more sncessful in securing the requisite color than in ob- 
taining the Cochin shape. In early days these fowls were tall and leggy, and close feathered, both in the males and females. By shape they would hardly have been recognized as belonging to the Cochin family as described by the present American Standard. In the early days they were known as almost non-sitters.

Four years later, at the National Poultry Show at Chicago, the Blacks on exhibition was one of the strong classes. During this short space of time they had made considerable improvement in shape, but the color had somewhat depreciated.

In 1879 we owned our first Black Cochins. They were somewhat undersized and coarse in their general malie up though they filled the requirements of this variety at that time, I took up the breeding of Black Cochins with the fixed determination to secure if possible birds of larger size, of Cochin shape, with more profuse feathering, and at the same time retaining their economic qualities as to grg production and early maturity. How well I have followed this determination is best shown by the fact that I have continuously and without interruption bred this variety twentytwo years and produced fowls that have received the highest recognition at the local and national exhibitions of our country.

Starting with the Williams strain, for two years we inbred the fowls, selecting the fullest feathered for the purpose, using sire on daughter and granddaughter. This resulted in an increased size and an improvement in sbape. Later we purchased what was then known as tho Stone stock. The male line was not satisfactory. We selected two pullets that were extra heavily feathered on legs and toes and mated lnem with the old cock. From this nating the results were very satisfactory. The cockerels combined the good qualities of the sire, increasing the leg feathering and fluffiness so desirable in the Cochins. The best cuckerel was bred to his dam, and from this mating a line of sires was established that has remained unbroken to the present diay.

It seemed to be a natural tendency of the Blacks to be more closely feathered than the other Cochins. To obviate this, I concluded to try the cold weather theory of fluring. I had a brood hen come off in August with six youngsters. These chickens were given the elosest attention, shellered from the inclement weather and kept growing from the shell to maturity. In November they were black balls of fluffy down. From this lot four were selected for exlibition purposes. That they were excellent Cochins is evidenceo by the fact that they won sweepstakes prizes at two of the largest shows in the west, i. e., Chicago and Indianapolis.

\section{EXPERIMENTS WITH IMPORTED STOCK}

A number of importations of Blacks have been made since 1885. This blood must be used very sparingly to avoid

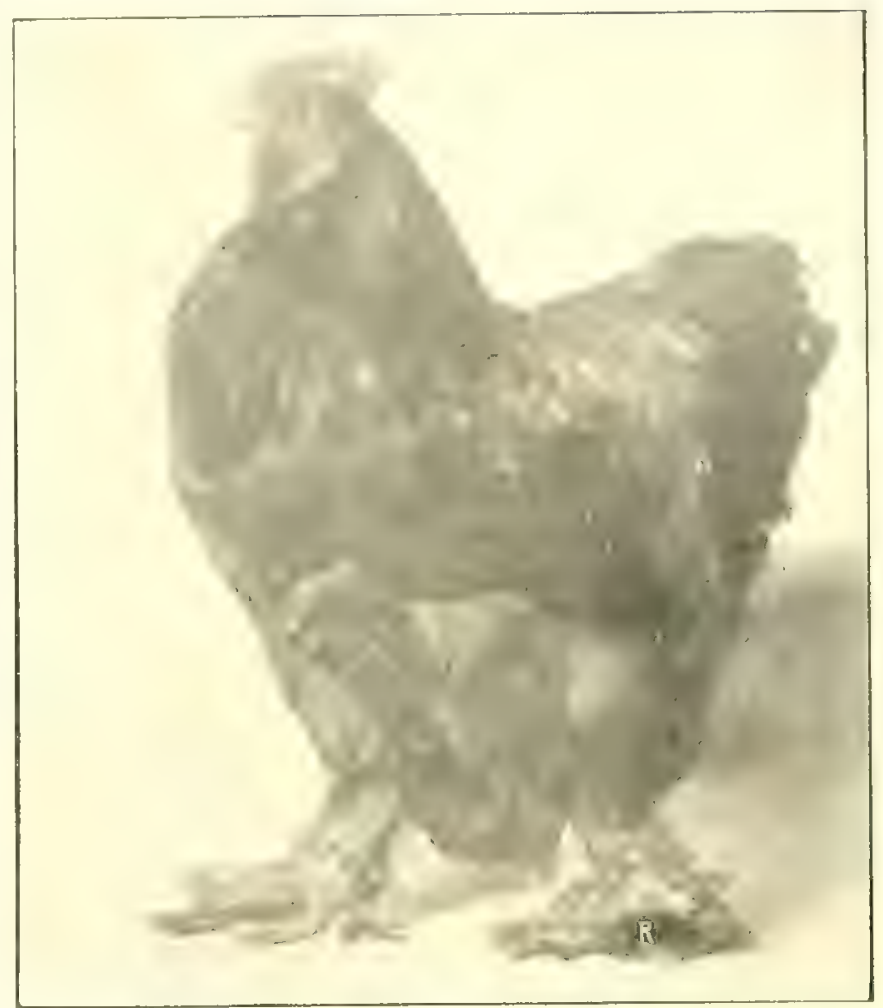

A Typical Black Cochin Cock. Bred by C. H. Khodes.

a stiff, harsh hock. On several occasions I have experimented somewhat with the English variety of Black Cochins, but have achieved my greatest success in confining the matings to the stock of my own production.

The increasing volume of my correspondence and the statement received from many fanciers, show conclusively that the Black Cochins are growing in popularity each year. From the present handsome and symmetrical Black Cochin, one would hardly recognize any resemblance to the tall and leggy variety of birds of twenty years ago. The development of this fowl to its present state of perfection illustrates what may be accomplished by careful matings and persistent effort to perfect a given variety of fowls. In the history of Black Cochins, there never has been a time when the variety has been given any great boom in the fanciers' world. 'They have grown steadily in public favor without the boom and reaction which is the fate of so many other varieties. With their intrinsic merits and from their past history, one has a right to believe they will con inue to grow in popularity as their excellence becomes better known. C. H. RHODES 


\title{
THE WHITE COCHINS.
}

\author{
A Useful Variety for Exhibition and Practical Purposes-The Standard Demands for Form and \\ Feather-A Bird Worthy of the Breeder's Skill.
}

\section{By EDWARD WYatT.}

$\rrbracket$

T IS with the utmost pleasure that I herewith present an article upon the justly entitled "Royal White Cochin." They are royal first, because of the admiration our late sovereign, Queen Victoria, had for them when she inported them direct from China into England, and second, because of their great excellence of merit, marvelous combination of form and color of the purest white. They seemingly possess all that can be expected of any fowl.

In this short article I will try and give, with the hope of aiding the tyro, the Standard demands of shape and color and the system of mating for best results. Many to-day find themselves shipwrecked upon a sea of wrong mating. To successfully raise the White Cochin for exhibition, one must necessarily be a fancier-a lover of his fowls. He must be an artist in his line, with an eye for the beautiful, for no breed is more beautiful if bred in their pureness of white, with an abundance of feathering to give it the shape of a large ball of snowy white. To breed them to almost perfection, the fancier must be an enthusiast, a specialist devoted to this one breed-this one variety.

If a person possesses not the taste to become a fancier, or is indifferent as to the proper care of his flock, he kad not better undertake to raise this illustrious fowl, or he will be doorned to disappointment. Such arrangements on the part of the indifferent have hatched ont many disasters and been the chief cause of repressing the great merit of the whole Cochin family, constraining themselves and many others to believe that this variety is of little use except for exhibition

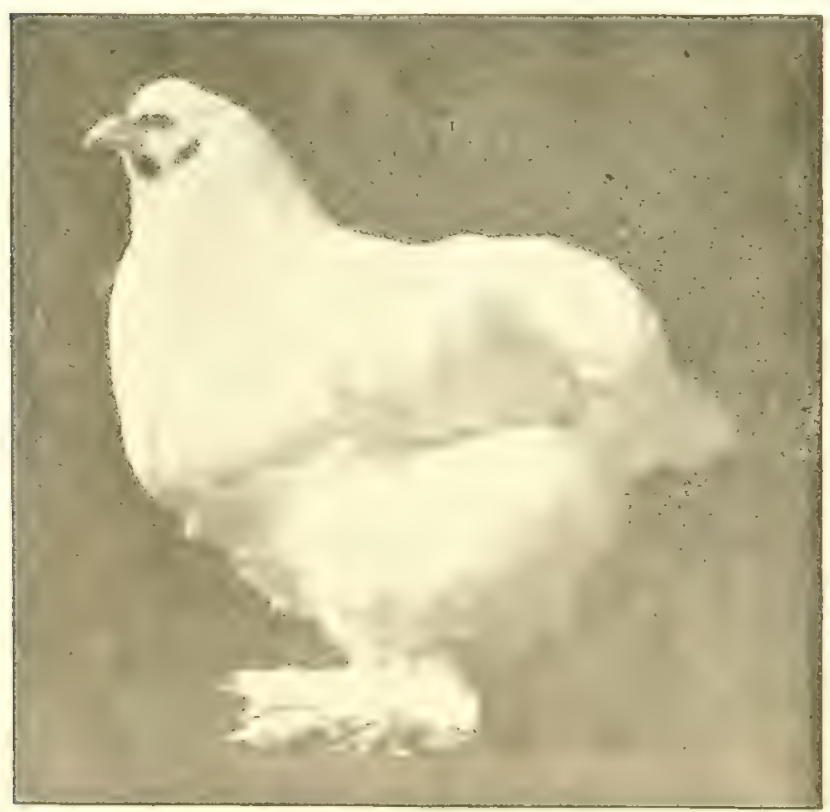

Second Prize white Cochin Pullet. at New York, 1904. Bred by Edward Wyate. purposes. But, my dear readers, learn from me this truththe whole Cochin family have stood the storm of criticism from jealous breeders for many years, and have come out of the controversy as one of the best all-round breeds in use to-day. 'I'hey stand upon their own merits and are rapidly becoming the favorites in every clime, country and state. True the Butfs are the most popular, but they do not excel the whites on any point save as a matter of taste on the part of the fancier. The writer frankly admits that the White Cochin is his first love and the fowl he most ardently admires, and he has been breeding them for ten years.

The typical White Cochin is a majestic fowl, a beauty in itself, and stands upon the canvas of the past distinct and vivid as the king-an exhibition fowl par excellence. Its lovers and breeders, though not so many as those of the Buff and Partridge, are on the increase and will be as long as the love of raising poultry warms the heart of man. The White Cochin is also one of the practical every day workers and money makers in Canadian and American yards to-day, provided, however, they have the proper care and food.

The up-to-date White Cochin, similar to its sister varieties, is a massive, profusely feathered fowl, the more heavily feathered the better; broad, blocky, globular in every outline. This presents a most grand and imposing form. Under the present Standard, the most grandly formed, the purest white, the fullest plumaged birds win the honors. To obtain the plumage one must breed for it. It can be had oniy by selecting each season for mating those showing profuse side fluff, massive frent and rear hock and foot plumage and great length of underfluff. This will gradually approximate that broad cushion or sadrle, which properly should be as broad as or broader than the widest point of the fowl. This and the desired full breast are only seen at our best shows and are hard to obtain. The full plumage will give the reciuired almost horizontal tail. The profusely feathered Cockin does not carry any more weight in feather than does a Light Brahma of like class. The feathers are longer and flufier-that's all.

The Standard color is a pure white-something beautiful inuleed. Too much stress should not be laid upon color. In my opinion shape comes first. The nearest and best illustration of a pure white is the newly driven snow as it descends from heaven. On the male bird the wavy, metallic iustre of the neck, wing and saddle is almost identical; while on the female, of course, it lacks life and gloss. The White Cochin is the easiest of all the Cochin varieties to breed as regards color, for in them there are no discordant colors as in the orhers. As for shape, they are all on a level, the shape of one variety being that aimed at in the others.

To breed White Cochins is work for an artist and a sreat repast for thought and study. They represent the world's greatest artistic work in serenely combining form and color, and as a result for exhibition qualities as a fowl, they reign suprewe. So much for the White Cochin, and long may they reigi.
EDWARD WYATT. 


\title{
STANDARD-BRED WHITE COCHINS.
}

\section{A Judge and Fancier of 'Thirty-three Years' Experience in Breeding Cochins Says a Few} Words in Favor of the Whites.

\author{
By J. D. Nevius.
}

(Firom the Reliable Poultry Journal.)

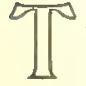

IIS variety of the Cochin family should differ only in color from that of the Buff, which is and has been for years considered the most perfect in shape, size and feathering of all the varieties. This can. I think, be easily accounted for from the fact that the Buffs have had far more admirers, consequently have had much more attention paid to their improvement, and being bred in much larger numbers, better specimens have been produced from which to select breeders. After thirty-three years experience as a breeder of Cochins, most of this time breeding the four varieties-Buff, Partridge, White and BlackI have found the Whites in all respects the equal of either of the other more popular varieties-Buffs and Partridges. In hardiness, either as fowls or chicks, they will stand confinement as well (but like all white birds, if not kept on grass runs, appear to a disadvantage in point of condition), are good sitters and splendid mothers, and are better layers and their eggs are much larger than those of either of the other varieties. The beauty of a well bred flock of White Cochins on a green lawn I do not think can be excelled by that of any other variety of all chickendom. From the demand for eggs and fowls for the past three years I am convinced that they are rapidly growing in favor, as they certainly deserve. We have been unable to supply the demand for either fowls or eggs the past two years. With White
Cochins, like all varieties of white fowls that the Standard demands shall have yellow legs and bay eyes, it has been difficult to breed stay-white males. I mean by this males that when exposed to the sun for a season will be free from any tendency to straw color. Such a cock, if first-class in size, shape and feathering, is almost priceless as a breeder. IVe lost a bird of this kind this year (a winner of many first prizes) that we had used as a breeder for five years, and was strong, active and vigorous up to within a short time of his death. We never bred a Cochin that was more vigorous at his age.

The White Cochin, like all the other varieties, should be a massive bird with broad, deep, well-rounded body and breast, small head for size of bird, comb small, with five serrations, eycs bay, neck short and full, the male's hackle cushion full and well rounded, that of the female almost extending well over the shoulders, back short and broad, hiding the entire tail, which should be so carried that the highest point does not appear above the highest point of cushion, breast deep, full and well rounded, and carried moderately low, legs yellow, short and abundantly feathered to end of middle toe. We believe that in a few years the White Cochin will in all respects be the equal of the best of any other variety of Cochins.

J. D. NEVIUS

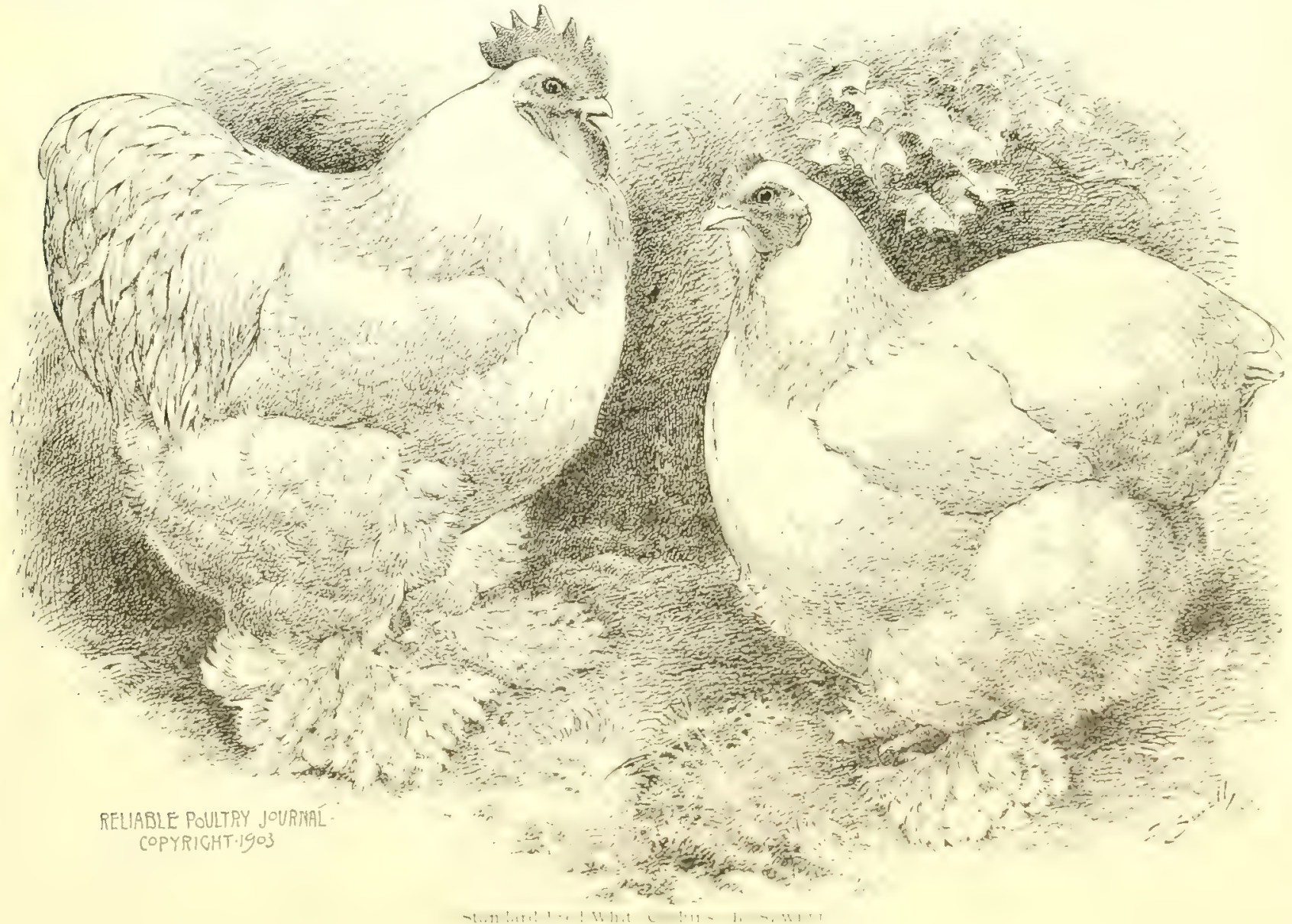




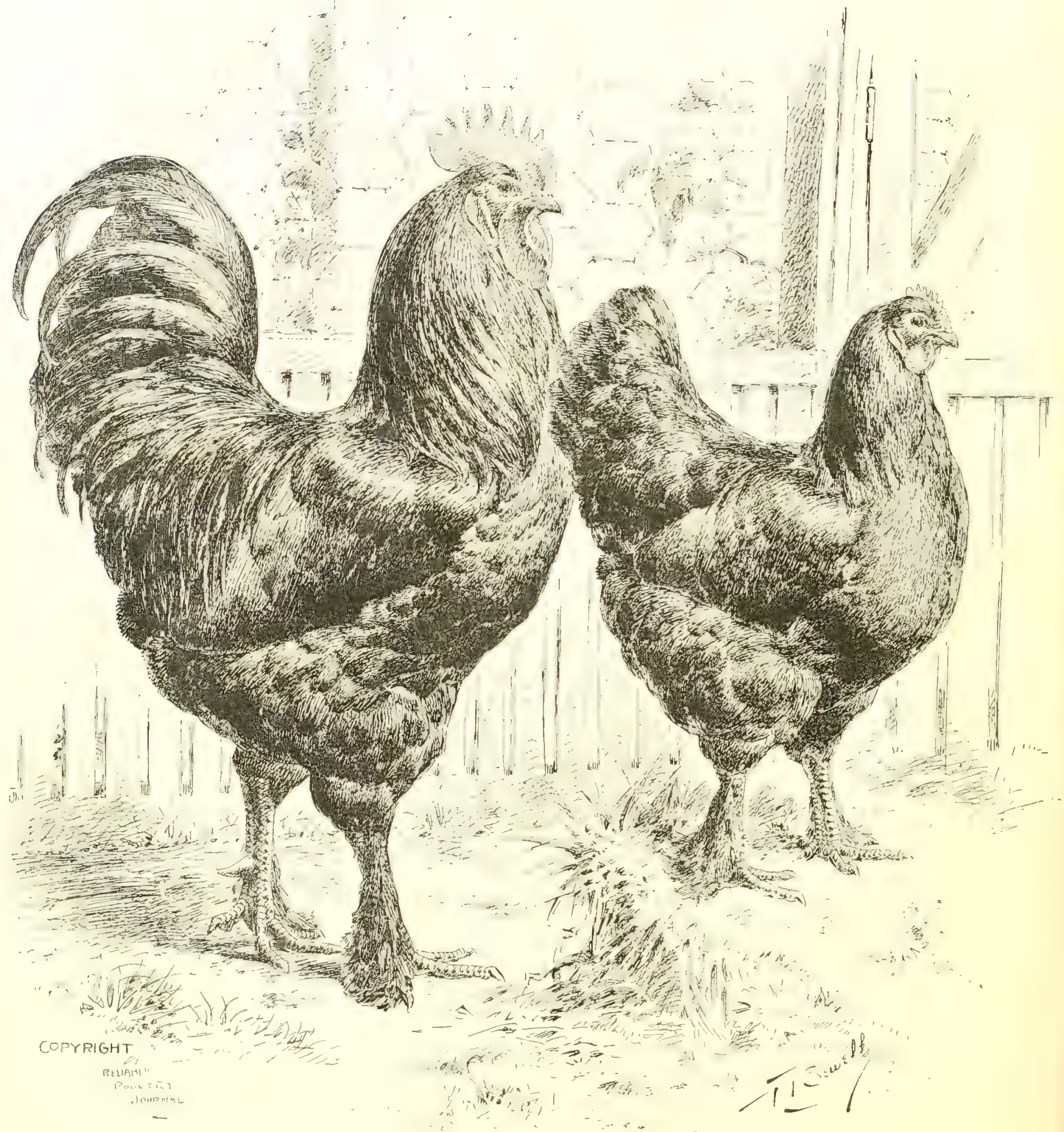

IDEAL BLACK LANGSHANS-By Sewe]l 


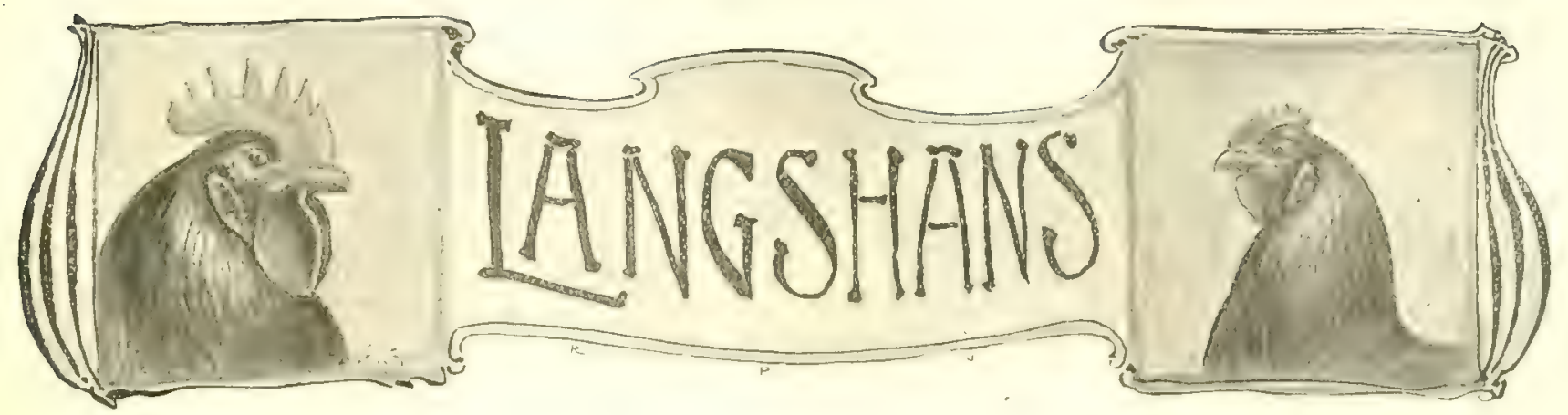

\title{
THE BLACK LANGSHAN.
}

\author{
A Product of the Langshan Hills of China-lts Admission to the American Standard and Subsequent \\ Development-Pen Pictures of Ideal Male and Female-The Defects Found and Cuts \\ Scored by the Judge-A Tried and Proven System of \\ Matıng for Best Results.
}

IBY I. K. I'ELCH.

$\mathbb{T}^{\mathrm{x}}$ st importation of them to America was made in 1876 , by E. A. Samuels, the ornithologist of Waitham, Mass., from the Langshan Hills of China. About four years before this (February, 1872) they were imported by Major Croad of Sussex, England, from the same quartel: Those of us who were active in poultry culture at that time remember the bitter antagonism exhibited toward them by those breeders then trying to make the Black Cochin popular; they terming these new importations as crude and indifferently-bred Cochins, but they reckoned badly, for they lived to see these black addition to our list prove beyond dispute a difference in type and exhibit more decided and brilliant color, which secured for them the appellation of "The black diamonds" in poultry culture. The clandestine use of them as crosses with the Cochins, both in England and America, in the hope of improving the color of their plumage, brought to the breeder thus working, the chagrin of seeing the Cochin character and color of shanks and feet absorbed by the Langshan instead, and in the end forcing him to acknowledge their superior strength of blood and breeding; the Langshan establishing itself as a thoroughbred of decided type and color and maintaining its decided merit as producers of eggs, taking rank as the best layers among the Asiatics.

They have many admirers and those not prejudiced against the color of the skin of poultry (it being white skinned), find no fault with its merit as a meat supply.

The Langshan Hills of northern China is the criginal home of this breed, as it was from there that the first specimens, sent both to America and England, were imported. It matters not how fully one may write of its advent, its history in America is what interests the readers of to-day. During the seven year's from its advent to 1883 , when at Worcester it secured admission to the American Standard, its path was a thorny one for any breed-no breed probably ever had such opposition and probably none ever had a greater triumph in its acceptance. A petition of nearly a thousand names accomplished its admission.

It is now nineteen years since they were acknowledged as thoroughbreds by the American breeders and accepted by the A. P. A. at Worcester, Massachusetts.

It was my privilege to write out a standard for them as a disinterested party. Those being on exhibition (a full row across the hall) comprised birds of all ages, imported and American bred; no finer lot has ever graced an exhibition since. After having made a standard for them, which was accepted at that meeting, it was my lot to repair to the hall to judge and score the exhibits; thus was I the first judge to score and award the prizes to the first exhibit of Langshans under A. P. A, law. At that time arbitrary demands for disqualifications were necessary to secure their admission, in order to make them as distinct from the Black Cochin as possible. For all that, by the simple change of the disqualifying clauses of that date for those of to-day, we claim that the weights and other demands of their standard, if they had been allowed to stand intact, and the breeder forced to ive up to and breed to them, would have given us to-day in America a larger and handsomer breed than we now have.

The color appearing in neck, saddle, tail coverts and sickles, wing coverts and lower web of secondaries is a changeable one of dark green to black. Looking at the plumage at right angles it is a coal black, while at an angle of forty-five degrees it is a rich, sheeny green-might be said to be a calendered green-over black. The breasts, thighs, primaries, fluff and tail proper are a solid black in first-class specimens. In these sections we have little if any of the green sheen spoken of above, for the reason that they are protected from the direct rays of the sun, being almost constantly in the shadow of the body. A dark slate color for under fluff will be found in the best colored specimens, this with black under color being the only ones that should be passed uncut by the fudge in adjudicating for prices.

I have no desire to alter or amend that which I suggested to the Langshan Club in 1891, which is herewith submitted, neither have I any desire to change my criticisms of the illustrations then in rogue and of the character of foot plumage. Excessive shank and foot plumage changes the appearance and pure Langshan shape into a similarity to Cochin shape. This, as is well known, disgusts every firstclass breeder of Langshans. But to return to color in this estimable breed. How many do we see of a rusty shade of blick, with no lustre or green sheen, and is it not the truth that these birds are most leniently consldered by the judges. There is another defect that is objectionable. Some specimens are actually barred with bronze bars, or a color akin 
to claret shaded with bronze. We had rather see this than a dirty, rusty black, for this evil creeps into the nice colored specimens and seems to grow ont of excessive lustre or metallic shading; yet it should be watched and such males chosen as the mates for females that secm to lack in lustre. The fact that pullets dull in shading show a marked improvement in the plumage of their progeny by such males leatis us to make the assertion that the evil glows out of excessively high 'color, for dull black specimens are never thus marlied. These males and females having the pure black with green reflection free from the barring alluded to should be able to prove that "like begets like" to a greater" degree than in any other breed extant. Such should literally reproduce themselves - and being in health and furnished with a generous supply of grain, meat and vegetable foorl, with shade that they can retire to at will, they will do all this. A dull, sooty black Langshan, no matter what its type, is a cull, and no judge is doing justice to the best specimens who in judging gives a Langshan the benefit of a loubt in color. This should be the rule with any solid coicred bird, if we would secure a just color discrimination hetween breeds.

The neck of a Langshan is longer and slimmer than the Brahma or Cochin, therefore is less arched. The term well arched is not a good one-it being rather longer than medium. We should say more than medium length, slightly: yet neatiy curved, with hackle long and flowing. Breast while full, has a long oval sweep from throat to thighs, which while equally full, shows less prominence than in the Brabma. This is due to the longer neck and long tail plumage, which accompanies it. The back is exceedingly short and flat, and therefore looks very wide when hackle is lifted. the saddle being more of an inclined plane than a concave sweep. The first description ever given, we think the best; "gently rising from the back to high upon the tail, while the tail is carried in an upright position, but short of being a squirrel tail." This high carriage is necessary to secure the fountain tail, so called, the long sickles, lesser sickles and side hangers gracefully falling in long trails over and about the taii proper, almost completely hiding the same in the males. (See dotted lines to rear of male and female.) Instear of saying the sickles extending beyond the tail proper six inches, the term falling in trails six inches long at the rear of the tail proper would express it literally. The wing like that of the Brahma is larger than that of the Cochin. Artists malie a mistake when they portray them with small wings, for they lift themselves in the air very readily when frightened. The side hangers on lower part of tail take a half turn as they lop about the rear of the tail and viewed from the rear show flat to the gaze of the inspector.

Now, the females of this type should all show this characteristic, and those that do are the dams of our winning males. They show at the surface only about four at the most of the upper stiff tail feathers which give a slightiy thicker set appearance to body, and in fact a larger look to body proper. It is for the club to vote what the correct type for the breed shall be; that the type that I uphold here is the original one not a breeder who has followed the breed since 1883 can deny.

Whatever cut the elub adopts it must be a natural one; if not upheld by nature, then its use as a rule of form and shape will subject nature to a cut for being perfect. The Langshan breast was never seen so prominent as to reach within one inch of a drop line from beak to ground at its most prominent point, just above the point of keel bone. Its breast seems farther to the rear because of its longer, slimmer, less archerl neck than any other Asiatic. We are aware that all pictures are not exact measurements in proportion with the original. We have to portray them as they look on tlat surface; could we emboss the picture we could adhere to exact proportions, but on a flat surface a pure profile presents the fowl in the nearest proportion and measurement. To get fullness and width of breast, we cannot, however, take more license than to even the curve of breast up to this drop line; if we do we are forced to add fictitious length and depth to fluti and rear of tail, to balance the picture which is thrown all outside of nature's lines. We have taken this license in our cut, but know, as herein stated, a live Langshan never yet showed a breast in normal shape that protruded to meet this line described, But no breeder can deny that we find these types in nature and that they are desirable. It is folly to tinker with nature's best. We can only entice nature to be prolific with her best; this we do and secure in greater degree by furnishing all the year round, so far as we can artificially, the foods and conditions of nature's breeding and most prolific months, which are April and May for the Middle and New England states. It is absolutely necessary for a club to agree upon a fixed type and standard description for color, and to revise the weights to, cocks ten pounds, cockerels eight and one-half pounds, hens eight pounds, pullets six and one-half pounds. Then declare the standard final and unaiterable.

They should return to the original description of shank and foot feathering, to-wit: Shank and outer toe well feathered, to a degree that the outer toe be covered from sight. The disqualifications should be: Shanks not feathered down outside, outer toe neither feathered to the end nor well covered by the shank plumage.

It is the height of folly to declare a first-class specimen a cull by disqualifying it because no feather grows on the toe itself when the toe is completcly covered by a profusion of the shank plumage, for the effect and looks are the same as when the shank plumage is extended by the feathers growing to the tip of the toe.

The breeder should watch out for medium sized, evenly serrated combs, green sheen to plumage, full fountain tail, well feathered shanks and feet, close profiled hocks that give the specimen an "up and up," smart appearance as the English express it, all excellence being backed by the fitness of things.

We class it as one of the most productive layers of the Asiatic class, its prolific egg production in winter and color of shell being in conformity with the other Asiatics, but the shells are the darkest shade of all. Aside from this it presents an independent character: Long in its joints, long in comb, neck, wings, tail, thighs and shanks, thus giving it a character all its own, while its green sheen over black precludes the thought of any other breed in the beholder. But as to texture and close adhesion of its plumage, it is akin to the whalebone texture of the original Brahmas. Notwithstanding many of the oppositions to its white skin, its friends and breeders are multiplying in the west and southWost, and why should they not? It came to us a thoroughbred, it has passed through no transition, has reproduced itself ever since, and our care of it has only enabled us to produce a large per cent to scores above ninety-two points.

Nature's best in 1883 were and are the equal of the best in 1903, and though we saw them once almost rejected, we now see them one of the principal Asiatics to-day; as a purely utility breed, the equal of the best in its class, while as a fad and exhibition variety we have seen them popular, so shall we again see their classes large in our large exhibitions. Their merit has placed them with us to stay in our American lists of thoroughbred fowls. It is a fact that no breed stands long in public favor as a fad of fashion that 
fails in true productive merit; so true is this, that when a breed holds such a position it is prima facle evidence of merit and utility.

Oddities have never stood popular long with the so-called fancy breeders. They are seldom sought for by the practical poultry keeper and as the prejudice against the color of skin and fat in this breed gives way see them gain favor daliy with the poulterer; New England being the only section so strongly prejudiced in favor of golden colored carcass when dressed. This is the only objection which prevents the breed being a universal favorite, even in New England.

The early and prominent breeders of Langshans adhere to the original type. Their early acceptance protected then from breeders' hobbies and individual claims for strains. There were only claims of excellence for families or the gel of particularly meritorious sires. Charcoal, Paragon, Barcem C., Prince Cyclops, Thunder, Cyclone are among those of American reputation during all these years. To-day do we see the best types, and they are the types admired in 1883 .

The breeder no longer ignores egg production in a breed; none but the very best, in an exhibition sense, now sell at the price of beauty. In a breed beauty is quality to be sure, and the very few having this exhibition excellence sell at extravagant prices, but the rank and file are the boce and sinew of poultry culture and herein comes the question of egg production; these produce the dividends that make all stock profitable. None can deny that the Langshan is one of the best and most prolific layers among the Asiatics.

To produce a layer we have to produce a brother to her and herein comes the question of poultry meat. The poultry question in any breed is an item to be looked after, for as a rule tve look for the money to be received from marketing of the males up to six months of age, to pay for

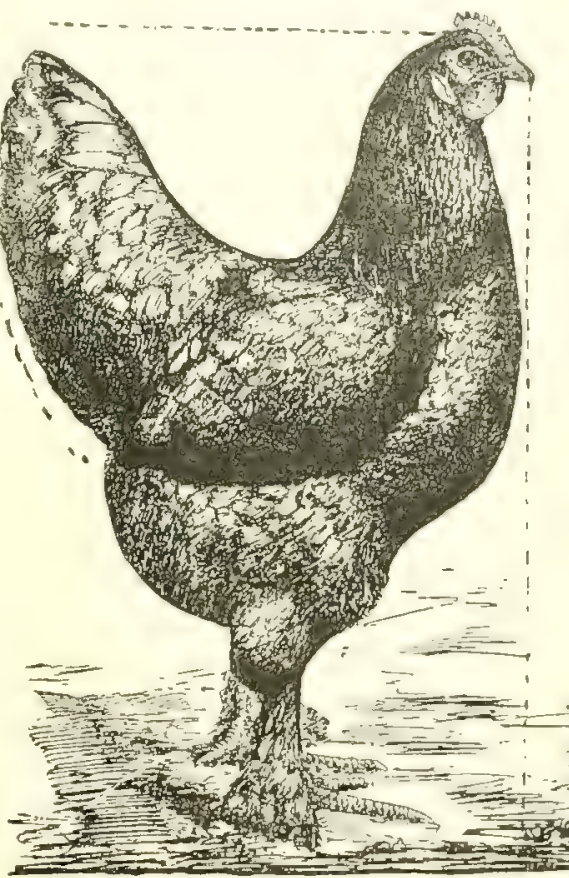

meeting our demands, be far more appreciated by, and bring a better price in the thoroughbred market. In our present standard the language is too meager and the dividing of the subject of color and shape not appreciated by the novice or beginner. We have outgrown the belief that standards are for the sole use of the judges in our exhibitions; they are and should be the text book for the boginner in poultry culture. It is for such we are endeavoring to write this essay.

We are thcrefore opposed to that heresy which demands that standards shall be formed and illustrations made otherwise than true likenesses of nature's best. We hear the expressions used often, "We want the standard better than we have seen, for the breeder to breed up to"; what nonsense. The Almighty as a rule gives us in the best efforts of nature the best merit and productive power; what folly to distort this handiwork of the Creator.

When we describe each section according to the best nature has produced, doing this in all sections, we have per- the raising of the entire flock. This they will do, leaving the females as they commence to lay free of the cost of feeding. when they commence the dividends in poultry culture, which we may safely reckon in October as a dollar and twenty-five cents and the value of the hen as in the marliet added. In this breed the males will pay better in proportion as capons. as in appearance when dressed they resemble a small turkey more than does any other breed, therefore sell better as capons.

Our novice and beginner demands a pen picture of all the breeds. How essential then that all such, in the absence of specific standards, be truthful descriptions of nature's excellence, and that all illustrations be found within the lines of nature. The artist has no right to go beyond nature, even if by so doing he gives the same impression. Measurement should have weight as well. See our illustrations.

Thus should our pen pictures and illustrations become true and instructive standards for the novice, and rules of action in adjudicating prizes in our exhibitions. We do not think, should we be followed, that the specimens will score any the less by the A. P. A. law, but hope they will when fection as a whole. It is true nature produces individual sections perfect, but perfection as a whole is impossible, for it is written, "None are perfect, not one"

The chance to produce a specimen to score one hundred points is just one in a million, eight hundred and twentyeight thousand, eight hundred. Then why augment this difficulty by making standards foreign to nature in the breeds

Now to our task of presenting a pen picture that may well be adopted as a standard for Black Langshans:

\section{THE LANGSHAN MALE.}

Their weight and condition: To our mind a cock should noc weigh less than ten pounds, cockerel eight and one-half pounds, hen eight pounds, and pullets six and one-half. Any less weight is to give undue advantage to small undersize specimens, when judging by scale of points. The cutting of two points to the pound for any deficit thereuf is a just rule to follow. The present American Standard demands only ten, eight, seven and six pounds weight, but is it not folly to list an Asiatic female at less than in some 
breeds in the American classes, which is but to acknowledge that the breeders fall in the handling? When pens of twelve birds, one male and eleven females, are seen at full one bundred pounds weight-thirteen pounds above adult weight even, does it not present an argument for an increased standard weight for this breed: We have demanded for them ten, eight and one-half, eight and six and one-half pounds.

The present condition of things makes the awards in our exhibitions hinge solely on color, hecause standard weights

\section{THE COMB}

Rather more than medium in size and longer in its reach back, as compared with the whole class of single combs, even?y serrated into five points so that the center one is largest and stands highest. The rear point is counted with the flange (the minute points at rear upon the flange are not counted, nor are they mentioned, as they are almost never illustrated by our artists), the whole fine in texture, erect and straight upon the head, smooth at the sides, and free from all wrinkles or corrugations.

Defects. Ton large; not setting firmly upon the head; corrugated along the sides; curved from a straight line from front to rear; unevenly serrated. For these cut one-half to one and one-half, as in degree. Cut one point for each side sprig developed.

If twisted into a letter $\mathbf{S}$ shape at back, or lopped in a male, the bird should be condemned as a breeder and score card record withheld.

\section{HEAD AND ITS ADJUNCTS}

Carriage slightly forward and high, being medirm long in skull and deep in face, which is a dark shade of red; eyes a dark hazel or approaching black; the yellow discoloration being a defect; beal fairly well curved to point and of dark horn color or black, shading to light slate in lower edge or rim; the lower bill of the latter color.

Earlobes well developed, hanging low with well developed wattles, their lower extremities hanging below lower line of the earlobes, all this embellishment being in color crimson red.

Defects. Depressicn in front of eyes; want of proper arch to upper mandible; pale or yellow eyes. For these cut onehalf to one and one-half as in degree. Diminutive size in earlobes and wattles one-half to two points. In the case of absence of wattles, crossed beaks or enamel in earlobes, withhold a score card record or prizes.

\section{NECK}

Long; thereby has less apparent juncture with head; the arch is less pronounced than in other Asiatics; hackle plumage long, covering well shoulder and cape; the surface color, reaching well up to the $w e b$, is a metallic black, which at other than a direct angle gives off a green sheen; under-color black or dark slate. are so low that they are inoperative. It also handicaps all other weight controlled breeds competing with them for sweepstakes prizes, and this handicap is fully a point in favor of the Langshan, giving them at least eight chances in ten to win. Condition is simply a resultant which only in a general way can be considered under the head of health. Uncleanliness or accident from bad conditions is invariably disclosed in the sections which are affected by it, so far as this section (condition) goes it becomes an intuitive consideration for the judges, as an additional defect other than is punished in the several sections; this double application being seldom applied.
Defects. Head carried so far forward as to cause a too straight appearance of neck and want of breast development; want of sheen to hackle plumage; under-color too light, approaching a gray or white; hackle short, falling in a full flow over cape. For each, cut one-half to one and onehalf points, in degree, as they fall short of description. In under-color, carry cuts to two points before disqualifying for positive white.

\section{BACK.}

Back proper, short; cape, broad and flat; saddle, rising in an inclined plane from in front of hip joints to high upon tail coverts; saddle plumage long, merging with tail coverts 
and flowing well down over tips of wing bays; in color, shading from an intense black into a green sheen orer black to the rear.

Defects. Deen concave saddle; roached back; bronze bars in plumage; plumage short and straight in the teather; oval capes; dull black failing in the green sheen near tail and on wing bays; back long and narrow; under-color gray, approaching white. These are to be cut one-half to one and one-half points, as in degree. Birds with crooked shell bone, slipped hip, white in any part or under-color, are to be passed as unworthy specimens and score card withbeld.

BREAST,

Fairly broad and deep; the long sweep from throat to keel bone detracts somewhat from its apparent fullness; quarter fairly well developed; color a brigit almost metallic black; showing somewhat of the green sheen in upper part rear throat; under-color black or dark slate.

Defects. Smutty black plumage; wedge shape from insufficient prominence of its quarters; too flat in front of wing fronts; too light under-color; gray streaking the feather and near the quills, approaching white. For these cut onehalf to one and one-half points, extending to two points for defective color before condemning the specimen.

\section{BODY AND FLUFF.}

Keel bone carried only moderately Iow; sides fairly oval in their lines to keel; keel bone straight, with keel muscle well developed and firm to touch; plumage close and clinging to body and thighs more than in other Asiatics, thus leaving lower extremities of thighs and hocks in profile below body line; in color, a coal black, with dark slate or black in the undercolor. The fluff proper, but fairly developed, being in harmony with a clcse clinging plumage elsewhere; the color black.

Defects. Keel so crooked as to affect the general shape; shrunken keel muscle; too light, or light gray undercolcr. For these cut one-half to one point each.

Positive white under-color and yellow skin in any part must deprive them of a score card record or prizes in exhibitions.

\section{WINGS.}

Close and smoothly folded, with fronts reaching well to fore part of breast and points well into fluff; rose fairly well cupped; in color, black with a rich green sheen in rose, coverts and bay.

Defects. Loosely folded; bronze bars across feathers; dead or smutty black in color; bluish gray spots in primaries or secondaries. For these cut one-half to one and onehalf, as in degree, carrying the cuts for gray spots to two points before disqualifying for color.

For red, white or mixed gold and black in plumage, or for primaries folded outside of secondaries, condemn and withhold score card record.
TAIL

Fountain shape (a technical term in this connection), it being large, carried prominently upright with the sickles; lesser sickles and large coverts exceedingly long and ribbon like; tail proper length, closely combed, spread laterally at a little less angle than the capital Ietter A. Coverts, termed side hangers by some English breeders, profuse and long; they with sickles completely enveloping the tail and hanging three to seven inches at the rear of tail proper. Upper tail ïurnishings all flowing; plumage being a rich

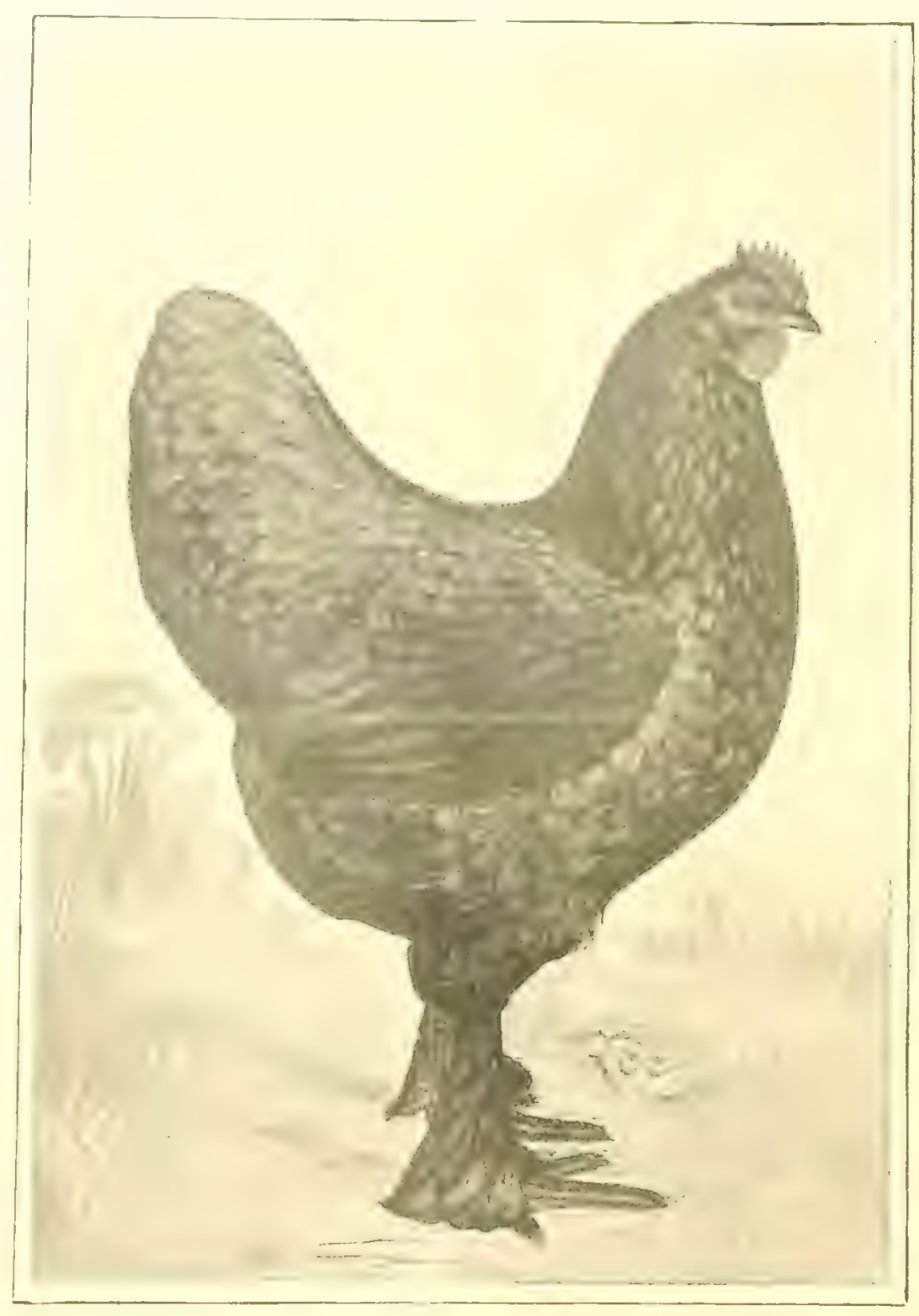

Idea! Black Iangshan Female. Inustrated by the Late Artist I.ee, nuder the Direction of J. K. Felch.

green sheen over black; tail proper coal black; under-color of coverts black or slate; the highest point of tail being on the level with the eye, or cromn of head.

Defects. Carriage, squirrel or drooping to the other extreme; short and Cochin-like in character; tail proper carried wide like the Brahma; side hangers failing to cover tail proper; bronze bars across the feathers; want of green sheen: gray or slate tips to tail proper. Cut one-half to one and one-half poiuts for these as in degree developed; with even two points for small Cochin character or bluish gray 
tips in tail proper: cutting one-half to two and one-half for carriage between upright and full squirrel position of same.

Positive white beyond that allowed in all black plumase, to condemn a score card record.

\section{SHANKS AND FEET.}

Lower thighs and shanks long, but not crane-like; the former clothed in coal black clinging plumage curved close about the hock, having the line in perfect profile below the lower body line. Shanks well feathered down the outside, mon and covering the feet to the web and covering full length of outer toes; the present demand being for plumage to grow upon onter toe to the tip joint. Scales and skin a blue black, showing pink shadings or violet between scales ani in web of feet. Toes medium in length, straight and well spread. Bottoms of feet flesh color or having a pink shaile to same

Defects. Insufficient shank and foot plumage; knees turned in at hock; shanks faded to a willow color, or very short in bone. For these cut one-half to one and one-half noints.

Yellow botfoms to feet; outer toe not feathered to tip joint, if not completely covered by shank plumage; nositive knoek knees. Paszall such as unworthy of prizes or score card record.

Outer toes if feathered beyond the web, balance be completely covered by shank plumage, surely should not be cut beyond one point and should save the otherwise worthy specimen from disqualification. Feathering of middle toe is and should be immaterial and of no value in a score card record. It is folly to make feathering of middle toe a defect, when if nature were to give us all outer toes feathered to tip joint, she would feather all of seventy per cent of the midnle toes. It is folly to punish nature for that which follows her fulfilment of our desires.

\section{THE FEMALE}

The remarks for weight and condition are fully met under the deseription for the male.

\section{COMB.}

In the female, medium size: fine in texture (but it is a fact that nature has furmished them rather large and thin at the base, which makes it hard to secule a majority in an upright position and straight upon the head). The smaller we can secure them, the better, serrated into the regulation five points, so graduated as to make the center one the largest, all being a rich scarlet color.

Defects. Too large and thin, twisted or lopped; corrugated along the sides. Fol these cut one-half to one and one-half points. Side sprigs cut one point for each. We do not believe in disquaîfying for lopped combs in females of this breed.

\section{HEAD}

Apparently carried more prominently forward than in the male. Skull medium in width and long. Face less deep, giving less surface of red in proportion than the male. Eyes large, in color dark brown or hazel. Beak medium in Jength, evenly arched to point, being fairly stout at juncture with skull. Color, black or dark horn color, so-called. Earlobes medium in size and development with wattles clearly defined, but rounded close up to lobes, both scarlet red in color.

Defects. Narrow in skull; pale or light colore.1 eyes; elongated beak, the same too straight; depressed in front of eyes; white in earlobes. For these cut one-half to one and one-half as in degree. We think, however, that white appearing to any extent or beaks crossed, shouid class the specimen as unworthy and withhold the score card.

\section{NECK.}

Apparently long; the arch being rather a moderate curve from head to cape. Plumage not especially fill, but long in feathers, which cover completely the cape. Surface color a hard metallic black, but lustrous in a green sheen in lower portion; under-color being black or a very dark slaie.

Defects. Neck short; lack of green sheen; failure of plumage to cover cape; under-color too light, approaching gray. For these cut one-half to a full point for each. White in under-color should debar the specimen from winning and score card should be withheld.

\section{BACK}

Back proper, short; cape flat and medium widtn; the plumage flowing from cape to high upon tail; so near straight is the concave line as to appear more of an inclined plane in outline in our best specimens; the feathers at extreme rear of saddle, with the tail coverts, curve downward. Color, black at cape, shading into a green sheen or metallic lustre toward tail and back of thighs; under-color black, shading to slate color.

Defects. Conrexed or marked in a deep concave line from cape to tail coverts; plumage short and straight; want of the green sheen; bronze bars across feathers; dull black throughout; nnder-color approaching gray. Each of which are to be cut one-half to one full point. For crooked shell bone slipped hips, under-color reaching positive white, or positive white in web of feather deprive specimen of seore card or prizes.

\section{BREAST}

Jong in its sween from throat to point of keel; quarter, medium full; color a deep black, with under-color black.

Defects. Dull or sooty black surface color; flat across from wing to wing; decided wedge shape from dapressed quarters; under-color approaching gray. Cut one-half to one point for each. White in under-color, when found, should condemn specimen as unworthy.

\section{BODY AND FLUFF,}

Keel bone curved low, with full keel muscles; from forward part of keel to thigh a slight concave line; plumage smooth and clinging, leaving hock in profile; fluff but fairly developed so as to give a slight oblong appearance to body structure; color of all, coal black; under-color black or dark slate.

Defects. Dull sooty black plumage, falling down of abdomen; crnoked keel bone, so marked as to mar lower line of hody structure; too light in under-color. For these onehaif to one and one-half points, is the usual cut. Positive white in under-color or yellow shin in any part of body should condemn the specimen as unworthy a score card record.

\section{WINGS.}

I arge in an Asiatic sense: the rose well cupped to give apparent roundness to sides; fronts buried in breast plumage quite near the front, with the points well buried between sadale hangers and fluff; color, fronts, primaries, upper web of secondaries a coal black; rose, coverts and bay a rich green over black.

Defects. Flat in the rose; not folded smoothly; wanting in the green sheen; slaty spots in primaries and secondaries: bronze bars in surface plumage. For these make a 
cut of one-half to even two points before condemning them as unworthy. Primaries folded outside of secondaries; white, red or mixed yellow and red color in any part of plumage; refuse score card record or prizes to such.

\section{TAIL.}

Large; carried upright; tail proper, spread laterally at a less angle than the letter $\mathbf{A}$, but combed closely so as to admit of lower two-thirds becoming enveloped by the upper tail furnishings, as they meet the curly plumage under the tail, only the tips of the three or four top feathers appearing beyond the coverlets: these with lesser coverts hanging curved in symmetrical shape downward: tail proper a coal black, furnishings and coverts a green sheen over black.

Defects. Fan-shaped like a Brabma; coverlets short. not reaching beyond lower portion of tail proper; wint of green sheen on the furnishings and coverlets; bronze bars in surface plumage: pointed or drooping carriage, like Cochin; dull sooty black in color; slaty gray tips or spots in tail proper. For these cut one-half to one and one-half points; cutting one-half to two and one-half points for carriage between the proper upright position and full squirrel character. Those having white at base of tail or in undercolor of coverlets, pass as unworthy of score card record.

\section{LOWER THIGH. SHANKS AND TOES.}

Lower thigh and hock well below body line, the former closely feathered in coal black plumage that curls close abo"t the hock joint, thus preserving hock in profile; the shank medium long and feathered down the outside, the fcathers blending with a foot plumage sufficiently profuse to completely cover the outer toe and growing on the same to the tip joint; feathering of middle toe immaterial and of no value in score carci application of the standard; shanks straight and parallel, with leaden blue or black scale, with pinkish violet or flesh color in soft parts between scales and inside of shanks; bottom of feet flesh colored, so-called; free from yellow skin in any part.

Defects. For shanks turned inward at hock at a less angle than positive deformity, shanks and outer toe scantily feathered, cut one-half to one and one-half points, cutting one full point for each crooked toe. Shanks short, with hocks not in profile below body line, one-half to a full point; for positive knock knees, pronounced deformed feet, or yellow in scale or skin. pass the specimen as unworthy of score card record.

\section{COMMENT}

There are characteristics of color that need a more extended consideration than is usually given in our standard descriptions of the breeds and condensed formulas of shape and color supposed to be sufficient for score card judging. We have in this essay endeavored to cover all that is necessary to make the work a fair standard. But there is a tendency in this broed, as in all breeds of a metallic black plumage, to show fights and secondaries and tail proper with slaty, sheeny spots, and tips of feathers lacking in the intense black of the general plumage. But these spots are a long way from being white or gray. While these are defects to deal with, the judges should first place such tips upon the white back of his score card, when he will be surprised to see that they are nearly black. Even the reflection of light on a highly sheened plumage will produce a white appearance, which is snmetimes deceptive. These spots I speak of placed upon the metallic black of their own plumage look almost white, but this all disappears when laid upon a white surface.

I am aware of the influence of the grave error we made in the first standard when we made white, appearing when laid upon a black surface, a disqualification. But that has long since been abolished and all disqualifications administered in the spirit of giving the specimen the benefit of the doubt. If to disqualify jars upon your sense of justice, you surely are not giving the specimen the benefit of your judgment; but bear in mind that this clause in our standard was put there to save almost perfect specimens from disqualification, not to save poor, unworthy specimens for the sake of giving them a score card record. White, red, red and yeliow, mixed feathers, then must show beyond the presence of a singic feather. There must be a reasonable conviction of taint in blood that would transmit the evil indicated. The mere fact of one isolated, small, single white feather other than in what is called the quill plumage, is not sufficient nor just cause to disqualify. To so severely punish such minute defec's is better justice than to condemn the specimens.

The comb of females of this breed, because of the thin skin and fine texture, is seriously affected by the heat of the show room; also by the approach of laying. They easily, from these causes, lop or fold; thus does this breed suffer more than other breeds with single combs. The appreciation of their merit as egg producers, the practical work they accomplish for us out of the show season, should cause the judge to be alert and lenient as possible in applying the general laws governing our exhibitions. To be cut for these defects a reasonable amount is all the females of this breed can stand in justice.

\section{THE MATING OF THE LANGSHAN.}

To mate them seems an easy matter, by first discarding all hens scoring less than ninety and all pullets scoring less than ninety-two and one-half and reserving no male under ninety-two points. This any breeder can well afford to do. Then divide the birds reserved for breeding into two flocks: the one rich in green sheen, the other of metallic black with little or no green.

We are ready to again divide each division into the largest and longest in bone structure, and those smallest and shortest in the joints, selecting their male mates from the opposite of these conditions, using no male not strictly firstclass in shape. It would be folly to use those of poor shape even to secure good color.

Pen No.1 should always be mated in any breed to produce the best results from the male line of ancestry, and when the breeder is to rely solely upon his own yard, the male should be the best both in shape and color and as near to our pen picture as possible.

To him we would mate an even shade of pure black plumed femaies: not showing the green sheen in a very marked degree; being absolutely free from bronze bars in the feathers. The specimens being large in size and weight; neck, thighs, shanks such as to make them look large and commanding in appearance, but roid of anything of a crane like appearance.

Pen No. 2. For this a male tall, commanding. with full flowing fountain tail; plumage black. with a reasonable amount of the green sheen in lower hackle, rose and bay of wing and in tail coverts; well plumed shanks and leet.

The fomales having all the green sheen possible, while selecting medium length of neck, back, tail and shanks and of full weight as recommended in our Standard; with full inclined plane of back to tail.

Pen No. 3. Male very large, with full length of joinis: hocks well below body line. with heavy green sheen to plumage.

To him mate females the shortest in neck, back, shanks and tail of our second division; coal black. with absence of sheen. 
Pen No. 4. Male very large, full fountain tail; heaviest in weight: netallic black, but not heavy in green over-color.

The females shortest in joints, but having intense green sheen. In all our mating we, of course, have considered only the first selected for mating, all being strictly first-class specimens. Each pen so selected as to be even in shape and color: having been so selected to secture a uniform lot in the mogeny.

\section{THE TREATMENT}

There is no race of fowls that needs more to be kept from the direct scorching rays of the sun, which does more to bar the plumage with those objectionable purple or bronze bars, than all else they are subjected to. One need not be much of an observer to see that early hatched chicks that get their adult coats during the heat of our harvest sun and those confined in shadeless yards, are more severely tarnished by these objectionable bars. This should influence you to secure for them all the shade possible during August and September, especially when the last coat of feathers are in their pin feaiher state.

These bars never appear upon birds with a dull or smutty colored plumage, but who considers such as firstclass Langshan color? All the nse I see for such color is a secondary one, i. e., mating a few very large, strong bens of this color to males of intense sheeny character, even if somewhat barred with bronze, that have become thus colored by the mating of both sexes highly colored. Then to breed a set of his pullets of first-class color back to him, when as a cock and having lost ihe bar, he has molted into perfect form as a cock. These pullets then three-fourths of his own blood, would be most likely as near perfection of color as is often seen, and many such have been produced in this manner. The male product of this first cross of the dull color had best be sacrificed as capons, or market poultry of some sort.

If there is a breed where it is especially necessary to divide the sexes at an early age, if show specimens are de. sired, it is the Langshan, and we would do this at the age of four months, lieeping the males by themselves and the females in small flocks, free from the males. As soon as the breeding season is over select your best hens, allowing them to molt in celibacy, that they may molt in quiet, and not again be put with the males until after the show season is over. When it is a fact that often a single point blankets the first three prizes of an exhibition, one sees how useless it is to exhibit a pullet or a hen with a flattened or mutilated pitumage of the saddle. Watch the growth of plumage, keeping all foul growth and broken feathers removed, in order that perfect new ones may replace them. See, too, that wings are smootbly folded, for there is not a breed so dependent upon minar details to secure for them the blue ribbon. Keep them clean, with green lawn and clean dust batis, furnshing nature's foods that are found in the following proportion: Fifteen per cent meat as found in beef scraps, dessicated fish or green cut beef bones; twenty-five per cent regetables, the best of all being green clover; sixty per cent being grain in the proportion of fifteen per cent corn-balance in oats, wheat and buckwheat.

They are prolific layers of eggs. After they reach six months of age it is hard to keep them in exhibition condition, so that May hatch chicks will generally prove the best exhibition specimens in January and males hatched a month earlier, their stronger mates. But the poulterer who cares notbing for the exhibition, and those who cater for the egg trade for hatching, will do well to mate up in large numbers, and as fast as the females become broody to allow them to incubate a sitting of eggs, for the rest will save you many a death in your breeding yards and enable you to send out larger and nicer colored eggs to your trade; which you will find will be appreciated, and besides all this the eggs will batch nicer and stronger chicks for it.

The difference in lime to break them up or set and allow them to bring up a clutch of chicks will not be over two weeks; for they invariably go to laying when chicks are two weeks old. It is nature's rest, after which they lay a larger litter of larger eggs than if broken up to secure a second litter before allowing them to sit. I. K. FELCH. 


\title{
BLACK LANGSHANS.
}

Early Ideals and Recent Improvement-Commendable Laying and Market Qualities-Breeding for Color and Shape-Toe Feathering and Standard Weights-Preparing for Exhibition.

\author{
BY JoHN HeTTICH.
}

$\prod^{30}$

THE question of "What do you know of the origin and history of the Black Langshans?" there is little to be said, since we are convinced that it is a distinct breed and not a variety made by crossing a number of other breeds as are many of the varieties we have to-day

The first accounc we had of the Langshan was in 1872, when an English army orficer stationed in the northern part of China sent home some of these fowls to his uncle, Major Croad, of Birmingham, England. The first report of their exhibition was in connection with the Crystal Palace show in the winter of that same year, when they came in competition with the then more popular Black Cochins and were described by the Cochin breeders of that day as nothing more than poor Cochins.

The first Langshan club was started in England in 1877, and the first importation to America was in the same year. While this most excellent variety met with all kinds of prejudiced opposition in those earlier days, more so in England than in America, yet it was not long before their many good qualities became known.

Major Croad, no doubt, improved them very much from the time the first ones were received by him up to the time of their first importation to this country, and the Langshan in America to-day is a great improvement over its ancestors, so much so that they hardly resemble the first importation if we may judge from the illustrations made of them by the best poultry artists of their day. I saw an illustration some time ago made by the late B. N. Pierce in 1882 of a pair of Black Langshans belonging to Fred Greensland, of Highland Fark, Ill. of course they represented an ideal pair at that time, but I am sure that at the last show at which Judge Pierce made the awards on the Langshan class he did not judge them by that ideal illustration. Nor did his son "Mac" judge the big class of Langshans at the late Chicago show by his father's ideal of the first American Langshans. Another early illustration that I saw was drawn in 1880 by Ludlow from an imported pair. No doubt that was a fine pair of birds at that time. There is but little difference in these two dramings in either style or carriage, which shows that the Langshans of that time were of a uniform style, but very different from the Langshan we have to-day.

\section{LANGSHANS AS LAYERS}

In an old article that I read some time ago it said: "Aftel" the appearance of the Langshan at Birmingham a local paper stated that its only good quality was that of being a good layer. Another publication said: 'One of the judges was heard to say that the Langshan was a good table fowl. but fit for nothing else.' " The former was right as to their laying qualilies, the latter as to its good table qualities, but both wrong in saying that they were fit for nothing else. for they possess both of these good qualities and many mole.

As egg producers the Langshans unquestionably take. front rank. They will lay just as many eggs the whole year round as any breed, except perhaps Leghorns and Minorcas, and in winter when egys are scarcest and command the highest prices they will lay proportionately more. This proposition has never been successfully contradicted. MI earliest puliets nearly always begin to lay by October 1st, and many a promising exhibition pullet has gone back on my expectations on account of her laying just a little too early for my purpose.

I mated my yards for last season in January; I began filling orders for eggs for hatching in February. Nearly every pullet was laying when I made my mating, four yards of ten females each. Up to April 10th I had only four hens broody, and had I depended on sitting hens from my own yards for my early hatches I would not have had many early chicks, but thanks to the invention of the incubator, I do not depend upon the hens. I have in my yards two yearling hens that were laying some time before I put them in my breeding pens and they have laid continualiy up io this time-April 10th.

\section{LANGSHANS ASS MARKET FOWLS.}

While I do not raise Langshans for market, but strictly for the fancy, yet I market a few every fall after carefully culling the flock, and they always bring the very lighest price that is paid for market pouitry at that season. There is no better table fowl than a Langshan, especially when it is fully matured. The flesh is white, very fine grained, tender and juicy. The skin is a clear white, not a dark bluish white, but creamy white. The chief objection offered against a Black Langshan is, as 1 said before, their colorthey are black. It is said they are hard to pick and show pin feathers, but I am sure no one that has ever dressed a pure-bred Langshan will raise such an objection. The Langshans are a rather loose feathered fowl, unlike the short and close feathered Black Leghorn, Minorea, of Black Spanish, and they are for this reason more easily picked, and show fer pin feathers.

It is not adrisable to ase a cock in the breeding pon after the third year. I have always had very satisfactory results from mating a cock with pullets, and a cockerel with heas: in fact, I am convinced that this is the proper way to mate Langshans. If the pullets are fully matured then a well-matured cockerel will gire equally good results. What I mean by good results is in producing strong. vigorous chicks. During the hreeding season I was compelled in make a change ir. one of my rards, one of my cock birds having contracterl something like chicken pox. I put in his place a big full grown cockerel and the chicks hatched from that mating are as big and strong as any I have ever seen. 


\section{BREEDING FOR COLOR.}

In breeding Black Langshans for the show room I find more difficulty in getting them free from purple barring in plumage than from any other defecr, yet I find that in mating a rich greenish colored male with a dark slate under-color, to a female equally rich in color, I get nearly all good colored birds. I believe that when the parent stock is full of purple the offspring will be the same. I am not a believer in the theory that the sun or dry winds produce the purple barring. While it may affect the surface color by turning it brown or rusty, yet I have had some very fine colored Langshans that were as free from purple barring as they grow run out in the hot sun the entire season and they never had their color affected in the least.

One thing almost convinces me that the hot sun does not cause this purple barring in the plumage. It is a case of a bird that won first at the Northeast Missouri Show. This bird was from a sitting of eggs that I gave to a friend late in the season of 1900 . Several cockerels were hatched

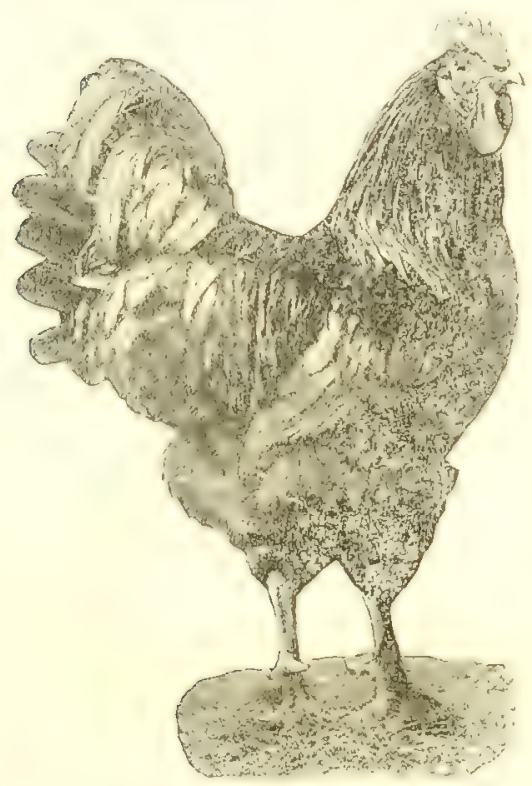
from the sitting, but the bird in ouestion was always the besi in every way except in color, which was almost as bad as conld be, and he was sold with a lot of mixed stock as common poultry to a second party. The latter part of last summer when passing by the place where the cockerel was, I jokingly remarked that I would give fifty cents for him. A few days later the neighbor came to see me with the bird, saying, "Here is your rooster; give me the fifty cents." The bird had been allowed to rough it and had had no care whatever; had been running out in the burning hot sun, and yet he molted out as good in color and as nearly free from purple as any cock bird I have ever seen. He scored $941 / 2$, by Hewes, after receiving an extra cut for a slightly frosted comb. I have always been able to produce some extra good colored Langshans. Not all of them, liowever, are good in color and free from purpie, but if the hot dry winds were the cause of so much purple barring in Langshans, why shonld it not affect all alike under the same conditions:?

Three years ago I raised exceptionally good colored Langshans, but among them were some that were as full of purple as they couid be. That winter I exhibited three cockerels and a number of pullets at the Missouri State Shuw, one of each sex being passed by Russell, with only one-half point cut on color, and I found him none too easy to please, as he is a pretty good cutter. These good colored birls were raised in the same yards and under the same care and conditions that those were that had purple bars.

I find that the color of Langshans has been very much improved since I first began breeding them, and especially since the revision of the last standard, which at first fixed the punishment for purple in any section at one point, but which was afterwalds changed to read from one-half :o one point. There is no other defect that puts a Langshan out of competition in the show room as quickly as bad color or purple barring, and many an otherwise common bird has won a place simply on color. In breeding for color I am convinced that the male exercises the greater influence.

White feathers in plumage of Black Langshans I have always contended should disqualify, except where it appears in toe feathering. I watch this very closely and find that it does not accompany the best or most brilliant colored plumage, but on the contrary I find that most of it appears in my poorest colored (the purple barred or the dull rusty blach) birds. These show more white and nearly always have white or gray tips on wing flights.

Many an otherwise good specimen, having a little white in some part of the plumage, which under the old standa:d would have been discarded, is now put into the breed.ng pen and the result is a lot of Langshans with white-tipped feachers. It was Judge Wale, by the way, one of the best Langshan judges in America, who said that the oniy way to get rid of white in plumage was not to breed it. 1 mention Judge Wale lrecause from him I received my first instructions in breeding Langshans and his lessons have done me a great deal of good. I have all always will have for him a kindly feeling.

I enjoy telling of my first experience with the judge. When I began breeding Langshans, I started with what I thought were some fairly good hens bought in this country, and a ten dollar cocherei, bought of a New Yoris siate breeder. Late that fall Judge Wale came to my place to score my birds and pick some winners for a show in the adjoining county. I had them all up and banded, expecting at least 125 out of the 150 I had would show scores of 95 eacls. The first ten or fifteen that the judge picked up went ont of the window. I asked him what was the matter with them and why he lid not score them. "Didn't you see those white feathers:" he asked. Then he found a pullet that he considered very good. She had no white tips and good under-color, and then some more went out of the window, and when he got through I had just thirteen scored birds out of my one hundred and fifty. I was a pretty sick enthusiast. Had my ten dollar cockerel and my good looking hens been free from white in plumage I would not have had one-tenth of the white-tipped feathers. I asked Judge Wale if it would be wrong to pull out the white feathers (I was younger then), and he was honest and said yes. Since then I bave asked other judges the same question and they always smile. I will never forget my first lesson on Langshans, nor my teacher.

I do believe that in breeding for dark under-color, and the brilliant greenish surface color, we often get red feathers in hackle or in back or on butt of wings. I have never seen a red feather in a very dull or purple bird, but always in the most brilliant plumage, and always in the males. I have never seen a pullet with a red feather. Last season I discoverea two red feathers in the back of what I regarded a very promising cockerel. I sold a sitting of eggs from the yard he was in to a breeder in this locality and he has now out of that hatch as fine styled, big Langshan cockerei as one could wish to see. If he had not a few red feathers he would be worth $\$ 15$ to anybody for a breeder. These red feathered cockerels were sired by one of the best colored birds I ever saw; a brilliant green bird, scoring $951 / 2$ by Hewes, and receiving a cut of only one-half point on color of plumage. Several years ago I purchased the first prize cockerel at the Mid-Continental show of Kansas City. That cockerel received the highest score of any Langshan male I ever saw or heard of -97 points by Wale, who was one of the judges at this show. He did not get a single cut on color. 
He had dark slate under-color, very rich brilliant surface, and not a trace o: purple anywhere. About three weeks after I had him I discovered two reddish feathers cropping out in the hackle. These feathers had black centers with reddish lacing and in a certain light the defective color was not noticeable. I used him as a breeder that season, and got five cockerels that showed red in hackle and wing at maturity: most of the others possessed extra good rich color; one of them in particular winning first at Missouri State Show that winter, being cut only one-half point in color, by Russell.

\section{BREEDING FOR SHAPE}

As to shape in males, I find that after we have them up on the right kind of legs, which should be rather long, especially in thigh, the hardest sections to breed to perfection are the back and tail. To get medium length of back, broad at shoulders, curving gradually upwards from the middle to the root of tail, with abundant saddle feathers, and what is called a fan-skape or well spread tail rising upward from its junction with back so as not to form a break at this point (and not carried perpendicularly, approaching the squirrel tail), is not easy, even though we use a male with an almosc perfect back and tail shape. I have always selected the very best shaped male birds in these two sections and yet I get lots of straight backed, narrow, pinched tail cockerels. I am undecided whether the male or the female has the most influence in producing good back and tails on cockerels.

The cornb of the Langshan has proved with me the easiest: section to get; for when I use a male bird with a good comb, I have few cockerels with bad combs, and the same is true with females.

\section{STANDARD WEIGHTS.}

I have but little trouble in getting my Langshans up to standard size, especially in hens, cockerels and pullets, and I consider the weights as fixed by the standard about right. I noticed some time ago that Judge Russell recommended the raising of the weights one-half pound on hen, pullet and cockerel. I oppose this, for while we can bring them up to their weights and lots of them over, yet there are many that never come up to weight. It is difficult to bring the cocks up to the standard weight of ten pounds. Of course lots of them come up to it, and some of them go over that weight. I have one now that weighs eleven and one-half pounds, another ten and one-half, and yet I am satisfied that there are more Langshan cocks that weigh nine and nine and onehalf pounds than there are cocks of ten pounds weight. At a recent Kansas City show there were ten cocks in competition; most of these weighed less than ten pounds, and some of them were disqualified on weight. Most associations are very lenient on weight, allowing one-fourth to one-half pound on each birds; this allows many under-weight cocks to come into competition. The same number of cocks were on exhibition at the late Chicago show, and some of the winners were not up to standard weight, yet some of the exhibitors claim that their cocks weighed twelve and thirteen pounds.

\section{PREPARING FOR THE SHOW}

Black Jangshans are one of the most attractive show fowls, and $I$ experience little trouble in preparing them for the show or getting them in good show condition; in fact, about all a good specimen needs is to be kept clean and in good health. They require no washing except their legs and toes, which should be cleansed with soap and water, and afterward rubbed with oil. The face, beak and comb should receive similar attention. Cockerels will remain in better show condition if kept in roomy quarters, or given an outsido run. They seldom do well in very close confinement (that is, in small coops) and will not take on flesh. Hens and pullets I prefer to keep in a light roomy house with a plank floor, covered lightly with clean chaff or short cut straw, as it is easier to keep their toe feathering in good condition if they are kept on plank floors. Seratching in hard or long straw always breaks the toe feathers.

Heavy outer toe feathering is one of the points Langshar breeders are striving for, and I believe with Judge Felch that slight middle toe feathering is no serious objection, as it is only an accompaniment of heavy outside toe feathering. I have never seen a Langshan disqualified on toe featheringthatshowerl sligh t midcle toe feathering, but many perfectly clean middle toe birds have I seen that were very shy, or almost free from onter toe feathering. A nise straight, clean micidle toe is a fancy point and very desirable; I like to have them, but I never discount an otherwise good bird with few feathers on middie toe. I purchased the first prize hen at the late $\mathrm{Chicago}$ show, a fine Langshan female with a periectly clean middle toe. She is well

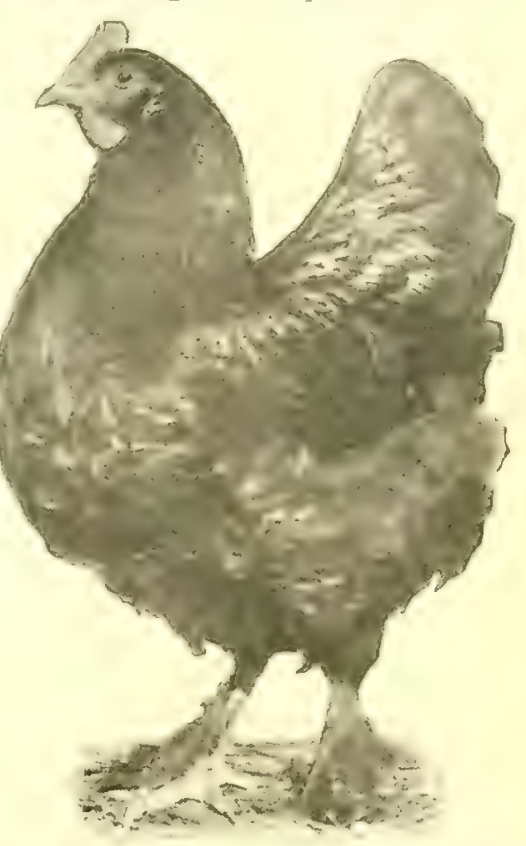
feachered on shanks First Prize Black Langshan Pullet at Southeast and upper part of Missouri Show; also Eirst as Ilen at St. toe, but almost bare at the extremities, or from the last joint downward. This hen I am satisfied would if mated to a cockerel also shy on toe feathering produce lots of bare outside toed youngsters, but mated as $I$ have her, to a cockerel heavily feathered, with a few feathers in middle toe, I look for a well feathered lot of Langshans from her.

Langshans have grown more popular each year since I have been breeding them. Farmers are taking them up as an all purpose fowl. They are learning their good quali $y$ as a table fowl. The prejudice that has existed against them on account of color is passing away. Their extra good laying qualities are now well established and their attract:veness as show fowls proven by the extra big classes at the breeding shows last winter. The big demand for them, the sales of boih stock and eggs by all the Langshan breeders of my acquaintance, the big prices paid for good birds as breeders, and the high prices received by the ieading breeders of this variety for eggs for hatching are proof enough that the meritcricus Langshan is one of the popular var:eties of the clay, and still coming. JOHN HETTICH. 


\title{
THE CARE AND MATING OF BLACK LANGSHANS.
}

Their Value for Market Proved-A Novel Stock House-White in Plumage Considered Less Dangerous Than Purple Barring-Shape Deserves Close Attention.

\author{
IFY I. A. KILINE.
}

$\pi$ AM smiprised at times to note the unreasoning projudice that exists among some people against black fowls. I have seen it rery effectively overcome in numerous instances, by a taste of a well cooked Black Langshan. Among the so-called general purpose fowls, there are noce with finer grained or better flavored meat than the Laugshan, and I believe there are nove so good. The resemblance to turkey in flavor is unmistakable, and is often noticed and remarked by those who have tasted this breed of fowl for the first time. They dress rely plump and nice, with rather more breast meat than the average. A few years ago I got an incubator and experimented a short time with raising broilers. Not having enough eggs of my ofm to fill the machine, I got some Bared Plymouth Rock eggs from a neighbor. In this way I had an opportunity to observe their comparative growth. The Langshans kept pace with the Rocks in feathering and development. I sold the bunch on the Chicago market, and they brought top price, netting me twenty-four cents per pound. No objection was made on account of color, and I have never heard such an objection urged by a poultry dealer, unless he happened to be a fancier of another breed. 'They mature earlier than the other Asiatics. I find that many people are misinformed on this point, and are laboring under the mistaken belief that they develop very slowly, when, as a matter of fact, they mature as quickly as the Rocks or Wyandottes. A large part of my flock last year was hatched during the month of May, but a great many of them were up to weight by December 1st. As a rule, the chicks feather quickly, and, unlike the other Asiatics, are seldom troubled by a lack of feathers. A chick that is bare for weeks at a time is a rarity, and for linat reason I have never bothered myself about the cause of the trouble or its possible prevention and cure. The chicks are strong and hardy and where given free range, will bear all the food they will eat, without developing any trace of leg weakness. I start my chicks either with a good brand of chick food, or with bread crumbs and rolled oats, later on giving them corn bread and whole wheat, and finishing off with oats, corn (preferably new corn) and milk if I have it. I have always regarded leg weakness, as a result of lack of exercise coupled with a forcing ration. I suppose it might develop in the Langshan chicks if too closely confined and fed high, but on a good range it will never bother and a fair range is conduclve to good growth and development.

HOUSING

The matter of housing is an important one with any breed of fowls, especially in a northern climate where winter eggs are much desired and hard to get. I am more and more of the opinion that a house with too much glass is worse than one with no glass. My first venture in my present location was a shed roof house with plenty of glass on the south. Walk into it on a sunny winter day, and it was as comfortably warm as a room in the house. But when the sun left the glass, it cooled quickly, and the sud. den change was injurious to the fowls, resulting in a decrease in the egg yield. And then, in summer, although I took the windows out, it always seemed stiflingly warm. After a few years' experience with this kind of a house, I tore it down and built a two-story octagon house, with seven small windows downstairs and four upstairs. The lower floor is partitioned with poultry netting, and the arrangement of the windows gives each pen the benefit of some sunshine during the day, and at the same time the temperature inside is not raised so much above normal as it was in the old house, avoiding sudden extremes of temperature. The result has been an increased egg yield. The upper story is used for exhibition coops, and during the winter for surplus cockerels.

Langshans should have low roosts. Heavy hens are often injured by flying from high roosts. A little experience with egg eaters, has made me an ardent admirer of the darkened nest. I am satisfied that it is the only sure preventive, as well as the best cure for this most discouraging habit.

\section{MATING.}

In mating Langshans, early in the season, one male to five or six females is enough, but later on, when fowls have free range, I believe ten to twelve females will give better results. As a rule, I mate cocks with pullets and cockerels with hens, believing that more vigorous chicks are secured in this way. Of course, there may be individual cases where a certain result is to be obtained, where the rule can not be followed. As the general outline of both male and female is the same, and the color the same, I can see no advantage to be gained by a double mating system. If both male and female approximate closely in type to the ideal, the progeny will be as nearly as possible the correct shape.

$$
\text { COLOR. }
$$

The question of color is another thing, and is no doubt the hardest problem with which the Langshan specialist has to grapple. Experience seems to prove it an evanescent quantity, perhaps all right this year and all wrong the next. It is very evident that we do not thoroughly understand the laws which govern it, and I have myself had one or two pet theories upset.

Some writers upon this subject advocate making white in any section a disqualification. At first blush this might appear to be a reasonable proposition, but a long experience in the breeding of Black Langshans leads me to believe it would be a mistake, I will tell you why.

I have an old hen in my yards that is at least eight years old-perhaps nine. I am keeping her in the first place as a sort of curiosity, and also because she has been exceedingly useful in her day, having produced many fine chicks and having been a first prize winner at one show and a second at another. She has passed under the hands of such judges as Hewes and Shellabarger and never showed a white feather, nor did I ever pluck a feather from her. Judge 
then of my astonishment the other day on picking ker up to find one wing full of white feathers. I suppose some one will say that this is the result of old age. But, listen. I have also frequentIy had an experience like the following: A pullet wouid score well, showing no white feathers, and at the next molt would bob up with enough white feathers to disqualify. White feathers may also appear in places where the skin has been torn or otherwise injured. I have a friend who breeds Black Minorcas, and he has had the same experience. He says he often finds hens with white feathers enough to disqualify; which passed all right as pullets. No doubt breeders of other black fowls could recount instances of a similar character. Of course I have always discarded specimens which showed enough white feathers to disqualify, so have had no experience which would enable me to determine whether the converse of the above is true viz.: That birds having white feathers would be likely, at the next molt, to replace them with clear, black feathers, but I believe that it is likely to occur, and I mean to test it in the near future. Black and white seem to be very closely correlated, and if the theory I have developed from $\mathrm{my}$ observations thus far is correct, the white in the plumage of a black fowl is a variable quantity, liable to become either more or less abundant at each succeeding molt. Your disqualified fowl of this season may become your prize winner of next season, and vice versa. This, too, without any feather' pulling.

Perhaps we Langshan breeders have made a mistake in discarding all specimens showing white in plumage. Perbaps it would be a still greater mistake to make the disqualifications in this direction any more stringent than they are at present. I think it will be found very often that a specimen showing a few white tips will have more of the desired green sheen and less of the purple than those specimens which are strictly free from white. These questions are all worthy of more careful thought and study on the part of Black Langshan breeders, and if many will unite in the effort, their united testimony would soon establish a rule which would be far superior to any man's opinion as a safe guide to follow in breeding. Personally, I should still hesitate to breed from a bird having white feathers, but I feel safe in yredicting that with increasing study, this fault will be considered less of a disqualification than it is at present.

The question of white in feathers is not so serious as purple barring. At times the green sheen seems to be decidedly elusire. When the careful breeder thinks be has the purple almost eliminated, it crops out in the most unexpected place. It is almost certain that it is a case of atavism, aggravated in some instances by lice, improper food, and lack of shade and pure water, and it is equally certain that the utmost care in breeding will not entirely prevent it, although encouraging progress has been made. A prominent judge told me not long since, that a friend of his who has long been a breeder of Langshans, had the finest colored birds one season that he ever saw. He thought he had the color question forever settled. The next year he mated his yards with the best of his green birds, conttuently expecting the best birds he ever raised, but to his astonishment and intense disgust, the purple barring was as much in evidence as ever. The same judge said that some breeders believed that mating a finely colored male bird to a dull or dead black female, would produce the finest green specimens. I give the opinion for what it is worth, not having had an opportunity yet to tesi it. I have been inclined to believe that a little white in plumage was accompanied by a more brilliant green sheen, having seen a number of specimeas in which this was the case, and yet I know that it is not always so. I do know, positively, that white will often appear after a molt in a specimen which before was free from it, and I am persuaded that the reverse :s often the case. This subject is worthy of all the study that Langshan breeders can give it. 
SHAPE.

One of the chief difficulties in breeding to standard shape is to get the back and tail shape correct. I feel certain that many breeders and some judges, have laid too much stress on color: and too little on sbape. Glance at the cut of an ideal Langshan, and then compare it with some of the photographs of 95 and 96 point birds which appear in the pouitry papers from time to time. I maintain that frequently birds are given high scores merely on the strength of size and color, which ought never to pose as Langshans. This is confusing to the novice, and opens the way for a large degree of carelessness in his selection of next year's breeders. It also results in keeping a large percentage of the Langshans throughout the country below the average in shape. The ideal gives us a short, broad back in both male and fomale, with a long fountain tail in the male, and a decidedily long tail in the female, carried well up in both. But the cuts of winners, too, frequently exhibit a long back, with a decidediy short tail, carried low down. Making all due allowance for difficulty in posing, etc., it would still seem that in a great many instances, the punishment for bad shape has been too light.

L. A. KLINE.

President American Langshan Club.

\title{
BLACK LANGSHANS TO DATE.
}

\author{
Twenty-five Years' Breeding Has Not Changed the Breed Type-Generous Producers of Fine Grain \\ Meat and Dark Brown Eggs-Fineness a Distinctive Quality \\ of the Langshan.
}

By Frankiane L. SEWELL.

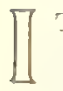
TRUST that I shall not in any way discourage the lovers of some of our modern styles of fowls by telling them tinat one of the strongest reasons for the Langshan's value as an economic fowl is its undisturbed type and ancient origin. The more we let the Langshan revert to its natural bent-or perhaps I should say to the type it first presented when Europeans and Americans took it up-the more profitable, vigorous and productive it becomes, both in quality of flesh and number of eggs.

You know that the reason a flock of mixed hens is more difficult to handle profitably is that there are so many different natures in the flock. What is good for the few will starve some and spoil the rest by overfeeding. The more the flock is crossed and intermixed, the more complicated the successful management of it becomes. The average farmer's flock of hens presents as many types as it contains birds. This is the reason that on free range, where they can suit themselves as to exercise, food, etc., they do passably well. But as a man regularly in the poultry business cannot handle his fowls in that way-all in one rambling flock-he must have a distinct race of fowl that will all respond productively to one method of management.

The Langshan (pure) to-day is the same type as it was twenty-five generations of birds back. It seems to have passed its "artificial selection" stage long before che English people found it. The Old English Game and the Dorking are also counted among the few races that keep reasonably to their understood type. A fancier or farmer need not spend a great amount of study on these races in selecting for fancy requirements. It is the few among them that show a turning out of the line, while with our later made varieties only the few are fit to rely on to produce their like, or better. This prepotency in the Langshan has kept its type in spite of many misinformed and misdirected matings, where the race has been alluwed to remain pure, It has been found more difficult to change the pure Langshan type in England, to follow the whims of the judges, than it is to preserve its original shape, and many breeders found it impossible to keep pace with the demands of some of their misinformed judges without resorting to a cross.
We took up the Langshan twenty years ago, because we liked their looks. People said they were hardy and productive and that they were an old established race. At that tim, we were keeping the Brown Leghorns and Plymouth Rocks. We had started when twelve years of age with Game fowls, the only pure-bred fowls then kept in our town, but after three years' enduring their quarrelsome nature we decided to keep Houdans. We liked this breed, but they did not fully satisfy us. At seventeen we learned of the Langshan, and have kept them ever since.

THEIR PRACTICAL AND FANCY CHARACTERISTICS.

The older nations that have tried all kinds of fowls and fed and prepared them in all sorts of ways to suit their appetites, require white-skin fowls. The Dorking, the Houllan, the La Fleche, all have white skins. The La Fleche has black legs, but this in France seems to make no difference in the market value of a fowl. However, it is not the color of skin that is most important in a table fowl, it is the fineness of grain, the depth and length of keel bone and succulency of flesh. In our experience the Langshan shows the smoothest skin and finest grained flesh of any fowl equal to its size. The size of carcass in a Langshan can be overdone. The quantity of the true Langshan is (and should be in all races kept for profit) on the breast, and he is proud to carry it well forward.

You will not overfatten the Langshan easily unless in very close confinement. Like the Jersey cow for cream, the Langshan turns, its food to the production of eggs that are rich in their contents. I believe they are the only white skin race of fowls producing dark brown eggs.

As to their fancy characteristics we have so often told them in word and in picture that we may be pardoned for here writing only briefly of them. The fancy points of the Langshan need not change to make them attractive, and they are already of a genuinely practical type.

I will add a few words that may prevent mistakes for those who do not understand the real Langshas. Our friend, Mr. Harrison Weir, who always stood so firmly for the Jangshan, not Iong ago wrote $\mathbf{m e}$, "A bird can be too large and too coarse to be good." Remember that, when 
thinking of the Langshan Standard and recall the most typical and productive Langshan you have seen or possessed. The best were not the greatest in size, not those stilty, close hocked, coarse boned roosters with heads for ward and tails drooping, but the deep bodied, spirited birds whose length was in the keel bone rather than in the back.

Among the worst and most common drawbacks to the Langshans seen at our shows of late has been coarseness of feather, bone and head furnishings. The Langshan wanting in fineness lacks in the qualities that set the race distinctively apart from other Asiatics.

'The col'cly-limbed, smooth-plumaged, fine-headed Langshan has often prompted commendatory remarks from expertstockbreedersvisiting the poultry shows. The long years of successive breeding stand out in the tense, nervy carriage and proud bearing. Coarse hearls, loose feather and heavy bones and clumsy action do not belong to the profitable nol the showy type of Langshan. They are the outgrowth of mongrel blood or contimuous careless breeding.

The Langshan is peculiar in its show type-carries a very large, expanded tail, profusely furnished witL flowing sickles, side hangers and covert feathers. In the Langshans the plumage in this section is sought in abundance in contrast to the short plumage sought for in the Cochins and Brañmas.

The erect carriage of this abundant plumage adds to the appearance of depth and height, especially in the rear of the bird.

The show Langshan then requires deep breast and full development of it to appear well balanced. This possession of "balance" is not too common in our show rooms. Our American fanciers, it is gratifying to observe, have never striven to select or breed stiltiness in their Langshans, plainly recognizing the impractical qualities that became common with that ungainly extreme. A few long iegged specimens have occasionally appeared, but their narrow bodies and close hock joints have warned away any tendency toward that type.

During the early 90's the Black Langshan was among the bestadvertised races, was much written, talked about and shown-its classes in numbers compared well with the most popular in the leading exhibitions. It is evidently not because the Langshan bas a reputation of producing less fine lesh or abundance of large eggs than the more extensively advertised breeds. One of which owes its best qualities to its parent, the Langshan.

In an Australian egg laying contest we lately read that the Langshans were one of six pens that had produced 202 to 241 eggs during the first three months (April, May and June), there being six hens in each pen.

It is plainly a lack of push and printer's ink that causes the Langshans to lag instead of leap along the highway of popular favor. The "Orpington" (a white skin fowl) comes along with its mixture of Jangshan, Rock and Minol:a blood-cacilies no louder nol oftenel" than the "Lordly Langshan" and his wives, in the barnyard, but hangs his shingle high in the leading publications and keeps it there. Pride of ancestry, perhaps, prevents the Langshan from putting himself so prominently before the people-while Americau dollars and poulry stalls are calling for "hetter poultry and more of it."

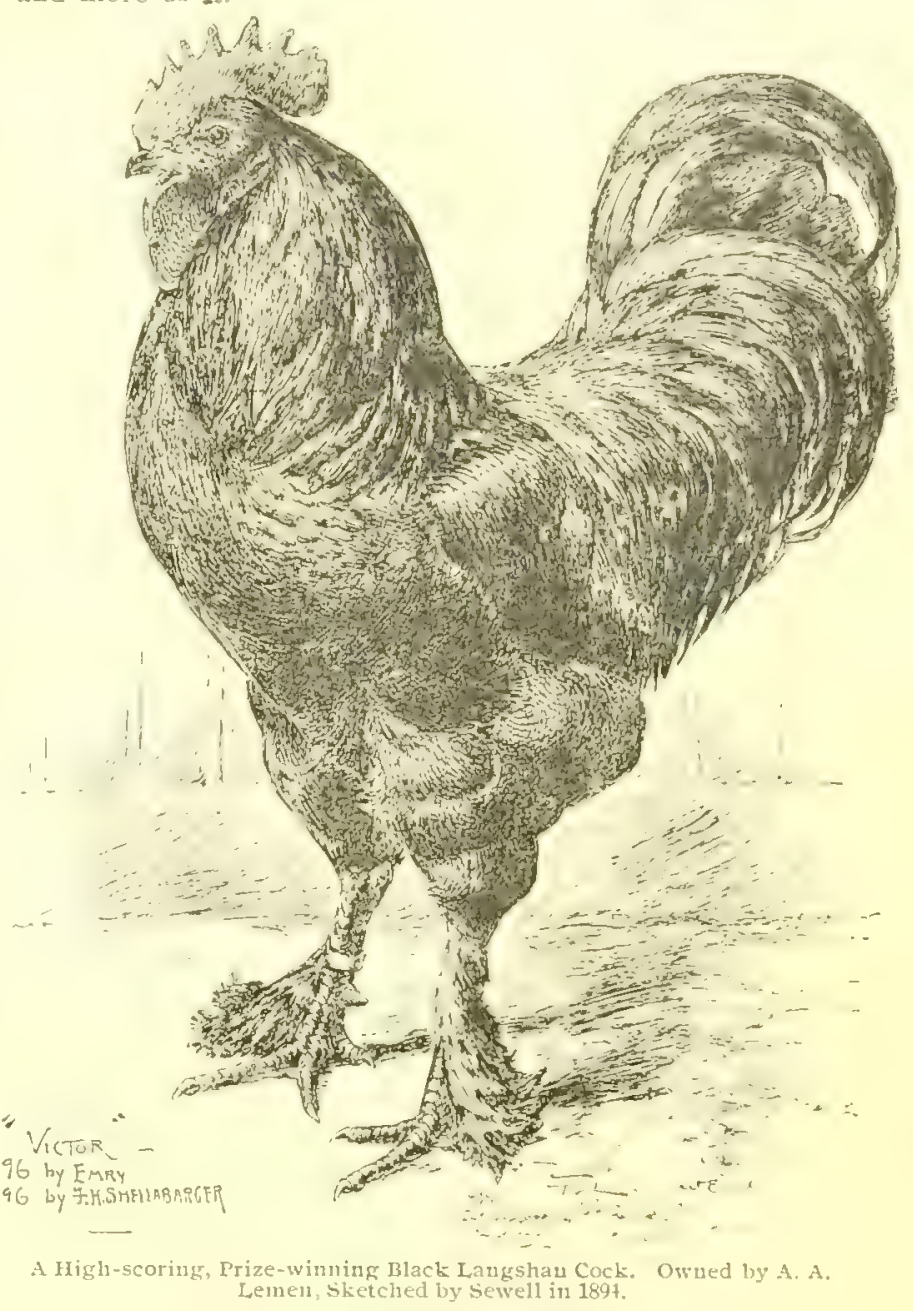

All the prejudice against dark leg fowls can be orercome by good exhibits of well eonditioned Langshans at the dressed poultry displays of our leading shows. It is only because the people leave it to the poultrymen to tell themand nobody shows them the difference-that they believe all this "white slin" talk. I remember when some B'ack Russians were shown at the dressed poultry display at Madison Square Garden they had a host of admirers, when they never would have been thought of as a table fowl with their feathers on.
F. L. SEWVEI.L. 


\title{
BREEDING BLACK LANGSHANS.
}

\author{
A Beautiful Variety With Genuine Practical Worth-Notes From Fifteen Years' Experience With \\ These Superior Fowls
}

DE HENIX L. ALLEN

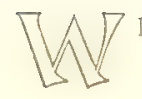

ITH the exception of a short period early in life. my experience as a breeder of fowls in the Asiatic dirision of breeds has been confined entirely to the Biack Langshan; in fact, it may be said that to the Black Langshan has been devoted all the time which could be spared from an exacting business. for nearly fifteen years. I have never been blind to the beauty and excellent points of other breeds, in fact, I have always been willing in admit that there are other breeds more desirable for some people to breed, but for me. I know that no other breed or variety could ever come to possess the same interest that the Black Langshan does and I feel that the same can be said by any one who has become thoroughly familiar with the qualities of the lordly black beauties, both from a fancy and a ntilitartan standpoint.

To begin with, the Black Langshan, although almost unexcelled as a producer of eggs all the vear round and as a table fowl, is pre-eminently a fanciers' fowl on acount of the great beauty of plumage and carriage which characterizes the breed. Its lordly stateliness combined with an activeness which is not a characteristic of any other family in the Asiatic jivision, makes the Langshan stand out in sharp contrast with the other Asiatics. In color the Black Langshan is, to those who have come to know its coloring in its highest perfection, a fowl of surpassing beauty. Looking at one in the sunlight, one forgets that it is a black fowl, the rich green sheen making it appear more like a piece of beautiful green silk, so brilliant is its lustre, and he who imagines that perfection in color is easy to attain in the Black Langshan because the breed is of "solid color"

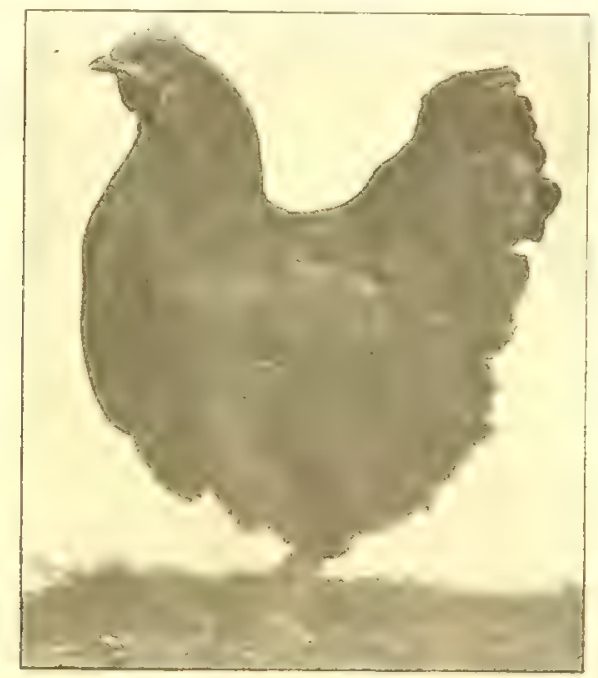

First I'rize Black Iangshan Hen at Ininois State Show. Score $953 / 4$. Bred by Je-ine T. Bateman.

has only to make the attempt in a careless way to learn how wocfully he may be mistaken,

As a rule, I have found that the best and most satisfactory mating is that of one's best male with the pick of the females. There are some who coutent that the best show biris are tot the best breeders, and while that may be so in instances where the natural vigor of the birds has been impaired by long continued showing or by improper treatment, while preparing them for the shows, my own experience has been that $m y$ best youngsters have been raised from a pen of my best show females headed by my best show male. By this it should not be inferred that one can always succeed by simpiy mating a good show male with a pen of show females. In the first place, there is a marked difference, somerimes, in good show birds.

\section{ANCESTRAL CHARACTERISTICS IMPORTANT.}

Then, too, a breeder can get the best results who is familial with the characteristics of the ancestors of the birds being nated. A good show specimen decidedly oft in some one point should be used cautiously. For instance, an otherwise perfect male with a decidedly poor comb should be used experimentally before being placed at the head of a large breeding yard. The same holds true if the male is good in other respects but weak in leg and toe feathering. A nearly perfect male, but lacking some in size can safely be used if the females are a iittle over rather than under the weight limit. Light weight females are not desirable, and when used should be mated with a heavy weight male.

Color and the part it plays in the mating of Black Langshans has been a much discussed subject. Some of the most eminent authorities have asserted that the objectionable puiple barring is likely to result from mating the best colored males and females, that is, those having the metallic green lustre in an accentuated degree. Those who hold to that belief say that a dead black female, one possessing little of the green sheen, mated with a perfect colored male will produce the best colored chicks. In this respect I am unable to agree with the authorities referred to. By mating females possessing the green sheen so much desired in a show bird with a male similiarly characterized year after year, I have had so small a proportion of chicks marked with the purple barring as to lead me to believe that, with other things being equal, the proper mating is male and female colored as one wants the chicks to be colored.

In trying to get the proper type outlined to follow, the beginner should remember that the Langshan is not intended to have the massive blockiness of the Cochin or the majestic angularity of the Brahma. Neither should one go to the extreme which has made the Langshan a laughing stock in Eingland and atlempt to get a type which is stilty and lacking in style. 'The Langshan, as recognized by the standard, is, first of all, an upstanding, stately fowl of remarkable beaury. To allow it to take on the chunky characteristics of the Cochin or the stiltiness of the exhibition Game robs it of those attributes which the breeder shouid mos: carefully cherish and which when properly conceived in the breeder's mind and embodied in the product of his breeding yards, make the Black Langsian an example of the breeder's art that will draw the admiration of every genuine tancier.
HENRY L. ALLEN. 


\title{
THE HANDSOME BLACK LANGSHAN.
}

\section{An Attractive Fowl With Sound Utility Merit-Hints or Breeding and Raising.}

\author{
BY JESEE' T. BATEMAN.
}

(From the Reliable poultry Journat.)

$\mathbb{1}$ BREED Black Langshans because of their beauty and utility. A Langshan of true shape and color is in my opinion the most beautiful fowl bred. Take a male bird with his red face, comb, wattles and ear lobes, attired in his beautiful plumage, black and glossy with that greenish sheen, standing up so tall and stately with his arched neck, long flowing hackle, concave back, well spread tail full of long flowing sickles, and he is a thing of beauty and a bird that every one admires.

As winter layers they are among the best. Any lind of hen will lay when spring and grass come. I get plenty of eggs all winter, and when spring comes, too, and $I$ don't have to wait until April for biddy to set.

Some people object to the white skin and black pinfeathers of Black Langshans. I have time and again seen Black Langshans and Barred Plymonth Rocks dressed equally well by the same party, placed in the show window, and the white skinned birds.have gone first invariably. As for pinfeathers, they have no more than other kinds and not as many as some, for they are a loose feathered fowl. There is an advantage in black pinfeathers, for we see them and pick them out, while if invisible by reason of color they are eaten. That's all right for those who are partial to that kind of thing, but please excuse me. Some say a black bird will not bring as much on the marker, as other linds. I always get the top price for my culls and the poultry dealers are anxious to get them. I have heard them advise the pickers not to rub the white skinned chickens so hard, as their skin is thinner than the others. This being the case, there would be more meat and less waste. Langshans have

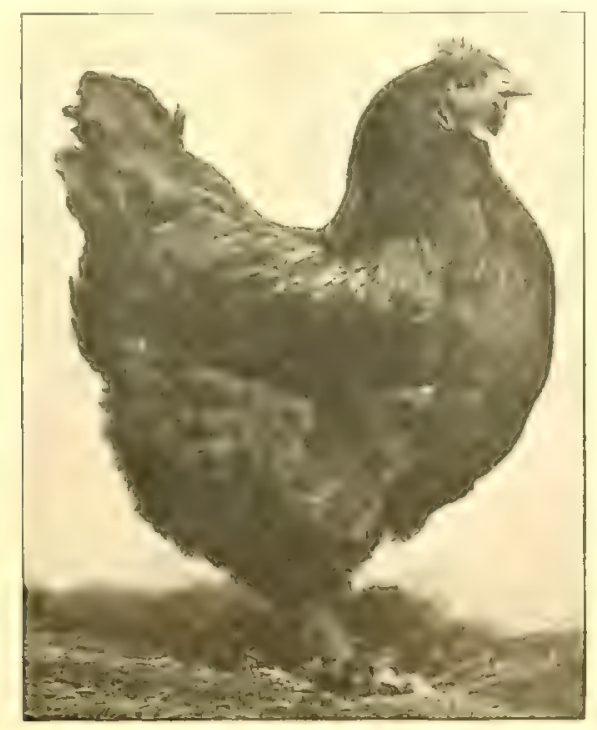

Second Prize Black Langshan Hen at Chicago, November. 1903. Bred by Jesse T. Bateman.

long deep breasts; their meat is of delicate flavor and as good as the best.

Langshans will stand confinement well. A four-foot fence will keep them in. I have some yarded, and some have free range. I get more eggs (and a larger majority are fertile) from the former than the latter. Often more than one male bird with a flock of females causes interference one with another and this prevents fertility in the eggs. I find the eggs from mature pullets are more frequently fertile than those from hens. The oldet the hens the fewer fertile eggs; yet I would rather' have a chicli from a hen thas a pullet. I think they are stronger. similaxiy with regard to cocks and cockerels: the young one is more certain than the old one. The cock is liable to be no good at all and you rarely see a young bird but he is all right as a breeder. I thinli it right to mate cockerels and pullets, if they are both weIl matured. but it is not best to use $\mathrm{th} \in \mathrm{m}$ in $\mathrm{the}$

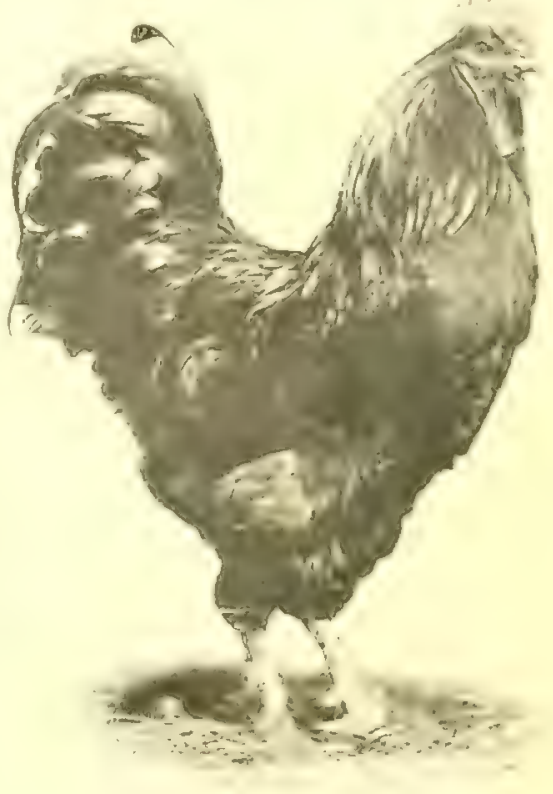

Black Langshan Cuckerel, scoring 95 , lied by Jesie T. Bateman. breeding yard if they are not so, no matter to what they are nated.

Sometimes in full feathered breeds we find a chick that will not feather out. It is pracically naked. I know of no remedy for this. I think it is hereditary, for his associates may be in full dress, although they all have similar food and care, while he is as bare as if he had been picked.

I think leg weakness, which often appears in Asiatics, is caused by too much fat producing food. Aiy remedy is to take away corn and such food and give bran mash with some good poultry food added.

I do not think the standard too hard on Black Langshans. If we have an easy standard we will not improve our stock. The cocks are hardest to get up to standard weight, but if a cockerel develops as he should he will be up in weight. If he does not, let him go or he will decrease the size of your stock. The thing to do is to cull and cull closely, and, if the white and gray tips are eliminated from the breeding yards, there will be less of them next year, and still less the next. If not, the white will increase.

More attention should be paid to symmetry. There are more Langshans off in shape of back and tail than any other points. Many a bird wins in shows which the judge or owner would never suppose to be a Langshan if he saw its outline.

As for color, some are breeding to the brownish black to overcome the purple. I think the remedy about as bad as the defect. 


\title{
MATING AND HOUSING BLACK LANGSHANS.
}

\author{
Selecting the Breeders-Two Males for Each Pen-Fifty Birds Yield Five Hundred Dollars Income \\ in Twelve Months.
}

By L. E. MEYER.

(From the Reliable Poultry Journal.)

$\Delta \sqrt{1}$

ATING for good results is one of the knotty questions for all breeders of fancy fowls. Langshans have some bad defects to overcome that often puzzle the breeder, such as red and yellow eyes; gray or white tips in wings; white in toe feathering; crooked breast bones; lopped combs in females; side sprigs and purple barring. These defects may all be transmitted. The breeder who is always preaching that like begets like has a hard time making all his customers and friends believe it. Even the old line breeders who often produce high class specimens have a hard time to get offspring that are the equal of their parents. I have tried all sor's of matings. MIy first idea was to mate in pairs, which is a very good way of mating. I got about ten per cent first class birds from such matings. If I had females weak in some sections I would select a maje strong in section where females were weak. This is a good way to mate, but the best plan I

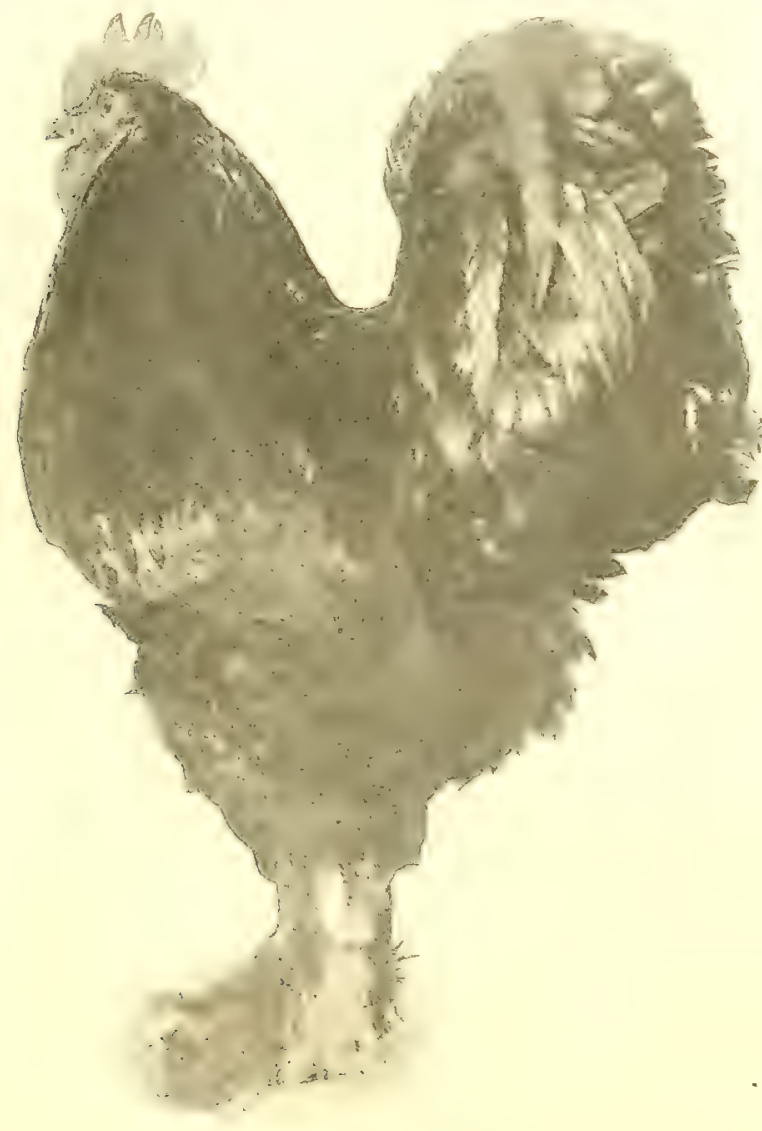

"Choice Goods" - A Magnificent Langshan Male-A Winner.

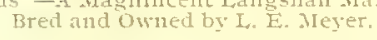

have ever adopted is to select the females and put from ten to twelve in each pen. Be sure to get them with good straight combs, having from four to six spikes; long, deep bodies with broad backs; good length to legs and toes with plenty of toe and shank feathering. If the pen I have described is composed of pullets I would select two cock birds to mate to them, allowing only one at a time to run with them, say three or four days at a time. Keep one cooped all the time.

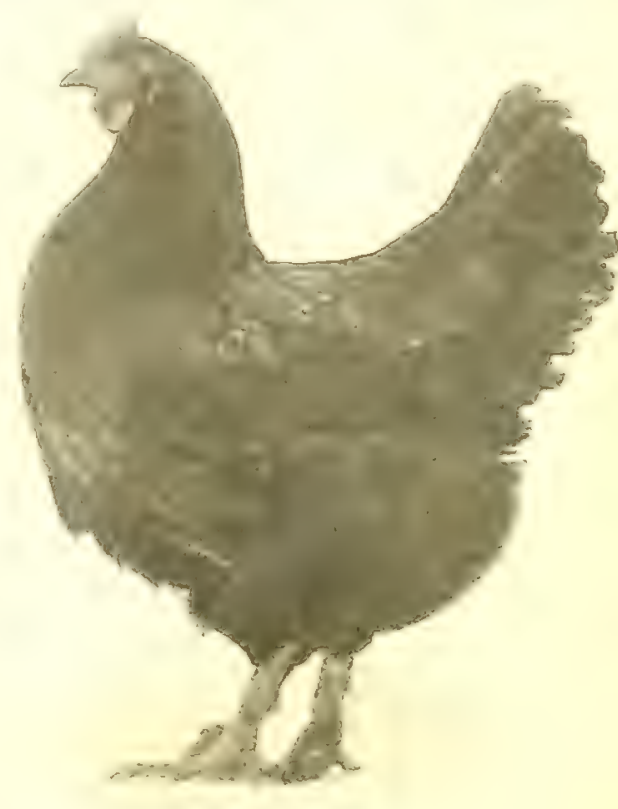

Fourth Prize Black Langshan Hen at Chicago Bred and Owned by L. E. Ireyer.

This keeps the males vigorous. I find if you allow the same male to run with the pen all the time they are inclined to take three or four females away from the rest and give them nearly all of their attention. My method of mating makes eggs more fertile and I think gets stronger chicks. and I can get fully as many show specimens.

In selecting a male to breed from I select one that is strong in color, with as perfect a hear and comb as I can get; short. broad back; large, spready tail, with an abundance of sickles-the more the better.

When my cockerels are maturing I select those that I expect to breed from, and they are not for sale at any price. In this way I have improved my birds every year. "Choice Goods," whose photo appears here, would be my ideal if he had a better comb. This season I am using six cockerels that will all be his equal when fully matured. If you want to get rid of defects quit breeding them. That is the quickest and surest way.

Never erowd your fowls. Keep their roosting place warm and clean; have your yards as large as possible; feed good wholesome food and be liberal with it. From fifty hens hept in this way I sold in 1902 nearly $\$ 500$ worth of stock and eggs. That's very good pay for a farmer.

L. E. IIEYER. 


\title{
THE REGAL WHITE LANGSHAN.
}

\author{
The "Sacred Bird" of the Chinese-Produced in This Country From Sports-A Fowl for Fancier and \\ Farmer-Hints on Selecting and Breeding.
}

By ReEs F. MATSON.

$\mathbb{T}^{\mathrm{H}}$

E only pure White Langshans are sports from the Black Langshans or descendants of such sports. During the early existence of this breed, whon, as is usually the case with a new breed, the demand exceeded the supply, many cross-bred mongrels were sold as White Langshans. These were mostly of White Dorking, White Leghorn and White Cochin extraction, and even yet, though it is rare, one runs across birds that show some of this foreign blood. The Dorking and Leghorn crosses can easily be detected by their large, coarse combs and the Cochin birds by their loose feathering and yellow skin. Thanks to the untiring efforts of the breeders of this excellent bird, these crosses have been almost entirely eradicated and $I$ doubt if there is a breed of its age that shows a more uniform type than the White Langshan. I should have said its age in this country, for it is known that the White Lang. shan has existed for, possibly, hundreds of years in China, its birthplace, where it is known as the "Yop" or Sacred Bird, but, because of the fact that the Chinese consider it sacred, it has been almost impossible to secure any specimens for importation.

Whatever can be said of the Black Langshans can be said of the Whites for the only difference is in color. I find amongst my own birds that the Whites lay the larger egg, but I am inclined to believe this is attributable to strain. In the spring of 1893 I set fourteen eggs, all laid by my best Black Langshan hen, which was mated to an excellent cockerel, scoring 94. From these eggs, hatched twelve White Langshans, the first sports I had ever seen and the foundation of my strain of White Langshans. This black hen laid an unusually large egg and to this fact $\mathrm{I}$ attribute the large size of the eggs from my Whites. All specialty breeders are accused of being unreasonably prejudiced in favor of their "hobby," but I recommend the Langshan after trying nearly all the popular varieties of pure-bred poultry. As a winter layer they have no superior and I doubt an equal, for not only in winter, but throughout the entire year, they lay with gratifying regularity. Their eggs are large and of varying shades of brown and pink. For table use the White Langshan is excellent, having small bones and a juicy flesh, which retains tenderness at an age when most fowls are relegated to the table of the proverbial boarding house. The White Langshan is particularly well adapted to the farm, being splendid foragers, hardy, prolific and easily managed. Let's take the chick, a bundle of "smutty" down, some as dark as a mole, others almost white, with tints of canary here and there on their breasts. Who would suppose they would ever be white? Several customers have complained that I had sent out mongrel stuff, when they first viewed the little fellows in the nest, but their disappointment was turned to joy when in two months they were as white as snow and the brightest, liveliest chicks they had ever seen. I will confess that at from three to five months of age the Langshan cockerel is an awkward, ungainly fellow, no more than other Asiatics, but where can you find a more beautiful specimen than the matured male, all life, style and beauty.

In the show room no breed attracts more attention not only because of their beauty, but because of their gentleness, you might say friendliness. At the ' 03 Chicago show, my first prize pullet occupied a corner coop, from the bars of which she pecked at the rings and buttons of all who passed her way, and was a friend of all. The following description of her, by Editor Curtis, in the Reliable Poultry Journal, is applicable to Langshans in general, for they all have that "Regal bearing," that "Distinguished air":

"At this show, for the first time in our experience, we became really interested in the White Langshan, as a result of the exhibit of beautiful specimens made by Rees $F$. Matson. The stately white beauties forcibly remind you of the demure 'ladies of quility' of a hundred years ago going through the evolutions of the minuet. Pardon this flight of fancy, but Mr. Matson's first prize White Langshan pulwas easily the stateliest creation in the form of a standard fowl we have seen."

The graceful, neatly proportio ned Langshan of to-day.
A High Scoring. Prize Winning White Langshan Cockerel, Bred and owned by Rees F, Matson.

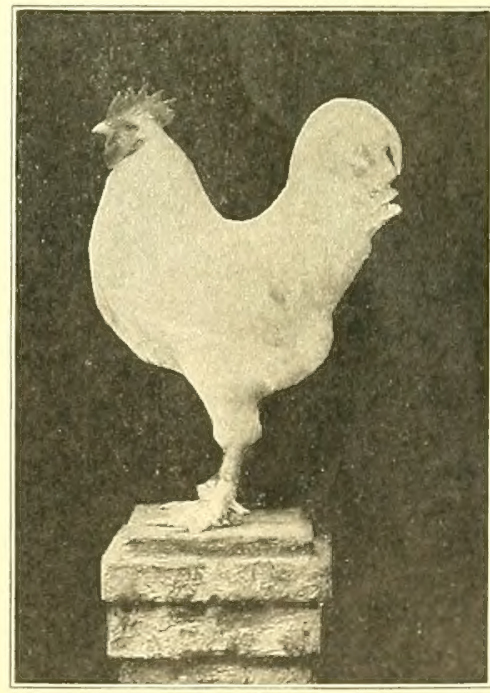

is nearer the accepted ideal than either the "squatty" or "snaky" extremes met with so often in the past. By careful selection and close culling this type can be improved. We must keen away from the loose-feathered Cochin type and. too, we must not go to the other extreme, the hard-feathered Game type. The true Langshan is neither hard feathered nor loose feathered, but, while seemingly close feathered, is yet soft and fairly fluffy. In shape the defects to avoid are: Large, beefy combs, fiat, meatless breasts, long, narrow, straight backs and low, scantily furnished tails. In color breed for pure white, both in web and quill, shanks and feet of a blue slate color, pink skin and a dark brown eye.

Summing it up, the especially laudable characteristics of the Langshan are its docility, winter laying proclivity, large size combined with small bone, tender and juicy flesh, abundance of breast, and beauty, unsurpassed.

REES F. MATSON. 


\title{
THE WHITE LANGSHAN.
}

\author{
A Variety Fortunate in the Langshan Shape and Style-Valuable for Winter Laying-Offering Two \\ Sources of Profit if Properly Handled.
}

By GeO. D. BLACK.

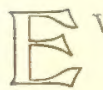

ERY breed of towls has its admirers and champions; there are many good varieties, and the value of many of them is so nearly equal as to make it difficult to choose among them. I am going to praise the White Langshan, and this I am very willing to do, for having tried it for a number of years by the side of other pure-bred fowls, I have come to be a decided admirer of the breed. There are birds that may be better suited to the fancy and to the wants of other people, but to me there are none whose style and general characteristics appeal to mo as those of the White Langshan do. If there is such a

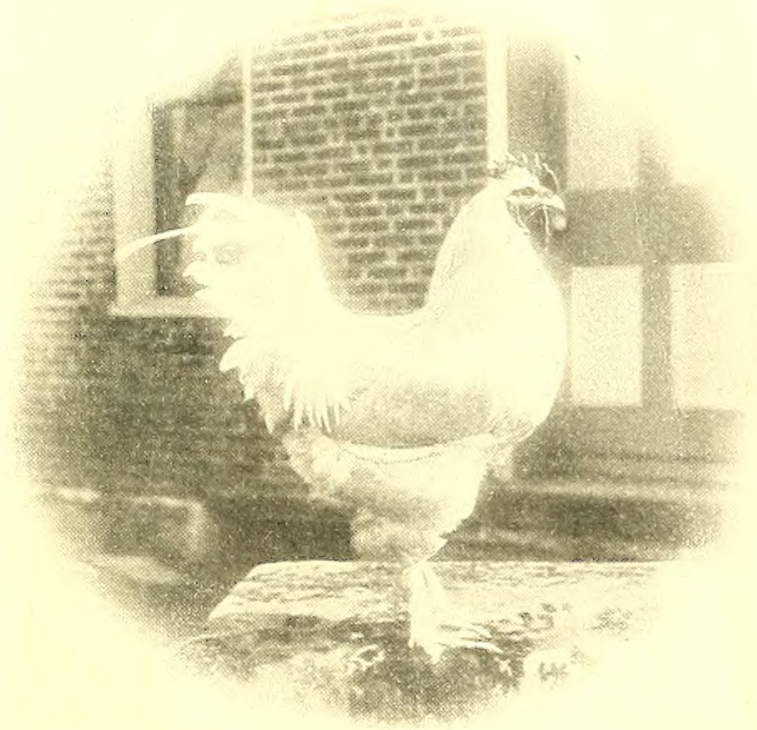

First Prize Winning White Langshan Cockerel at Dayton, Ohio, Bred and Owned by George D. Black.

thing as the artistic in chicken conformation, the Langshan has it. For stateliness, for elegance of form, it easily stands at the head of the poultry lingdom. This is true of both the male and female. Every one who knows the breed recognizes that there is a Langshan style which is so distinctive that it never can be confounded with that of any other breed. We say that form differentiates breeds; but the American breeds, for instance, are so near alike, as we see them in some yards, that one form easily passes for another to the rovice; and this is sometimes true in the show room. But a judge would have to be form-blind and style-blind ever to mistake the Langshan conformation.

The White Langshan is a beautiful fowl; but if it is at the same time a highly useful one, its friends have good ground for their attachment to it.

For several years I have been trying the White Langshan by the side of other breeds, and I have found no chickens that will lay more eggs during the year than my Langshans, and few that will lay as many. I have had none that wijl come anywhere near them in winter laying. The White Langshan hen has the knack of laying just at the time when eggs are at the tip-top price in the market. Last winter when eggs got so high that only millionaires could afford to eat them, my Langshan hens kept laying. The coldest days did not stop them, and they were not housed and fed difierently from the others. I think it may confidently be claimed that the White Langshans are excellent winter layers.

When it comes to table qualities, this breed will hold its own with the best. The flesh is especially tender, and it remains so in the mature hens beyond any other fowls I have ever had any experience with. Their freedom from dark pinfeathers adds greatly to their value when dressed. They can be cleaned in about half the time that is required to clean most other linds, and when they are dressed they look clean.

One other thing I prize in them especially is the ease with which one can handle them. They are naturally quiet and gentle. A wild chicken I have no use for. It is annoying, to say the least, to go into your poultry yard or poultry house and have the whole flock flying and scurrying around as if you had started up a covey of partridges. My White Langshans will hardly get out of my way as I go among them, and if I come suddenly upon a bunch of them they do not raise a general hubbub and fly all over the barnyard. I pick up my sitting hens and put them in a house used as a hatching place, giving each one a box with a clutch of eggs, and they sit there as contentedly as if the place were of their own choosing. This docility of disposition makes them unexcelled sitters and mothers. You can handle them with their broods without their flying into your face or tramping the chicks to death. And yet the Langshan is not a lazy, stupid fowl. It is sprightly and active, and a good forager.

This auality of docility in the Langshan to me counts for much. I esteem it so highly that I could not be induced to harbor about the place chickens that were nervous and flighty.

The qualities which I have enumerated are the ones that combined make a good all-purpose chicken, and it may be claimed with assurance that the White Langshan is of this sort. The general farmer keeps from fifty to a hundred hens. If they are good layers and have good carcasses he has two sources of profit from them, and the meat profit, if he manages his business skillfully, will amount to considerabie in the course of a year, to say nothing of the fries and roasts that go to his own table. I am so well convinced of the worth of the White Langshan as a farmer's fowl that $I$ shall be glad if this book does much toward calling the attention of farmers and breeders to it. There is a marked increase of interest in it, as I happen to know, and I am sure that if its merits were better known it would become one of the most popular breeds.

GEORGE D. BLACK. 


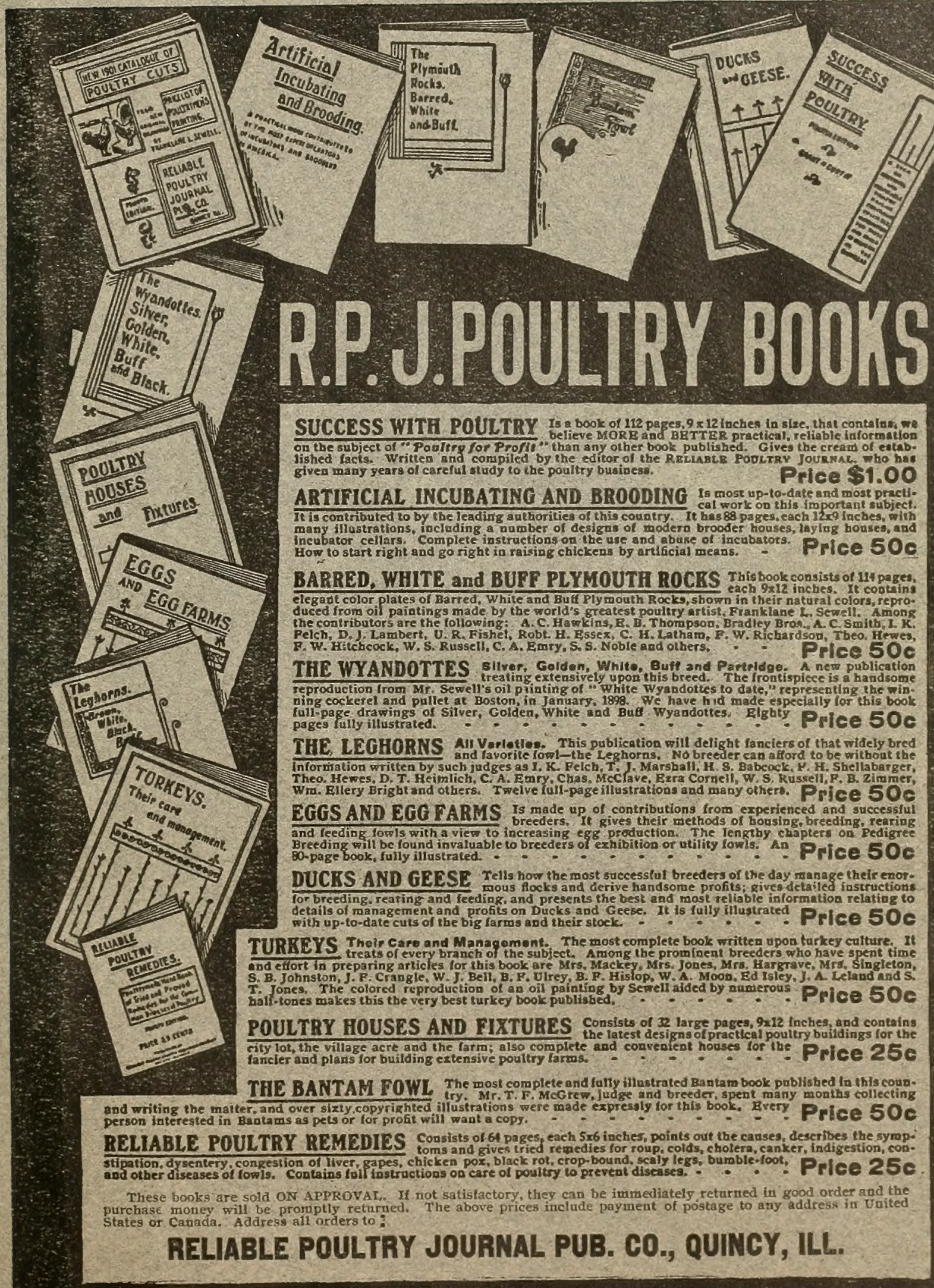


